\title{
COMUNICAÇÃO CIENTÍFICA NA ÁREA DE SAÚDE PÚBLICA: PERSPECTIVAS PARA A TOMADA DE DECISÃO EM SAÚDE BASEADA EM CONHECIMENTO
}

REGINA CÉLIA FIGUEIREDO CASTRO

Tese de Doutorado apresentada ao

Departamento de Prática de Saúde Pública

da Faculdade de Saúde Pública da

Universidade de São Paulo para obtenção do Grau de Doutor

Área de Concentração: Serviços de Saúde Pública

ORIENTADORA: PROFa ${ }^{\mathrm{a}}$ DR ${ }^{\mathrm{a}}$. EVELIN NAKED DE CASTRO SÁ

São Paulo 
Autorizo, exclusivamente para fins acadêmicos e científicos, a reprodução total ou parcial desta tese, por processos fotocopiadores. 


\section{RESUMO}

Castro RCF. Comunicação científica na área de saúde pública: perspectivas para a tomada de decisão em saúde baseada em conhecimento. São Paulo; 2003. [Tese de doutorado - Faculdade de Saúde Pública da USP].

Objetivos. Reflexos das transformações sociais promovidas pela Sociedade do Conhecimento são percebidos no contexto da gestão em saúde no Brasil. Apresentam-se referencial teórico sobre essas mudanças, gestão do SUS, sistemas de informação em saúde, produção científica e uso da informação na gestão. Foi analisada a produção científica brasileira em saúde pública como fonte de apoio à tomada de decisão em saúde. Metodologia. Foram feitos estudo exploratório qualitativo e análise documental em três áreas: bases de dados bibliográficas disponíveis na Biblioteca Virtual em Saúde, agendas estaduais de saúde e sites das Secretarias Estaduais de Saúde. Resultados. Os principais resultados foram: as bases de dados LILACS e MEDLINE foram as fontes de apoio mais abrangentes para localizar produção brasileira publicada no país e no exterior, respectivamente; a produção científica brasileira destaca-se nessa área, correspondendo a 39\% dos registros da LILACS-SP; as principais instituições produtoras são universidades e organismos governamentais; a produção de saúde pública encontra-se distribuída em revistas de outras áreas da saúde; a internet, já utilizada pelo ministério e pelas secretarias de saúde, seria favorável para disseminação de conhecimento científico para a gestão em saúde. Conclusões e recomendações. A informação científica e técnica disponível poderia apoiar os processos de tomada de decisão, mas o caminho entre sua produção e uso não é linear e precisa ser estimulado. São apresentadas sugestões para promover integração e articulação entre pesquisa científica e decisão política.

Descritores: Informação científica e técnica. Gestão de Saúde Pública. Formulação de políticas. Bases de dados bibliográficas. Tomada de decisão em saúde. 


\section{SUMMARY}

Castro RCF. Public health scientific communication: perspectives for knowledge based health decision making. São Paulo; 2002. [Thesis Faculdade de Saúde Pública da USP].

Objectives. Social changes introduced by Knowledge Society are perceptible in the health management context in Brazil. Literature on these social changes, on National Health System - SUS legislation, on health information systems, on the health scientific production and on its use for decision making was reviewed. Brazilian public health scientific literature as support to health decision making was analyzed. Methods. Qualitative exploratory methods and document analysis were used to study bibliographic databases available at the Virtual Health Library, health agendas and sites of the State Secretaries of Health. Results. The main results were: LILACS and MEDLINE databases were the most comprehensive sources for searching Brazilian public health literature; 39\% of LILACS-SP records corresponds to Brazilian public health literature; universities and government institutions are the main producers of public health scientific literature; public health journal articles are published also in journals from other health fields; Internet, which is already being used by Ministry and State Secretaries of Health for communication, could be a favorable environment for dissemination of scientific information for health decision making. Conclusions and recommendations. Available health scientific and technical information could support health decision making processes but the channels between its production and use are not linear and need to be strengthened. Recommendations to improve relationship and interaction between health research and policy were presented.

Descriptors: Scientific and technical information. Public health management. Policy making. Databases, bibliographic. Health decision making. 


\section{ÍNDICE}

1 INTRODUÇÃO

2 O ESPAÇO DO CONHECIMENTO

3 O SETOR SAÚDE 18

3.1 Contexto histórico das transformações do setor saúde 19

3.2 A gestão no SUS 29

3.2.1 O gestor na NOB/SUS/96 31

3.2.2 O gestor na NOAS/SUS/01/01 32

3.3 Instrumentos de gestão $\quad 35$

$\begin{array}{ll}\text { 3.3.1 Agenda de Saúde } & 37\end{array}$

3.3.2 Plano de Saúde $\quad 40$

3.3.3 Relatório de Gestão

3.3.4 Plano Diretor de Regionalização $\quad 42$

3.3.5 Programação Pactuada e Integrada $\mathbf{4 2}$

3.4 Informação para a gestão 43

4 SISTEMAS DE INFORMAÇÃO EM SAÚDE 49

4.1 Conceitos $\mathbf{5 0}$

4.2 Sistemas de informação em saúde existentes $\mathbf{5 5}$

4.2.1 Sistemas de informação estatística e epidemiológica em saúde $\quad \mathbf{5 5}$

4.2.2 Sistemas de informação científica e técnica em saúde $\mathbf{5 9}$

5 PRODUÇÃO CIENTÍFICA, TÉCNICA E NORMATIVA EM SAÚDE

$\begin{array}{lll}5.1 & \text { Revistas científicas em saúde pública } & \mathbf{7 7}\end{array}$

5.2 Livros, teses e trabalhos apresentados em eventos científicos $\quad \mathbf{8 0}$

5.3 Produção científica e técnica governamental $\mathbf{8 2}$

5.4 Legislação e outros instrumentos normativos $\mathbf{8 3}$

6 USO DA INFORMAÇÃO NO PROCESSO DE DECISÃO EM SAÚDE $\quad 85$ 
$\begin{array}{lll}7.1 & \text { Objetivo geral } & 108\end{array}$

$\begin{array}{lll}7.2 & \text { Objetivos específicos } & \mathbf{1 0 8}\end{array}$

8 METODOLOGIA $\quad 109$

8.1 Produção científica e técnica brasileira em saúde pública $\mathbf{1 1 0}$

$\begin{array}{ll}\text { 8.1.1 Bases de dados bibliográficas } & \mathbf{1 1 0}\end{array}$

$\begin{array}{lll}\text { 8.1.2 Revistas científicas } & \mathbf{1 1 5}\end{array}$

8.1.3 Instituições produtoras de informação científica e técnica em saúde pública $\quad 116$

$\begin{array}{ll}\text { 8.1.4 Análise temática da produção científica } & 117\end{array}$

$\begin{array}{lll}\text { 8.2 Agendas Estaduais de Saúde } & 117\end{array}$

8.3 Sites do Ministério da Saúde e Secretarias Estaduais de Saúde 119

8.4 Informação científica para tomada de decisão local $\mathbf{1 2 0}$

9 RESULTADOS 123

9.1 Análise da produção científico-técnica brasileira em saúde pública

123

9.1.1 Produção científico-técnica registrada em bases de dados $\mathbf{1 2 3}$

$\begin{array}{lll}\text { 9.1.2 Revistas científicas da área de saúde pública } & \mathbf{1 3 7}\end{array}$

9.1.3 Instituições produtoras de informação científico-técnica $\begin{array}{ll}\text { em saúde } & 140\end{array}$

9.1.4 Análise da distribuição da produção científica por temas $\mathbf{1 4 3}$

9.2 Análise descritiva das Agendas Estaduais de Saúde de $2001 \quad 146$

9.3 Análise descritiva dos sites do Ministério e Secretarias Estaduais de Saúde $\quad 155$

9.4 Informação científica para tomada de decisão local $\mathbf{1 6 2}$

10 DISCUSSÃO 170

11 CONCLUSÕES E RECOMENDAÇÕES 179

12 REFERENCIAS 


\section{ANEXOS}

Anexo 1 - Categorias temáticas da BVS-SP Brasil

Anexo 2 - Formulário para análise dos sites das Secretarias Estaduais de Saúde

Anexo 3 - Roteiro utilizado nas entrevistas

Anexo 4 - Revistas da área de saúde pública indexadas em bases de dados internacionais

Anexo 5 - Revistas científicas nacionais incluídas na LILACS-SP Brasil, 1982-2002, por ordem decrescente de número de registros 


\section{LISTA DE TABELAS}

Tabela 1 - Instrumentos de gestão do SUS

Tabela 2 - Revistas brasileiras na área de saúde pública indexadas na base de dados LILACS em 2002

Tabela 3 - Instituições publicadoras de monografias registradas na LILACS-SP Brasil, por tipo de instituição, com total e porcentagem de registros na base

Tabela 4 - Distribuição dos registros de dissertações e teses na LILACS-SP Brasil, por instituições em que as mesmas foram apresentadas

Tabela 5 - Distribuição da literatura brasileira em saúde pública, de 1990 a 2002, indexada na LILACS-SP Brasil, por áreas temáticas da BVS-SP, com totais por tipo de documentos e porcentagem dentro de cada área temática

Tabela 6 - Demonstrativo das metas das Agendas Estaduais de Saúde em relação à Agenda Nacional de Saúde para o ano de 2001

Tabela 7 - Demonstrativo das metas específicas das Agendas Estaduais de Saúde

Tabela 8 - Análise descritiva dos sites das Secretarias Estaduais de Saúde

Tabela 9 - Resultado de pesquisa sobre dengue nas fontes de informação da BVS-SP

Tabela 10 - Distribuição da informação recuperada na BVS-SP sobre dengue, com resultados e totais da amostra, por fonte de informação

164

Tabela 11 - Distribuição da informação recuperada na BVS-SP sobre dengue, por autoria e por fonte de informação

Tabela 12 - Distribuição da informação recuperada na BVS-SP sobre dengue, por tipos de documentos e fontes de informação

Tabela 13- Distribuição da informação recuperada na BVS-SP sobre dengue, por temas e fonte de informação 


\section{LISTA DE FIGURAS}

Figura 1 - Tipologia da pesquisa em saúde

Figura 2 - Revistas nacionais de saúde pública por ano inicial de publicação

Figura 3 - Revistas de saúde pública indexadas no Index Medicus em 2002, por país

Figura 4 - Mapa de atores e contextos relacionados à pesquisa e política

Figura 5 - O processo de pesquisa

Figura 6 - Distribuição dos registros da base de dados LILACS, de 1990 a 2002, por tipos de documentos

Figura 7 - Distribuição dos registros da produção científica latino-americana em saúde pública, de 1990 a 2002, indexados na base de dados LILACS-SP, por país de publicação

Figura 8 - Distribuição dos registros da produção brasileira de saúde pública na LILACS-SP Brasil, de 1990 a 2002, por tipos de documentos

Figura 9 - Distribuição dos registros da produção brasileira de saúde pública na LILACS-SP Brasil, de 1990 a 2002, por ano de publicação

Figura 10 - Distribuição dos registros da produção científica brasileira indexada na base de dados AdSAÚDE, de 1990 a 2002, por tipos de documentos

Figura 11 - Distribuição dos registros da produção científica brasileira indexada na base de dados REPIDISCA, de 1990 a 2002, por tipos de documentos 


\section{SIGLAS UTILIZADAS}

ABRASCO - Associação Brasileira de Pós-Graduação em Saúde Coletiva

BDAIH - Banco de Dados de Autorizações de Internações Hospitalares

BDSP - Banque de Données Santé Publique

BID - Banco Interamericano de Desenvolvimento

BIREME - Centro Latino-Americano e do Caribe de Informação em Ciências da Saúde

BVS - Biblioteca Virtual em Saúde

BVS-SP - Biblioteca Virtual em Saúde - Saúde Pública - Brasil

CIB - Comissão Intergestores Bipartite

CIT - Comissão Intergestores Tripartite

CNPq - Conselho Nacional de Desenvolvimento Científico e Tecnológico

CONASEMS - Conselho Nacional de Secretários Municipais de Saúde

CONASS - Conselho Nacional de Secretários Estaduais de Saúde

CVE - Centro de Vigilância Epidemiológica da Secretaria do Estado de São Paulo

DATASUS - Departamento de Informática do SUS

DECIT - Departamento de Ciência e Tecnologia em Saúde, SPS

DOTS - Tratamento Supervisionado Diretamente Observado

ENSP - Escola Nacional de Saúde Pública

FAPEAL - Fundação de Amparo à Pesquisa do Estado de Alagoas

FAPESP - Fundação de Amparo à Pesquisa do Estado de São Paulo

FIOCRUZ - Fundação Oswaldo Cruz

FSP - Faculdade de Saúde Pública da Universidade de São Paulo

IBGE - Instituto Brasileiro de Geografia e Estatística 
IDRC - International Development Research Council

INAMPS - Instituto Nacional de Assistência Médica da Previdência Social

ISI - Institute of Scientific Information

LILACS - Literatura Latino-Americana e do Caribe em Ciências da Saúde

LILACS-SP - LILACS - Saúde Pública

LILACS-SP Brasil - LILACS - Saúde Pública Brasil

LIS - Localizador de Informação em Saúde

MPAS - Ministério da Previdência e Assistência Social

MS - Ministério da Saúde

NOAS - Norma Operacional de Atenção à Saúde do SUS

NOB - Norma Operacional Básica do SUS

OMS - Organização Mundial da Saúde

OPAS - Organização Pan-Americana da Saúde

PAHO - Pan American Health Organization

PNCTeI/S - Política Nacional de Ciência, Tecnologia e Inovação em Saúde

PNUD - Programa de Desenvolvimento das Nações Unidas

PSF - Programa de Saúde da Família

RIPSA - Rede Interagencial de Informações para a Saúde

RNIS - Rede Nacional de Informações em Saúde

SciELO - Scientific Electronic Library Online

SPS - Secretaria de Políticas Públicas do Ministério da Saúde

SUS - Sistema Único de Saúde

UNESCO - Organização das Nações Unidas para a Educação, Ciência e Cultura WHOLIS - Base de dados da Organização Mundial da Saúde 


\section{CAPÍTULO 1}

\section{INTRODUÇÃO}

A sociedade contemporânea caracteriza-se pela multiplicidade de estruturas organizacionais, pela diversidade de atores sociais, pela organização de trabalho multi e interdisciplinar e pela necessidade de compreender as relações humanas para o progresso e bem-estar social. Baseia-se nos princípios da descentralização, flexibilidade, autonomia e tomada de decisões no nível local, com participação popular. O maior limite dessa sociedade é justamente não ter limites; é ter que definilos diante das constantes transformações sociais da sociedade mundial nas últimas décadas.

Reflexos dessas transformações podem ser vistos no contexto da saúde no Brasil. Percebe-se, nas propostas de descentralização da gestão em saúde, a influência da Sociedade do Conhecimento, que impôs uma nova organização social, estendendo o processo de tomada de decisão em saúde a todos os níveis da sociedade. O processo de globalização, a nova economia do saber, o conhecimento como força produtiva da sociedade, os processos de inteligência coletiva provocaram mudanças na estrutura social e na relação do ser humano com a sociedade. A globalização trouxe uma nova hierarquização dos espaços, transformando o papel das cidades, com uma gradual reconstituição dos espaços comunitários. A informação dinamizou o processo de

construção do conhecimento coletivo, fazendo convergir num único espaço a comunicação, a decisão, a demanda, a resposta e a ação.

No modelo de atenção à saúde proposto pela Reforma Sanitária foram introduzidos conceitos, de alguma maneira influenciados pelo novo paradigma, como a descentralização dos processos decisórios, a contextualização das informações para ação em nível local e para promoção da saúde, a participação comunitária e o exercício da cidadania. 
No processo de descentralização proposto pelo SUS, as situações complexas e diferenciadas passaram a exigir mais participação dos atores sociais afetados pelas políticas, e os problemas mais específicos teriam de ser transferidos para espaços de decisão próximos aos cidadãos. A tendência para um reforço da gestão política nos níveis locais representou uma evolução para uma democracia participativa, em que grande parte das decisões sobre ações cotidianas passaria a ser gerida pelos próprios cidadãos.

Para a tomada de decisão local, comunidade e profissionais da área, gestores e tomadores de decisão em saúde necessitariam ampliar seu conhecimento sobre a realidade por meio da busca, coleta e análise de informação nas mais variadas formas de apresentação. E, na maioria das vezes, a informação disponível não é suficiente por si mesma ou não é suficientemente conhecida e divulgada.

O desafio está no desenvolvimento de recursos humanos capacitados para os processos de gestão em saúde de forma a atender essa nova demanda e na preparação de fontes de informação ágeis, flexíveis, integradas e abrangentes, que permitam, em qualquer momento e lugar, o acesso a informações para tomada de decisões políticas e sociais na área da saúde.

Neste contexto, insere-se o objeto deste estudo. Passados mais de quinze anos de implementação do modelo do SUS, ainda se discutem como essa participação social poderia constituir um canal ativo para o desenvolvimento do modelo de atenção à saúde e como os gestores e tomadores de decisão do poder público poderiam otimizar o processo de análise de situações locais, de definição de políticas e de estabelecimento de prioridades de gestão. Os instrumentos normativos e técnicos orientam a gestão local, mas não têm sido suficientes para que o modelo de descentralização do SUS atinja os níveis esperados. Poder-se-ia apontar como uma das possíveis causas a baixa utilização de informações disponíveis sobre as situações locais de saúde para o planejamento e a gestão.

Algumas questões constituíram os pontos de partida para o desenvolvimento desta pesquisa: como o processo de comunicação científica em saúde poderia dinamizar e apoiar a tomada de decisão em saúde; que conhecimento científico está disponível; qual informação é produzida na área de saúde pública e como ela é disseminada pelos canais de comunicação e sistemas de informação existentes; que conhecimento 
ou fontes de informação poderiam ser utilizados pelos gestores para apoiá-los em suas decisões em saúde; quais instrumentos de gestão do SUS poderiam apoiar-se na utilização de conhecimento científico-técnico ou reproduzi-lo.

A linha de investigação seguida pretendeu contribuir para desvelar o fluxo da comunicação científica, o processo de produção do conhecimento científico em saúde pública no Brasil e sua possível relação com o processo de decisão em saúde. Ao delinear o objeto de análise, partiu-se do princípio de que o conhecimento cientifico é subsídio importante para o aprimoramento dos processos de gestão em saúde. Considerou-se também que a produção científica brasileira em saúde ocupa lugar de destaque na América Latina. Existem várias iniciativas no país para controle e disseminação dessa produção em bases de dados e outras fontes de informação, que permitiriam à produção científica ser conhecida e utilizada nos processos de tomada de decisão política em saúde.

Para contextualização desta pesquisa, foram utilizados textos básicos e recentes considerados importantes como referencial teórico para a análise e interpretação dos dados levantados. Inicialmente procurou-se identificar, por meio da literatura existente, as transformações políticas, culturais e sociais decorrentes da construção do denominado Espaço do Conhecimento e os impactos na comunicação científica e nos processos de gestão; o contexto histórico do modelo de gestão do SUS e a evolução do papel dos gestores do Sistema Único de Saúde; a situação atual da produção científica na área de saúde pública; e as perspectivas de uso da informação científico-técnica na tomada de decisão em saúde.

A descrição detalhada dos instrumentos de gestão do SUS e da evolução do papel dos gestores estaduais e municipais no processo de descentralização e de tomada de decisão local, de acordo com as normas operacionais básicas, foi considerada necessária para o embasamento das propostas de aproximação entre os processos de gestão do SUS e os pesquisadores da área de Saúde.

A revisão da literatura sobre os sistemas de informação em saúde existentes no país, nos quais os gestores têm se apoiado durante o processo de decisão política, mostrou que os conceitos de 'sistemas de informação em saúde' e de 'informação em saúde' têm conotações distintas na área da saúde e na área de comunicação e informação. Nesta pesquisa, 'informação em saúde' foi considerada tanto informação estatística e 
epidemiológica, que reflete as realidades locais dos serviços e das ações de saúde, como informação científica e técnica na área da saúde.

Estudos sobre o uso da informação científica por gestores na tomada de decisão em saúde procuraram analisar as dificuldades encontradas para que o conhecimento científico e técnico fosse eficientemente utilizado e apresentaram propostas para uma aproximação entre a pesquisa e a ação em saúde. Um dos estudos encontrados na literatura, realizado no México, foi descrito detalhadamente por ter servido de base para algumas reflexões desta pesquisa.

Provavelmente não seria possível esgotar o tema com esta pesquisa, pelo amplo leque de questões envolvidas no processo de tomada de decisão em saúde e no de produção do conhecimento científico. Assim, procurou-se optar por enfoques de análise que permitissem apontar caminhos para a disseminação do conhecimento científico de forma apropriada e para sua efetiva utilização no processo de tomada de decisão, de forma a atender progressivamente às demandas do SUS.

Decidiu-se analisar a literatura de saúde pública, partindo-se do pressuposto que ela seria a mais adequada como subsídio aos processos de gestão, pelos próprios temas constitutivos dessa área. Além disso, várias fontes de informação têm sido preparadas, filtrando-se as informações específicas dessa área, o que nos permitiria observar também as características dessa fragmentação.

Considerou-se a internet o ambiente privilegiado para a disseminação do conhecimento científico, em que deveriam estar disponíveis as fontes de informação científico-técnicas produzidas no país e ser promovidos o intercâmbio e a disseminação de informações entre e para os gestores das esferas federal, estadual e municipal. Apesar de o acesso à internet não ser ainda extensivo a toda população e a todos municípios brasileiros, a tendência de utilizá-la como meio de disseminação massiva de informações na área da saúde é uma realidade. O Ministério da Saúde, as Secretarias Estaduais de Saúde e várias Secretarias Municipais de Saúde desenvolveram sites na rede mundial de computadores para divulgar informações visando a atingir toda população, desde o cidadão até os gestores do SUS.

A análise concentrou-se em três conjuntos de dados: as fontes de informação disponíveis relativas à produção científica brasileira da área de saúde pública e como 
elas poderiam subsidiar o gestor em situações de decisão política; as Agendas Estaduais de Saúde, como instrumentos de gestão que poderiam estar fundamentados em informação científica; e as informações que são divulgadas para os gestores pelos órgãos governamentais em saúde como apoio aos processos de gestão do SUS, especificamente nos sites do Ministério da Saúde e das Secretarias Estaduais de Saúde. A idéia foi percorrer todo o fluxo da comunicação, desde sua produção até a disseminação e as condições de uso pelos gestores.

Os resultados foram apresentados após cada análise pontual realizada sobre o conteúdo das bases de dados nacionais e internacionais; a situação das revistas científicas da área; a distribuição por áreas temáticas; a identificação das instituições produtoras de informação científica e técnica; as metas específicas das agendas de saúde; e o conteúdo dos sites das secretarias. O quadro de análise foi complementado com uma simulação de uma demanda local específica sobre dengue.

Para a análise das fontes de informação científicas, privilegiou-se especificamente a Biblioteca Virtual em Saúde - Saúde Pública Brasil (BVS-SP), por ter sido identificada pelo Ministério da Saúde* como um espaço privilegiado para o acesso à informação científico-técnica como apoio à tomada de decisão em saúde e gestão do SUS e por representar o esforço conjunto de várias instituições nacionais representativas da área e da OPAS (Organização Pan-Americana da Saúde), por meio da BIREME (Centro Latino-Americano e do Caribe de Informação em Ciências da Saúde), na construção de fontes de informação apropriadas ao processo de gestão do SUS.

Embora fosse inicialmente um objetivo desta pesquisa, não foi possível aprofundar reflexões para a construção de instrumentos que facilitem e apóiem o processo de comunicação entre gestores e pesquisadores. Procurou-se, no entanto, sugerir possibilidades existentes e futuras para disseminação mais ampla dos resultados da pesquisa científica dirigida aos tomadores de decisão, de forma a contribuir para que os processos de decisão sejam progressivamente baseados em conhecimentos científicos e técnicos relevantes, pertinentes e atualizados. Ficou patente que essa

\footnotetext{
* Notícia publicada no boletim Ministério da Saúde Informa, Brasília, março de 2002 sob o título "BVS: nova era para a Saúde".
} 
aproximação é complexa e exigirá a mobilização e participação ativa de muitos atores sociais. 


\section{CAPÍTULO 2}

\section{O ESPAÇO DO CONHECIMENTO}

Vários fatores influenciaram diretamente o processo de informação e informatização da sociedade: a globalização, a pós-modernidade, odesenvolvimento das tecnologias de informação e comunicação, entre outros . A economia informacional é global. Segundo CASTELLS (2000), a globalização é um processo pelo qual as atividades decisivas em um âmbito de ação determinado (a economia, os meios de comunicação, a tecnologia, a gestão do meio ambiente) funcionam como unidades em tempo real no conjunto do planeta (p. 111). Ao mesmo tempo em que unifica os espaços econômicos, ela desarticula os espaços sociais e institucionais.

Com a pós-modernidade, discute-se a relatividade do conhecimento, abandonando a visão de que a ciência estava construída sobre uma base firme de fatos observáveis. A ênfase recai sobre o social, com interesse pelo local em lugar do universal. Como mostraram os pensadores pós-modernos, "o conhecimento como é concebido tradicionalmente se evapora para ser reconstituído como superfícies construídas ou como se pode ver mais claramente em Foucault - como poder sobre os outros" (LYON 1998, p. 23).

Até recentemente, a sociedade moderna era concebida em termos de propriedade e trabalho como bens de capital. A transição da moderna sociedade para uma 'Sociedade do Conhecimento' deu-se principalmente pelo conceito de conhecimento como bem de capital, fonte de crescimento econômico e de desenvolvimento de atividades com valor agregado. A ação humana sempre foi baseada em conhecimento, mas só recentemente ele se tornou fundamental e até mesmo estratégico em todas as esferas, modificando ou substituindo fatores que antes influenciavam a ação social. "Nessa síntese entre sociedade e conhecimento, (....) emerge cada vez mais a necessidade de o conhecimento ser apreendido à luz de sua dimensão social" (BAUMGARTEN 2001, p. 10).

CASTELLS (2000) fundamenta que as sociedades se organizam em processos estruturados por relações de produção, experiência e poder. A produção representaria 
a matéria da qual a humanidade se apropriaria para transformá-la em produto de consumo. A experiência se referiria à ação dos seres humanos em relação aos ambientes sociais e naturais. O poder seria a relação entre os sujeitos humanos que impõe, com base na produção e na experiência, a vontade de alguns sobre os outros. As instituições sociais seriam constituídas para determinar as relações de poder em cada momento histórico. O autor identificou, na história da humanidade, três modos de desenvolvimento: agrário, industrial e informacional, definidos pelo elemento fundamental do processo produtivo. A informação sempre esteve presente na história da humanidade, mas, no modo informacional, passou a ser a força produtiva direta no sistema de produção, promovendo novas formas de interação e controle social (p. 33-36).

No modo informacional de desenvolvimento, a fonte de produtividade acha-se na tecnologia de geração de conhecimentos, de processamento da informação e de comunicação de símbolos. $\mathrm{Na}$ verdade, conhecimentos e informação são elementos cruciais em todos os modos de desenvolvimento, visto que o processo produtivo sempre se baseia em algum grau de conhecimento e no processamento de informação. Contudo, o que é específico ao modo informacional de desenvolvimento é a ação de conhecimentos sobre os próprios conhecimentos como principal fonte de produtividade (p. 35).

TOFFLER (1992) também classificou a história da civilização em três períodos definidos como ondas, que colidiriam e se sobreporiam provocando mudanças em seu entorno. A Primeira Onda corresponderia à revolução agrícola, a Segunda, à revolução industrial, e a Terceira, à revolução da tecnologia e da informação. O autor definiu a civilização da Terceira Onda como algo novo,

(....) que deitará por terra as burocracias, reduzirá o papel do estado-nação e irá gerar economias semi-autônomas, num mundo pós-imperialista. Exigirá governos mais simples, mais eficazes e, não obstante, mais democráticos do que qualquer um dos que conhecemos atualmente. Será uma civilização com sua própria 
perspectiva diferente do mundo, seus próprios métodos de lidar com o tempo, o espaço, a lógica e a causalidade (p.24).

Nessa civilização, o insumo central seria a informação. E, quanto mais variada ela fosse em relação a tecnologias, formas de energia e população, mais informação deveria fluir entre seus integrantes e mais coesos e rápidos se tornariam os relacionamentos.

LÉVY (1999) caracterizou a humanidade em 'espaços antropológicos' - a Terra, o Território, o Espaço Mercantil e o Espaço do Saber -, em que as regras do jogo social e a identidade dos jogadores foram alteradas no decorrer do tempo. Assim como TOFLLER (1992), LÉVY acreditava que nenhum dos espaços seria superado pelo outro, mas, pelo contrário, representaria uma evolução com possibilidade de comandar os anteriores, sem fazê-los desaparecer. "Hoje se abre um novo 'espaço antropológico', o Espaço do saber, que poderia muito bem comandar os espaços anteriores: a Terra, o Território e o Espaço mercantil" (p. 22).

A Terra, segundo o autor, foi o primeiro espaço de significação da humanidade, em que se desenvolveram a linguagem, a técnica e as formas complexas de organização social. O Espaço do Território surgiu com a agricultura, a cidade, o Estado e a escrita, que originou o aperfeiçoamento dos saberes de tipo sistemático, teórico. Nessa fase, surgiram as instituições com suas hierarquias, regras e fronteiras. Desde o século XVI, ampliou-se o Espaço das Mercadorias, cujo princípio organizador seria o fluxo de energias, de matérias-primas, mercadorias, mão-de-obra e informações. Neste, a riqueza não proveria do domínio das fronteiras, mas do controle dos fluxos, da informação e da indústria de tratamento da matéria. A ciência experimental surgiu nessa etapa, e o trabalho definiu a nova identidade social (p. 22-25).

O Espaço do Saber, apresentado pelo autor como um novo horizonte, seria caracterizado pela velocidade da evolução dos saberes, que lideraria as outras evoluções da vida social pelo volume de pessoas que produziriam conhecimentos e pelas novas ferramentas tecnológicas (o "ciberespaço").

Constituir o Espaço do saber seria, em especial, dotar-se dos instrumentos institucionais, técnicos e conceituais para tornar a informação "navegável", para que cada um possa orientar-se e 
reconhecer os outros em função dos interesses, competências, projetos, meios, identidades recíprocos no novo espaço (LÉVY 1999, p. 25).

Em termos sociais, esse novo espaço de interações permitiria a criação do que o autor denominou inteligência coletiva, "uma inteligência distribuída por toda parte, incessantemente valorizada, coordenada em tempo real, que resulta em uma mobilização efetiva das competências" (p. 28).

No Espaço do Saber, o tratamento da informação deveria ser distribuído e coordenado por toda parte, não sendo mais exclusivo de órgãos sociais separados, mas, ao contrário, integrado a todas as atividades humanas para ser possível sua utilização por cada indivíduo novamente.

Essa nova dimensão da comunicação deveria, é claro, permitir-nos compartilhar nossos conhecimentos e apontá-los uns para os outros, o que é a condição elementar da inteligência coletiva. Além disso, ela abriria duas importantes possibilidades, que transformariam radicalmente os dados fundamentais da vida em sociedade. Em primeiro lugar, disporíamos de meios simples e práticos para saber o que fazemos juntos. Em segundo lugar,

manejaríamos, com facilidade ainda maior do que o fazemos com a escrita, os instrumentos que permitem a enunciação coletiva (LÉVY 1999, p. 18).

Diante do processo de inteligência coletiva, o conhecimento individual seria potencializado ao tornar-se um coletivo inteligente, que representaria uma nova forma democrática. Os indivíduos exporiam os problemas que parecessem importantes para a vida coletiva, posicionar-se-iam frente a eles e formulariam argumentos de apoio a suas posições. As decisões, uma vez em prática, poderiam ser avaliadas pela própria coletividade, reforçando a responsabilidade dos cidadãos nos processos de decisão local. A organização social, neste contexto, exerceria um papel de dinamizadora de processos de conhecimento coletivo e não serviria apenas para reforçar territórios. 
STEHR (2001) definiu a saúde como forma e componente do "capital" sanitário individual e coletivo. $\mathrm{Na}$ área da saúde, segundo o autor, poderiam ser observados, de maneira mais convincente, benefícios e desvantagens associados à mobilização do conhecimento como recurso de capital. Toda pessoa e toda sociedade nasceriam com um estoque inicial de saúde, que diminuiria com a idade, mas esse processo poderia ser alterado na Sociedade do Conhecimento. Os indivíduos informados poderiam interferir até na evolução natural das doenças e, como cidadãos, exerceriam o controle social. O conhecimento implicaria uma 'capacidade para ação': produziria aumento das propriedades de decisão ou da habilidade do 'saber-fazer', que poderia ser apropriado pelos indivíduos em particular. Essa capacidade para a ação, apesar de aberta a todos os indivíduos, dependeria de um contexto de condições sociais, econômicas e intelectuais específicas. As sociedades modernas tenderiam a ser frágeis, pois as instituições sociais poderiam ter maior dificuldade de impor suas normas, planos e estratégias a toda a sociedade, uma vez que os indivíduos informados adquiririam mais capacidade de decisão.

O conhecimento, segundo STEHR (2000), entendido enquanto capacidade para a ação, estaria inserido no processo de formação de desigualdades sociais e poderia ser 
"conceituado como um pacote de competências (....) que produz diferentes benefícios (ou custos) sociais para aqueles que são capazes de mobilizar seus recursos em situações apropriadas” (p. 9).

Dentre as competências sociais, ligadas ao conhecimento, que poderiam dirigir a desigualdade social no mundo contemporâneo, esse autor destacou:

- a capacidade de tirar partido do discernimento e extrair vantagens comparativas;

- $\quad$ a facilidade de organizar recursos de proteção;

- a autoridade para falar, baseada na capacidade de dominar conhecimentos;

- $\quad$ a capacidade de preparar-se para desafios;

- a capacidade de evitar e excluir.

Essas competências fariam com que os sujeitos tomassem conta de si mesmos, não sendo passivos perante as circunstâncias sociais. Deveriam preparar-se para ocupar seu lugar na sociedade. "As novas realidades exigiriam uma nova linguagem, que deveria acentuar, dentre outros aspectos, a ação e a heterogeneidade das estruturas sociais” (p. 12).

Nesse cenário da sociedade do conhecimento, surgiriam espaços importantes para interconectividade e convergência de idéias. Segundo LÉVY (2001), “a melhor maneira de manter e desenvolver uma coletividade não é mais erguer, manter ou estender fronteiras, mas alimentar a quantidade $e$ melhorar a qualidade das relações em seu próprio interior, assim como com outras coletividades" (p.27).

O desenvolvimento dos processos de inteligência coletiva seria facilitado pela evolução de tecnologias das redes digitais, da informática e da rede mundial de computadores, a World Wide Web, que permitiria a criação de um espaço virtual para convergência de idéias. Nesse espaço, cresceria a possibilidade de translucidez e universalidade das ações, tornando a sociedade humana transparente para si mesma. Seria possível a cada pessoa mostrar a indivíduos de todo planeta tudo o que fosse 
produzido ao mesmo tempo e no mesmo espaço. Por sua vez, todos poderiam ver e acessar essa produção, divulgada simultaneamente na mesma mídia, independentemente do lugar em que estivessem.

$\mathrm{Na}$ Web, tudo está no mesmo plano (....). E, no entanto, tudo é diferenciado. Não há hierarquia absoluta, mas cada site é um agente de seleção, de orientação, de hierarquização parcial. (....)

A Web anuncia e realiza progressivamente a unificação de todos os textos em um único hipertexto, a fusão de todos os autores em um único autor coletivo, múltiplo e contraditório. Não há mais que um único texto, o texto humano (LÉVY 2001, p. 141).

CASTELLS (2000) também ressaltou que o novo paradigma tecnológico estaria transformando o padrão organizacional em redes:

Pela primeira vez na história, a unidade básica da organização econômica não é um sujeito individual (como o empresário ou a família empresarial) nem coletivo (como a classe capitalista, a empresa,o Estado). (....) as unidades da rede, formada de vários sujeitos e organizações, modificam-se continuamente conforme as redes adaptam-se aos ambientes de apoio e às estruturas de mercado (p. 216).

As tecnologias de comunicação, trabalhando em rede, serviriam de sustentação para o pensamento coletivo, numa intrincada união de conhecimentos e práticas, envolvendo uma complexa trama de atores sociais.

LÉVY (2001) discutiu as principais causas da diferença entre a situação que prevalecia antes do aparecimento das tecnologias de comunicação e a realidade atual. Uma delas seria a velocidade de transmissão dos conhecimentos, à qual se associaria um aumento da proximidade e da densidade de interconexão entre os indivíduos. $\mathrm{O}$ tempo que separa a descoberta de sua divulgação encurta à medida que diminuem as distâncias entre os interlocutores. Outra seria a desfragmentação das idéias. " $O$ conhecimento da sociedade por ela mesma, que começamos a antever no horizonte da cibercultura, não terá 'disciplinas' para impedir a compreensão do que ela vive”. 
Além das distâncias de tempo e espaço que se tornaram praticamente inexistentes no universo virtual, nenhuma dimensão da vida social estaria separada uma da outra. " $A$ economia possui uma dimensão sanitária e a saúde, uma dimensão econômica, apesar do fato de que a economia e a saúde são administradas cada uma por um ministério separado" (p.70).

A dinâmica da ciência e da pesquisa na sociedade contemporânea foram influenciadas por essas novas formas de organização social e de conhecimento coletivo. Segundo GIBBONS et al. (2000), mudanças estruturais estariam alterando as relações entre a comunidade científica e a sociedade em geral, e o conhecimento seria socialmente distribuído para um segmento mais amplo da sociedade. Esses autores denominaram essa nova forma de produção de conhecimento de 'Modo 2', em contraposição à forma tradicional de produção do conhecimento científico, denominada por eles de 'Modo 1'.

A ciência e a pesquisa, no Modo 1, seguiriam normas cognitivas e sociais que determinariam quais problemas deveriam ser considerados significativos, quem deveria praticar ciência e o que constituiria a boa ciência. Os problemas no Modo 1 seriam trabalhados no contexto da comunidade científica, constituído principalmente por instituições acadêmicas, num ambiente homogêneo em seu método de pesquisar, mas dividido em disciplinas e hierarquizado. O Modo 2 aconteceria num contexto de aplicação, de transdisciplinaridade e heterogeneidade, aberto à reflexão e ao controle social. Incluiria um conjunto mais amplo e heterogêneo de indivíduos, colaborando em situações específicas e problemas localizados (p. 1-7).

A produção do conhecimento, na visão desses autores, tornar-se-ia difusa em toda a sociedade, podendo ser considerada como ‘conhecimento socialmente distribuído'. O saber deveria ser útil para determinado interlocutor, e esse objetivo deveria ficar claro desde o início das pesquisas.

A transdisciplinaridade na produção do conhecimento, descrita por GIBBONS et al. (2000), teria quatro características distintas:

- desenvolveria um ambiente propício para solução integrada de problemas, desde a concepção da pesquisa; 
- a solução compreenderia componentes teóricos e empíricos, não necessariamente limitados por conhecimentos específicos de uma disciplina;

- os resultados seriam disseminados aos que estivessem envolvidos no processo, à medida que fossem sendo alcançados, e não necessariamente através dos canais formais de comunicação;

- haveria dinamismo e capacidade de resolução de problemas à medida em que estes surgissem.

Os resultados não necessariamente deveriam estar inseridos no contexto de uma disciplina em particular. Poderiam ser continuamente interligados, formando conjuntos ou configurações específicas, de forma temporária, nos contextos para os quais estivessem em aplicação.

Dessa maneira, o impacto das pesquisas integraria o contexto de aplicação e seria construído desde o início das atividades. Segundo os autores, o trabalho no contexto da aplicação aumentaria a sensibilidade dos cientistas e técnicos para as implicações gerais do que estivessem fazendo. A reflexão sobre os problemas e as soluções seria estimulada, pois a pesquisa poderia não encontrar respostas apenas em termos científicos e técnicos, uma vez que teria de considerar o contexto social.

As demandas para pesquisa viriam de muitas frentes: da sociedade, do governo, de instituições formais, grupos de interesses e indivíduos que necessitassem saber mais sobre temas específicos. Esse complexo sistema de atores poderia estimular a demanda e a oferta de conhecimento especializado (p. 12).

Os processos de legitimação dos resultados teriam de ser ampliados, e os critérios para medir o sucesso ou impacto das pesquisas deveriam ser redefinidos de maneira a incluir, além das normas de excelência científica tradicionais, medidas de eficiência ou utilidade em relação às contribuições dos trabalhos para a solução de problemas freqüentemente transdisciplinares (p. 22).

NOWOTNY et al. (2001) avançaram as reflexões sobre o Modo 2 de conhecimento e trataram de identificar as transformações da sociedade que teriam causado as mudanças na dinâmica de produção de conhecimento. Um dos pontosdestacados 
pelos autores seria o processo de descentralização da autoridade política, que fez com que os cidadãos deixassem de ser receptores passivos de bens públicos e passassem a manifestar suas idéias e necessidades. Outro ponto seria a demarcação cada vez mais frágil entre as instituições produtoras de conhecimento, como as universidades e os institutos de pesquisa, e outros tipos de organizações.

Segundo esses autores, o conhecimento científico passaria a ser testado não mais no abstrato, mas em situações concretas e locais, dirigidas a contextos específicos. A confiabilidade desse conhecimento deveria ser complementada e fortalecida socialmente. Uma das formas de conseguir contextualizar as pesquisas seria tornar as pessoas atingidas ou beneficiadas em agentes ativos no processo de conhecimento. Os especialistas passariam a responder não somente a questões científicas ou técnicas e teriam de considerar audiências compostas por outros atores, que não somente os especialistas. O conhecimento, como força social, seria produto de uma interação intensa e contínua entre a informação gerada e os resultados. "A contextualização significa que as implicações (desconhecidas) assim como as aplicações (aplicáveis e previsíveis) da pesquisa científica teriam que abraçar-se” (p. 245-53).

Nessa forma de integração entre o conhecimento e a percepção social, “os papéis do cientista e do político se redefinem, mesclam-se e implicam mudanças importantes em seus padrões éticos de conduta, com conseqüências em sua formação e a atuação cotidiana". Enquanto o cientista tem o dever e o compromisso com a verdade, cabe ao político a adoção de soluções práticas, o que acarreta a necessidade de se buscar a qualidade e a objetividade acadêmicas e a relevância social (TRIGUEIRO 2001, p. 62-63).

Diante do novo paradigma da Sociedade do Conhecimento, a estratégia da Biblioteca Virtual em Saúde (BVS) pretende promover a convergência de produtores de informação, intermediários e usuários, num único espaço virtual, possibilitando a produção e o acesso às informações produzidas pelos diferentes atores na internet. A utilização de novas metodologias e tecnologias de informação deverá permitir a expansão e consolidação de um espaço coletivo, que experimentará novas formas de 
organização e de tratamento da informação, descentralizadas e interativas, que poderão estimular o processo de tomada de decisão em saúde e de socialização da resolução de problemas.
A BVS contribui para construir um "espaço de conhecimento" onde todos podem participar com seu saber e suas vivências. Nesse espaço, as pessoas se encontram não por terem uma profissão ou uma posição social, mas por possuir vivências, experiências e conhecimentos. Este espaço de alto significado ético, pois não exclui a ninguém, permite um esforço solidário na criação de ambientes e comportamentos saudáveis, de sistemas de saúde mais equitativos, eficazes e eficientes, e de agendas de pesquisa participativas que respondam a múltiplos interesses e necessidades (PELLEGRINI FILHO 2000, p.85). 


\section{CAPÍTULO 3}

\section{O SETOR SAÚDE}

Os princípios que nortearam os processos de Reforma da Saúde refletiram a nova ordem social estabelecida pela Sociedade do Conhecimento. A busca por uma maior participação da comunidade, a introdução de vários atores sociais no processo de gestão, a descentralização das decisões em nível municipal, a realização de orçamentos participativos e o intercâmbio de experiências e de recursos seriam princípios desse novo paradigma.

A área da saúde pública passou historicamente por sucessivos movimentos de transformação das práticas sanitárias em decorrência de mudanças nas articulações entre Estado e sociedade, caracterizadas por distintas respostas sociais às necessidades e aos problemas de saúde. Da Higiene, no século XVIII, à Medicina Social e ao Sanitarismo, após a Revolução Industrial, da Medicina Preventiva e Saúde Comunitária até os movimentos da Reforma do Setor Saúde, o campo da saúde foi transformado em resposta aos contextos sócio-político-culturais vigentes (PAIM e ALMEIDA FILHO, 1998).

No Brasil, essas mudanças do setor saúde conduziram a um modelo de gestão compatível com as demandas sociais atuais, em que se privilegiam o exercício da cidadania e a participação de toda a sociedade. Esse modelo poderia proporcionar, nessa área, o desenvolvimento de uma inteligência coletiva capaz de promover o aprimoramento da atenção e da gestão do setor saúde. A capacitação dos gestores para o exercício dessa atividade e o desenvolvimento de mecanismos que levem à geração desse conhecimento coletivo seriam dois dos princípios importantes da política de implantação do modelo de gestão do Sistema Único de Saúde. 


\subsection{Contexto histórico das transformações do setor saúde}

Desde princípios dos anos 70, intensificaram-se no Brasil movimentos organizados envolvendo profissionais de saúde e outros interessados no setor que denunciavam a crise do sistema, as más condições de saúde da população e a precariedade do exercício profissional, e iniciou-se um processo de discussão para a reestruturação do modelo de atenção e a constituição de um sistema único de saúde no país.

A reunião de Alma Ata, patrocinada pela Organização Mundial da Saúde, realizada em 1978, influenciou fortemente as discussões sobre um novo modelo de saúde, pela difusão do princípio da atenção primária à saúde.

O processo de discussão para a reestruturação do modelo de saúde no Brasil e a constituição de um sistema único se estendeu pela década de 80 , culminando com as resoluções da $8^{\text {a }}$ Conferência Nacional de Saúde em 1986 - foro histórico de negociações entre governo e diversos atores sociais - e a inclusão de temas específicos sobre saúde na Constituição Federal, promulgada em 1988.

A $8^{\text {a }}$ Conferência Nacional de Saúde defendeu a necessidade de uma ampla e profunda Reforma Sanitária no Brasil, que permitisse o deslocamento do poder político para as camadas populares e a criação de um sistema único de saúde. Além disso, aprovou definições e propostas relativas ao conceito ampliado de saúde, ao direito da cidadania, ao dever do Estado e às bases financeiras do sistema.

Esta Conferência resultou de um processo democrático de discussão, com alta participação da comunidade, que teve início com as pré-conferências estaduais, culminou na Conferência em si e desdobrou-se em 1986/1987 nas discussões das chamadas conferências "específicas" por temas e áreas de atuação. Esse processo teve dois desdobramentos principais: a constituição da Comissão Nacional de Reforma Sanitária e a conformação da Plenária Nacional de Entidades de Saúde. A Comissão Nacional de Reforma Sanitária era composta pelo governo e a sociedade civil e realizou um trabalho técnico. A Plenária Nacional de Entidades de Saúde apresentou várias propostas à Constituição e fez-se representar ativamente para aprová-las. O resultado principal desse processo de discussões foi a aprovação de um capítulo sobre saúde, inédito na história constitucional. 
Art. 196. A saúde é direito de todos e dever do Estado, garantido mediante políticas sociais e econômicas que visem à redução do risco de doença e de outros agravos e ao acesso universal igualitário às ações e serviços para sua promoção, proteção e recuperação (BRASIL 1999, p.111).

A $8^{\mathrm{a}}$ Conferência encerrou um ciclo ideológico com a formação de uma proposta de Reforma Sanitária caracterizada por três aspectos principais, expressada no RELATÓRIO FINAL (1986):

- o conceito abrangente de saúde:

a saúde é resultante das condições de alimentação, habitação, educação, renda, meio ambiente, trabalho, transporte, emprego, lazer, liberdade, acesso e posse da terra e acesso a serviços de saúde (Tema 1, Parágrafo 1, p. 382).

- a noção de saúde como direito do cidadão e dever do Estado:

o direito à saúde significa a garantia, pelo Estado, de condições dignas de vida e de acesso universal e igualitário às ações e serviços da promoção, proteção e recuperação da saúde, em todos os seus níveis, a todos os habitantes do território nacional, levando ao desenvolvimento pleno do ser humano em sua individualidade (Tema 1, Parágrafo 3, p. 382).

- a instituição do Sistema Único de Saúde:

A reestruturação do Sistema Nacional de Saúde deve resultar na criação de um Sistema Único de Saúde que efetivamente represente a construção de um novo arcabouço institucional separando totalmente saúde da previdência, através de uma ampla reforma sanitária (Tema 2, Parágrafo 1, p. 384).

Na Constituição Federal, foram definidas as diretrizes para o SUS: 
Art. 198. As ações e serviços públicos de saúde integram uma rede regionalizada e hierarquizada e constituem um sistema único, organizado de acordo com as seguintes diretrizes:

I - descentralização, com direção única em cada esfera de governo;

II - atendimento integral, com prioridade para as atividades preventivas, sem prejuízo dos serviços assistenciais;

III - participação da comunidade (BRASIL 1999, p.111).

A Reforma Sanitária constituiu uma verdadeira Reforma de Estado, inscrevendo-se na Constituição Federal e passando a ser considerada na agenda política da sociedade, ligada ao Estado por uma política permanente de bem-estar e promoção de saúde. A Carta da $10^{\mathrm{a}}$ Conferência Nacional de Saúde reafirma que "o SUS representa o exemplo mais importante de democratização do Estado, em nosso país" (RELATÓRIO DA $10^{\text {a }}$ CONFERÊNCIA..., 1996).

O Sistema Único de Saúde (SUS) foi regulamentado com a aprovação da "Lei Orgânica da Saúde" ou Lei 8.080, de 19 de setembro de 1990, que "dispõe sobre as condições para a promoção, proteção e recuperação da saúde, a organização e o funcionamento dos serviços correspondentes e dá outras providências” (BRASIL 1990a).

Segundo a Lei 8.080, as ações e os serviços de saúde que compõem o SUS deveriam ser desenvolvidos de acordo com as diretrizes previstas no artigo 198 da Constituição Federal, obedecendo também aos princípios de universalidade, integralidade da assistência, autonomia, igualdade, direito à informação sobre saúde, divulgação de informações sobre serviços, utilização da epidemiologia para definição de prioridades, participação da comunidade, descentralização político-administrativa e integração, em nível executivo, das ações de saúde, de meio ambiente e de saneamento básico. As ações e os serviços de saúde deveriam ser organizados, de forma regionalizada e hierarquizada, em níveis de complexidade crescente. Esse sistema foi baseado no princípio da descentralização de recursos e delegação de 
poder para os níveis estadual e municipal para formulação de políticas de saúde específicas que obedeçam, ao mesmo tempo, às diretrizes nacionais.

A Lei 8.142, aprovada em 28 de dezembro de 1990, “dispõe sobre a participação da comunidade na gestão do Sistema Único de Saúde (SUS) e sobre as transferências intergovernamentais de recursos financeiros na área da saúde e dá outras providências". O artigo $1^{\circ}$ dessa lei expressa que "o SUS contará, em cada esfera de governo, com as seguintes instâncias colegiadas: a Conferência de Saúde e o Conselho de Saúde” (BRASIL 1990b).

No âmbito da política nacional de saúde, as Conferências Nacionais de Saúde constituem palcos e momentos privilegiados para análise da relação Estado/Sociedade, na medida em que congregam um conjunto amplo de atores do governo e da sociedade civil e possibilitam a manifestação dos diferentes interesses. Atuam tanto como instâncias de controle social quanto de análise da sociedade em geral, representando demandas e pressões não somente do setor saúde mas também das relações sociais.

Segundo manifestou o Secretário de Saúde do Estado do Rio de Janeiro na Introdução do Manual do Gestor, do Conselho de Secretários Municipais de Saúde do Rio de Janeiro,

O SUS, concebido enquanto processo social, tem uma forte dimensão política, dado que sua construção e consolidação abarca no espaço democrático a participação de diversos atores que portam interesses e projetos diferenciados. Apresenta uma dimensão ideológica que parte da concepção ampliada do processo saúde-doença e nesta lógica da reorientação do modelo 
de atenção à saúde. E ainda uma dimensão tecnológica que envolve a produção e utilização de conhecimentos e técnicas que devem ser implementadas tendo como foco a garantia dos princípios e diretrizes do SUS (CONSELHO DE SECRETÁRIOS... 2001, p. 12).

O SUS implicou também, para a gestão local, a criação dos Conselhos Nacional, Estadual e Municipal de Saúde, compostos por representantes do governo e da sociedade (usuários, trabalhadores de saúde e prestadores de serviços), do Conselho Nacional de Secretários Estaduais de Saúde (CONASS) e do Conselho Nacional de Secretários Municipais de Saúde (CONASEMS), como instâncias intermediárias

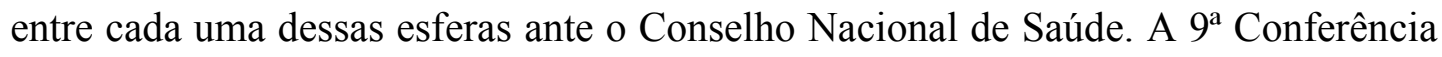
Nacional de Saúde, realizada em 1992, cujo tema foi a municipalização, contribuiu para que fossem criados os Conselhos de Saúde, nos estados e municípios onde ainda não estivessem estruturados, e para que fossem consideradas as experiências locais na discussão nacional.

À medida que o SUS avançava, foram aprovadas Normas Operacionais Básicas para a definição de estratégias e movimentos táticos que orientavam a operacionalidade do sistema. A implantação das Normas Operacionais Básicas do Sistema Único de Saúde (NOB 01/91, NOB 01/92, NOB 01/93 e NOB 01/96) desencadeou um processo de descentralização intenso, transferindo para os estados e, principalmente, para os municípios, um conjunto de responsabilidades e recursos para a operacionalização do Sistema Único de Saúde.

A NOB 01/91 previa a formalização de convênios entre o INAMPS/MS e os estados e municípios, mas esses eram tratados como meros prestadores de serviços. Essa situação não favorecia as demandas reais da sociedade e, após discussão pela comunidade, foi modificada no mesmo ano, acrescentando propostas do Conass, Conasems e outros setores da área da saúde. A NOB 01/92, editada em fevereiro de 1992, resultou de negociações com a sociedade e apontou para a necessidade de normatizar as ações para a construção e maturação do SUS. 
A partir da NOB 01/93, estabelecida pela Portaria 545 do Ministério da Saúde, de 20 de maio de 1993, em seguimento às resoluções da $9^{a}$ Conferência Nacional de Saúde, foram estipuladas regras para transferências de recursos, mecanismos de controle, de avaliação e de pactuação política e níveis progressivos de gestão local do SUS.

A NOB 01/96 trata da conformação de um novo modelo de atenção à saúde, com ênfase na gestão local da atenção em cada esfera de governo e na construção da rede regionalizada e hierarquizada de serviços.

A presente Norma Operacional Básica tem por finalidade primordial promover e consolidar o pleno exercício, por parte do poder público municipal e do Distrito Federal, da função de gestor da atenção à saúde dos seus munícipes (Artigo 30, incisos V e VII, e Artigo 32, Parágrafo $1^{\boldsymbol{o}}$, da Constituição Federal), com a conseqüente redefinição das responsabilidades dos Estados, do Distrito Federal e da União, avançando na consolidação do SUS (MINISTÉRIO DA SAÚDE, 1996).

A Carta da $10^{a}$ Conferência Nacional de Saúde, realizada em 1996, reafirmou que o novo modelo de atenção à saúde deveria passar pela maior autonomia dos municípios e regiões, com participação popular e controle social, com a atuação de conselhos paritários, tripartites e deliberativos. Destacou, ainda, que "através do processo de descentralização e consolidação da municipalização plena da saúde e a regionalização dos serviços, o SUS vem permitindo, nas cidades que avançaram na aplicação de seus princípios e diretrizes, a reversão de indicadores, a resolução dos problemas de saúde e a satisfação da população, provando assim sua viabilidade."

Segundo a Carta da $11^{\text {a }}$ Conferência Nacional de Saúde, realizada em 2000,

[.... passados quatorze anos da $8^{a}$ Conferência Nacional de Saúde, início do processo de construção do SUS, é possível constatar avanços. É significativa a transformação urbanística, sanitária e de criação do arcabouço jurídico institucional ocorrida. 
Construímos um processo de reforma setorial impulsionado por um movimento composto de vários atores sociais e ao longo destas três últimas décadas, produzimos saberes e práticas políticas, discursivas e paradigmáticas (RELATÓRIO FINAL DA $11^{\mathrm{a}}$ CONFERÊNCIA ... 2000, p. 13).

Nessa conferência foi afirmada a relevância da produção e divulgação de informações sobre o controle social por meios variados, conforme a realidade e as possibilidades locais, indicando várias estratégias possíveis e recomendáveis, entre elas as de:

criar redes de informação e comunicação entre as várias instâncias do controle social;

articular a academia, os Centros de Formação de Recursos Humanos das Secretarias da Saúde e os Pólos de Educação em Saúde para disponibilizar cursos de formação para conselheiros de saúde e usuários do SUS em geral; e

divulgar amplamente as atas das reuniões dos Conselhos, inclusive com sua distribuição via Internet (RELATÓRIO FINAL DA $11^{\mathrm{a}}$ CONFERÊNCIA ... 2000, p.66-8).

Com relação ao modelo assistencial e de gestão, os participantes da conferência enfatizaram as políticas intersetoriais, a incorporação de tecnologias e a formação de recursos humanos (pessoal de saúde, gestores e conselheiros de saúde).

A garantia de eqüidade e de acesso passa pelo conceito de regionalização da rede com amplas parcerias sociais $e$ intergestores. A informação em saúde desponta como um insumo fundamental ao planejamento e ao aperfeiçoamento das lutas por saúde. E educação na área da saúde nunca foi tão enfatizada, e não se trata mais de formar pessoal competente tecnicamente, mas que tenha vivido e refletido sobre o acesso universal, a qualidade e 
a humanização na atenção à saúde, com controle social

(RELATÓRIO FINAL DA $11^{\mathrm{a}}$ CONFERÊNCIA ... 2000, p.102).

Recomendou-se que as ações de informação, educação e comunicação deveriam tornar o SUS conhecido da população, dos profissionais de saúde, dos poderes constituídos e da sociedade não só em seus princípios, diretrizes, programas e metas mas também em suas dificuldades de recursos e de gestão.

Como conseqüência dos avanços alcançados no processo de descentralização, foi aprovada em 2001 a Norma Operacional de Atenção à Saúde (NOAS/SUS 01/01),

que amplia as responsabilidades dos Municípios na Atenção Básica; estabelece o processo de regionalização como estratégia da hierarquização dos serviços de saúde e de busca de maior eqüidade; cria mecanismos para o fortalecimento da capacidade de gestão do Sistema Único de Saúde e procede à atualização dos critérios de habilitação de Estados e Municípios (MINISTÉRIO DA SAÚDE 2001a, Artigo $1^{\circ}$ ).

Essa norma estabelece a regionalização como estratégia fundamental para o aprimoramento do processo de descentralização e para a consolidação dos princípios de universalidade, eqüidade no acesso e integralidade da atenção, propostos pelo SUS.

O processo de regionalização deverá contemplar uma lógica de planejamento integrado, compreendendo as noções de territorialidade na identificação de prioridades de intervenção e de conformação de sistemas funcionais de saúde, não necessariamente restritos à abrangência municipal, mas respeitando seus limites como unidade indivisível, de forma a garantir o acesso dos cidadãos a todas as ações e serviços necessários para a resolução de seus problemas de saúde, otimizando os recursos disponíveis (MINISTÉRIO DA SAÚDE, 2001a, Capítulo I).

A NOAS-SUS 01/01 propôs três grupos de estratégias articuladas que visam a contribuir para o processo de regionalização em saúde: 
1) elaboração do Plano Diretor de Regionalização;

2) fortalecimento das capacidades gestoras do SUS para o desenvolvimento de funções como planejamento, programação, regulação, controle e avaliação;

3) atualização dos critérios e do processo de habilitação de estados e municípios.

É importante destacar que, pelo artigo 18 da Constituição Federal, "a organização político-administrativa da República Federativa do Brasil compreende a União, os Estados, o Distrito Federal e os Municípios, todos autônomos nos termos desta Constituição" (BRASIL 1999). Essa característica confere complexidade ao processo de construção do SUS e ao de regionalização proposto pela NOAS/SUS 01/01, refletida no texto da Introdução da Norma,

os Estados, e mais ainda os Municípios, são extremamente
heterogêneos e será sempre mera casualidade que o espaço
territorial-populacional e a área de abrangência político-
administrativa de um município correspondam a uma rede
regionalizada e resolutiva de serviços com todos os níveis de
complexidade, ou mesmo que esta se localize dentro de um estado
sem exercer poder de atração para além de suas fronteiras legais (MINISTÉRIO DA SAÚDE, 2001a).

Em 2002, foi aprovada a NOAS-SUS 01/02, que retomou as tentativas de diferenciar o papel dos três gestores no sistema, enfatizando a importância da regionalização da assistência à saúde. Enfatizou a importância da descentralização de ações e serviços para os municípios e o comando único pelo gestor municipal que estiver na condição de "gestão plena do sistema" sobre todos os prestadores situados em seu território. Destacou o papel do gestor estadual no planejamento regionalizado da atenção e mediação das relações intermunicipais.

Dessa evolução histórica, nota-se que os processos de reforma do setor saúde introduziram mudanças significativas nas relações e funções em diferentes níveis do setor saúde. Novos atores públicos e privados, incluindo a comunidade, foram 
introduzidos no processo de tomada de decisão em saúde, com o objetivo de aumentar a eqüidade, a eficiência administrativa, a qualidade dos serviços, a descentralização de funções e a satisfação das necessidades de saúde da população.

Pode-se notar que o papel dos gestores foi modificado à medida que avançou o processo de descentralização expresso nas distintas normas operacionais do SUS. Enfatiza-se, cada vez mais, que o gestor municipal deve ter autonomia no processo de gestão e, portanto, mais conhecimento da situação local e da necessidade de informação, que possa subsidiar o processo de tomada de decisão. Exige-se cada vez mais que o gestor municipal defina uma agenda de prioridades locais, estabeleça um plano de metas para atenção de saúde local, com alto grau de autonomia administrativa, embora deva respeitar as Agendas Nacional e Estaduais de Saúde. Exige-se também planejamento integrado, explorando ao máximo os recursos de cada município, rumo à territorialização das ações de saúde que transcendam os territórios municipais considerados individualmente.

Planejamento integrado, conhecimento das realidades locais, definição de metas e de prioridades e atendimento territorializado exigiriam acesso a informações organizadas sobre condições de saúde locais e a informações complementares como subsídios para a tomada de decisão.

\subsection{A gestão no SUS}

O SUS e a legislação derivada visam, fundamentalmente, a atingir propósitos essenciais à concretização dos ideais constitucionais e do direito à saúde: um deles seria a consolidação de vínculos entre diferentes atores sociais e o SUS, visando a desenvolver uma programação de atividades publicamente pactuada; outro, a criação de condições para melhorar a qualidade da gestão.

Segundo o Plano Diretor da Reforma do Aparelho do Estado, elaborado pelo Ministério da Administração Federal e da Reforma do Estado, em 1995, 
o paradigma gerencial contemporâneo, fundamentado nos princípios de confiança e de descentralização da decisão, exige formas flexíveis de gestão, horizontalização de estruturas,

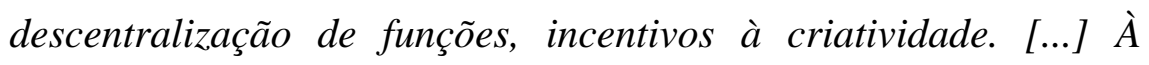
avaliação sistemática, à recompensa pelo desempenho, e à capacitação permanente [...] acrescentam-se os princípios da orientação para o cidadão-cliente, do controle por resultados e da competição administrada (PRESIDÊNCIA DA REPÚBLICA, 1996).

O Plano Diretor propôs a transição da administração pública burocrática para uma administração gerencial, que busca parcerias e cooperação com a sociedade e também entre governo, administradores e funcionários. Caberia ao gestor no poder público promover essa transição, definir objetivos, metas e estratégias articuladas entre os diversos setores da sociedade e definir indicadores de desempenho capazes de medir os resultados.

Os princípios previstos na organização do aparelho de Estado já haviam sido considerados na implementação do SUS, ao buscar a plena responsabilidade do poder público municipal, cabendo ao município o aperfeiçoamento da gestão e a reordenação do modelo de atenção à saúde, respeitadas as atribuições do Conselho Municipal de Saúde e de outras instâncias de poder. Os estados e municípios deveriam superar o papel exclusivo de prestadores de serviços e passar ao papel de gestores do SUS.

De acordo com a NOB/SUS/96,

a gerência é conceituada como sendo a administração de uma unidade ou órgão de saúde (ambulatório, hospital, instituto, fundação, etc.) que se caracteriza como prestador de serviços ao Sistema. Por sua vez, gestão é a atividade e a responsabilidade de dirigir um sistema de saúde (municipal, estadual ou nacional), mediante o exercício de funções de coordenação, articulação, 
negociação, planejamento, acompanhamento, controle, avaliação e auditoria. São, portanto, gestores do SUS os Secretários Municipais e Estaduais de Saúde e o Ministro da Saúde, que representam, respectivamente, os governos municipais, estaduais e federal (MINISTÉRIO DA SAÚDE 2001a, p. 8).

A integração e harmonização desses propósitos seriam viabilizadas com a Comissão Intergestores Tripartite (CIT), integrada pelos gestores municipal, estadual e federal, e a Comissão Intergestores Bipartite (CIB), integrada pelos gestores estadual e municipal. Essas comissões representam um espaço essencial para viabilizar os princípios de unicidade e organicidade nas três esferas de governo (MINISTÉRIO DA SAÚDE 2000).

As Normas Operacionais Básicas estabelecem o modelo de gestão do sistema e definem o papel dos gestores. A NOB/SUS/96 atribuiu plena responsabilidade ao poder público municipal, sendo a União e os estados sempre co-responsáveis. As NOAS/SUS 01/01 e 01/02, ao mesmo tempo em que ampliaram as responsabilidades dos municípios na atenção básica, deram ao gestor estadual a responsabilidade de coordenar um processo de planejamento global no estado, adotando critérios para evitar a superposição e a proliferação indiscriminada e desordenada de serviços, levando em consideração na organização de serviços as condições de acessibilidade, qualidade e racionalidade.

\subsubsection{O gestor na NOB/SUS/96}

Segundo a NOB/SUS/96, o gestor do sistema municipal é o responsável pelo controle, pela avaliação e pela auditoria dos prestadores de serviços de saúde situados em seu município. Como os sistemas municipais de saúde apresentam níveis diferentes de complexidade, é comum que estabelecimentos de saúde de um município atendam usuários de outros municípios. Caberia aos gestores municipais efetivar as negociações para programação integrada das ações entre os sistemas municipais (MINISTÉRIO DA SAÚDE 1996, p. 9). 
O gestor estadual deve desempenhar quatro papéis básicos:

1. exercer a gestão do SUS no âmbito estadual;

2. promover as condições e incentivar o poder municipal a assumir a gestão da atenção à saúde de seus munícipes;

3. assumir, em caráter transitório, a gestão da atenção à saúde de populações de municípios que ainda não tomaram para si essa responsabilidade;

4. promover a harmonização, a integração e a modernização dos sistemas municipais, compondo, assim, o SUS-Estadual (p. 10-11).

Ao gestor federal caberia:

1. exercer a gestão do SUS no âmbito nacional;

2. promover as condições e incentivar o gestor estadual com vistas ao desenvolvimento dos sistemas municipais;

3. fomentar a harmonização, a integração e a modernização dos sistemas estaduais;

4. exercer as funções de normalização e de coordenação no que se refere à gestão nacional do SUS.

A elaboração do Plano Nacional de Saúde, definindo estratégias, prioridades nacionais e metas da programação integrada nacional, caberia ao gestor federal, baseando-se nas programações estaduais e de outros órgãos governamentais que atuem no setor saúde (p.11-12).

\subsubsection{O gestor nas NOAS/SUS-01/01 e 01/02}

Na NOAS/SUS-01/01, dada à complexidade da situação dos municípios no processo de gestão, optou-se por estabelecer o processo de regionalização como estratégia de hierarquização dos serviços de saúde e de busca de maior eqüidade.

O processo de regionalização deverá contemplar uma lógica de planejamento integrado, compreendendo as noções de territorialidade na identificação de prioridades de intervenção e de conformação de sistemas funcionais de saúde, não 
necessariamente restritos à abrangência municipal, mas respeitando seus limites como unidade indivisível, de forma a garantir o acesso dos cidadãos a todas as ações e serviços necessários para a resolução de seus problemas de saúde, otimizando os recursos disponíveis (MINISTÉRIO DA SAÚDE 2001a, Capítulo I).

O capítulo I da NOAS/SUS 01/01 atribuiu as seguintes responsabilidades ao gestor estadual:

a) coordenar um processo de planejamento global no estado, elaborando o Plano Diretor de Regionalização, em consonância com o Plano Estadual de Saúde;

b) avaliar os municípios e definir se estão aptos a receber habilitação;

c) adotar critérios para a organização regionalizada das ações de média complexidade;

d) responsabilizar-se pela gestão da política de alta complexidade/custo no âmbito do estado, mantendo vinculação com a política nacional;

e) coordenar a programação pactuada e integrada no âmbito do Estado.

Segundo essa norma, os municípios poderiam habilitar-se em duas condições: Gestão Plena da Atenção Básica Ampliada e Gestão Plena do Sistema Municipal. Para habilitar-se, deveriam assumir responsabilidades de acordo com cada nível de gestão e comprovar que atenderiam aos requisitos básicos exigidos.

Caberia aos gestores municipais de municípios habilitados para Gestão Plena da Atenção Básica Ampliada:

a) elaborar Plano Municipal de Saúde, a ser submetido à aprovação do Conselho Municipal de Saúde, que deve contemplar a Agenda de Compromissos Municipal, harmonizada com as agendas nacional e estadual;

b) alimentar regularmente os bancos de dados nacionais do SUS; 
c) mostrar desempenho dos indicadores de avaliação da atenção básica no ano anterior, realizando avaliação permanente do impacto das ações do sistema sobre as condições de saúde de seus munícipes e sobre seu meio ambiente;

d) estabelecer pacto de melhoria dos indicadores de atenção básica no ano subseqüente;

e) demonstrar capacidade de assumir as responsabilidades mínimas nas áreas de atuação estratégicas: o controle da tuberculose, a eliminação

f) da hanseníase, o controle da hipertensão arterial, o controle do diabetes mellitus, a saúde da criança, a saúde da mulher e a saúde bucal;

g) elaborar Relatório Anual de Gestão, que deve ser aprovado pelo Conselho Municipal de Saúde (MINISTÉRIO DA SAÚDE 2001a, Capítulo III).

A NOAS-SUS 01/02 “amplia as responsabilidades dos municípios na Atenção Básica; estabelece o processo de regionalização como estratégia de hierarquização dos serviços de saúde e de busca de maior eqüidade; cria mecanismos para o fortalecimento da capacidade de gestão do Sistema Único de Saúde e procede à atualização dos critérios de habilitação de estados e municípios". Enfatiza o processo de elaboração do Plano Diretor de Regionalização, coordenado pelo gestor estadual, com a participação do conjunto de municípios. Propõe a formação de módulos assistenciais, formados por um ou mais municípios, que garantam acesso ágil a ações de saúde necessárias além dos limites municipais, considerando critérios de qualidade e economia de escala, qualificando regiões/microrregiões na atenção à saúde.

Para garantir o funcionamento do SUS em todos os níveis foram definidos, por normas e portarias de alcance nacional, alguns instrumentos de gestão que devem ser adotados pelos gestores das três esferas de governo. Há instrumentos de gestão em saúde, que dizem respeito às três esferas de governo, articulando-as para garantir o funcionamento de um sistema nacional, e instrumentos específicos de cada 
município, estado, Distrito Federal ou União, que fornecem informações complementares para o planejamento e a gestão em saúde.

"Para cumprir os preceitos constitucionais o SUS vem utilizando diversos instrumentos de gestão, que vêm sendo criados segundo a necessidade e a capacidade técnica, administrativa, gerencial e mesmo política dos diversos gestores do SUS ao longo do tempo e do espaço” (MINISTÉRIO DA SAÚDE 2001d, p. 5).

Porém, a forma de preparação dos instrumentos de gestão do SUS não estava muito bem definida para os gestores de saúde, inexistindo padronização. O Manual do Gestor, preparado pelo Conselho de Secretários Municipais de Saúde e pela Secretaria de Estado da Saúde do Rio de Janeiro, publicado em 2000, ressaltou esse fato:

Sabedores da apreensão de vários Municípios, na expectativa da existência de um documento padrão para a elaboração do Relatório de Gestão, lembramos que, lamentavelmente, não existe um modelo de tal documento, apesar de o próprio Ministério da Saúde, através da Secretaria de Políticas de Saúde e de Avaliação, haver disponibilizado um arrazoado como base para sua elaboração, em data de 13 de novembro de 1998, e a Secretaria Estadual de Saúde/RJ haver apresentado na Comissão Intergestores Bipartite, ao final de 1997, um documento-padrão, que seria utilizado como experiência em 10 (dez) Municípios do Estado, mas que até a presente data ainda não teve uma avaliação final (CONSELHO DE SECRETÁRIOS... 2001, p. 12). 


\subsection{Instrumentos de gestão do SUS}

A Portaria 548/GM/MS, publicada em 2001, aprovou o documento Orientações Gerais para a Elaboração e Aplicação da Agenda de Saúde, do Plano de Saúde, dos Quadros de Metas, e do Relatório de Gestão como Instrumentos de Gestão do SUS (MINISTÉRIO DA SAÚDE 2001c). Além desses, constituem também instrumentos de gestão vinculados ao planejamento o Plano Diretor de Regionalização (PDR) e a Programação Pactuada e Integrada (PPI).

No capítulo 2 - Visão Geral do Processo - dessa Portaria, é apresentado "um esquema geral dos instrumentos de gestão, em termos de sua descrição, sistemas de fluxos e processo de elaboração" (Tabela 1).

Tabela 1 - Instrumentos de gestão do SUS

\begin{tabular}{|c|c|c|c|}
\hline INSTRUMENTO & DESCRIÇÃO & FLUXOS & REFERÊNCIAS \\
\hline 1. AGENDA & $\begin{array}{l}\text { Prioridades e estratégias } \\
\text { justificadas e detalhadas } \\
\text { por esfera de governo; } \\
\text { etapa prévia do processo } \\
\text { de planejamento da } \\
\text { gestão em saúde. }\end{array}$ & $\begin{array}{c}\text { Descendente: gestores } \\
\text { federal } \rightarrow>\text { estaduais }-> \\
\text { municipais e } \\
\text { correspondentes } \\
\text { conselhos e comissões } \\
\text { intergestores. } \\
\end{array}$ & $\begin{array}{c}\text { Subsídios políticos e } \\
\text { epidemiológicos }\end{array}$ \\
\hline $\begin{array}{l}\text { 2. PLANO DE } \\
\text { SAÚDE }\end{array}$ & $\begin{array}{l}\text { Introdução, diagnóstico } \\
\text { situacional, prioridades, } \\
\text { estratégias, análise } \\
\text { estratégica, } \\
\text { programação, quadro de } \\
\text { metas, conclusões. }\end{array}$ & $\begin{array}{l}\text { Ascendente: gestores } \\
\text { municipais }->\text { estaduais } \\
->\text { federal e } \\
\text { correspondentes } \\
\text { conselhos e comissões } \\
\text { intergestores }\end{array}$ & $\begin{array}{l}\text { Metas e intenções da } \\
\text { gestão. }\end{array}$ \\
\hline $\begin{array}{l}\text { 3. QUADRO DE } \\
\text { METAS }\end{array}$ & $\begin{array}{l}\text { Metas quantificadas por } \\
\text { esfera de governo; base } \\
\text { para elaboração dos } \\
\text { relatórios de gestão. }\end{array}$ & $\begin{array}{l}\text { Ascendente: gestores } \\
\text { municipais }->\text { estaduais } \\
\rightarrow>\text { federal e } \\
\text { correspondentes } \\
\text { conselhos e comissões } \\
\text { intergestores }\end{array}$ & $\begin{array}{c}\text { Resumo do Plano, } \\
\text { destacando metas da } \\
\text { agenda. }\end{array}$ \\
\hline $\begin{array}{l}\text { 4. RELATÓRIO DE } \\
\text { GESTÃO }\end{array}$ & $\begin{array}{c}\text { Correlação entre as } \\
\text { metas, os resultados e a } \\
\text { aplicação de recursos. }\end{array}$ & $\begin{array}{c}\text { Ascendente: gestores } \\
\text { municipais }->\text { estaduais } \\
\rightarrow>\text { federal e } \\
\text { correspondentes } \\
\text { conselhos e comissões } \\
\text { intergestores }\end{array}$ & $\begin{array}{c}\text { Tópicos do Quadro } \\
\text { de Metas } \\
\text { demonstrados e } \\
\text { justificados. }\end{array}$ \\
\hline
\end{tabular}

Fonte: Portaria 548/GM/MS, de 12 de abril de 2001, Capítulo II - Visão geral do processo (MINISTÉRIO DA SAÚDE 2001c) 
Segundo o Ministério da Saúde,

os instrumentos de Gestão em Saúde contribuem para:

- a estratégia de regionalização implantada pela Norma Operacional de Assistência à Saúde (NOAS/O1);

- a articulação entre os diversos gestores do SUS, nas três esferas de governo;

- o aprimoramento da qualidade e o monitoramento contínuo do desempenho dos gestores;

- a tomada de decisão a partir de um diagnóstico analítico;

- o fortalecimento da capacidade de planejamento e de organização dos sistemas estaduais, regionais e municipais de saúde (MINISTÉRIO DA SAÚDE 2001d, p. 6-7). 
As Agendas e os Planos de Saúde, os Quadros de Metas e os Relatórios de Gestão devem balizar-se por princípios como: normatização, para permitir comparabilidade das informações; objetividade; sintonia com o Plano Plurianual para o quadriênio 2000-2003; definição de indicadores de saúde adequados às diferentes realidades políticas, institucionais e epidemiológicas do país; alcance e adequação aos Sistemas de Informação em Saúde.

Quanto à adequação aos Sistemas de Informação em Saúde, a Portaria 548/GM/MS estabelece que:
os instrumentos aqui propostos contemplam aspectos que ultrapassam a assistência médica hospitalar e ambulatorial, alcançando os campos da saúde coletiva, das vigilâncias sanitária e epidemiológica, da inter-setorialidade, do controle social, da capacitação, da produção de insumos, da produção científica [grifo nosso], etc.. Tais instrumentos estão também ajustados às lógicas dos sistemas de informação em saúde em operação (SIAB; SIM; SINASC; SINAN, etc.), bem como de outros projetos em curso, como SIOPS e Cartão SUS (MINISTÉRIO DA SAÚDE 2001c, Introdução).

\subsubsection{Agenda de Saúde}

As Agendas de Saúde - nacional, estaduais e municipais - devem destacar e justificar os eixos prioritários de intervenção, os objetivos, os indicadores e as metas principais da política de saúde em cada esfera de governo e em cada exercício anual. Para sua preparação, devem ser consideradas as orientações de governo e dos fóruns de saúde e referências políticas (planos de governo, pactos, deliberações dos conselhos etc.), técnicas e epidemiológicas em cada esfera de governo.

As Agendas de Saúde, ao serem consolidadas e adaptadas em cada esfera de governo, comporão um processo de responsabilização progressiva, tendo por base as referências políticas, 
epidemiológicas e institucionais de cada esfera, sempre com a homologação do Conselho de Saúde correspondente. O processo de construção da Agenda tem, assim, um percurso sucessivamente federal, estadual, municipal (MINISTÉRIO DA SAÚDE 2001c, Anexo, Capítulo 3.1 - Agenda de Saúde).

Representam um processo participativo, pois resultam de negociação e consenso entre órgãos gestores, conselhos de saúde e comissões intergestores.

Esse processo de definição de prioridades do nível nacional para o estadual e, em seqüência, para o municipal, visa ao estabelecimento de um entendimento entre os gestores em torno de objetivos fundamentais para a melhoria da situação de saúde e da qualidade da atenção oferecida à população brasileira (MINISTÉRIO DA SAÚDE 2001b, Anexo I).

Pela Portaria 548/GM/MS, o papel do gestor estadual na preparação da Agenda de Saúde ficou assim definido:

A formulação e o encaminhamento da Agenda Estadual de Saúde são de competência exclusiva do gestor estadual, cabendo ao Conselho Estadual de Saúde apreciá-lo e propor as alterações que julgar pertinentes. As referências políticas e técnicas a serem utilizadas para sua elaboração são as seguintes: (a) a Agenda Nacional de Saúde; (b) os documentos disponíveis contendo as diretrizes de governo para a saúde; (c) tanto o Plano Estadual de Saúde como Relatório de Gestão preexistentes, mesmo se elaborados em outra administração; (d) informações institucionais e epidemiológicas locais disponíveis; (e) decisões oficiais do Conselho Estadual de Saúde que tenham implicação no conteúdo da Agenda; (f) outros documentos técnicos e políticos existentes e pertinentes à realidade local [grifo nosso] (MINISTÉRIO DA 
SAÚDE 2001c, Anexo, Capítulo 4.2 - Esfera Estadual, alínea a).

Da mesma forma, a Portaria 548/GM/MS define o papel do gestor municipal na preparação da Agenda de Saúde:

A formulação e o encaminhamento da Agenda Municipal de Saúde são de competência exclusiva do gestor municipal, cabendo ao Conselho Municipal de Saúde apreciá-lo e propor as modificações que considerar necessárias. As referências políticas e técnicas a serem utilizadas para sua elaboração são as seguintes: (a) a Agenda de Estadual de Saúde, que por sua vez deriva da Nacional; (b) os documentos disponíveis contendo as diretrizes do governo local para a saúde; (c) tanto o Plano Municipal de Saúde como Relatório de Gestão preexistentes, mesmo se elaborados em outra administração; (d) informações institucionais e epidemiológicas locais disponíveis; (e) decisões oficiais do Conselho Municipal de Saúde que tenham implicação no conteúdo da Agenda e, além disso, outros documentos técnicos e políticos existentes e pertinentes à realidade local [grifo nosso] (MINISTÉRIO DA SAÚDE 2001c, Anexo, Capítulo 4.3 - Esfera Municipal, alínea a).

Considerou-se importante destacar a orientação da Portaria 548/GM/MS para utilização de informações técnicas e epidemiológicas na definição dos eixos prioritários de intervenção, na esfera estadual e municipal. A utilização de informações científicas e técnicas, aliada às informações técnicas e epidemiológicas correspondentes às realidades locais, poderia talvez contribuir para o aperfeiçoamento desse instrumento de gestão.

A Portaria 393/GM/MS, de 29 de março de 2001, aprovou a Agenda Nacional de Saúde para 2001:

Art. $1^{o}$ Aprovar, nos termos do Anexo I, a Agenda Nacional de Saúde para o Ano de 2001. 
Art. $2^{\circ}$ Para fins de elaboração das respectivas agendas relativas ao ano de 2001, os Estados e Municípios deverão seguir o modelo da Agenda Nacional, nos moldes do Anexo II, adequando-a às características epidemiológicas e especificidades locais (MINISTÉRIO DA SAÚDE 2001b).

Foram estabelecidos os seguintes eixos prioritários de intervenção:

a) redução da mortalidade infantil e materna;

b) controle de doenças e agravos prioritários;

c) reorientação do modelo assistencial e descentralização;

d) melhoria da gestão, do acesso e da qualidade das ações e dos serviços de saúde;

e) desenvolvimento de recursos humanos do setor saúde;

f) qualificação do controle social.

\subsubsection{Plano de Saúde}

Os Planos de Saúde - nacional, estaduais e municipais - constituem as bases das atividades e da programação de cada nível de gestão do SUS, onde constam as prioridades estabelecidas nas Agendas de Saúde e a previsão dos mecanismos necessários para a execução das mesmas.Tem periodicidade quadrienal, mas devem ser revistos anualmente em função de novas metas de gestão e de atenção eventualmente incorporadas, bem como em decorrência do processo de Programação Pactuada e Integrada, que é anual.

"Os Planos de Saúde são documentos de intenções políticas, de diagnóstico, de estratégias, de prioridades e de metas, vistos sob uma ótica analítica”, conforme expressado na Portaria 548/GM/MS.

Os Quadros de Metas são parte integrante dos Planos de Saúde e constituem uma síntese das metas e da programação em saúde propriamente dita, servindo de base para elaboração dos Relatórios de Gestão. 


\subsubsection{Relatório de Gestão}

Os Relatórios de Gestão - nacional, estaduais e municipais - deverão avaliar o cumprimento dos objetivos e das metas explicitados no Quadro de Metas, bem como da aplicação dos recursos em cada esfera de governo, em cada exercício anual.

O Relatório de Gestão destina-se a sistematizar e divulgar informações sobre os resultados obtidos e sobre a probidade dos gestores do SUS às instâncias formais do SUS, ao Legislativo, ao Ministério Público e à sociedade como um todo. Este instrumento deve possibilitar o acompanhamento da conformidade da aplicação de recursos à programação aprovada. $O R G$ proporciona ainda subsídios para a avaliação e para a confecção das Agendas de Saúde e, conseqüentemente, dos Planos de Saúde subseqüentes (MINISTÉRIO DA SAÚDE 2001c, Anexo, Capítulo $3.4)$.

O Relatório de Gestão é elaborado a partir da matriz de informações constituída pelo Quadro de Metas, tendo por elementos típicos: o diagnóstico situacional, ao qual se agregam as prioridades estabelecidas; e uma análise estratégica que permita a comparação crítica entre o previsto e o realizado, mediante a focalização do quadrosíntese das metas, da programação em saúde explicitadas no Quadro de Metas e da aplicação dos recursos financeiros (MINISTÉRIO DA SAÚDE 2001c, Anexo, Capítulos 3 e 4$)$. 


\subsubsection{Plano Diretor de Regionalização}

O Plano Diretor de Regionalização é parte integrante do Plano Estadual de Saúde, baseado em pacto entre os gestores municipais, devendo servir de subsídio para os Planos Municipais de Saúde. Determinados serviços de saúde extrapolam a lógica territorial do município, e devem ser planejados em âmbito regional, com pleno aproveitamento dos recursos e serviços de saúde disponíveis.

Foi instituído pela NOAS/SUS 01/01 “como instrumento de ordenamento do processo de regionalização da assistência em cada Estado e no Distrito Federal, baseado nos objetivos de definição de prioridades de intervenção coerentes com as necessidades de saúde da população e garantia de acesso dos cidadãos a todos os níveis de atenção" (MINISTÉRIO DA SAÚDE 2001a, Anexo, Capítulo I.1, Parágrafo 2) .

Esse Plano serve de base para a Programação Pactuada e Integrada (PPI), que dá efetividade ao que foi combinado entre os gestores municipais e estaduais.

\subsubsection{Programação Pactuada e Integrada}

A Programação Pactuada e Integrada é o instrumento de gestão por meio do qual se programam as ações que serão realizadas, com base no Plano Diretor de Regionalização. Nesse instrumento se traduzem as responsabilidades de cada gestor do sistema, de forma a garantir o acesso da população aos serviços de saúde, tanto no próprio município quanto em um de referência, como resultado das negociações entre os gestores municipais mediadas pelo gestor estadual.

“A Programação Pactuada e Integrada, aprovada pela Comissão Intergestores Bipartite, deverá nortear a alocação de recursos federais da assistência entre Municípios pelo gestor estadual, resultando na definição de limites financeiros claros para todos os Municípios do estado, independente da sua condição de 
habilitação” (MINISTÉRIO DA SAÚDE 2001a, Anexo, Capítulo II.1, Parágrafo 26).

\subsection{Outras informações para a gestão}

Além dos instrumentos específicos de gestão do SUS, o gestor também precisa lidar com sistemas administrativos próprios da administração pública, aplicáveis ao governo local do qual faz parte, como as licitações, os orçamentos públicos e as prestações de contas, e com instrumentos de planejamento orçamentário de iniciativa do poder executivo, estabelecidos em cumprimento ao disposto no artigo 165 da Constituição, tais como:

- Plano Plurianual (PPA), que estabelece, de forma regionalizada, as diretrizes, os objetivos e as metas da administração pública para as despesas de capital, e outras delas decorrentes, e para as relativas aos programas de duração continuada;

- Lei de Diretrizes Orçamentárias (LDO), que compreende as metas e prioridades da administração pública, incluindo as despesas de capital para o exercício subseqüente;

- Lei Orçamentária Anual (LOA), que estima as receitas e fixa as despesas do governo, seus poderes e seus fundos;

- Lei de Responsabilidade Fiscal ou Lei Complementar $n^{\circ} 101$, de 4 de maio de 2000, que "estabelece normas de finanças públicas voltadas para a responsabilidade na gestão fiscal e dá outras providências”;

- Emenda Constitucional 29, de 13 de setembro de 2000, que "altera os arts. 34, 35, 156, 160, 167 e 198 da Constituição Federal e acrescenta artigo ao Ato das Disposições Constitucionais Transitórias, para assegurar os recursos mínimos para o financiamento das ações e serviços públicos de saúde”. 
A interação entre os instrumentos de gestão em saúde e os de planejamento do governo, ao mesmo tempo em que limita as ações executivas, representa oportunidades e desafios para a gestão do SUS nas três esferas de poder e contribui para a efetividade das políticas em saúde.

“As políticas de saúde consistem em decisões de caráter geral, destinadas a tornar públicas as intenções de atuação do governo e a orientar o planejamento, no tocante a um determinado tema, em seu desdobramento em programas e projetos. As políticas definem os propósitos de uma ação de governo, as diretrizes e as responsabilidades das esferas e órgãos de governo envolvidos". O processo de formulação de uma política pode partir do Ministério da Saúde, dos governos locais, de áreas técnicas da saúde ou da sociedade civil (MINISTÉRIO DA SAÚDE 1999, p. 7-13).

No processo de gestão descentralizada, os gestores podem ser alimentados por dois tipos de informação:

1) impositiva, constituída por manuais, normas e portarias do Ministério da Saúde que definem os tipos de informações e instrumentos que devem ser utilizados nos processos de gestão;

2) técnica e científica, constituída por informações de caráter epidemiológico, ambiental e social, que descrevem o contexto de desenvolvimento humano e de saúde local, regional, nacional ou internacional. 
Para refletir as necessidades locais, o planejamento descentralizado em saúde deveria considerar, além das informações operacionais e legais, os dados sobre condições de vida e saúde da população atingida, coletados por meio de serviços e ações de saúde locais; e outras informações em saúde, divulgadas pelos sistemas nacionais, incluindo as científicas e técnicas. Assim como há necessidade de interação entre os instrumentos de gestão específicos do SUS e os de planejamento da administração pública, o conhecimento científico correlato, gerado pelas instituições de ciência e tecnologia deveria ser considerado também no planejamento. Esse ponto tem sido discutido nas Conferências de Saúde e de Ciência e Tecnologia em Saúde.

Conforme documento da I Conferência Nacional de Ciência e Tecnologia em Saúde, "para se constituir um sistema orgânico e eficaz de Ciência e Tecnologia em Saúde, há que se construir pontes entre os universos atualmente isolados do Sistema Único de Saúde e do Sistema de Ciência e Tecnologia, criando-se mecanismos de articulação entre os atores envolvidos” (ANAIS DA I CONFERÊNCIA... 1994, parágrafo 96, p. 31).

Para que possam ser utilizadas eficientemente, as informações para a gestão deveriam ser amplamente disseminadas para os gestores e também para os integrantes dos conselhos e a comunidade em geral. Nesse sentido, a 10 Conferência Nacional de Saúde propôs que fossem utilizados meios de divulgação criativos, ágeis e eficientes para acesso a informações em saúde e que fossem aperfeiçoados os mecanismos de gestão e integração do SUS. No relatório dessa conferência, no capítulo que trata da 'Política Nacional de Informação, Educação e Comunicação em Saúde', dentro do tema da 'Gestão e Organização dos Serviços de Saúde', foi proposto que:

Os Gestores do SUS devem estimular, apoiar e promover estudos e pesquisas sobre assuntos e temas de interesse social na área da saúde, divulgando-os amplamente aos Usuários, com a finalidade de favorecer o pleno desenvolvimento do SUS. Entre estes: 
1. pesquisas sobre a satisfação dos Usuários do SUS com o atendimento recebido, com o acompanhamento dos respectivos Conselhos de Saúde;

2. pesquisas que analisem a efetividade das práticas populares alternativas em Saúde (fitoterapia, alimentação alternativa, etc.), com o apoio das agências oficiais de fomento à pesquisa e realizadas em parceria com Universidades Públicas;

3. análise e acompanhamento das Informações em Saúde fornecidas à sociedade, para garantir sua fidedignidade e qualidade (RELATÓRIO DA 10ª CONFERÊNCIA ... 1996, Capítulo 2.6.1, Parágrafo 6).

As proposições da $11^{\mathrm{a}}$ Conferência Nacional de Saúde com relação à produção, à organização e ao uso das informações para a gestão, apontam, entre outras, para a necessidade de:

- garantir a produção de informações qualificadas sobre as condições sanitárias e de vigilância epidemiológica, incluindo as condições sociais, culturais e econômicas, que podem dar a dimensão social da saúde da população, visando ações governamentais e da sociedade;

- implementar mudança cultural e ações que superem as resistências ao uso das informações e tecnologias mais avançadas na gestão da saúde;

- democratizar os dados monopolizados pelo Ministério da Saúde, secretarias municipais e estaduais, possibilitando análises situacionais adequadas, planejamento, execução $e$ controle social em saúde; 
- transformar os bancos de dados existentes em informações, para que as pessoas possam avaliar e acompanhar o desenvolvimento das ações (RELATÓRIO FINAL DA $11^{\mathrm{a}}$ CONFERÊNCIA... 2000, parágrafos 220, 224-6).

A transformação do espaço de gestão proposto pelo SUS em um espaço de decisão deveria conduzir ao estabelecimento de novos dados a ser coletados, de novos vínculos entre bases de dados existentes, de novos critérios e definições de todo o processo da informação em saúde. A $11^{\text {a }}$ Conferência Nacional de Saúde propôs a criação de um "foro para padronização de vocabulário, conteúdo e trocas eletrônicas de dados a serem implementados em todos os sistemas de informação em saúde, com a participação de sociedades científicas, instituições de pesquisa, prestadores de serviços, conselhos profissionais e Governo" (RELATÓRIO FINAL DA $11^{\text {a }}$ CONFERÊNCIA... 2000, parágrafo 236, p. 171).

Várias formas de articulação entre as instituições de ensino e pesquisa e a área de gestão e prestação de serviços foram impulsionadas no Brasil, desde as iniciativas de integração docente-assistencial iniciadas na década de 80 até os esforços atuais do Ministério da Saúde para capacitação de recursos humanos do SUS. Essas formas de articulação são necessárias, pois, embora os objetivos da pesquisa em saúde e das ações de saúde sejam comuns no sentido de melhorar as condições de saúde da população, as duas áreas têm intencionalidades bastante distintas.

A capacitação de recursos humanos para a gestão pode ser considerada uma das principais estratégias do Ministério da Saúde para fortalecimento da gestão do SUS. Iniciativas instituídas recentemente, coordenadas pela Secretaria de Políticas de Saúde, em cooperação com instituições da área de ensino e pesquisa e a OPAS, revelam o esforço para apoiar tecnicamente os gestores na organização dos sistemas municipais de saúde e no fortalecimento da capacidade de descentralização das ações e da tomada de decisão local: 
- os Cursos de Capacitação para Gestores Municipais, que tiveram por objetivo capacitar secretários municipais de saúde para o exercício de suas funções, enfatizando a organização dos serviços municipais de saúde a partir do contexto político-normativo do SUS e o papel do gestor na condução da política municipal de saúde;

- o projeto Gerus (Desenvolvimento Gerencial de Unidades Básicas de Saúde do SUS), que integra gestores do SUS e instituições acadêmicas em um programa cooperativo de apoio ao desenvolvimento gerencial dos estabelecimentos de saúde;

- a Rede Observatório de Recursos Humanos, cujo objetivo é fortalecer as políticas de desenvolvimento de recursos humanos no contexto dos processos de reforma dos sistemas de saúde na América Latina. A estratégia principal desse programa é gerar conhecimento e evidências para melhorar a qualidade e efetividade das políticas de desenvolvimento gerencial de recursos humanos, favorecendo a publicação e o acesso ao conhecimento científico para desenvolvimento de recursos humanos em saúde. 


\section{CAPÍTULO 4}

\section{SISTEMAS DE INFORMAÇÃO EM SAÚDE}

A introdução de novos atores públicos e privados, incluindo a população em geral, no processo de tomada de decisão em saúde e no controle social, conforme previsto nos princípios de organização do SUS, tem gerado demandas de informação cada vez mais diversificadas. $\mathrm{O}$ acesso à informação passou a ser requisito indispensável para que os sujeitos, envolvidos ou potencialmente envolvidos em atividades de gestão em saúde, pudessem utilizar essas informações para a definição de políticas locais.

Acesso à informação para a gestão em saúde significa, nesse contexto, recuperação e contato com todo e qualquer tipo de informação de interesse para a área, seja esta estatística, administrativa, normativa, técnica ou científica ou relacionada a doenças e agravos, condições climáticas, saneamento, moradia, distribuição populacional etc. Neste estudo, será dada ênfase à informação científica e técnica na área da saúde pública e aos sistemas de informação bibliográfica em saúde que podem subsidiar os processos de tomada de decisão local.

A informação, como objeto de valor econômico, social, político e histórico da Era da Informação ou da Sociedade do Conhecimento, tem recebido inúmeras definições e conceitos, alguns completamente distantes entre si. Todas as abordagens conceituais são corretas, dependendo unicamente do contexto e da dimensão em que são utilizadas. Como foi visto no capítulo 2, a questão central na Sociedade do Conhecimento passou a ser a produção e a administração do saber, com o objetivo de aplicá-lo para gerar novos conhecimentos (economia do conhecimento), num processo crescente e contínuo de contextualizações.

Para compreensão e delimitação dos conceitos utilizados neste trabalho, houve a necessidade de rever e contextualizar os conceitos de 'informação', 'informação em saúde' e ‘sistemas de informação em saúde’. 


\subsection{Conceitos}

A informação, no processo de comunicação, é a 'representação de um significado', que seria transmitido de um emissor para um receptor. A informação não é sinônimo de conhecimento, mas é imprescindível para que este se realize, assumindo o papel de 'agente mediador na produção de conhecimento' (Barreto 1994, p.3 apud MORAES 2001, p. 55). No processo de comunicação, os atores envolvidos são sujeitos atuando ora como emissores ora como receptores, dependendo do contexto em que se encontram no momento da ação. Para que a informação seja compreendida nesses dois pólos comunicacionais, pressupõe-se o estabelecimento anterior de códigos de comunicação que permitam inter-relações entre emissor e receptor. Como afirma MORAES 2001, "neste embate entre ação e sujeição, a informação circula ora como produto, ora como 'meio para algo', mas sempre enquanto espaço de relações de poder e produção de saber" (MORAES 2001, p.65).

Neste estudo, privilegiar-se-á a 'informação para a ação', que pressupõe a existência de um emissor e um receptor que possam, independentemente da linguagem ou do canal utilizados, da transmissão direta ou à distância em um espaço virtual, interrelacionar-se e transformar o conteúdo informacional da mensagem em um processo de produção de conhecimento para a gestão e tomada de decisão local em saúde. A informação, nesse sentido, teria de ser direcionada e utilizada para algum objetivo, conhecida e assimilada no processo de tomada de decisão.

Fernandes (1993), citado por MORAES (2001, p. 68), identificou três grupos de definições de informação:

1) na Teoria Matemática, a informação é definida como um redutor da incerteza, vista como um conceito preciso $e$ quantificável, enfatizando nesta visão a informação administrativa elou estatística;

2) na visão documentalista, a informação é considerada como observável sob a forma do conhecimento comunicado através 
de documentos, publicados, que são tratados pelos sistemas de registro, controle e acesso aos documentos (informações científicas e tecnológicas);

3) na visão de processo, a informação é vista como o processo mental humano de conhecimento.

No contexto deste estudo, foi considerada a visão documentalista, onde informação corresponde ao conhecimento publicado em qualquer tipo de documento técnico, científico ou normativo.

A informação científica é resultado de informações sistematicamente codificadas e absorvidas, obtidas por meio de pesquisas ou reflexões sobre o avanço do conhecimento nas distintas áreas. A maneira como o cientista transmite essas informações depende do veículo escolhido, da natureza e conteúdo das informações e do público a que se destinam (MEADOWS 1999).

A revista científica constitui o meio mais utilizado para veiculação do conhecimento científico, pela rapidez com que a informação é publicada e pela possibilidade de ampla divulgação para a comunidade científica e público em geral. As características principais das revistas são a periodicidade, com intervalos de publicação prédefinidos, o que facilita sua coleta e registro em bases de dados, e a publicação de vários artigos em um só volume, o que possibilita a divulgação rápida do conhecimento.

Outros tipos de documentos comumente utilizados na comunicação científica são livros, dissertações e teses acadêmicas, relatórios técnicos, trabalhos apresentados em eventos científicos (congressos, conferências, reuniões etc.) e manuais. Em algumas áreas, como a de Ciências Sociais, os livros são muito usados, pois os trabalhos científicos nesses setores, em geral, constituem reflexões sobre temas que exigem mais tempo para acumular conhecimentos.

Há ainda os documentos normativos (leis, decretos, portarias, deliberações, jurisprudências etc.) publicados pelos órgãos legislativos do governo, que 
representam o papel regulador do Estado, comumente utilizados na Saúde Pública. Esses documentos dão conta de regulamentar procedimentos administrativos e gerenciais, de estabelecer direitos, deveres e proibições, de fixar mecanismos para controle de qualidade e avaliação, de criar e aprovar projetos e programas.

A 'informação científica em saúde' corresponde àquela produzida nos campos do conhecimento que compõem a área da saúde, ou seja, medicina, enfermagem, odontologia, epidemiologia, saúde pública etc. Essa informação é resultante de pesquisas científicas, produzida em geral com caráter investigativo, crítico e avaliador pelas instâncias de ciência e tecnologia (escolas, faculdades, universidades e instituições de pesquisa, sociedades científicas) e também pelas instituições nãocientíficas prestadoras de serviços de saúde (Secretarias Estaduais e Municipais de Saúde e Ministério da Saúde), ONG, Conselhos etc.

$\mathrm{Na}$ área da Ciência da Informação, a 'informação científica em saúde' pode ser encontrada simplesmente como 'informação em saúde', caracterizando 'informação relacionada à área temática da saúde'. Mas, na área da Saúde Pública, esse conceito se confunde com o de 'informações em saúde', normalmente utilizado na forma plural, com conotação bastante distinta. Assim, para efeitos deste trabalho, preferiuse sempre adjetivar a informação como científica ou técnica para diferenciá-la de informações em saúde.

Informações em saúde significam informações epidemiológicas e estatísticas sobre o setor saúde, ora norteadas para uma lógica contábil, quantitativa e/ou administrativa da gestão institucional de práticas e ações, ora voltadas para o processo saúde-doença e para os procedimentos médicos, programas e campanhas para determinados agravos ou grupos de risco. Correspondem a dados coletados e registrados pelas instituições de saúde e instituições executivas que integram bases de dados locais e governamentais. 
Segundo MORAES (2001),

as informações em saúde, nos moldes como se expressam até os dias atuais, vêm se consolidando como instrumentos estratégicos imersos nesse processo, ao amplificar e atualizar, paulatinamente, o "olhar do médico" sobre o corpo do paciente para o "olhar dos aparelhos de Estado" sobre os corpos das populações (sexo, idade, órgãos, diagnósticos, fertilidade, estado civil, nível educacional, tipo de moradia, etc.), constituindo-se em espaço de disputas de relações de poder e produção de saber. Neste esforço firma-se, enquanto analítica central, o poder. Não qualquer poder, mas o poder vigilante que institucionaliza as informações em saúde como parte integrante dos dispositivos de governo de controle da população (p.2).

RODRIGUES (1995) distingue o dado em saúde da informação em saúde quando afirma que:

os dados em saúde raramente se tornam informação em saúde. São produzidas e registradas quantidades massivas de dados no setor saúde, mas a variedade da informação potencialmente útil que pode ser gerada a partir desses dados raramente é explorada em sua totalidade, em muitos casos, não há mecanismos para processar os dados em informações e para disponibilizar a informação para a pessoa certa no momento certo, no formato que possa ser facilmente entendido (p. 2).

MORAES (1994) ressaltou que o campo de abrangência das informações em saúde é amplo e compreende também informações acerca das condições gerais de vida e de trabalho, como alimentação, moradia, saneamento etc. (p.30).

O conceito 'Sistemas de Informação em Saúde' é utilizado de forma ampla na literatura da área de Saúde Pública, identificado pela sigla SIS, para caracterizar os sistemas de informações administrativas e gerenciais, os de informações estatísticas e epidemiológicas, os de informações econômico-sociais, entre outros. No entanto, os 
sistemas de informação científica e técnica não são considerados nessa definição. Para este trabalho, os sistemas de informação em saúde abrangem todo tipo de sistemas de informação de interesse para a área da saúde e os sistemas de informação científica em saúde correspondem aos sistemas de bases de dados bibliográficas e referenciais sobre a produção científica publicada. Assim sendo, sempre que for necessário, acrescentar-se-á um adjetivo para caracterizar o que está em discussão no momento.

As definições da OMS e da OPAS para os Sistemas de Informação em Saúde foram citadas por MORAES (1994, p. 26). Observa-se que a definição da OMS está mais dirigida ao processo saúde-doença e a da OPAS, a sistemas quantitativos e integrados, que poderiam apoiar os processos de gestão em saúde.

Segundo a OMS,

Sistema de Informação em Saúde é um mecanismo de coleta, processamento, análise e transmissão da informação necessária para se organizar e operar os serviços de saúde e, também, para a investigação e o planejamento com vistas ao controle de doenças.

Segundo a OPAS,

Sistema de Informação em Saúde é o conjunto de componentes (estruturas administrativas, departamento de estatística de saúde, unidades de informação em saúde) que atuam de forma integrada e que têm por finalidade produzir a informação necessária $e$ oportuna para implementar processos de decisões no sistema de serviços de saúde.

ALMEIDA (1995) caracterizou os sistemas de informação em saúde e afirmou: analisando-se os sistemas de informação em saúde existentes observa-se que há uma dicotomia entre os sistemas de informação epidemiológica e os sistemas de gerenciamento dos serviços de saúde.(....) As lógicas dos sistemas de informação epidemiológicas 
são distintas. Nos sistemas de informação epidemiológica a base da coleta de dados é a população. (....) A concepção de sistemas de informações gerenciais dos serviços de saúde pressupõe a obtenção de informações sobre quantas, quais e onde foram produzidas as ações de saúde, por quem e a que custo operacional, tendo como base de coleta os serviços de saúde (p. 39-40).

RODRIGUES (1995) afirmou que "o principal objetivo de qualquer sistema de informação é a redução do grau de incerteza que estaria associado a qualquer processo de tomada de decisão". O autor identificou quatro requisitos básicos para os sistemas de informação em saúde: "coordenação da infra-estrutura física e dos recursos descentralizados, apoio para correção de problemas, tomada de decisão em tempo hábil e acesso rápido à informação clínica e administrativa [grifo do autor]". Ressaltou que muitos sistemas de informação não contemplariam saídas orientadas ao processo de gestão que apoiassem a tomada de decisão operacional ou de planejamento num sentido amplo (p. 10-16).

\subsection{Sistemas de informação em saúde existentes}

\subsubsection{Sistemas de informação estatística e epidemiológica em saúde}

Segundo MORAES (2001), os sistemas de informação em saúde tiveram início no final do século XVII e, somente no final do século XIX e no século XX, é que a informação consolidou seu significado estratégico de instrumento técnico de governo. Os SIS evoluíram e deixaram de ser apenas instrumentos-meio de organização dos serviços para converter-se em recursos para planejamento estratégico de políticas de governo.

A necessidade de estatísticas relativas à Saúde foi discutida durante a $1^{\mathrm{a}}$ Conferência Nacional de Educação e Saúde, realizada em 1941, quando se tratou de firmar princípios de articulação entre os Ministérios da Educação e da Saúde e as 
administrações estaduais e municipais com a finalidade de tentar racionalizar a coleta. Até 1975, no entanto, a coleta, a organização e a divulgação de dados estatísticos nacionais couberam basicamente ao IBGE (Instituto Brasileiro de Geografia e Estatística).

Os SIS foram constituídos por iniciativa do Ministério da Saúde nessa época, quando se realizou a $1^{\text {a }}$ Reunião Nacional sobre Sistemas de Informações de Saúde, em Brasília, com o objetivo de analisar a situação das informações disponíveis, as possibilidades de produção de informações no setor Saúde e as perspectivas de implantação de um Sistema Nacional de Informações em Saúde.

Foram identificados, inicialmente, dois tipos de SIS: o do MPAS/Inamps, com informações norteadas por uma lógica contábil, quantitativa e centralizadora, tendo como elemento básico de interesse o procedimento médico; e o do Ministério da Saúde, voltado para campanhas e programas relacionados a determinados agravos e grupos de risco.

No final dos anos 90, foi constituída no Brasil a Rede Interagencial de Informações para a Saúde (Ripsa) $^{*}$, uma iniciativa conjunta do Ministério da Saúde e da Representação da OPAS/OMS no Brasil, direcionada para subsidiar os processos de estruturação e avaliação de políticas e ações públicas de interesse para órgãos do SUS, entidades técnico-científicas e organismos internacionais do setor saúde.

A Ripsa tem, entre seus objetivos principais, o propósito de permitir o acesso a dados básicos, a indicadores e análises de situação sobre as condições de saúde e suas tendências no país, com vistas ao aperfeiçoamento da capacidade de formulação, coordenação, gestão e operacionalização de políticas e ações públicas dirigidas à qualidade de saúde e de vida da população.

Sua criação baseou-se no reconhecimento de que: (a) os múltiplos sistemas de informação existentes estavam desarticulados e não contemplavam todos os fatores

\footnotetext{
* Informação disponível em: http://www.datasus.gov.br/rnis/RIPSA/Ripsa-01.htm
} 
relacionados ao processo saúde-doença; (b) os processos de análise da situação de saúde, de avaliação de serviços e de difusão da informação em saúde não eram sistemáticos e regulares; (c) a informação em saúde não era adequadamente utilizada para a condução e gestão de políticas e ações de saúde.

Segundo a Ripsa, haveria necessidade de informação na área da saúde para formulação de políticas públicas e programas governamentais, gestão do SUS e mobilização de recursos e difusão pública das condições de saúde no Brasil. $\mathrm{Na}$ área de difusão pública, inclui a divulgação para orientar a população e a produção científica sobre condições de saúde no país.

Segundo a NOB/96, “os bancos de dados nacionais, cujas normas são definidas pelos órgãos do MS, constituem instrumentos essenciais ao exercício das funções de controle, avaliação e auditoria”. O objetivo final é permitir a transparência na implementação das diversas ações do governo, bem como a disponibilidade das informações para as instâncias do poder executivo e a sociedade em geral. No entanto, os dados registrados muitas vezes se encontram dispersos, não consolidados, armazenados em sistemas e bancos de dados desarticulados entre si, o que dificulta sua utilização efetiva nos processos de gestão local. O que realmente acontece é que, em geral, esses sistemas foram criados para atender a necessidades administrativas e não foram planejados para atender objetivos gerenciais ou para ser entendidos pelo público em geral.

Existe, na área da saúde, uma infinidade de bases de dados informacionais que coletam dados sobre as realidades locais de saúde, consolidados posteriormente na esfera federal, permitindo o monitoramento das condições de saúde da população e dos processos técnicos e administrativos da gestão dos serviços, como o Sistema de Informações sobre Nascimento (Sinasc), o Sistema de Informação de Mortalidade (SIM), o Sistema de Informações de Agravos de Notificação (Sinan), o Sistema de Informações Ambulatoriais, o Sistema de Informação Hospitalar, entre outros. 
Em 1996, durante o I Fórum Nacional de Usuários de Informações, na III Conferência Nacional de Geografia e IV Conferência Nacional de Estatística, promovidas pelo IBGE, as sociedades científicas das áreas de Saúde Coletiva, Estatística, Economia, Ciências Sociais, Geografia, Planejamento Urbano, Cartografia, Engenharia Biomédica e a SBPC (Sociedade Brasileira para o Progresso da Ciência) se reuniram, discutiram princípios e propostas e elaboraram o documento "Informação para uma sociedade democrática: por uma política nacional de produção e disseminação de informações sociais, econômicas e territoriais". Como conseqüência do fórum, a SBPC constituiu um grupo técnico com a participação dessas sociedades científicas, com o objetivo de promover estudos para a constituição de uma Política Nacional de Informações. Os princípios e as propostas discutidos representavam não somente as informações em saúde mas também toda a rede de informações governamentais.

A Rede Nacional de Informação em Saúde (RNIS), criada como um projeto do Ministério da Saúde, financiado pelo Reforsus e pelo Banco Mundial, tem por objetivo integrar e disseminar, via internet, as informações em saúde existentes no país, para gestão, planejamento e pesquisa para gestores, agentes e usuários do SUS. Essa rede, iniciada com projetos-piloto na Paraíba, Paraná e Rio de Janeiro, integra atualmente todos os municípios brasileiros por meio de projetos das secretarias estaduais de saúde de todas as unidades da Federação. Foram definidos dados básicos que deveriam ser coletados para definir a situação de saúde, criando o conceito de 'sala de situação em saúde' do município, que deveria servir de apoio para os conselhos municipais de saúde e para a comunidade em geral.

A RNIS teve um papel importante na expansão da coleta de dados locais, na integração dos sistemas de informação em saúde e também na instalação de estrutura de informática e de acesso à internet nas secretarias de Saúde, o que permitiu um avanço no desenvolvimento de sites em muitos municípios, com divulgação das informações locais e de links para os sistemas nacionais. 


\subsubsection{Sistemas de informação científica e técnica em saúde}

Os sistemas de informação científica em saúde são constituídos por bases de dados bibliográficas, resultantes do controle e registro da literatura científica e técnica em saúde produzida em nível institucional, nacional, regional ou temático. Com o desenvolvimento da internet, a tendência atual é a expansão dessas bases de dados referenciais para bases de texto completo, interligadas às referenciais, que permitem acesso direto aos documentos recuperados.

A produção científica e técnica da área de saúde pública está representada em bases de dados bibliográficas da área médica e de saúde e nas da área de ciências sociais, de demografia, de meio ambiente etc. As mais importantes para a saúde pública estão incluídas na BVS-SP:

- $\quad$ LILACS - Literatura Latino-Americana e do Caribe em Ciências da Saúde, produzida por uma rede descentralizada, coordenada pela BIREME/OPAS/OMS;

- $\quad$ AdSAÚDE, produzida por uma rede descentralizada, coordenada pela Faculdade de Saúde Pública da Universidade de São Paulo, Brasil;

- $\quad$ REPIDISCA, produzida por uma rede descentralizada, coordenada pelo CEPIS/OPAS/OMS - Centro Panamericano de Ingenieria Sanitária y Ciencias del Ambiente, Lima, Peru;

- $\quad$ MEDLINE, produzida pela U.S. National Library of Medicine (NLM);

- $\quad$ POPLINE, produzida pelo Center for Communication Programs, Johns Hopkins University School of Public Health, Estados Unidos;

- BDSP - Banque de Données Santé Publique, coordenada pelo Atelier d'Études et Development, localizado na École Nationale de la Santé Publique, Rennes, França;

- $\quad$ CAB Health, produzida pela CAB International, Reino Unido;

- $\quad$ EMBASE (Excerpta Medica Database), produzida pela Elsevier Science, Holanda. 
Além das bases de dados bibliográficas tradicionais, foram criadas, na Biblioteca Virtual em Saúde, bases de dados de sites na internet e de textos completos, como é o caso do LIS (Localizador de Informação em Saúde) da BVS-SP e da SciELO Scientific Electronic Library Online).

O LIS tem por objetivo o controle e registro dos documentos e das informações científico-técnicas divulgados em sites de instituições acadêmicas, governamentais, sociedades científicas e outras instituições produtoras de conhecimento científicotécnico.

A SciELO contém textos completos de revistas científicas selecionadas, base de dados para consulta (por autor, palavras do título ou do resumo e assunto) e indicadores de uso e citações. Criada especificamente para a área de saúde pública, a SciELO - Saúde Pública inclui atualmente sete revistas: três da América Latina (Cadernos de Saúde Pública e Revista de Saúde Pública, do Brasil, e Salud Pública de México, do México), duas da Espanha (Gaceta Sanitaria e Revista Española de Salud Pública), a Revista Panamericana de Salud Pública, da OPAS, e o Bulletin of the World Health Organization, da OMS.

Na BVS-SP foi criada também uma base de dados de textos completos, que destaca os textos completos registrados nas bases de dados tradicionais e inclui outros não registrados nas outras fontes de informação existentes na BVS-SP.

São de interesse para a área de saúde pública as bases de dados de legislação, embora não estejam disponíveis na BVS-SP. Existe uma base regional sobre legislação básica de saúde da América Latina e Caribe - LEYES -, coordenada pelo Programa de Legislação da OPAS, que registra dados bibliográficos de legislação em saúde publicada em vários países da América Latina e Caribe, disponível para consulta na BVS regional. 
No Brasil, estão em desenvolvimento bases de dados de texto completo de legislação em saúde, que permitem acesso a esses textos e consulta em base de dados. O Portal da Saúde, do Ministério da Saúde, contém textos completos de portarias, medidas provisórias, decretos e leis federais, com consulta por assunto e entidades vinculadas. A Secretaria de Estado da Saúde de São Paulo e o Centro de Pesquisas em Direito Sanitário (CEPEDISA), da Faculdade de Saúde Pública da Universidade de São Paulo, estão desenvolvendo bases de dados em texto completo de legislação estadual e nacional, respectivamente.

\subsubsection{Descrição das bases de dados bibliográficas em saúde}

Com o objetivo de fornecer embasamento teórico que permita acompanhar as análises realizadas neste estudo sobre o conteúdo das bases de dados bibliográficas de interesse para a área de saúde pública, será apresentada a seguir uma descrição sucinta das bases de dados disponíveis na BVS-SP, com dados gerais sobre conteúdo e abrangência temática ou temporal.

A base de dados LILACS (Literatura Latino-Americana e do Caribe em Ciências da Saúde) é a principal fonte sobre a produção científica em saúde produzida nos países da América Latina e Caribe. Contém artigos de 618 títulos de revistas científicas, livros, capítulos de livros, teses, anais de eventos científicos, relatórios técnicocientíficos, publicações governamentais e documentos não-convencionais, publicados nos países da América Latina e Caribe desde 1982. É uma base de dados cooperativa, para a qual contribuem centros cooperantes de 37 países da América Latina e Caribe. Conta atualmente com mais de 300.000 registros de documentos científicos e técnicos da área de saúde, dos quais cerca de 100.000 correspondem à área de saúde pública.

Como parte do Sistema LILACS são desenvolvidas bases de dados temáticas, nacionais ou regionais, que utilizam a mesma metodologia para tratamento da informação e para entrada de dados descentralizada e cooperativa, com critérios de 
seleção de documentos próprios. Os registros incluídos nessas bases de dados, que cumprem ao mesmo tempo os requisitos de seleção da LILACS, são exportados também para esta, o que gera, de certa forma, duplicação de registros entre as bases. Destacam-se na área de saúde pública as bases de dados AdSAÚDE (nacional) e REPIDISCA (regional).

A base de dados AdSAÚdE indexa livros, teses, manuais e artigos de periódicos publicados no Brasil ou escritos por autores brasileiros e publicados em outros países, desde 1986, na área de administração de serviços em saúde. Inclui aspectos políticos, econômicos e sociais relacionados à administração, à organização, ao planejamento e a áreas afins, aplicados aos sistemas e às práticas de saúde.

A base de dados REPIDISCA indexa literatura de engenharia sanitária e ciências ambientais. Contém mais de 128.000 registros de todo tipo de documentos técnicos e científicos de interesse para a área, sem limite de data, país de publicação ou idioma. As revistas selecionadas podem ser informativas, técnicas ou científicas abrangendo as áreas de saúde pública, saneamento, economia, química, engenharia sanitária, ambiental, entre outras.

Dentre as bases de dados internacionais, a MEDLINE é a mais consultada na área da saúde. Pode ser acessada na BVS-SP, com interface em três idiomas desenvolvida pela BIREME, ou diretamente pela interface PubMed, da U.S. National Library of Medicine. Contém aproximadamente 12 milhões de registros da literatura, desde 1966 até o momento, e indexa mais de 4.300 títulos de revistas das ciências da saúde e da vida (medicina, biomedicina, biologia, enfermagem, odontologia, veterinária, saúde pública etc.), publicadas nos Estados Unidos e em outros 70 países, dos quais dez da América Latina e Caribe (Argentina, Brasil, Chile, Colômbia, Costa Rica, Cuba, Jamaica, México, Panamá e Venezuela). Desse total de títulos, 3.799 são selecionados por um Comitê de Seleção para o Index Medicus, o produto impresso dessa base de dados, segundo critérios rigorosos de qualidade científica e política de seleção própria. 
Das revistas selecionadas para MEDLINE/Index Medicus em 2002, apenas 44 $(1,16 \%)$ são da América Latina e Caribe, sendo 16 do Brasil. Dos 16 títulos brasileiros, seis (37\%) podem ser considerados de interesse para a saúde pública, sendo dois especificamente da área (Cadernos de Saúde Pública, Revista de Saúde Pública) e quatro de medicina tropical ou de pesquisa básica e aplicada em doenças infecciosas e transmissíveis, que publicam muitos artigos de interesse para a epidemiologia (Revista do Instituto de Medicina Tropical de São Paulo, Revista da Sociedade Brasileira de Medicina Tropical, Brazilian Journal of Infectious Diseases e Memórias do Instituto Oswaldo Cruz).

A base de dados bibliográfica POPLINE é especializada em saúde reprodutiva, estudos sobre população, planejamento familiar e outros temas de saúde. Contém atualmente cerca de 290.000 registros. Indexa livros, teses, artigos de revistas, relatórios técnicos, artigos de jornais, trabalhos apresentados em eventos científicos, documentos não-convencionais, manuais técnicos e legislação.

A base de dados Banque de Données Santé Publique (BDSP) contempla a literatura científica e técnica em saúde pública produzida na França e no exterior desde 1978. Foi concebida para atender às necessidades de todos os atores da área da saúde pública: pesquisadores, profissionais da saúde, gestores e tomadores de decisão, profissionais da informação etc. Para a definição do escopo dessa base, é considerada a definição de saúde pública da OMS, na qual 'saúde pública' é entendida em sentido amplo, como a atenção aos problemas de saúde de uma população, a situação sanitária da coletividade, os serviços de higiene e meio ambiente, os serviços sanitários gerais e a administração de serviços. Essa base é particularmente importante para recuperar a literatura francesa, principalmente a não-convencional ou de produção limitada, que não está acessível em outras bases de dados internacionais.

A BDSP registra média mensal de 2.000 novos registros, contando atualmente com cerca de 255.000 , dos quais $51 \%$ correspondem a trabalhos em inglês, $47 \%$ em francês, e $2 \%$ em outros idiomas. Em relação ao tipo de documento, $76 \%$ 
correspondem a artigos de periódicos, e o restante, a livros, separatas, relatórios, teses, trabalhos de congressos e outros documentos (BANQUE DE DONÉES..., 2001).

A CAB Health é uma base de dados especializada em nutrição humana, plantas medicinais e doenças parasitárias, transmissíveis e tropicais. Dá acesso à literatura científica internacional de 1973 em diante. Indexa mais de 3.500 periódicos, de mais de 125 países, livros, relatórios de pesquisa, patentes e normas, teses, trabalhos apresentados em congressos e literatura não-convencional de países em desenvolvimento. Conta atualmente com mais de 860.000 registros, sendo 45.000 a média anual. $\mathrm{O}$ acesso a essa base de dados só pode ser feito por meio de assinatura em provedores privados, o que restringe sua consulta aos usuários cadastrados nos respectivos serviços de acesso.

A base de dados bibliográfica EMBASE indexa atualmente documentos publicados em 4.242 revistas científicas, trabalhos apresentados em eventos científicos, livros e teses de 65 países, nas áreas biomédica, médica, farmacológica e de saúde pública. Dos títulos indexados, aproximadamente 55\% são publicados na Europa, 33\% nos Estados Unidos, 9\% na Ásia e Oceania, 1,9\% na América Latina e Caribe, 1,3\% no Oriente Médio, e 0,3\% na África. Dos 80 títulos da América Latina e do Caribe indexados, 41 (50\%) são do Brasil. 


\section{CAPÍTULO 5}

\section{PRODUÇÃO CIENTÍFICA, TÉCNICA E NORMATIVA EM SAÚDE}

O avanço do conhecimento é inerente ao próprio desenvolvimento da humanidade, pela observação de fatos do cotidiano e pela busca de respostas para esses fatos. $\mathrm{O}$ conhecimento científico se caracterizou à medida que se desenvolveram procedimentos para a observação e análise crítica desses fatos. A produção do conhecimento científico, ou atividade científica, envolve os pesquisadores, preparados para adotar os instrumentos e métodos científicos, e também os próprios métodos científicos, desenvolvidos e utilizados em ambientes ou centros de pesquisas.

O fluxo da comunicação científica é mais amplo: inicia-se pela produção do conhecimento e se estende até a publicação, a disseminação dessa produção e a assimilação do conhecimento. Esse fluxo é contínuo, já que conhecimentos publicados e assimilados dão origem a novos conhecimentos, novas pesquisas e novas publicações, e é regido por uma dinâmica específica e influenciado por fatores externos (relações com a sociedade) e internos (procedimentos específicos).

Esses três processos básicos da atividade científica - produção (pesquisa), circulação e incorporação do conhecimento - estão imersos em uma totalidade social à qual influenciam; por sua vez, também são influenciados, principalmente através de instâncias mediadoras como as de financiamento, formação de recursos humanos, legitimação, legislação e normas, canais de disseminação e comunicação de informação, estrutura dos sistemas de saúde, etc. ( PELLEGRINI FILHO 2000, p. 3). 
A produção científica reflete os diferentes contextos sociais, econômicos e políticos da sociedade. "A produção e utilização do conhecimento são funções sociais: respondem a demandas sociais expressadas de diferentes maneiras que as legitimam e as tornam possíveis”, afirmou Carlyle Guerra de Macedo (PELLEGRINI FILHO 2000, ix).

No entanto, diz PELLEGRINI FILHO, "se não existe o necessário amadurecimento dado pela acumulação de conhecimentos e instrumentos, determinadas demandas sociais não encontrarão resposta adequada por parte da ciência, assim como certas descobertas científicas não avançarão se a sociedade não estiver preparada para incorporá-las" (p. 3).

A produção científica em saúde pública é de caráter eminentemente social, pois atende a demandas provenientes de toda a população e procura encontrar respostas dirigidas a ela. FRENK (1992b) define a saúde pública como "a aplicação das ciências biológicas, sociais e de conduta ao estudo dos fenômenos de saúde em populações humanas".

FRENK et al. (1986) distinguiram quatro tipos de pesquisa na área da saúde: biomédica, clínica, pesquisa em necessidades de saúde e pesquisa em sistemas de saúde. A pesquisa biomédica está dirigida às condições e determinantes da saúde e doença em nível individual, celular, molecular etc. A pesquisa clínica estuda as respostas terapêuticas, preventivas e de reabilitação individual. A pesquisa em saúde pública abarcaria os dois últimos tipos: a pesquisa de necessidades de saúde, que corresponderia a condições de saúde da população que requerem atenção (epidemiologia, análise de situação de saúde, análise de riscos etc.), e a pesquisa em sistemas de saúde, que corresponderia às respostas sociais às condições de saúde (utilização e organização de serviços, disponibilidade de recursos, políticas de saúde, entre outros) (FRENK et al. 1986, p. 479-80 e 489). 
A representação gráfica dessa tipologia pode ser verificada na Figura 1. FRENK (1992b) explicou que as células representadas na Figura 1 não são compartimentos estanques e podem conectar-se entre si, como no caso da bioepidemiologia, a epidemiologia clínica, a avaliação de tecnologias etc. Expôs também que o cruzamento entre os objetos e os níveis de análise tem como resultado os três tipos principais de pesquisa na área da saúde: a biomédica, a clínica e a de sistemas de saúde (p. 77-78).

\begin{tabular}{|c|c|c|}
\hline \multirow{2}{*}{$\begin{array}{l}\text { NÍVEL DE } \\
\text { ANÁLISE }\end{array}$} & \multicolumn{2}{|l|}{ OBJETO DE ANÁLISE } \\
\hline & Condições & Respostas \\
\hline Individual & $\begin{array}{l}\text { Pesquisa biomédica } \\
\text { (Processos biológicos básicos; } \\
\text { estrutura e função do corpo humano; } \\
\text { mecanismos patológicos) }\end{array}$ & $\begin{array}{l}\text { Pesquisa clínica } \\
\text { (Eficácia de procedimentos } \\
\text { preventivos, diagnósticos e } \\
\text { terapêuticos; história natural das } \\
\text { doenças) }\end{array}$ \\
\hline Populacional & $\begin{array}{l}\text { Pesquisa epidemiológica } \\
\text { (Freqüência, distribuição e } \\
\text { determinantes das necessidades de } \\
\text { saúde) }\end{array}$ & $\begin{array}{l}\text { Pesquisa em sistemas de saúde } \\
\text { (Efetividade, qualidade e custos dos } \\
\text { serviços; desenvolvimento e } \\
\text { distribuição de recursos para a } \\
\text { atenção) }\end{array}$ \\
\hline
\end{tabular}

Fonte: FRENK 1992b, p. 78 (modificada de FRENK et al. 1986, p. 480)

Figura 1 - Tipologia da pesquisa em saúde

PELLEGRINI FILHO (2000) preferiu utilizar 'atividade científica para o desenvolvimento da saúde' em vez de 'atividade científica em saúde' em sua análise sobre a comunicação científica na área da saúde, destacando, assim, a ênfase no caráter essencial da ciência para a melhoria das condições de saúde (p.35). Essa diferenciação havia sido proposta também por FRENK et al. (1986) em relação ao que chamaram de orientação primária da pesquisa: a 'pesquisa para a saúde' teria como objetivo principal resolver algum problema concreto de saúde, e a 'pesquisa sobre saúde' estaria orientada principalmente ao avanço do conhecimento na área. 
Essas orientações se aplicariam a qualquer um dos quatro tipos de pesquisa definidos pelos autores (p. 485).

A saúde pública é formada por uma convergência de áreas que abarca as ciências da saúde (medicina, ciências biomédicas, odontologia, enfermagem, nutrição), as ciências humanas, sociais e econômicas (economia, administração, sociologia e política, educação) e até mesmo as ciências exatas (engenharia sanitária e ambiental). Em geral, os autores classificam a produção científica dessa área em duas vertentes básicas: (1) a epidemiologia e a área de políticas de saúde e (2) a organização dos serviços e as práticas de saúde, mais relacionada às Ciências Sociais (aspectos sóciopolíticos ou sócio-antropológicos da saúde).

Segundo FRENK (1992b), a saúde pública não é unicamente um campo do conhecimento mas também um espaço de prática profissional, ao realizar esforços sistemáticos para a identificação das necessidades de saúde e a organização de serviços integrais com uma base definida na população. Quanto ao universo da saúde pública, o autor afirma que os esforços para gerar conhecimentos e para atuar sobre a realidade se expressam em diversas áreas de aplicação: grupos populacionais específicos (jovens, idosos, mulheres etc.), problemas particulares (saúde mental, saúde oral etc.) ou programas (saúde ambiental, saúde ocupacional etc.) (p. 82).

De acordo com a taxonomia do conhecimento científico utilizada no Brasil pelo CNPq na Plataforma Lattes, que divide o conhecimento em 75 grandes áreas, a saúde pública, a epidemiologia e a medicina preventiva constituem áreas específicas no âmbito da grande área da 'saúde coletiva' (CONSELHO NACIONAL... 2002).

\section{Segundo GUIMARÃES (2001),}

existe uma forte corrente de opinião entre os epidemiólogos e demais profissionais da saúde coletiva na defesa de que essa taxonomia não é a melhor para a organização do conhecimento na área, por não ser capaz de discriminar os três campos de ensino e pesquisa a ela pertencentes e hoje consagrados: a epidemiologia, o 
campo das ciências sociais e saúde e o campo das políticas, planejamento e gestão da saúde (p. 324).

BURLANDY e BODSTEIN (1998) afirmaram que as transformações decorrentes do período de Reforma Sanitária no Brasil podem ter provocado reflexos teóricos na área de saúde coletiva, dando lugar a novas categorias temáticas pouco presentes na literatura do campo, como cotidiano e representação social, gerência e administração local de serviços, valores culturais da população usuária e sua influência na concepção saúde/doença etc. (p. 548).

TERRIS (1992), citado por PAIM (1998), apresenta uma nova definição de saúde pública como "a arte e a ciência de prevenir a doença e a incapacidade, prolongar a vida e promover a saúde física e mental mediante os esforços organizados da comunidade” (PAIM 1998, p. 4).

PAIM (1998) propõe que se discuta a questão da saúde no âmbito público-coletivosocial e as propostas de ação subseqüentes. Nesse sentido, afirma que “o campo da Saúde Coletiva surgido na América Latina nos últimos 20 anos permite a identificação de pontos de encontro com os movimentos de renovação da saúde pública institucionalizada, seja como campo científico, seja como âmbito de práticas, e mesmo como atividade profissional” (p.4).

A constituição da saúde coletiva, tendo em conta os seus fecundos diálogos com a saúde pública e com a medicina social (....) permite uma delimitação compreensivelmente provisória desse campo científico, enquanto campo de conhecimento e âmbito de práticas. (....) A saúde coletiva pode ser considerada como um campo de conhecimento de natureza interdisciplinar cujas disciplinas básicas são a epidemiologia, o planejamento/administração da saúde e as ciências sociais em saúde. São disciplinas complementares desse campo a estatística, a demografia, a geografia, a clínica, a 
genética, as ciências biomédicas básicas, entre outras (PAIM 1998, p.15).

O conceito de saúde pública em que a OPAS se baseou, em 2000, quando definiu as funções essenciais de saúde pública, é "ação coletiva, tanto do Estado como da sociedade civil, dirigida a proteger e melhorar a saúde das pessoas".

Foram definidas as seguintes funções essenciais de saúde pública para a América Latina e Caribe:

- monitoramento e análise da situação de saúde da população;

- $\quad$ vigilância de saúde pública, pesquisa e controle de riscos e danos em saúde pública;

- $\quad$ promoção da saúde;

- $\quad$ participação social e reforço do poder dos cidadãos [empowerment] em saúde;

- desenvolvimento de políticas, planos e capacidade de gestão;

- $\quad$ regulação e fiscalização em saúde pública;

- $\quad$ avaliação e promoção do acesso eqüitativo da população aos serviços de saúde necessários;

- desenvolvimento de recursos humanos e capacitação em saúde pública;

- $\quad$ garantia de qualidade dos serviços de saúde individual e coletiva;

- $\quad$ pesquisa, desenvolvimento e implementação de soluções inovadoras em saúde pública;

- redução do impacto de emergências e desastres em saúde (ORGANIZACIÓN PANAMERICANA...2000 p. 5, 12-8).

Destaca-se dentre elas, por estar diretamente relacionada ao objeto desta análise, a função de pesquisa, desenvolvimento e implementação de soluções inovadoras em saúde pública, que inclui, entre seus componentes, o estímulo às parcerias entre o setor saúde e os centros de pesquisa e instituições acadêmicas para a realização de estudos que apóiem a tomada de decisões em saúde em todos os níveis (ORGANIZACIÓN PANAMERICANA DE LA SALUD 2000, p. 17). Essa função 
segue tendência internacional de análise e promoção do desenvolvimento dos processos de gestão baseados em conhecimento científico e de aproximação entre a pesquisa científica e o processo de tomada de decisão e definição de políticas em saúde.

A interdisciplinaridade e variabilidade das disciplinas constitutivas da saúde pública foram ressaltadas por COIMBRA JUNIOR (1999) quando afirmou que:

em relação à saúde pública latino-americana, há uma enorme variabilidade interna no que diz respeito às suas disciplinas constitutivas, o que vem associado a práticas de publicação e citação particulares. Não raro num mesmo fascículo de uma revista nessa área, são publicados artigos de ciências sociais, epidemiologia, avaliação nutricional, microbiologia de alimentos ,toxicologia, política de medicamentos e controle de vetores, para mencionar somente uma fração dos temas eventualmente cobertos (p. 886).

Em 2001, foi desenvolvida uma taxonomia das grandes áreas da saúde pública para a classificação das fontes de informação da BVS-SP*. Nesta, foram identificadas 24 áreas temáticas representativas da área de saúde pública, que se encontram listadas no Anexo 1, com o escopo de cada área.

Não seria objeto específico desta pesquisa aprofundar a discussão sobre a melhor classificação da área do conhecimento da saúde pública e de suas disciplinas constitutivas ou sobre a definição mais exata da saúde pública. No entanto, considerou-se importante apresentar diferentes visões e percepções sobre o tema, registradas na literatura analisada, para caracterizar as dificuldades de identificar o âmbito da produção científico-técnica em saúde pública.

\footnotetext{
*Essa taxonomia foi elaborada por um grupo de especialistas da área de saúde pública e referendada pelo Comitê Consultivo Nacional da BVS-SP, constituído por representantes das principais instituições nacionais da área, o que lhe confere autoridade.
} 
Para esta pesquisa, a saúde pública foi entendida como toda ação dirigida a proteger e melhorar a saúde das pessoas, em todos os seus aspectos, e a promover ambientes saudáveis para o desenvolvimento social. Nesse conceito, considera-se que a saúde pública deva permear vários campos do conhecimento, desde as ciências sociais, ambientais, administrativas e do direito público até as áreas biomédicas, clínicas e de saúde individual, desde que o objetivo seja melhorar a saúde do coletivo social. $\mathrm{O}$ conhecimento em saúde pública não pode ser visto de maneira fragmentada e isolada das outras áreas do conhecimento em saúde, pois passa por todas elas. Saúde pública é saúde em geral, desde que dirigida ao público e não aos indivíduos em particular. $\mathrm{O}$ que a diferencia das outras áreas da saúde é seu objeto e não o conhecimento em si.

A produção científica corresponde à forma expressa e publicada do desenvolvimento científico e tecnológico. Publicar os resultados dos avanços do conhecimento científico e tecnológico atende à função social da ciência. A dinâmica de produção científica é específica de cada área temática e reflexo da totalidade social na qual está inserida, influenciando-a, ao mesmo tempo em que é influenciada por ela. Por meio da análise da produção científica, seria possível reconstituir os momentos históricos, políticos e sociais que influenciaram as várias áreas do conhecimento. O que nem sempre é possível é identificar de que forma essa produção influencia a sociedade, pois os indicadores de produção científica existentes não têm sido suficientes para a medição do impacto social.

Na América Latina, a pesquisa em saúde foi iniciada nos primeiros anos do século $\mathrm{XX}$, mas a organização da atividade científica consolidou-se mais claramente como objeto de políticas públicas nos anos 50 e 60, com a criação de organismos governamentais responsáveis por essa tarefa. Nos anos 50 e na primeira metade dos 60, a organização da atividade científica foi marcada por interesses nacionalistas de setores oficiais e militares e por interesses da comunidade científica. No Brasil, já no início dos anos 50, foi criado o Conselho Nacional de Desenvolvimento Científico e Tecnológico (CNPq - Conselho Nacional de Pesquisas, na época), diretamente subordinado á Presidência da República, com a finalidade de promover e estimular o aprimoramento científico e tecnológico em todas as áreas do conhecimento. Desde o início, o investimento na área da saúde foi significativo: o primeiro orçamento previa 
recursos de 34,4\% para as ciências biológicas e de 65,6\% para as ciências físicas, em que a prioridade era a área de energia nuclear (PELLEGRINI FILHO 2000, p. 5-7).

A pesquisa em saúde sempre se destacou em relação aos demais campos da ciência na América Latina e Caribe. Um relatório do BID, publicado em 1998, citado por PELLEGRINI FILHO, mostrou que a produção científica em saúde, em 1973, correspondia a $60 \%$ da produção científica da América Latina, tendo diminuído para 42\% na segunda metade da década de 80 (BID 1998, citado por PELLEGRINI FILHO, 2000, p. 48).

De acordo com o relatório "Science and Engineering Indicators, 1998" da U.S. National Science Foundation, cerca de um terço da produção mundial de artigos científicos, em 1995, correspondia à área médica (incluindo a saúde pública), e outros 25\% relacionavam-se à área de pesquisa biomédica e biologia; ou seja, toda a área de ciências da vida equivalia a mais de 50\% da literatura mundial (UNITED STATES. NATIONAL ... 1998).

A produção científica brasileira em saúde, em 1995, correspondia a 0,5\% da produção mundial de artigos científicos, destacando-se entre os países da América Latina, cujo total era de $0,14 \%$ da literatura mundial. Além do Brasil, apenas Argentina (0,3\%), Chile (0,2\%) e México (0,2\%) se destacavam. A área das ciências da vida (medicina, pesquisa biomédica e biologia), no período 1981-1995, equivalia, em média, a 50,5\% da produção científica brasileira publicada em artigos científicos, sendo a área médica (incluindo a saúde pública) responsável, na média, por 23\% dessa produção (UNITED STATES. NATIONAL ... 1998, tabelas 5-49 e 5-51).

Segundo o relatório da U.S. NATIONAL SCIENCES FOUNDATION (2002), o maior aumento do número de publicações em relação à produção mundial, durante o período de 1986 a 1999, ocorreu na América Latina, com concentração em três países (Argentina, Brasil e México), responsáveis por $80 \%$ da produção da região. 
Em relação à produção por áreas do conhecimento, o relatório de 2002 separou a área de ciências da saúde* da de medicina clínica. Os resultados indicaram que em 1999, na América Latina, a produção das ciências da vida ocupou 51,3\% da iniciativa científica da região, distribuída em 24,2\% na área de medicina clínica, 13,9\% em pesquisa biomédica e 13,2\% em biologia. A produção científica da área de ciências da saúde correspondeu a $0,9 \%$ em relação ao total da região, sendo que a produção científica brasileira nessa área foi responsável por 1,6\% do total do país no período.

Cabe ressaltar que esses dados foram extraídos da base de dados do Institute of Scientific Information (ISI), que inclui um número bastante reduzido de publicações da América Latina (72 revistas no total, sendo 20 do Brasil) em comparação com outras regiões do mundo.

GUIMARÃES (2001), em seu artigo sobre a atividade de pesquisa em epidemiologia no Brasil, afirmou que, pelo número de linhas de pesquisa identificadas nas bases de dados do $\mathrm{CNPq}$ - Plataforma Lattes, a área da saúde é a de maior atividade no país. Os resultados mostraram que, em relação ao número de grupos de pesquisas, a saúde coletiva é a oitava colocada dentre as 75 áreas do conhecimento, com crescimento proporcional sustentado ao longo da segunda metade da década de 90.

FRENK (1992b) já havia destacado que a pesquisa em saúde pública ocuparia um lugar secundário se comparada à pesquisa biomédica ou clínica, baseando-se em dados do relatório de 1990 da Comissão de Pesquisa em Saúde para o Desenvolvimento [The Commission on Health Research and Development].

$\mathrm{O}$ autor atribuiu esse resultado à fragmentação dos objetos de estudo e à consolidação de disciplinas independentes na pesquisa científica na área da saúde que se chocavam com o espírito integrador que deve caracterizar a saúde pública. " $A$ riqueza da saúde pública é que se presta à conjunção de diversas ciências biológicas, sociais e de conduta ao redor de um problema comum” (p.83-84).

\footnotetext{
* A área de Ciências da Saúde nas bases do ISI inclui Gerontologia e Envelhecimento, Política de Saúde e Serviços, Enfermagem, Saúde Pública, Reabilitação, Ciências Sociais em Saúde [Social studies in medicine], Fonoaudiologia e Audiologia.
} 
PELLEGRINI FILHO et al. (1997) confirmaram, em seu trabalho, que a análise dos problemas de saúde em nível individual predomina sobre a realizada em nível populacional, já que apenas $2,7 \%$ dos artigos produzidos por autores latinoamericanos indexados no Institute of Scientific Information (ISI) podem ser classificados como de pesquisa em saúde pública (p.28). Também não há uma clara correspondência entre essa produção e os problemas de saúde prevalentes; por exemplo, dos artigos publicados no início dos anos 90 na área de epidemiologia (66\% de autores brasileiros), $83 \%$ se referiam a doenças infecciosas, apenas $4 \%$ a doenças crônicas, e 13\% a outros assuntos (especialmente na área de saúde maternoinfantil). Nesse mesmo período, $78 \%$ dos artigos da literatura internacional correspondiam a doenças crônicas (p. 30).

COIMBRA JUNIOR (1999) também afirmou que, como as pesquisas da área de saúde pública normalmente abordam temáticas locais/regionais e citam mais outros tipos de documentos que não os artigos, as revistas dessa área dificilmente serão consideradas para indexação nas bases de dados do ISI, sendo que isso valeria não somente para as revistas latino-americanas mas para toda a área da saúde pública.

Esse autor destacou que "a pesquisa em saúde pública pode ter impactos sobre políticas, planejamento de estratégias de intervenção e de programas de saúde, ou sobre organização de serviços, que de muito extrapolam a mera quantificação de referências elou citações bibliográficas", [como fazem as bases do ISI] (p. 887).

Segundo indicadores de 2002 do Ministério de Ciência e Tecnologia, a produção científica brasileira publicada em periódicos internacionais na área de clínica médica (que abrange todas as disciplinas das ciências da saúde, inclusive a saúde pública) correspondia, em 1981, a 23\% da produção da América Latina e a 0,34\% da literatura mundial, tendo alcançado, em 2000, 41\% da produção da América Latina e 0,89\% da literatura mundial (MINISTÉRIO DE CIÊNCIA E TECNOLOGIA 2002, Cap. 6, tabela 6.1.1.1).

Segundo DE MEIS (1996), a produção científica brasileira na área de medicina social (que inclui medicina social e ambiental e saúde pública) equivalia a 1,6\% da 
produção científica nacional no período de 1981 a 1993, tendo se mantido praticamente constante o volume de produção ao longo desses anos. Nesse mesmo período, a produção da área de Ciências Biomédicas equivalia a 25,7\% e a da Medicina a 12,2\%. Na área de medicina social, mais de $70 \%$ dos artigos vêm da área de saúde pública (p. 51).

A análise da produção científica em saúde pública na área acadêmica brasileira realizada por ANDRADE (1992) mostrou que a produtividade científica dos docentes dos cursos de pós-graduação analisados no estudo esteve mais dirigida à busca de soluções para os problemas de interesse da população local, caracterizandose como pesquisa científica aplicada.

Como afirmou a autora,

$$
\begin{aligned}
& \text { a temática da pesquisa em Saúde Pública é muito variada e } \\
& \text { fortemente relacionada aos problemas da população. } \\
& \text { Conseqüentemente, a pesquisa acadêmica acaba se voltando para } \\
& \text { a solução desses problemas e dando menor ênfase à pesquisa } \\
& \text { básica. Tais problemas estão ligados sobretudo à questão de } \\
& \text { estudos como saúde materno-infantil, doenças infecciosas e } \\
& \text { parasitárias, nutrição, que são próprios de países em } \\
& \text { desenvolvimento (p. } 25) \text {. }
\end{aligned}
$$

A produção científica brasileira em saúde pública não está bem representada nas bases de dados internacionais, o que dificulta a análise completa dessa produção. Os instrumentos tradicionalmente utilizados pela agências de ciência e tecnologia para extração de indicadores de produção científica na área da saúde são as bases de dados do ISI e a base de dados MEDLINE. Apenas duas revistas representativas da área no Brasil são indexadas nessa base - Cadernos de Saúde Pública e Revista de Saúde Pública -, e, nas bases do ISI, apenas a Revista de Saúde Pública. 


\subsection{Revistas científicas em saúde pública}

A produção de revistas científicas na área da saúde pública nos países latinoamericanos é relativamente recente, tendo se iniciado há não mais de três décadas. Com exceção do Boletim do Instituto de Higiene de São Paulo, iniciado em 1919, e do Boletín de la Oficina Sanitaria Panamericana, iniciado em 1922, as principais revistas latino-americanas de saúde pública passaram a ser publicadas desde a segunda metade do século XX.

No Brasil, revistas específicas dessa área existem desde o início dos anos 90. O Boletim do Instituto de Higiene de São Paulo existiu de 1919 a 1946, tendo sido substituído, de 1947 a 1996, pelos Arquivos da Faculdade de Higiene e Saúde Pública da Universidade de São Paulo. Posteriormente, transformou-se na Revista de Saúde Pública, que atualmente é uma das principais publicações nacionais da área, indexada em várias bases de dados nacionais e internacionais, como LILACS, MEDLINE, bases de dados do Institute of Scientific Information (ISI) e SciELO.

Outra revista específica desse setor é a Cadernos de Saúde Pública, iniciada em 1985, publicada pela Escola Nacional de Saúde Pública da Fundação Oswaldo Cruz. Essa revista é indexada na base de dados MEDLINE desde 1998 e tem recebido na SciELO um alto número de consulta e citações, o que evidencia seu papel de destaque na área.

Além destas, cabe destacar algumas revistas científicas nacionais que, embora dedicadas à pesquisa médica e biológica das doenças tropicais, das doenças infecciosas e parasitárias e da medicina preventiva, são importantes para a área de saúde pública e epidemiologia. Algumas delas foram criadas no início da segunda metade do século XX: a revista Memórias do Instituto Oswaldo Cruz, uma das primeiras publicações científicas nacionais com mais de 100 anos de existência, iniciada em 1909, a Revista do Instituto Adolfo Lutz, iniciada em 1941, a Revista do Instituto de Medicina Tropical de São Paulo, criada em 1959, e a Revista da

Sociedade Brasileira de Medicina Tropical, iniciada em 1962. Mais recentemente, também da área de doenças infecciosas, aparece a Brazilian Journal of Infectious 
Diseases, criada em 1996. Todas essas revistas são indexadas na base de dados MEDLINE.

O Catálogo de Revistas de Saúde Pública da BVS-SP identifica 45 revistas nacionais correntes de saúde pública e áreas correlatas. A distribuição dessas revistas por ano de publicação mostra que 22 (48\%) foram iniciadas entre 1971 e 1990, e 12 (27\%) desde 1991. Apenas 8 (18\%) títulos haviam sido publicados até 1970 (Figura 2).

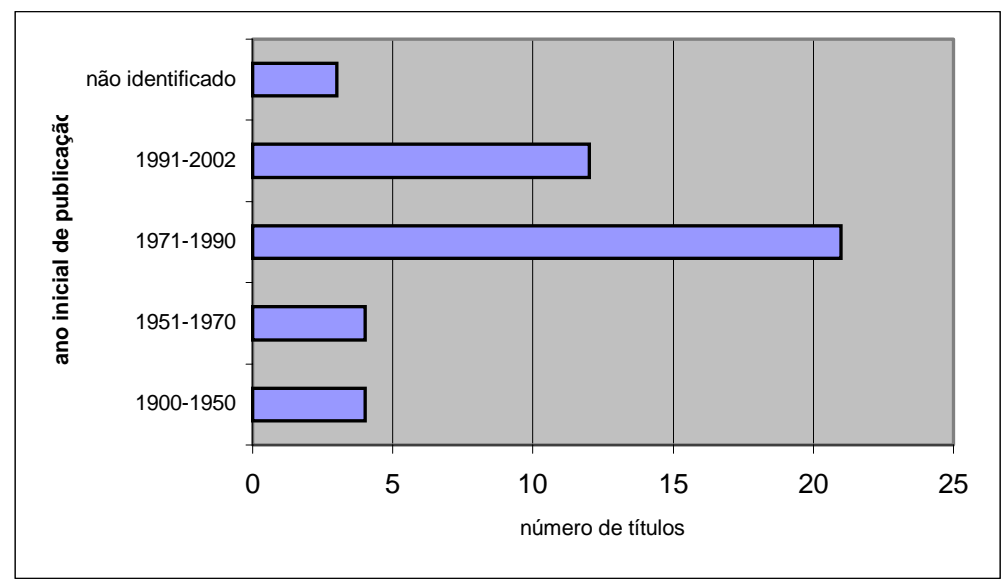

Fonte: BVS-SP - Catálogo de revistas de saúde pública

Figura 2 - Revistas nacionais de saúde pública, por ano inicial de publicação

Devido ao caráter multidisciplinar da área, a identificação das revistas de saúde pública indexadas nas bases de dados tem sido muito variada, abrangendo publicações de ciências sociais, de medicina preventiva, medicina tropical, pesquisas médicas e biológicas de vetores de doenças transmissíveis, alimentação e nutrição etc. Não parece haver consenso, entre os produtores de bases de dados, sobre a classificação das revistas que representam a produção científica da saúde pública; essa ampla abrangência faz com que algumas revistas apareçam classificadas nessa área em algumas bases de dados e em outras não. Como afirmou COIMBRA (1999), até mesmo as revistas específicas, como a Cadernos de Saúde Pública, publicam uma ampla variedade de temas num mesmo fascículo.

A representatividade das revistas da área de saúde pública nas bases de dados internacionais é a seguinte: na MEDLINE são indexadas 110 revistas da área, e no Index Medicus, 87 (dados de 2002); nos Journal Citation Reports do ISI, 88 revistas 
na Science Edition e 54 na Social Sciences Edition (dados de 2001) (Anexo 4). Desses títulos indexados em bases de dados internacionais, apenas quatro são latinoamericanos: Revista de Saúde Pública, Cadernos de Saúde Pública, Salud Pública de México e Revista Panamericana de Salud.

A distribuição das 87 revistas de saúde pública indexadas no Index Medicus, em 2002, por país de publicação, pode ser vista na Figura 3. Esse total corresponde a revistas de 26 países. Nesse gráfico, a categoria "Outros" se refere a 13 países com apenas uma revista indexada (Austrália, Bulgária, Egito, Escócia, Holanda, Índia, Israel, Madagascar, México, Nova Zelândia, Tailândia, Tchecoslováquia, Tunísia). O Brasil, assim como Alemanha, China, Espanha, Itália, Polônia, Rússia e Suíça, tem duas revistas indexadas. As revistas dos Estados Unidos e da Inglaterra correspondem a $52 \%$ do total.

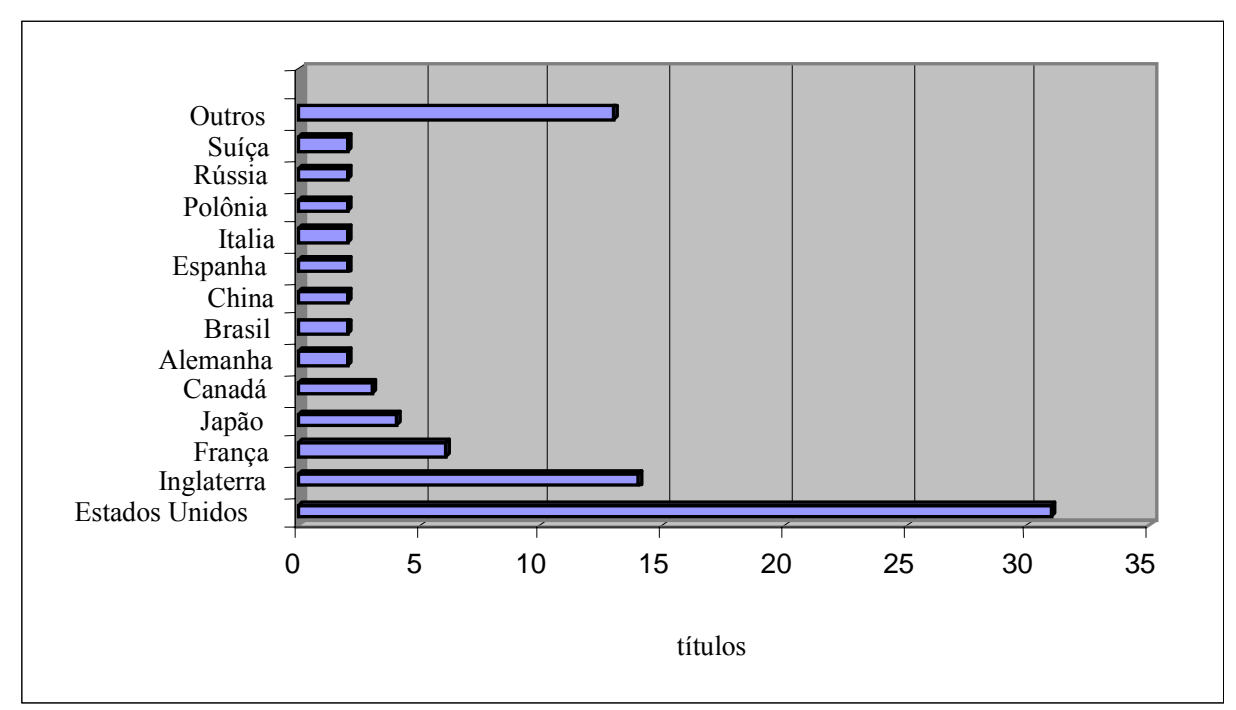

Fonte: List of Journals indexed in Index Medicus 2002

Figura 3 - Revistas de saúde pública indexadas no Index Medicus em 2002 por país 
$\mathrm{Na}$ base de dados LILACS, foram identificadas 15 revistas brasileiras da área de saúde pública (Tabela 2).

Tabela 2 - Revistas brasileiras na área de saúde pública indexadas na base de dados

LILACS em 2002

\begin{tabular}{|c|c|c|}
\hline Titulo & Local & Ano Inicial \\
\hline Cadernos de Saúde Coletiva & Rio de Janeiro & 1987 \\
\hline Cadernos de Saúde Pública & Rio de Janeiro & 1985 \\
\hline Ciência e Saúde Coletiva & Rio de Janeiro & 1996 \\
\hline Divulgação: Saúde para Debate & Londrina & 1989 \\
\hline História, Ciências, Saúde & Rio de Janeiro & 1994 \\
\hline $\begin{array}{l}\text { Mundo da Saúde (continuação de Hospital: } \\
\text { administração e saúde (1986-94) }\end{array}$ & São Paulo & 1995 \\
\hline $\begin{array}{l}\text { Physis (Rio de Janeiro): Revista de Saúde Coletiva } \\
\text { RASPP: Revista da Associação de Saúde Pública }\end{array}$ & Rio de Janeiro & 1991 \\
\hline do Piauí & Teresina & 1998 \\
\hline Revista Baiana de Saúde Pública & Salvador & 1974 \\
\hline Revista Brasileira de Epidemiologia & São Paulo & 1998 \\
\hline $\begin{array}{l}\text { Revista Brasileira de Crescimento e } \\
\text { Desenvolvimento Humano }\end{array}$ & São Paulo & 1991 \\
\hline Revista de Saúde do Distrito Federal & Brasília & 1990 \\
\hline $\begin{array}{l}\text { Revista de Saúde Pública (substituição de Arquivos } \\
\text { Faculdade de Higiene e Saúde Pública da } \\
\text { Universidade de São Paulo (1947-1966)) }\end{array}$ & São Paulo & 1967 \\
\hline Revista do Instituto Adolfo Lutz & São Paulo & 1941 \\
\hline Saúde e Sociedade & São Paulo & 1992 \\
\hline
\end{tabular}

\subsection{Livros, teses e trabalhos apresentados em eventos científicos}

A literatura da área de saúde pública se assemelha muito à da área de ciências sociais, e, portanto, os livros representam uma fonte de informação muito utilizada para a disseminação de informações nela. São produzidos em geral por editoras universitárias, comerciais, por institutos de pesquisa como a Fiocruz, associações como a Abrasco, ou organismos internacionais sediados no Brasil, como a OPAS.

As teses da área de saúde pública são produzidas por faculdades e escolas específicas da área e por escolas médicas, de enfermagem, odontologia, sociologia, direito, economia etc. NORONHA (1998) verificou que, nas citações de dissertações e teses 
da área de saúde pública produzidas por pesquisadores de três instituições representativas da área no Brasil de 1990 a 1994, 30,4\% corresponderam a livros, $3,4 \%$ a dissertações e teses, 4,2\% a comunicações em eventos, e 1,9\% a relatórios técnicos. A autora apontou que a baixa porcentagem de uso desses documentos poderia estar relacionada às dificuldades de acesso e de identificação, pela inexistência de fontes específicas de divulgação ou pelo desconhecimento de sua existência por parte dos pesquisadores.

Os congressos brasileiros de saúde pública têm constituído um espaço privilegiado para disseminação e troca de conhecimentos, mas estão sub-representados nas bases de dados bibliográficas. Normalmente são encontradas referências aos anais dos eventos, mas não a todos os trabalhos apresentados nos mesmos. Isto se deve, principalmente, ao fato de nos anais serem publicados apenas os resumos dos trabalhos apresentados, o que limita sua indexação nas bases de dados.

MORAES (2001), em sua análise sobre a produção científica na área de informações em saúde, identificou 5.503 resumos de trabalhos apresentados nos Congressos Brasileiros de Saúde Coletiva, de Epidemiologia e Ciências Sociais, que estavam, em geral, ausentes das bases de dados bibliográficas consultadas.

Os livros, teses e trabalhos apresentados em eventos são indexados em várias bases de dados bibliográficas da área da saúde, como as do Sistema LILACS (LILACS, AdSAÚDE e REPIDISCA), a BDSP, a CAB Health, a POPLINE. Mesmo assim, a cobertura da produção científica desses tipos de documentos nessas bases de dados está longe de representar a totalidade dessa produção.

A baixa representatividade desses tipos de documentos nas bases de dados poderia estar relacionada à inexistência de uma prática instituída ou de um interrelacionamento sistemático entre as instituições produtoras dos mesmos (editoras, universidades e comissões organizadoras de eventos) e os produtores de bases de dados, que permitiria a estes conhecer e indexar toda a produção existente nos países. 
A consulta a esses documentos também representa uma dificuldade, uma vez que o acesso fica praticamente restrito às coleções tradicionais das bibliotecas. A utilização desses documentos é pouco conhecida, pois os indicadores de produção científica divulgados pelas agências de ciência e tecnologia se referem principalmente a artigos de revistas.

Como afirmou MORAES (2001),

os métodos avaliativos de mensuração da produtividade de pesquisadores e instituições de pesquisa não dão conta da diversidade e complexidade dos saberes produzidos, nem nas próprias instâncias acadêmicas, quanto mais em outras instâncias da sociedade brasileira, muitas vezes produtoras de um conhecimento considerado como não-científico, como as ONG, instituições executivas de governo, o legislativo, o judiciário, o Ministério Público, sindicatos e outras (p. 78).

\subsection{Produção científica e técnica governamental}

A produção científica e técnica produzida pelas Secretarias de Saúde, pelo Ministério da Saúde, por centros de pesquisa vinculados a instituições governamentais refere-se a documentos como manuais, relatórios, projetos de pesquisa, programas de trabalho, diagnósticos de situação, relatos de experiências, entre outros, dirigidos especificamente à gestão do sistema e dos serviços de saúde. São documentos que não passam pela avaliação de pares ou por outro processo de controle de qualidade da comunidade científica e, por isso, tendem a ser pouco considerados pelos pesquisadores. São dirigidos principalmente a gestores, profissionais de saúde atuantes nos serviços, auxiliares e técnicos da área. Poderiam corresponder ao que FRENK (1992b) apontou como 'pesquisa essencial em saúde', definida como "aquela pesquisa que todo país deve realizar, não importa seu nível de desenvolvimento, se almeja desenvolver conhecimento sobre seus próprios 
problemas de saúde, diminuir a distância entre o conhecimento e o sucesso alcançado” (p. 85).

Essa produção, muitas vezes classificada como documento não-convencional ou literatura cinzenta, por não seguir o fluxo tradicional da publicação científica acadêmica, está praticamente ausente das bases de dados bibliográficas internacionais. Pode ser encontrada principalmente nas do Sistema LILACS (LILACS, AdSAÚDE, REPIDISCA), embora com um porcentual baixo em relação à produção total. Sua identificação e acesso são dificultados pela inexistência de um fluxo de registro e de disseminação desses documentos por essas instituições.

\subsection{Legislação e outros instrumentos normativos}

O arcabouço jurídico-legal do SUS compreende a Constituição Federal, as Leis Orgânicas de Saúde e as Constituições Estaduais e as Leis Orgânicas Municipais. Além destes, a legislação em saúde é constituída por leis, decretos, portarias, normas operacionais, resoluções e outros instrumentos normativos que orientam gestores e profissionais da saúde sobre procedimentos, condutas, normas e instrumentos para operacionalização do SUS ou para as atividades de vigilância (sanitária, epidemiológica, farmacológica, alimentar etc.).

Os instrumentos legais brasileiros estão amplamente divulgados nos sites governamentais (do Ministério da Saúde, das Secretarias da Saúde, dos Conselhos de Saúde, da Agência Nacional de Vigilância Sanitária - Anvisa) e em bases de dados nacionais específicas da área de legislação, como a do Prodasen, do Senado Federal. A legislação é publicada nos Diários Oficiais da União, dos Estados e dos Municípios.

Pela importância e necessidade de sua consulta por gestores e profissionais de saúde, esses documentos são os que mais constam em formato de textos completos disponíveis na internet. Há uma tendência crescente para a criação de bases de dados de textos completos que permitam busca por assuntos e que inter-relacionem a legislação entre si, de forma a manter a informação atualizada sobre revogações e acréscimos na legislação em vigor. 
A legislação em saúde é uma informação de caráter normativo e tem, portanto, de ser obrigatoriamente utilizada pelos gestores para garantir o pleno funcionamento dos serviços e o desenvolvimento de ações de saúde e da gestão do SUS. Além de ser indispensável para os gestores, é bastante utilizada pelos pesquisadores da área de saúde pública. NORONHA (1998) observou que, nas teses e dissertações desse setor, havia uma forte presença de utilização de documentos legislativos (leis, decretos, acórdãos, resoluções etc.), pois muitos trabalhos se referiam a regulamentações de ações governamentais e de serviços (p. 4). 


\section{CAPÍTULO 6}

\section{USO DA INFORMAÇÃO NO PROCESSO DE DECISÃO EM SAÚDE}

Dentre os estudos analisados na revisão de literatura sobre o uso da informação científica para tomada de decisão política em saúde, dois foram realizados na América Latina: no México e em São Paulo, Brasil, respectivamente. O estudo mexicano serviu de base para o desenvolvimento do tema desta pesquisa e será discutido detalhadamente neste capítulo.

Os problemas na interação entre pesquisadores e tomadores de decisão na área da saúde e nas propostas de como melhorar essa interação foram relatados em diversos estudos recentes, dentre eles FRENK (1992a), WALT (1994), DAVIS e HOWDENCHAPMAN (1996), BROWSON et al. (1997), POUVOURVILLE (1999, 2001), TROSTLE et al. (1999) e BRONFMAN et al. (2000). A questão inicial, em muitos desses estudos, foi identificar como o conhecimento científico era utilizado para a tomada de decisão em saúde pública. Os resultados apontaram para uma outra questão: a necessidade de saber como melhorar a efetividade na interação entre pesquisadores e tomadores de decisão.

Apesar da crescente quantidade de informação científico-técnica produzida na área da saúde, de sua ampla disseminação, principalmente pela internet, e especialmente da velocidade com a qual as informações podem ser transferidas aos usuários interessados, os estudos encontrados na literatura mostraram evidência de que o conhecimento científico e técnico não estaria sendo eficientemente utilizado pelos gestores no processo de tomada de decisão.

Os trabalhos analisados indicaram que há uma falta de interatividade entre pesquisadores, gestores e tomadores de decisão e que vários fatores contribuem para essa situação; entre eles, o próprio acúmulo de informação, que torna mais complexa a tarefa de selecionar, entre tantas fontes disponíveis, aquela que possa reforçar ou apontar soluções no processo de tomada de decisão.

Vários fatores importantes para a falta de interatividade entre esses grupos foram apresentados pelos autores acima citados, destacando-se:

a) falta de canais de comunicação bem definidos;

b) ênfase em contatos pessoais, e não em literatura publicada;

c) pouca divulgação de resultados em nível social;

d) falta de continuidade das prioridades;

e) distanciamento entre as agendas de pesquisa acadêmica e governamental na área da saúde.

Pelos argumentos apresentados pelos autores, percebe-se que o caminho entre a pesquisa científica e a tomada de decisão política não é linear, e, ao percorrê-lo, um sem número de atores e situações influencia o processo decisório. Além disso, 
embora a pesquisa científica possa apoiar no estabelecimento de políticas, essa influência nem sempre é previsível.

$\mathrm{Na}$ década de 80, várias iniciativas internacionais foram criadas e incentivaram os governos a incrementar recursos para pesquisas em saúde, com enfoque para a área social e para a pesquisa aplicada. As atividades desses programas estiveram voltadas para a capacitação de gestores e profissionais externos ao ambiente acadêmico, para a realização de cursos, oficinas, conferências e outros eventos científicos e para o aumento do vínculo entre pesquisadores e tomadores de decisão. Os organismos internacionais como a Organização Pan-Americana da Saúde (OPAS), o International Development Research Council (IDRC), do Canadá, a Organização das Nações Unidas para a Educação, Ciência e Cultura (Unesco), o Programa de Desenvolvimento das Nações Unidas (PNUD) e o Banco Mundial tiveram papel decisivo no financiamento de pesquisas que promoveram avanços no conhecimento sobre a interação entre os resultados de pesquisas e os processos de tomada de decisão em saúde (BRONFMAN et al. 2000, p. ix).

Um problema discutido principalmente por FRENK (1992a) e BRONFMAN et al. (2000) foi a percepção sobre a natureza do produto final da pesquisa e sobre o público-alvo. FRENK afirmou que os pesquisadores abordariam questões claramente definidas, mesmo que significassem a fragmentação do objeto de análise, sendo que os tomadores de decisão buscariam respostas amplas para o problema como um todo. Além disso, os resultados de pesquisas, em geral, seriam divulgados para a própria comunidade científica que, inclusive, daria a medida do impacto dos resultados das pesquisas, pela citação dos trabalhos de seus pares. Entretanto, para os tomadores de decisão, a pesquisa não terminaria até que influenciasse uma decisão (p.1399).

Segundo BRONFMAN et al., os pesquisadores teriam a expectativa de que a divulgação de resultados em revistas científicas seria suficiente para seu eventual uso e não estão preparados ou desejosos de comunicar seus resultados ao público em geral ou aos tomadores de decisão. Os tomadores de decisão, por seu lado, às vezes necessitariam de pesquisa rápida e inequívoca ou desejariam respostas definitivas (ou respaldo a suas decisões) em vez de conclusões previsíveis de que "seria necessário mais pesquisa" (BRONFMAN et al. 2000, p. x).

Entretanto, concluíram esses autores, os objetivos de pesquisadores e tomadores de decisão são em longo prazo similares. Eles afirmaram que "os pesquisadores esperam que os conhecimentos por eles produzidos sejam usados e contribuam ao bem estar da população. Por seu lado, os tomadores de decisão se esforçam para tomar decisões com maiores probabilidades para beneficiar a população”. A questão, segundo os autores, seria identificar por que ambos os grupos somente interagem e se apóiam de maneira tão esporádica e quais as soluções para romper as dificuldades de aproximação (BRONFMAN et al. 2000, p. 157).

O interesse em realizar estudos sobre a interação entre pesquisadores e tomadores de 
decisão na área de saúde pública pode ser exemplificado no trabalho de POUVORVILLE (1999). O autor afirma que a pesquisa em saúde pública tende a ser, por vocação, aplicável à ação, tratando do funcionamento de sistemas sociais, e que o impacto na saúde das populações e seus resultados despertariam mais interesse se fossem transformados em políticas. Outro aspecto favorável a essa área seria a crescente demanda dos tomadores de decisão na maior parte dos países por respostas e soluções para questões de saúde pública, o que poderia criar um golpe na comunidade científica à medida que não pudesse satisfazê-la. "A pesquisa em Saúde Pública tem uma demanda inevitável para produzir conhecimento destinado a ser utilizado para implementar políticas para o desenvolvimento das condições da população". E, desta forma, “a própria relação entre conhecimento e ação se torna um tema de pesquisa na área de Saúde Pública” (POUVORVILLE 1999, p. 890).

Esse mesmo autor discute o status epistemológico da pesquisa em saúde pública para justificar seus argumentos e utiliza o sistema francês como exemplo. Ele mostra que, na França, inicialmente a pesquisa nessa área era feita por médicos e epidemiologistas para estabelecer relação causal entre fatores de risco e problemas de saúde específicos. Essa orientação para a doença se justificaria, segundo o autor, pois "faltavam à maioria desses especialistas não somente conhecimentos sobre como os serviços de saúde estavam organizados, mas também habilidades em ciências políticas e administrativas e economia” (p. 891). Mas, com o tempo, ficou claro que as pesquisas sobre fatores de risco tinham de ser mais complexas, abrangendo outros determinantes da saúde e o próprio sistema de saúde, e as pesquisas em saúde pública deixaram de ser exclusivas de pesquisadores do setor e passaram a despertar o interesse de profissionais de outras áreas do conhecimento (p.891-2).

Os pesquisadores, segundo o autor, tendem a pensar que a única fonte legítima de conhecimento é a ciência, o que caracterizaria sua racionalidade, sendo que os tomadores de decisão teriam sua racionalidade limitada por uma rede de interesses interconexos. Mas a racionalidade dos pesquisadores seria também limitada, considerando-se que a ciência não dá conta de responder a todas as questões, principalmente em relação aos recursos e ao fato de os temas de pesquisa serem em geral escolhidos de acordo com a competição entre os cientistas. Os tomadores de 89 decisão teriam de integrar diferentes dimensões de um problema ao definir as políticas, enquanto os pesquisadores freqüentemente se concentrariam em algumas dimensões de uma mesma questão (POUVORVILLE 1999, p. 893).

BRONFMAN et al. (2000) afirmaram que "o conteúdo racional da pesquisa pode não ter necessariamente valor para o processo de formulação de políticas, pois a racionalidade política é dependente de outros fatores relacionados à arte de governar indivíduos" (p. x-xi). Destacaram que há necessidade de definições mais claras e de expectativas realistas na aplicação da pesquisa para formulação de políticas, com maior compreensão dos processos de planejamento, de divulgação de resultados de pesquisas e de elaboração de políticas, e afirmaram:

As expectativas têm sido pouco realistas de muitas maneiras e em muitos aspectos: muitos pesquisadores esperam que outros 
descubram usos para seus resultados; muitos esperam que a publicação dos resultados seja suficiente para dar-lhes um uso; outros demonstram pouca paciência frente às estimativas de probabilidades, quando desejam - e necessitam - prognósticos precisos. Inclusive aqueles que têm procurado avaliar o efeito da pesquisa sobre as políticas têm sido pouco realistas ao tratar de fazê-lo demasiado rápido, ou têm utilizado definições muito restritas sobre a forma adequada que deve ter o efeito da pesquisa em uma política concreta (BRONFMAN et al. 2000, p. xi).

WEISS (1977) identificou vários argumentos dos cientistas sociais nos anos 70 sobre o que consideravam 'perigos' de envolver as ciências sociais em favor da decisão política governamental:

- quando o governo financia pesquisas nas ciências sociais para fins de decisão política, ele deriva os pesquisadores para outras prioridades que não a de construir o conhecimento;

- quando os cientistas sociais aceitam recursos governamentais para pesquisas, eles podem se ver em uma situação de ter que aconselhar prematuramente algumas medidas com base em conhecimento inadequado;

- ao aceitar os problemas de pesquisa propostos pelo governo, os cientistas sociais acabam distorcendo o desenvolvimento das disciplinas da área. As pesquisas sociais nas quais o governo tem interesse acabam se desenvolvendo mais que as disciplinas teóricas das ciências sociais (WEISS 1977, p.2).

Essa autora discutiu esses argumentos dizendo que a pesquisa básica não é mais imune a juízos de valor em comparação à pesquisa nas áreas adjacentes à tomada de decisão e que acredita na possibilidade de as ciências sociais poderem auxiliar as decisões governamentais. Ela apresentou três premissas básicas, quase de senso comum, sobre o uso das pesquisas em ciências sociais para a tomada de decisão política. A primeira seria que "o uso é bom, quanto maior o uso melhor, e o aumento do uso da pesquisa social significa qualidade das decisões governamentais. Tanto que várias análises começam com a questão: como podemos melhorar o uso da pesquisa social?". A segunda afirma que a pesquisa social não seria bem utilizada pelos governos ou até mesmo rejeitada. A terceira premissa seria que os governantes poderiam fazer melhor uso da pesquisa social para a política se fossem feitas algumas mudanças nos procedimentos, nas tecnologias e no treinamento de pessoal (WEISS 1977, p. 3-6).

A autora afirmou também que o impacto e a influência da pesquisa social não estariam restritos à área da disciplina das ciências sociais, medidos pelas citações de outros pesquisadores na literatura, mas poderiam fazer diferença na atenção em saúde ou na política educacional ou econômica (WEISS 1977, p.8). 
PATTON et al. (1977), nessa mesma linha, confirmaram que há necessidade de redefinir o que se considera utilização efetiva de resultados de pesquisa:

Os resultados de nossas pesquisas sugerem que a imagem predominante da subutilização ou falta de utilização da pesquisa para a avaliação pode ser atribuída em alto grau a uma definição de utilização muito reduzida na ênfase de ver impacto concreto, imediato e direto nas decisões. Tal definição estreita não leva em consideração a natureza dos processos reais de tomada de decisões no desenvolvimento de programas (PATTON et al. 1977, p. 148).

BRONFMAN et al. (2000) afirmaram que muitos resultados de pesquisa influenciam de fato a tomada de decisões, mesmo que essa influência seja às vezes imprevisível e, com freqüência, ampla ou difusa. A noção de influência deve ser melhor conceitualizada, segundo os autores. Nesse sentido, eles citaram Weiss (1989), que sustenta "que a pesquisa avaliativa contribui com algo novo quando adverte sobre problemas, guia os atores para melhores ou piores decisões, redefine problemas conhecidos de maneira inovadora ou mobiliza apoios para as diferentes propostas [grifo do autor] (Weiss citada por BRONFMAN et al. 2000, p.1).

Segundo FRENK (1992a), um importante fator para divergências entre o grupo de pesquisadores e os tomadores de decisão é o valor relativo que cada grupo atribui à excelência e à relevância.

Excelência é a adesão estrita a uma série de regras para pesquisas que dão validade objetiva aos resultados. (....) Relevância para a tomada de decisão é a habilidade da pesquisa de considerar problemas que requerem solução. (....) $O$ valor da relevância está subordinado a um valor superior, que é a relevância das decisões para as necessidades da população (p. 1397-8).

Mesmo que os pesquisadores e tomadores de decisão considerem objetivos legítimos similares, sempre haverá tensão entre excelência e relevância, mostrou FRENK (1992a). A excelência seria enfatizada pelos cientistas, pois constituiria a base para o progresso de uma área de estudo. Por outro lado, os tomadores de decisão enfatizariam a relevância (p.1397-8).

POUVORVILLE (1999) também falou sobre métodos para validação de pesquisas por ambos os grupos e afirmou que a validação pragmática tenderia a ser muito mais eficiente que a científica (p. 893).

É interessante o modelo conceitual proposto por FRENK (1992a), que classificou as 
pesquisas em saúde segundo seus objetivos e orientações: os projetos cujo intuito principal fosse solucionar problemas seriam denominados 'pesquisas para a saúde', e aqueles que objetivassem o avanço do conhecimento seriam 'pesquisas sobre saúde'. Segundo o autor, a importância de determinar a orientação principal de um projeto seria o fato de a mesma influenciar a efetividade de diferentes estratégias para integrar relevância e excelência (FRENK 1992, p.1399).

TROSTLE et al. (1999) enfatizaram que "muitas tentativas de aplicar pesquisa à política tiveram expectativas irreais, definições pouco precisas e falta de compreensão sobre o processo de tomada de decisão". A tomada de decisão seria normalmente entendida como uma série de decisões tomadas por uma determinada pessoa ou por um conjunto de 'tomadores de decisão'. Os autores definiram "políticas como orientações governamentais ou organizacionais sobre alocações de recursos e princípios de um comportamento desejado", ressaltando que "a política é afetada por múltiplas forças além da pesquisa". Também definiram pesquisa como "o processo estruturado de coleta, análise, síntese e interpretação (explicação ou descrição) de dados para responder a perguntas teóricas não visíveis nos dados propriamente ditos" ou "também a forma de comunicação estruturada de compartilhar conhecimento, que é uma combinação de dados e teoria" (p. 104).

Segundo expôs WEISS (1977), a evidência que a pesquisa social oferece para a tomada de decisão poderia ser: (a) qualitativa e descritiva; (b) quantitativa, tanto para indicadores como atitudes públicas, quanto para indicadores de número de camas hospitalares; (c) relações estatísticas entre variáveis, conclusões generalizadas sobre associações entre fatores ou ainda teorias abstratas sobre causa e efeito (p. 12).

Um esquema sobre os atores e o contexto em que interagem pesquisa e política foi proposto por TROSTLE et al. (1999) e BRONFMAN et al. (2000) (Figura 4). Os círculos maiores representariam o Estado e a sociedade civil, que se sobreporiam parcialmente. Vários grupos de interesses (representados pelos círculos menores) atuariam sobre as políticas, sendo o grupo de pesquisadores apenas um entre muitos outros grupos. As políticas públicas estariam sob controle dos tomadores de decisão, localizados no espaço de congruência entre o Estado e a sociedade civil (TROSTLE et al. 1999, p. 105; BRONFMAN et al. 2000, p. 9) 


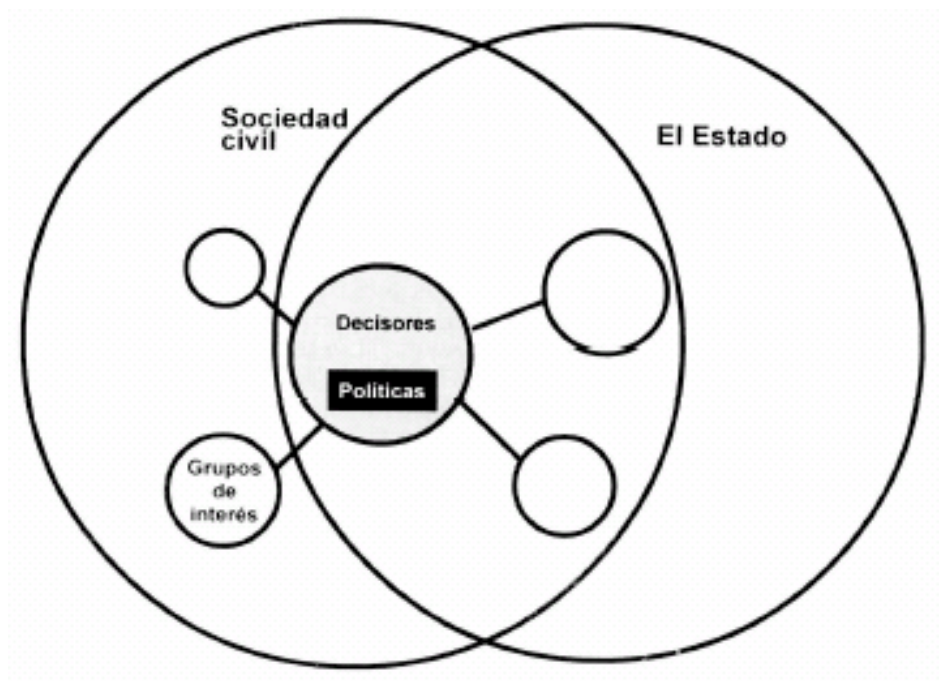

Figura 4 - Mapa de atores e contexto relacionados à pesquisa e política (BRONFMAN et al. 2000, p. 9)

A relação dinâmica entre os processos de pesquisa e de tomada de decisão foi também explicada de forma bastante simplificada e esquemática por TROSTLE et al. (1999) e BRONFMAN et al. (2000) (Figura 5). Esses processos normalmente aconteceriam de forma independente, mas eles poderiam se encontrar em 94 determinados momentos do processo, simbolizados no gráfico pelos pequenos círculos. Durante esses momentos de contato, os participantes de ambos os processos poderiam aprender ou contribuir com o outro grupo.

Na parte superior do diagrama, estaria representado o processo de pesquisa, desde a fase de geração de idéias, planejamento, coleta de dados (pesquisa), análise e aplicação. Seus resultados gerariam novas idéias e novos projetos (representados no diagrama como um retorno às etapas iniciais do processo), mas poderiam também dirigir-se à aplicação de resultados, que posteriormente poderiam produzir novas idéias e outros projetos de pesquisa. 


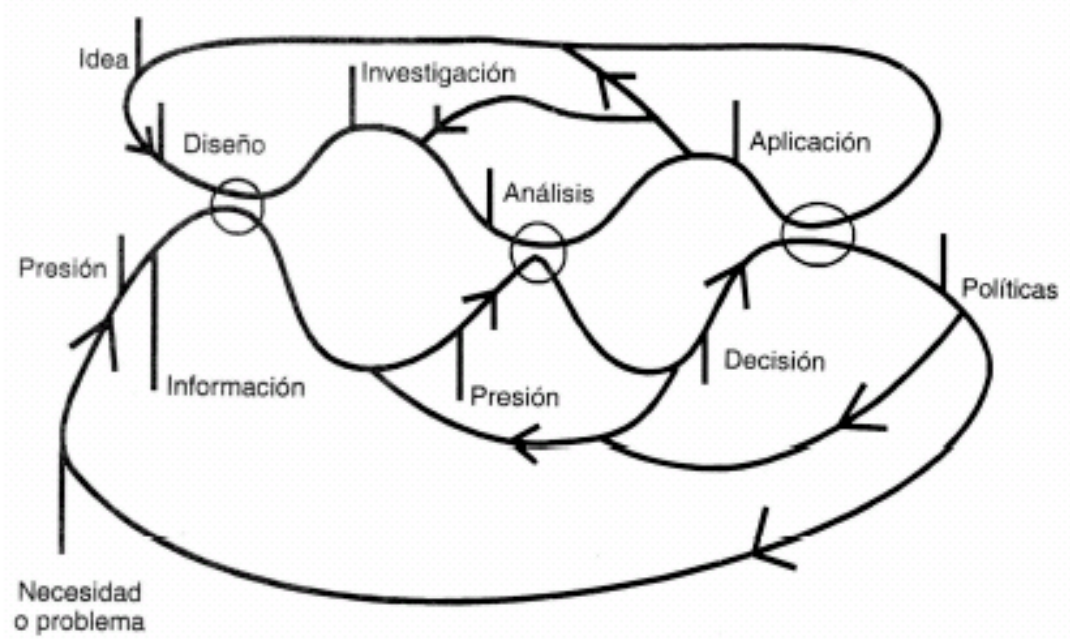

Figura 5 - O processo de pesquisa (BRONFMAN et al., 2000, p.8)

O processo de formulação de políticas estaria representado de forma similar na parte inferior do diagrama. Quando surgissem necessidades ou problemas que pudessem ser resolvidos por meio de políticas, a identificação de informação sobre problemas e necessidades seria coletada em diversas fontes. Grupos de interesse exerceriam pressão em várias etapas do processo: influiriam sobre os tipos de necessidades que se deveriam reconhecer ou ignorar, sobre os tipos de decisão e sobre as políticas que surgissem..

Assim como no processo de pesquisa, alguns circuitos voltariam à etapa de coleta de informações antes que se formulassem as políticas; algumas decisões motivariam busca adicional de informações e novas negociações, enquanto outras produziriam políticas. As novas políticas criariam novos grupos de interesse e novos desafios políticos (TROSTLE et al. 1999, p. 105; BRONFMAN et al. 2000, p. 8-10).

WALT (1994) propôs quatro categorias relevantes para analisar as contribuições específicas da pesquisa na formulação de políticas: conteúdo, atores, processo e contexto. Ele afirmou que "grande parte da política de saúde está centrada erroneamente no conteúdo das reformas, ignorando os atores envolvidos na reforma política, os processos eventuais no desenvolvimento e implementação das mudanças e o contexto em que se desenvolve a política" [grifo do autor] (p.354). Essas categorias de análise foram adotadas no estudo realizado no México, descrito a seguir.

A falta de canais de comunicação bem definidos poderia contribui para a baixa interatividade entre gestores e pesquisadores na divulgação recíproca dos resultados de pesquisa e das necessidades da gestão.

Como afirmou STONE (2001), 
algumas vezes a pesquisa não está delineada para ser relevante

para a política. Algumas vezes está delineada para esse fim,

mas deixa de ter impacto por causa de problemas associados

com oportunidade [timeliness], apresentação ou forma de

comunicação. Algumas vezes (possivelmente as mais freqüentes)

os tomadores de decisão não vêem os resultados das pesquisas

como prioritários na tomada de decisão. A relação entre

pesquisa e política é com freqüência tênue, com muita

freqüência frágil (p.2).

Segundo FRENK (1992a), “a linguagem científica é freqüentemente esotérica e a comunicação ocorre através de publicações especializadas que podem ser encontradas somente através de detalhadas buscas bibliográficas. Para o tomador de decisão, é importante que os resultados sejam expressados em linguagem compreensível e possam estar prontamente acessíveis" (p. 1398).

POUVORVILLE (2001) usou o termo 'tradução' ao sugerir a forma de aproximação entre pesquisadores e tomadores de decisão. A 'tradução' proposta por ele caminharia nos dois sentidos: tomador de decisão $\rightarrow>$ pesquisador e pesquisador $\rightarrow>$ tomador de decisão. No primeiro, a 'tradução' significaria explicar o contexto da decisão, com o objetivo de adaptar a agenda de pesquisas e antecipar as reações de todas as partes envolvidas. No sentido pesquisador -> tomador de decisão, a 'tradução' significaria explicitar ao tomador de decisão como foi trabalhada a sua demanda.

As informações mais comumente utilizadas pelos gestores no processo de tomada de decisão seriam a administrativa ou epidemiológica existentes nas grandes bases de dados governamentais ou até mesmo a informação divulgada pela mídia. Mesmo assim, como afirmou MORAES (1994), “o processo de geração de informações não vem sendo efetivamente utilizado pelo processo decisório das instituições em saúde. Observa-se um acúmulo de dados, mas com pouca transformação em informação que subsidie a tomada de decisão" ( p. 18). A autora concluiu que o "acúmulo de dados identificados nos Sistemas de Informação em Saúde brasileiros traz diversas conseqüências (....) acrescentando-se o esforço e recursos necessários para encontrar uma informação relevante para o apoio à decisão, identificando-a dentre as irrelevantes, o que significa uma perda de tempo tanto de pesquisa/levantamento quanto de trabalho criativo" (p. 34).

RODRIGUES (2000) afirmou que a informação contextual que se referia a fatores ambientais, sócio-econômicos e epidemiológicos para um determinado local e tempo seria de grande valor para a tomada de decisão, pela sua especificidade e disponibilidade imediata para o tomador de decisão. Nessa perspectiva, as evidências científicas divulgadas em documentos submetidos à revisão por pares poderiam ser 97

questionadas em termos de sua aplicabilidade científica, social, cultural e local (p. 1346).

As estratégias propostas pelos diferentes autores citados para solucionar os problemas de distanciamento entre pesquisadores e tomadores de decisão apontaram 
para uma mesma direção: a integração e a participação conjunta no processo de pesquisa. POUVORVILLE (1999) argumentou que deveria haver um mediador entre os dois mundos: o acadêmico, de pesquisas, e o político, da tomada de decisão, que deveria ter competências para acompanhar sistematicamente a implementação das políticas, identificando áreas em que a produção de conhecimento fosse necessária e útil e traduzindo, assim, não somente pesquisa em decisões mas também decisões em pesquisa (p. 893-4).

FRENK (1992a) destacou a necessidade de adotar estratégias educacionais para o grupo de pesquisadores e para o de tomadores de decisão para melhor entendimento de necessidades e expectativas em relação à pesquisa. Para a integração entre os dois grupos, sugeriu o modelo adotado pela Organização Mundial da Saúde, denominado 'pesquisa integrada à decisão' [decision-linked research], cuja abordagem aumentaria a chance das decisões serem feitas com base em confiança na informação.

Dependendo do grau de integração, ela poderia ser 'primária', quando a interação começasse antes do início do projeto, ou 'secundária', quando o projeto fosse iniciado pelo pesquisador, mas com a participação do tomador de decisão durante várias fases do mesmo. Uma maior participação de ambos os grupos desde o início da concepção dos projetos criaria mais vínculos entre as ações em vários momentos dos processos de pesquisa e da tomada de decisão (p. 1400).

Outra sugestão feita por FRENK (1992a) para reduzir as barreiras de comunicação entre pesquisadores e tomadores de decisão foi a preparação do que ele denominou 'sínteses executivas', que destacariam, de maneira compreensível, resultados de pesquisa relevantes para a tomada de decisão. Essa solução implicaria o desenvolvimento de um sistema de relato duplo de resultados: trabalhos acadêmicos para cientistas e sínteses executivas para os tomadores de decisão. $\mathrm{O}$ autor indicou 98 que essas sínteses poderiam ser complementadas com discussão conjunta de resultados em seminários participativos (p. 1400).

A implementação das soluções propostas pelos autores citados implicaria envolvimento de vários setores da sociedade. Como afirmou FRENK (1992a), o debate sobre a utilização do conhecimento deveria considerar que atores individuais fossem responsáveis pela implementação de soluções. Porém, a complexidade da produção de conhecimento exigiria soluções institucionais. As instituições deveriam criar estruturas diferenciadas para facilitar a capacidade de projetar o conhecimento científico em direção à tomada de decisão (p. 1401).

No Brasil, iniciativas no sentido de promover o uso de informação científica no processo de tomada de decisão, na lógica da descentralização e decisão local, têm sido discutidas desde a constituição do SUS. Uma de suas competências, conforme expressado no artigo 200, inciso V da Constituição Federal, é “incrementar em sua área de atuação o desenvolvimento científico e tecnológico".

Em 1994, foi realizada em Brasília a $1^{\text {a }}$ Conferência Nacional de Ciência e Tecnologia em Saúde, que, dentre outras questões, propôs o estabelecimento de uma Política Nacional de Ciência e Tecnologia em Saúde, como um componente da Política Nacional de Saúde. Segundo o relatório final dessa conferência, 
A elaboração da Política Nacional de Ciência e Tecnologia em Saúde - vista como um dos componentes da Política Nacional de Saúde - exigirá uma interação estreita entre o Sistema Único de Saúde, os componentes de C\&T e a política de formação de recursos humanos em saúde. (....) (A) (....) orientação lógica dessa política deve estar fortemente marcada por um claro compromisso ético e social de melhoria - a curto, médio e longo prazos -, das condições de saúde da população brasileira, considerando particularmente as diferenciações regionais e buscando a eqüidade (citado por ABRASCO 2002, p. 10).

O Ministério da Saúde instituiu, em 2000, o Departamento de Ciência e Tecnologia em Saúde..(Decit), vinculado à Secretaria de Políticas de Saúde (SPS), com a missão de promover a integração entre a produção científica e tecnológica e o Sistema Único de Saúde (SUS). "O Decit tem a atribuição de atuar em todas as etapas envolvidas na pesquisa voltada para a solução dos problemas nacionais de saúde, fases que vão desde as fontes de fomento à pesquisa até a validação dos resultados e sua incorporação às políticas e serviços de saúde".

O Decit deveria colaborar no estabelecimento de indicadores que orientassem a definição dos eixos prioritários de ação do Ministério da Saúde e elaborar uma metodologia de construção da Agenda Nacional de Prioridades em Pesquisa e Desenvolvimento Tecnológico em Saúde.

Em abril de 2002, a Comissão de Ciência e Tecnologia da Abrasco (Associação Brasileira de Saúde Coletiva) preparou uma proposta de Política Nacional de Ciência, Tecnologia e Inovação em Saúde (PNCTeI/S), encaminhada ao Ministério da Saúde. Em outubro de 2002, baseando-se nessa proposta, o secretário de Políticas Públicas do Ministério da Saúde submeteu à consulta pública um documento preliminar de Política Nacional de Ciência e Tecnologia e Inovação em Saúde (PNCTeI/S), publicado no Diário Oficial da União e disponível na internet no site do Ministério. "O objetivo maior da PNCTeI/S (....) é contribuir para o desenvolvimento nacional auto-sustentado, através de produção científica e desenvolvimento tecnológico ajustados às necessidades econômicas, sociais, culturais e políticas do país" (MINISTÉRIO DA SAÚDE 2002, Anexo, item 6, p.3). O Ministério da Saúde, com o objetivo de aproximar a área de pesquisas e os tomadores de decisão, instituiu o Prêmio de Incentivo em Ciência e Tecnologia para o Sistema Único de Saúde (SUS) - 2002., para pesquisas realizadas em 2000 e 2001 que atendessem aos princípios e às diretrizes do SUS e estivessem em consonância com a Agenda Nacional de Saúde, estabelecida em 2001. Esse prêmio poderia constituir não somente uma forma de incentivo à integração pesquisa e sistema de saúde, mas também de identificação de pesquisas em realização no país com potencial de aplicação no SUS.

Outro projeto do Ministério da Saúde/Decit, nessa mesma linha, é a BVS - Saúde Pública Brasil (BVS-SP), que integra universidades, institutos de pesquisa, associações profissionais, conselhos de saúde, a Representação da OPAS no país e a BIREME (Centro Latino-Americano e do Caribe de Informação em Ciências da 
Saúde). A expectativa com a BVS-SP é a possibilidade de contribuir para uma aproximação entre a pesquisa e a ação e a tomada de decisão em saúde, servindo de suporte às ações de profissionais e de gestores do Sistema Único de Saúde.

Em 2003, com o novo governo federal, a estrutura do Ministério da Saúde está sendo modificada. Estão sendo criadas a Secretaria de Ciência e Tecnologia e Insumos Estratégicos, a Secretaria de Gestão do Trabalho em Saúde, a Secretaria de Gestão Participativa e a Secretaria de Atenção à Saúde. Serão extintas as secretarias de Investimentos na Saúde, Políticas da Saúde e Assistência à Saúde. Essa nova estrutura parece indicar que a área de ciência e tecnologia em saúde terá relevância, pois estará situada no primeiro escalão do organograma institucional. À Secretaria de Ciência e Tecnologia e Insumos Estratégicos caberá a formulação das políticas nacionais de ciência e tecnologia em saúde e de assistência farmacêutica. Espera-se com isso que os projetos ora apoiados pelo Decit possam ter continuidade.

Dois estudos sobre uso de informação científico-técnica no processo de tomada de decisão política foram realizados na América Latina. Um dos estudos foi feito no México, em 1994-95, apoiado pelo Instituto Nacional de Salud Pública de México. Foi relatado sucintamente por TROSTLE et al. (1999) em um artigo científico e, de forma completa, em livro, por BRONFMAN et al. (2000), ambos da mesma equipe de pesquisadores do estudo. O outro foi realizado em 1999, no Estado de São Paulo, Brasil, num projeto intitulado "Informação científico-técnica no processo decisório em saúde: o caso do Estado de São Paulo", realizado por um grupo de pesquisadores da Faculdade de Medicina e da Faculdade de Saúde Pública da Universidade de São Paulo, e relatado por COHN e WESTPHAL, 2000.

O estudo realizado em São Paulo, embora inicialmente tivesse objetivos similares aos do mexicano, apresentou poucos resultados e conclusões em relação ao uso de informação científico-técnica. Como os resultados apresentados poderiam não ter sido suficientes para ser considerados como representativos da comunidade nacional de gestores ou mesmo da realidade do Estado de São Paulo, os mesmos não foram incluídos neste estudo. Como os próprios autores afirmaram, a metodologia definida para o estudo deveria ser aplicada posteriormente em outros municípios e regiões do país.

O estudo realizado no México voltou-se especificamente para a utilização de resultados da pesquisa científica no processo de decisão política e para a caracterização do processo e contexto de interação entre pesquisadores e tomadores de decisão.

Foi realizado com um enfoque qualitativo e exploratório. Centrou-se na análise de quatro programas verticais da Secretaría de Salud de México: AIDS, cólera, vacinas e planejamento familiar, originando quatro estudos de caso específicos. Os temas foram selecionados por terem ao menos alguma interação conhecida entre pesquisadores e tomadores de decisão. Especialistas em cada um dos temas entrevistaram 67 pesquisadores de ciências biológicas e sociais de diferentes instituições mexicanas, funcionários do setor saúde de diferentes níveis e hierarquias dos programas selecionados (muitos dos quais tinham antecedentes na área de 
pesquisa) e representantes de grupos de interesse e de organismos internacionais vinculados aos temas específicos dos programas analisados.

Os autores fizeram também uma pesquisa documental e revisaram as respectivas Normas Oficiales Mexicanas, que descreviam os tipos de procedimentos administrativos e técnicos que as instituições estatais deveriam seguir.

Os principais objetivos do estudo foram: reconstruir o processo pelo qual a pesquisa foi usada para tomada de decisões e políticas; caracterizar esses processos; e identificar os elementos que favorecem ou impedem a transferência de resultados de pesquisa.

Os resultados dos quatro estudos de caso foram revisados em conjunto por novos pesquisadores e funcionários do governo, dando origem a uma análise mais profunda sobre a interação entre pesquisa e tomada de decisão.

Foram consideradas as seguintes categorias de análise: conteúdo, atores, processo, contexto. Para cada uma delas, foram identificados os principais obstáculos para uma interação eficiente entre pesquisa e política.

Com relação ao conteúdo da informação, os principais obstáculos identificados pelos autores foram: os resultados de pesquisas nem sempre seriam considerados pertinentes para as políticas, adequados à complexidade das políticas ou ainda ideologicamente aceitáveis; muitas pesquisas não considerariam aplicação na prática ou não estariam disponíveis no momento em que fosse necessário tomar uma decisão política; os resultados nem sempre estariam escritos em linguagem acessível aos tomadores de decisão (TROSTLE et al. 1999, p. 106-7; BRONFMAN et al. 2000, p. 160-2).

Com relação aos atores, a aplicação de resultados de pesquisa pelos tomadores de decisão estaria influenciada pela qualidade, concluíram os autores. No entanto, essa qualidade não seria medida pela publicação ou pela revisão pelos pares, mas pela identidade ou fama e experiência do pesquisador que realizou o trabalho, a reputação da revista ou livro em que foram publicados os resultados e sua própria experiência em pesquisa. Os pesquisadores prefeririam publicar os resultados de pesquisa em revistas científicas, e não em formatos mais acessíveis para os políticos, e as publicações científicas geralmente não seriam as que mais influenciariam a tomada de decisão. No entanto, tanto pesquisadores como tomadores de decisão disseram que freqüentemente os funcionários baseariam suas decisões em experiências e responderiam a pressões imediatas, em vez de considerar a informação gerada pela pesquisa como um insumo útil (BRONFMAN et al. 2000, p. 161-4).

Um funcionário de saúde do governo mexicano entrevistado no estudo afirmou: “A pesquisa é, para os puristas, a geração de novos conhecimentos, mas o que se necessita para a tomada de decisões é a organização do conhecimento, de tal forma que o próprio ordenamento nos permita ver opções” (BRONFMAN et al. 2000, p.1).

Os pesquisadores e tomadores de decisão entrevistados concordaram que, em geral, 
dá-se mais importância aos resultados da pesquisa biomédica que àqueles da pesquisa social, apesar de esta ser incorporada em alguns programas de saúde como fonte de informação importante para a operação dos programas (BRONFMAN et al. 2000, p. 161).

Outro ponto importante identificado no estudo mexicano na relação pesquisador/tomador de decisão foi a questão dos canais de comunicação entre pesquisa e ação. Os autores relataram que, no México, com freqüência o pesquisador difunde o resultado de seus trabalhos em revistas especializadas ou em apresentações em congressos e que os políticos não lêem esse tipo de literatura e nem assistem a esses eventos, seja por falta de tempo, de formação científica ou de vontade (BRONFMAN et al. 2000, p. 165).

BRONFMAN et al. (2000) concluíram que, do ponto de vista dos tomadores de decisão, as pesquisas acadêmicas seriam muito lentas, pouco práticas e pouco direcionadas aos aspectos de pressão social que a decisão política poderia sofrer na implementação dos resultados. Os autores identificaram que a probabilidade de empregar resultados de pesquisa seria maior se os mesmos não entrassem em conflito com a operação dos programas, não interferissem no trabalho dos tomadores de decisão ou também não fossem contrários a interesses de outros setores governamentais ou da indústria privada (BRONFMAN et al. 2000, p. 167).

Na análise do processo de comunicação dos resultados de pesquisas para a ação, outro obstáculo destacado no estudo mexicano foi o das diferentes agendas e cronogramas das áreas da pesquisa e da tomada de decisão. Enquanto os pesquisadores poderiam dispender tempos mais ou menos prolongados na 104 formulação de hipóteses de pesquisas, na seleção de metodologias ou na coleta e interpretação de informações, os tomadores de decisão estariam submetidos a pressões do público, dos meios de comunicação e de circunstâncias políticas que os levariam a buscar respostas mais ou menos imediatas (BRONFMAN et al. 2000, p. 162).

No México, foram identificados no contexto nacional vários fatores que facilitaram ou promoveram a interação entre pesquisadores e tomadores de decisão: a situação política estável (por mais de 70 anos, o país foi governado pelo mesmo partido político), que permitiu certa continuidade de programas, prioridades e pessoas; o fato de pesquisadores e tomadores de decisão em geral pertencerem à mesma elite, muitas vezes se conhecendo desde a infância e podendo intercambiar funções de pesquisador e tomador de decisão em várias etapas do governo; a urgência dos problemas de saúde, seja pelo impacto sobre a saúde pública ou sobre a economia, como foi o caso, por exemplo, da epidemia de cólera e das negociações para o Tratado de Livre Comércio da América do Norte, respectivamente (BRONFMAN et al. 2000, p.158-9).

Entre os obstáculos gerais para um vínculo mais dinâmico entre pesquisa e políticas em saúde no contexto mexicano foram destacados: a falta de canais de comunicação bem definidos; a debilidade do papel do público e a pouca divulgação de resultados em nível social; as deficiências do sistema democrático, com centralismo do poder 
ou da tomada de decisão; a falta de continuidade das prioridades e políticas na mudança dos governos, embora do mesmo partido; a restrição de recursos econômicos; as comunidades científicas e de formuladores de políticas pequenas, o que poderia levar à maior ação de redes formais e informais de influência; a ênfase em relações pessoais (BRONFMAN e HERRERA 2001).

As conclusões do estudo mexicano indicaram que seria possível melhorar a comunicação entre pesquisadores e tomadores de decisão. Seria muito mais complexo aumentar a probabilidade de que os resultados da pesquisa científica fossem utilizados para desenvolver e aplicar políticas. As pesquisas seriam somente um insumo, entre tantos outros igualmente legítimos, a ser consideradas pelos tomadores de decisão e deveriam ser avaliadas em termos de custo e efetividade antes de ser aplicadas como base para uma política ou programa (BRONFMAN et al. 2000, p. 168-9 e TROSTLE et al., p. 112-3).

Em 2001, BRONFMAN e HERRERA apresentaram novamente os resultados desse estudo num evento organizado conjuntamente pelo Instituto Nacional de Salud Pública e a OPAS, em Cuernavaca, México, acrescentando nessa apresentação algumas propostas de agenda para maior utilização da informação científica na tomada de decisão em saúde, entre elas:

- capacitar os pesquisadores em comunicação e gestão de resultados e os

- tomadores de decisão para compreensão e aplicação dos resultados;

- incluir a presença de tomadores de decisão nos corpos consultivos das

- instituições de pesquisa; melhorar o processo de interação entre pesquisa

- e políticas: tradução, utilização, disseminação, implementação etc.;

- definir outros indicadores nos sistemas de avaliação de pesquisadores

- que permitam medir o impacto dos resultados na ação;

- melhorar a infra-estrutura de comunicação social, estabelecendo meios

- massivos interessados em ou preparados para oferecer cobertura a temas

- científicos e comentar políticas e programas; advogar pela

- democratização da informação;

- melhorar a infra-estrutura técnica e humana da comunicação social;

- promover um melhor clima político e convencer os líderes de que a pesquisa em saúde é uma inversão (BRONFMAN e HERRERA 2001).

Os estudos citados neste capítulo procuraram identificar se a informação científicotécnica existente é utilizada pelos gestores no processo de tomada de decisão e quais os fatores que facilitam ou dificultam sua utilização. Pelo que afirmaram os autores, para que o processo de tomada de decisão possa ser baseado em conhecimento científico, seria necessária uma aproximação maior do gestor com as fontes de informação disponíveis e também um aumento de sua capacidade de avaliar qual a informação mais apropriada para determinadas situações. O que ainda faltaria saber é onde, como e por quem deverão ser construídas essas 'pontes' entre esses atores.

Muitas das sugestões apresentadas para aproximar os pesquisadores dos tomadores 
de decisão no contexto mexicano se aplicam ao contexto brasileiro. A principal conclusão tirada desse estudo é que não é suficiente a disponibilidade de informação científica mas sim sua ordenação e apresentação aos gestores em um formato diferente. A estratégia sugerida de capacitar os pesquisadores para a comunicação dos resultados e os tomadores de decisão para sua compreensão e aplicação parece ser a mais adequada nesse caso.

Com relação ao processo formal de comunicação, seria conveniente indagar até que ponto a informação contida na produção científica acadêmica em saúde pode ser decodificada pelo receptor da área de gestão e de serviços de saúde. No processo de comunicação, emissor e receptor teriam de conhecer e utilizar o mesmo código para que a informação pudesse ser transmitida, assimilada e transformada em conhecimento. No processo de comunicação científica em saúde, têm-se como emissor de informação o pesquisador, que utiliza linguagem e metodologias científicas, e, como receptor, outros pesquisadores e profissionais em saúde atuando como gestores, mas que nem sempre são do setor ou terão utilizado metodologia ou linguagem científica em sua área de atuação. Seria provável que estivesse realmente faltando uma aproximação entre os códigos de comunicação do emissor e receptor, de tal forma que o conhecimento científico e técnico pudesse ser incorporado à rotina da gestão.

No que diz respeito ao fluxo de comunicação entre pesquisadores e gestores, os autores citados neste capítulo afirmaram que as realidades temporais da pesquisa e da prática são distintas. Enquanto o gestor precisaria dar respostas imediatas para problemas emergentes, diante de realidades complexas de orçamento, de normas administrativas, de ações intersetoriais integradas a outras esferas de governo, $o$ pesquisador trabalharia em situações até certo ponto controladas por ele para garantir análise de dados e dos resultados. As pesquisas poderiam levar meses ou até anos para ser concluídas, e, quando isso acontecesse, os resultados seriam normalmente transformados em um documento científico, que seguiria o fluxo da comunicação científica, podendo levar muito tempo para ser disseminado e conhecido pelos gestores.

Além disso, como é ressaltado na proposta de $\mathrm{PNCTeI} / \mathrm{S}$, "a produção de conhecimentos científicos e tecnológicos tem características bastante distintas da produção de serviços e ações de saúde, portanto, ainda que a política de CTeI/S faça parte da política nacional de saúde, para a organização do sistema de CTeI/S, os princípios organizacionais que regem o SUS nem sempre poderão ser adotados" (MINISTÉRIO DA SAÚDE 2002, parágrafo 11, p. 3).

FRENK (1992a) afirmou que “a pesquisa requer um alto grau de autonomia, pois o processo intelectual que conduz a uma descoberta é desconhecido e, portanto, não pode ser codificado e nem reduzido a rotinas" (p. 1402).

Para que a informação pudesse ser transformada em 'informação para a ação', alguns autores citados sugeriram que os gestores deveriam ter uma co-participação nos processo de geração da informação, interagindo com o pesquisador na busca de conhecimento apropriado para a ação. Observou-se um movimento para essa 
integração na proposta de $\mathrm{PNCTeI/S}$, que propõe como estratégia "a necessidade de construção de uma agenda nacional de prioridades para a pesquisa em saúde, que contemple as necessidades nacionais e regionais, e que seja capaz de aumentar a indução seletiva para a produção de conhecimentos e de bens materiais e processuais nas áreas prioritárias para o desenvolvimento das políticas sociais" (MINISTÉRIO DA SAÚDE 2002, parágrafo 50, p. 9). 


\section{CAPÍtULO 7}

\section{OBJETIVOS}

\subsection{Objetivo geral}

Analisar a comunicação científica, técnica e normativa na área de saúde pública no Brasil, tendo em vista determinar qual informação está disponível e as possibilidades de sua utilização pelos gestores na tomada de decisão em saúde em nível local.

\subsection{Objetivos específicos}

1) Identificar e analisar os tipos de informação científica e técnica produzidos na área de saúde pública no Brasil e a forma em que estão disponíveis;

2) Determinar quais são as instituições e os atores produtores de conhecimento científico e técnico na área de saúde pública no Brasil;

3) Identificar as principais áreas temáticas a que correspondem os documentos da área de saúde pública e verificar sua correspondência com os temas prioritários do governo federal e estadual;

4) Analisar instrumentos de gestão e fontes de informação disponíveis para os gestores para verificar possibilidades de utilização de informação científica e técnica no processo de gestão local. 


\section{CAPÍTULO 8}

\section{METODOLOGIA}

O estudo realizado foi de natureza exploratória e qualitativa, por meio de análise bibliográfica e documental, procurando concentrar-se em três conjuntos principais:

- $\quad$ as fontes de informação referentes à produção científica brasileira da área de saúde pública, como subsídio ao processo de tomada de decisão em saúde;

- os instrumentos que caracterizam o processo de gestão descentralizada do SUS e a elaboração das Agendas Estaduais de Saúde;

- e o provável uso da informação científico-técnica na gestão do SUS e a disseminação de informações para os gestores na internet pelo Ministério da Saúde e por Secretarias Estaduais de Saúde.

Esses três conjuntos foram analisados individualmente e posteriormente, foram verificadas as possíveis relações entre eles. Um estudo de caso específico simulando uma demanda de gestão local sobre um tema prioritário de saúde - dengue complementou o quadro de análise.

A delimitação temporal do estudo foi de 1990 a 2002, período que compreenderia as transformações na gestão em saúde no Brasil, após a implantação do Sistema Único de Saúde. Em alguns casos, não foi possível respeitar esse período de tempo, devido a características das fontes analisadas. 


\subsection{Produção científica e técnica brasileira em saúde pública}

A pesquisa das fontes de informação referentes à produção científica brasileira em saúde pública foi realizada nas bases de dados bibliográficas nacionais e internacionais, disponíveis na BVS-SP, considerando que este seria o ambiente utilizado pelos gestores para acesso à informação científico-técnica.

Na BVS-SP, estão disponíveis também bases de dados de acervos institucionais das instituições participantes, a base de dados LIS, de sites em saúde pública e uma de textos completos. Essas fontes de informação foram consideradas apenas no estudo de caso de informação científica e técnica sobre dengue, com o objetivo de verificar se poderiam complementar os resultados obtidos nas bases de dados bibliográficas e servir de subsídio para os gestores na identificação de fontes de informação sobre esse tema.

Dada a interdisciplinaridade característica da área de saúde pública, houve dificuldade para delimitar a área de abrangência e para caracterizar os temas ou disciplinas que a compõem, no momento de identificar a produção científico-técnica dessa área do conhecimento nas bases de dados.

\subsubsection{Bases de dados bibliográficas}

Para seleção das bases de dados a ser analisadas, foram adotados os critérios de acesso livre e de possibilidade de seleção de registros da base por país. Bases de dados indicadas na BVS-SP disponíveis por meio de provedores privados e que exigiam cadastro e assinatura para o acesso, como a EMBASE e CAB Health, foram eliminadas. Considerou-se que dificilmente os gestores utilizariam bases de dados em que fossem necessários cadastro e assinatura para permitir o acesso. Também foi eliminada a base de dados POPLINE, embora de acesso livre, por não permitir identificar o país de publicação e nem o de afiliação do autor, não sendo possível, portanto, verificar a produção científica brasileira ali representada. 
A base de dados francesa Banque de Données Santé Publique (BDSP), apesar de exigir assinatura, oferecia uma modalidade de acesso livre, com consulta parcial, o que permitiu uma aproximação aos dados da produção científica brasileira ali registrada. Assim sendo, essa base fez parte do universo estudado.

Foram analisadas as seguintes bases de dados: LILACS-SP, AdSAÚDE, REPIDISCA, MEDLINE e BDSP.

Em cada uma delas, foi feita uma recuperação bibliográfica procurando identificar os registros correspondentes à produção científica brasileira publicada desde 1990. Os registros recuperados foram caracterizados principalmente segundo os tipos de documentos registrados, buscando reconhecer que tipo de informação estaria disponível para os gestores no momento da consulta.

A identificação dos tipos de documentos correspondeu à classificação adotada para as bases de dados do Sistema LILACS, ou seja: artigos de revistas, monografias (que inclui livros, capítulos de livros, trabalhos apresentados em eventos científicos e documentos técnicos governamentais), teses e documentos não-convencionais (que significa documentos que não seguem o fluxo tradicional de publicação, sem instituição publicadora responsável).

Dependendo dos índices de consulta disponíveis nas bases de dados, foram feitas análises por outras características, como idioma, áreas temáticas etc.

\subsubsection{LILACS-SP}

Verificou-se que na BVS-SP existem dois subconjuntos criados a partir da base de dados LILACS: a LILACS-SP correspondente à literatura publicada em toda a América Latina e Caribe na área de saúde pública, e a LILACS-SP Brasil, apenas a documentos publicados no país. A existência dessas bases de dados facilitou a identificação da produção científica brasileira da área de saúde pública indexada na 
LILACS e permitiu uma verificação mais detalhada de seu conteúdo em relação às demais.

Antes de proceder à investigação da LILACS-SP, foi feita uma análise da LILACS quanto aos tipos de documentos indexados, para permitir comparação dos dados encontrados especificamente para a área de saúde pública. Foi feita também uma análise da distribuição dos registros da LILACS-SP em relação ao país de publicação, para verificar a posição ocupada pela produção científica brasileira na América Latina e Caribe.

O conteúdo da LILACS-SP Brasil foi caracterizado em relação aos diferentes tipos de documento, ano de publicação e idiomas.

\subsubsection{AdSAÚDE}

A análise da base de dados AdSAÚDE foi feita com todos os seus registros, publicados desde 1990. Eles foram analisados quanto aos idiomas e ao tipo de documentos.

Essa base, criada para ser complementar à LILACS na área de Administração de Serviços de Saúde, inclui registros que também são enviados para a LILACS. Na análise dos dados, esse fato foi desconsiderado, uma vez que o objetivo era medir a probabilidade de atendimento da demanda de informação dos gestores com a produção científica registrada nessa base de dados isoladamente, e não em comparação com outras.

\subsubsection{REPIDISCA}

Na REPIDISCA, foram verificados os documentos brasileiros publicados de 1990 até 2002. Assim como a AdSAÚDE, essa base de dados faz parte do Sistema LILACS, e 
os registros de interesse para a área da saúde também são exportados para ela, o que poderia resultar em duplicação de resultados. Nesta análise, esse fato foi desconsiderado.

\subsubsection{MEDLINE}

A interface de consulta à base de dados MEDLINE disponível na BVS-SP permite identificação da produção científica brasileira pelo campo de país de publicação e por título de revistas, enquanto na interface PubMed, disponível no site da $U$. S. National Library of Medicine, é possível recuperar registros dessa produção pelo campo de afiliação dos autores e por título de revistas.

Assim sendo, a identificação da produção científica brasileira em saúde pública nessa base de dados, pela interface da BVS-SP, foi realizada pelos campos de país, revistas e ano de publicação. O período pesquisado foi de 1989 a 2002, pois os arquivos estão divididos por períodos: 1989-1993, 1994-1998, 1999-2002.

Utilizando a interface disponível na NLM, a base de dados MEDLINE foi consultada pelo campo de afiliação de autores, o que permitiu uma análise mais ampla da produção de autores brasileiros no exterior. Essa base registra apenas o dado de afiliação para o primeiro autor e, portanto, nem toda a produção científica de autores brasileiros, publicada no exterior, pôde ser recuperada. De qualquer forma, esse é o indicador utilizado pelos pesquisadores e pelas agências de ciência e tecnologia quando se referem à produção científica nela representada.

Houve dificuldade para delimitar nessa base de dados apenas a produção científica de saúde pública, por ela não permitir a recuperação por grandes áreas temáticas. Para identificar a produção de saúde pública de autores nacionais publicada em revistas do país, foram selecionados os registros correspondentes às revistas de saúde pública e áreas correlatas, ou seja: Cadernos de Saúde Pública, Revista de Saúde Pública, Memórias do Instituto Oswaldo Cruz, Revista da Sociedade Brasileira de 
Medicina Tropical, Revista do Instituto de Medicina Tropical de São Paulo e Brazilian Journal of Infectious Diseases.

Além dessa seleção, foi feita uma recuperação pelo descritor 'public health' no campo de assunto, embora essa seja uma forma muito geral e imprecisa, apenas para sinalizar a dispersão da literatura em saúde pública publicada em revistas não específicas da área. Para os artigos publicados por autores nacionais em revistas internacionais, adotou-se a mesma estratégia de busca.

\subsubsection{BDSP}

Essa base de dados foi analisada parcialmente, pois a modalidade de acesso livre disponível na BVS-SP exibe o total de documentos recuperados, mas permite visualização somente dos títulos dos 100 últimos registros ingressados na base. Os dados completos desses registros podem ser visualizados, um a um, sem possibilidade de impressão dos resultados, solicitação dos documentos recuperados ou acesso ao texto completo. Essa dificuldade deverá ser também sentida pelos gestores na busca de informação para a tomada de decisão e deve limitar a utilização dessa base de dados.

A interface de busca na BDSP também apresentou algumas limitações, pois os índices disponíveis não foram suficientes para identificar toda a produção brasileira representada na base. O índice de país permite recuperação apenas por duas categorias: 'França' e 'Outros países'. Combinaram-se várias estratégias de recuperação, utilizando os seguintes índices: assunto, autor e/ou editor, país, idioma, data, título de revistas ou todos os campos (pesquisa livre).

Para identificar a literatura brasileira em saúde pública nessa base de dados de 1990 a 2002, foi realizada uma estratégia de busca considerando 'Brésil' como assunto, 'Brasil' ou 'BRA' no campo de autores e/ou editores, e 'anos 90', '2000', '2001' e '2002' no campo de ano de publicação. A consulta por 'Brasil' em 'todos os campos' da base de dados não foi precisa e recuperou documentos de autor com sobrenome 
'Brasil', por exemplo. Fez-se também uma recuperação por títulos de revistas.

Em cada resultado, só se pôde visualizar 100 registros, mas, como a interface permite identificar registros duplicados já apresentados em resultados anteriores, considerando as várias estratégias, conseguiu-se chegar a um resultado parcial. Este foi considerado como uma amostra dos registros existentes na base de dados e foi analisado quanto aos tipos de documento.

\subsubsection{Revistas científicas}

Além da análise da produção científico-técnica indexada nas bases de dados bibliográficas, foram identificadas e descritas as revistas científicas que publicam artigos sobre temas de saúde pública. Devido ao caráter multidisciplinar dessa área, essas publicações abrangem revistas de ciências sociais, de medicina preventiva, medicina tropical, pesquisas médicas e biológicas de vetores de doenças transmissíveis, alimentação e nutrição, entre outras.

Nesta análise, foram consideradas revistas da área de saúde pública as especificamente especializadas na área (Cadernos de Saúde Pública, Revista de Saúde Pública, Revista Baiana de Saúde Pública, Cadernos de Saúde Coletiva etc.) e as das áreas de epidemiologia, ciências sociais em saúde, planejamento e administração em saúde e áreas correlatas.

$\mathrm{Na}$ análise feita na base de dados MEDLINE, as revistas nacionais classificadas em saúde pública foram: Cadernos de Saúde Pública, Revista de Saúde Pública, Memórias do Instituto Oswaldo Cruz, Revista da Sociedade Brasileira de Medicina Tropical, Revista do Instituto de Medicina Tropical de São Paulo e Brazilian Journal of Infectious Diseases.

Como foi constatado que a produção brasileira de saúde pública não se concentra apenas em revistas específicas da área, estando distribuída em revistas médicas 
especializadas de pediatria, enfermagem, psiquiatria, medicina tropical, ginecologia e obstetrícia, saúde ocupacional, cardiologia etc., analisou-se a dispersão da produção científica em revistas dessas áreas correlatas. Essa análise foi considerada importante para identificar áreas temáticas ou especialidades nas quais são publicados documentos de interesse para a área de saúde pública, o que poderia orientar e aprimorar os processos de seleção de documentos e fontes de informação para a BVS-SP e contribuir para a definição de fontes de informação dirigidas aos gestores.

\subsubsection{Instituições produtoras de informação científica e técnica em saúde pública}

A análise das instituições produtoras de literatura nacional em saúde pública nas bases de dados consultadas foi limitada, pois nem sempre foi possível pesquisar o campo de afiliação de autores, pelo qual são produzidos os indicadores de produção científica. Além disso, o campo de afiliação dos autores é registrado principalmente para artigos de revistas, não sendo possível, portanto, utilizá-lo para análises de outros tipos de documentos.

No caso das revistas, a análise das instituições produtoras foi possível, em caráter exploratório, pelo campo de afiliação de autores das revistas específicas de saúde pública indexadas na LILACS, que também são registradas na SciELO. Os índices de afiliação de autores foram recentemente liberados para consulta nesse site. Assim sendo, foram analisadas as instituições de origem dos autores dos artigos das revistas Cadernos de Saúde Pública e Revista de Saúde Pública publicados em 2000 e 2001.

Para monografias, as instituições publicadoras foram analisadas pesquisando-se o campo de editora. A categoria 'monografias' na base de dados LILACS-SP inclui documentos - com instituição-editora responsável pela publicação -, como livros, capítulos de livros, manuais, guias, anais de eventos científicos e relatórios técnicocientíficos. Essas instituições foram classificadas em: governamentais, incluindo Ministério da Saúde, secretarias de Saúde e outros ministérios e secretarias (da Educação, Planejamento, Economia etc.); institutos de pesquisa, universidades e editoras universitárias, sociedades científicas, editoras comerciais e outras 
instituições (associações, hospitais, laboratórios, organizações não-governamentais, bancos etc.).

Para as dissertações e teses, a análise foi feita pelas instituições onde as mesmas foram apresentadas e defendidas.

\subsubsection{Análise temática da produção científica}

Pensou-se, inicialmente, em construir categorias de análise temática para grupamento dos registros da produção científica brasileira em saúde pública representada nas bases de dados. Mas, após se considerar as distintas reflexões sobre o tema, optou-se por adotar, para esta pesquisa, a classificação de áreas temáticas criada para a BVSSP. Essa escolha também se deve ao fato dela ter sido desenvolvida por especialistas da área, especialmente para ordenar as fontes de informação da BVS-SP.

Os registros da base de dados LILACS-SP Brasil, de 1990 a 2002, foram analisados por áreas temáticas e por tipos de documentos em cada área, utilizando a opção de pesquisa das fontes de informação da BVS-SP segundo essa classificação. Os resultados não são mutuamente exclusivos, e um mesmo documento pode ser recuperado sob um ou mais temas.

\subsection{Agendas Estaduais de Saúde}

As Agendas de Saúde foram selecionadas, dentre os instrumentos de gestão, para analisar os processos de gestão descentralizada, por apresentarem a possibilidade de utilização de conhecimento científico-técnico em sua elaboração. De acordo com a Portaria 548/GM/MS, para a elaboração da Agenda de Saúde devem ser utilizadas referências políticas e técnicas, dentre elas "outros documentos técnicos e políticos existentes e pertinentes à realidade local” (MINISTÉRIO DA SAÚDE 2001c, Anexo, Capítulo 4.2 - Esfera Estadual, alínea a). Para estabelecer, justificar e detalhar as prioridades da política de saúde, os gestores em geral baseiam-se em 
levantamentos de dados sobre condições de saúde locais, mas poderiam utilizar também evidências científicas registradas na literatura científico-técnica produzida no país.

Foram analisadas as Agendas Estaduais de Saúde do Distrito Federal e de 19 Estados: Acre, Alagoas, Amapá, Bahia, Ceará, Espírito Santo, Goiás, Mato Grosso do Sul, Minas Gerais, Pará, Paraíba, Paraná, Piauí, Rio Grande do Norte, Rio de Janeiro, Santa Catarina, Sergipe, São Paulo e Tocantins, em relação à Agenda Nacional de Saúde para o ano de 2001*.

As Agendas foram identificadas no site do Ministério da Saúde e, quando não localizadas, foram pesquisadas nos sites das próprias Secretarias Estaduais de Saúde. Pretendeu-se verificar as metas e os eixos de intervenção específicos acrescentados pelos gestores estaduais à Agenda Nacional de Saúde, que corresponderiam a realidades locais de saúde.

Como considerou-se a internet, neste trabalho, como ambiente privilegiado em que deveria ser promovido o intercâmbio de informação entre os gestores das esferas federal, estadual e municipal, não foram analisadas as agendas não localizadas nos sites, correspondentes aos seguintes Estados: Amazonas, Maranhão, Mato Grosso, Pernambuco, Rio Grande do Sul, Rondônia e Roraima.

Além de analisar os eixos prioritários locais, realizou-se uma busca nas fontes de informação disponíveis aos gestores na BVS-SP, para verificar se alguns desses eixos estariam representados na literatura científico-técnica e se a literatura apontava evidências em relação àquelas necessidades locais de saúde. A hipótese nesse ponto do estudo foi a de que a identificação de problemas locais pelos gestores, que, em geral, baseia-se em levantamentos de dados sobre condições de saúde locais, poderia ter sido subsidiada também pela literatura científico-técnica correspondente.

\footnotetext{
* As Agendas de Saúde de 2001 foram publicadas nos sites apenas no final de 2001. As de 2002 não foram localizadas na internet até o final do estudo
} 


\subsection{Sites do Ministério da Saúde e Secretarias Estaduais de Saúde}

Para identificar evidências de uso da informação científico-técnica na gestão do SUS e a disponibilidade de informação para os gestores na internet, analisaram-se os sites do Ministério da Saúde e das Secretarias Estaduais de Saúde. O objetivo foi verificar como e se essas instituições de governo poderiam incentivar os gestores a fazer uso de fontes de informação científico-técnica no processo de tomada de decisão em saúde, especialmente nos sites que indicavam espaços específicos para o gestor.

Para essa etapa da análise, foi criado um roteiro para observação de cada site (Anexo 2). Os principais aspectos observados foram: organização do site, atualização, conteúdo, existência de informação específica para os gestores, links existentes, fontes citadas nas tabelas de indicadores, inclusão ou indicação de fontes de informação científico-técnica.

O site do Ministério da Saúde foi reformulado durante a execução deste estudo. Inicialmente, estavam disponíveis informações técnicas, institucionais (programas, departamentos), legislação, instrumentos de gestão, agendas de saúde etc. Toda a legislação (normas operacionais, portarias, decretos) relativa à implantação do SUS estava reunida e podia ser facilmente identificada nas seções sobre gestão do SUS e descentralização. Em 2002, com a reformulação, foi criado o Portal da Saúde*, com três espaços especializados dirigidos aos seguintes públicos: cidadãos, profissionais de saúde e gestores da saúde.

O escopo do espaço do 'gestor da saúde', conforme indicado no Portal, corresponde a "serviços úteis para o gestor da saúde e ações ligadas ao MS". Nesse espaço, o Portal inclui as seguintes seções: recursos financeiros, informações de saúde, convênios, banco de preços, cartão nacional de saúde, pregão eletrônico, menu BDAIH e mercado de trocas, além da seção de destaques e notícias.

\footnotetext{
* Disponível em: http://portal.saude.gov.br/saude/
} 
No Portal, não foram localizadas as Agendas Estaduais de Saúde e outros documentos sobre a organização do SUS, disponíveis anteriormente no site do Ministério. A legislação do SUS, antes reunida em uma seção específica, passou a estar disponível no espaço do 'profissional de saúde', mas nem sempre em texto completo, ou na base de dados de legislação na Biblioteca Virtual do Ministério da Saúde ${ }^{* *}$, sob os temas 'gestão' e 'informes de suporte, não específicos, de controle, avaliação e auditoria’.

Essa dificuldade encontrada em consultas recentes ao site do Ministério da Saúde poderá influenciar o uso dessa informação pelo gestor. Assim sendo, além dos pontos acima citados, procurou-se observar nesse Portal, e em outros sites de Secretarias Estaduais de Saúde, qual tipo de informação seria identificada especificamente como 'informação para o gestor'.

\subsection{Informação científica para tomada de decisão local}

Para uma análise exploratória sobre a possibilidade de recuperação da produção científica nas fontes de informação disponíveis na BVS-SP foi selecionado o tema 'Controle epidemiológico de dengue' para um estudo de caso. O objetivo dessa análise foi identificar se um gestor local, na área de vigilância epidemiológica, diante da necessidade de tomar decisões locais sobre o tema da dengue, encontraria informação científica e técnica na BVS-SP que pudesse subsidiar o processo de tomada de decisão. A escolha do tema deveu-se à atual prioridade dada pelo Ministério da Saúde ao controle de dengue no Brasil.

A simulação da pesquisa foi feita pela interface disponível na BVS-SP, utilizando os mesmos recursos que os gestores encontrariam numa busca similar. Essa interface disponibiliza uma pesquisa livre em todas as fontes de informação da BVS-SP, a partir de palavras indicadas pelo usuário; no caso, o gestor. Foi utilizada a palavra 'dengue' no formulário de busca livre para recuperação de documentos nas fontes de

\footnotetext{
*. Disponível em: http://sna.saude.gov.br/legisla.htm
} 
informação disponíveis. Como a recuperação livre na BVS-SP inclui outras fontes de informação que não apenas as bases de dados bibliográficas analisadas anteriormente (LILACS-SP, AdSAÚDE, REPIDISCA), decidiu-se incluí-las nesse estudo de caso para verificar se complementariam os resultados.

Assim sendo, foram consideradas também:

- as bases de dados de acervos de instituições nacionais:

MS, do Ministério da Saúde

ENSP, da Escola Nacional de Saúde Pública

FSP, da Faculdade de Saúde Pública da Universidade de São Paulo

- o LIS - Sites em saúde pública

Das bases de dados bibliográficas LILACS-SP, REPIDISCA e MEDLINE foram selecionados os registros correspondentes à produção publicada no Brasil.

A seleção dos registros recuperados sobre dengue, em cada uma das bases de dados bibliográficas e institucionais, foi feita por amostragem aleatória: selecionaram-se os registros recuperados, de três em três, na ordem de apresentação dos resultados. Para os sites do LIS, os registros foram analisados em sua totalidade, uma vez que representavam um universo reduzido e um tipo de fonte diferenciado.

Os documentos sobre dengue selecionados na amostra foram classificados de acordo com as seguintes categorias: tipos de documentos, autoria e conteúdo.

Classificaram-se os documentos em seis tipos: artigos de revistas, livros ou capítulos de livros, trabalhos apresentados em eventos, teses, documentos não-convencionais e vídeos.

Para a análise de autoria, os autores foram classificados segundo sua origem institucional em: pessoais, institucionais e anônimos ou não identificados. Os 'autores institucionais' referem-se a instituições responsáveis pela autoria dos 
documentos, e não a entidades de origem de autores pessoais. Foram classificados em: universidades, instituições governamentais, organismos internacionais e empresas.

Para classificação do conteúdo dos documentos sobre dengue recuperados, definiram-se os seguintes aspectos:

- pesquisa básica (isolamento de vírus, diagnóstico laboratorial);

- aspectos clínicos;

- epidemiologia (estudos epidemiológicos, biologia e ecologia de vetores);

- prevenção e controle;

- educação em saúde (materiais educativos, campanhas, participação comunitária);

- políticas e programas;

- história;

- geral.

Quando os documentos tratavam de mais de um aspecto, optou-se por classificá-los pela característica predominante. Foram considerados gerais aqueles que se referiam a vários aspectos do tema, sem predominância de um deles, como trabalhos sobre evolução da dengue, desde etiologia e aspectos clínicos até prevenção e controle, ou sobre prevenção de doenças em geral, incluindo a dengue.

Considerou-se também que uma das possibilidades para complementar a questão da utilização de informação científica no processo de tomada de decisão local seria entrevistar gestores de programas técnicos. Assim, foram realizadas entrevistas exploratórias com duas gestoras que trabalham em áreas de decisão política de secretarias de Saúde. A primeira foi realizada na Coordenadoria de Vigilância Sanitária e Ambiente (CoViSa) da Secretaria Municipal de Saúde de Campinas. A segunda, na Diretoria da Divisão de Tuberculose do Centro de Vigilância Epidemiológica (CVE) da Secretaria de Estado da Saúde de São Paulo. O roteiro de entrevista utilizado, que se encontra no Anexo 3, buscou identificar que tipos de informações eram utilizadas no processo de gestão e quem as utilizava. 


\section{CAPÍTULO 9}

\section{RESULTADOS}

Os resultados serão apresentados de acordo aos conjuntos de análise propostos na metodologia: fontes de informação sobre a produção científica brasileira e instituições produtoras; agendas de saúde; e sites das Secretarias Estaduais de Saúde. O estudo de caso simulando uma demanda específica sobre dengue complementou o quadro de análise.

\subsection{Análise da produção científica e técnica brasileira em saúde pública}

A produção científica e técnica brasileira em saúde pública foi analisada para verificar sua representatividade nas bases de dados bibliográficas da área da saúde e nas revistas científicas nacionais, para identificar as instituições produtoras e a distribuição dessa produção por áreas temáticas.

\subsubsection{Produção científica e técnica registrada em bases de dados}

A análise inicial das bases de dados disponíveis na BVS-SP revelou que:

a) nem todas elas tinham acesso livre e, portanto, não seriam acessadas facilmente pelos gestores no momento da tomada de decisão em saúde;

b) nem todas permitiam busca por país de publicação ou país dos autores, o que dificultou ou até mesmo impossibilitou a identificação da produção científica brasileira indexada nas mesmas.

Assim sendo, foram analisadas apenas as bases de dados LILACS-SP, AdSAÚDE, REPIDISCA, MEDLINE e BDSP. 


\subsubsection{LILACS-SP}

Considerando-se os registros de documentos publicados desde 1990 existentes na base de dados LILACS, em abril de 2002, 75\% (140.630) corresponderam a artigos de revistas, 19\% (35.632) a monografias (livros, capítulos de livros, anais e trabalhos de eventos científicos), 5\% (9.609) a teses, e 1\% (1.929) a documentos nãoconvencionais (relatórios técnicos e outros documentos não publicados de forma tradicional), como mostra a Figura 6.

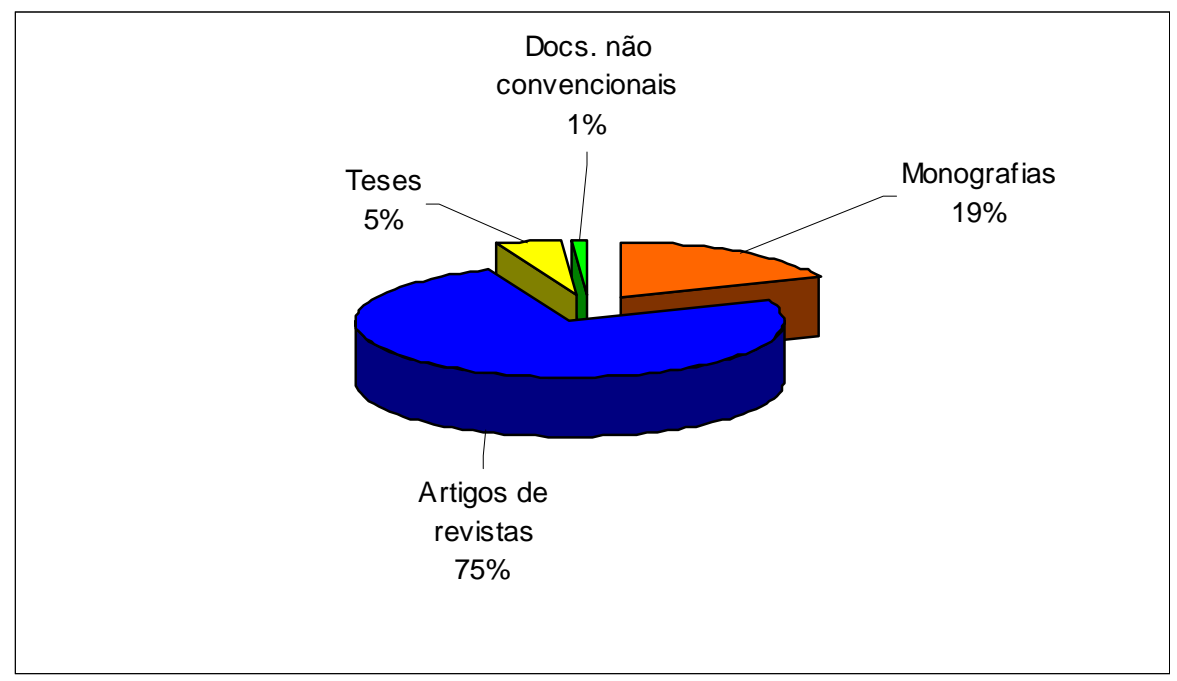

Fonte: LILACS, abril de 2002

Figura 6 - Distribuição dos registros da base de dados LILACS, de 1990 a 2002, por tipos de documentos

Os documentos da área de saúde pública corresponderam a 36\% (67.376) do total dos registros da LILACS, conforme observado na LILACS-SP. Nove países (Brasil, Chile, México, Argentina, Venezuela, Colômbia, Peru e Cuba) e a OPAS foram responsáveis por $85 \%$ da produção científica latino-americana dessa área registrada na LILACS-SP. O Brasil mostrou uma posição destacada (39\%), seguido da OPAS (representada no gráfico pelo código US - Estados Unidos), com 11\% da produção científica registrada na base, Chile (9\%) México (7\%) e Argentina (7\%). A distribuição dos registros da LILACS-SP por países pode ser verificada na Figura 7. 
PELLEGRINI FILHO (2000), utilizando outra metodologia de análise, observou que a produção científica em saúde na América Latina, representada nas bases de dados MEDLINE e ISI, estava altamente concentrada em poucos países da região, sendo Argentina, Brasil, Chile, México e Venezuela responsáveis por aproximadamente $90 \%$ da produção científica em saúde em geral. As pesquisas em saúde pública estavam concentradas basicamente no Brasil e na Argentina (p.49).

Para identificação da literatura científica e técnica brasileira da área de saúde pública na LILACS foi utilizada a base de dados LILACS-SP Brasil. Esta contava no momento da análise, em abril de 2002, com 36.039 registros, que correspondiam a $13 \%$ do total da LILACS (incluindo todas as áreas do conhecimento) e a 39\% dos registros da LILACS-SP.

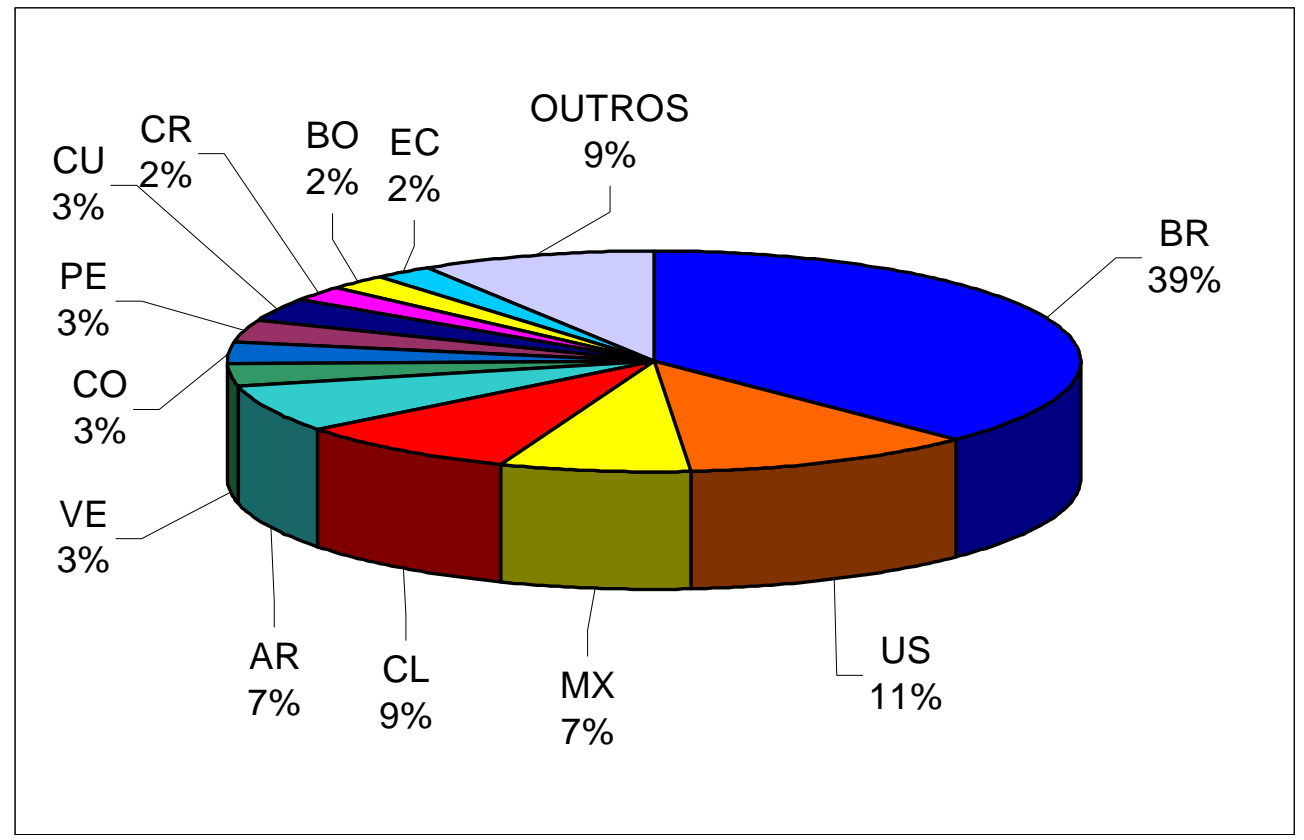

Fonte: LILACS-SP, abril de 2002

Figura 7 - Distribuição dos registros da produção científica latino-americana em saúde pública, de 1990 a 2002, indexados na base de dados LILACS-SP, por país de publicação 
Dos registros da LILACS-SP Brasil, 22.737 (63\%) referiam-se a artigos de revistas, $8.477(24 \%)$ a monografias, $3.736(12 \%)$ a teses, e $1.089(2 \%)$ a documentos nãoconvencionais (Figura 8). Na área de saúde pública, as porcentagens de documentos não-convencionais, de livros e teses foram maiores que as encontradas na LILACS no mesmo período.

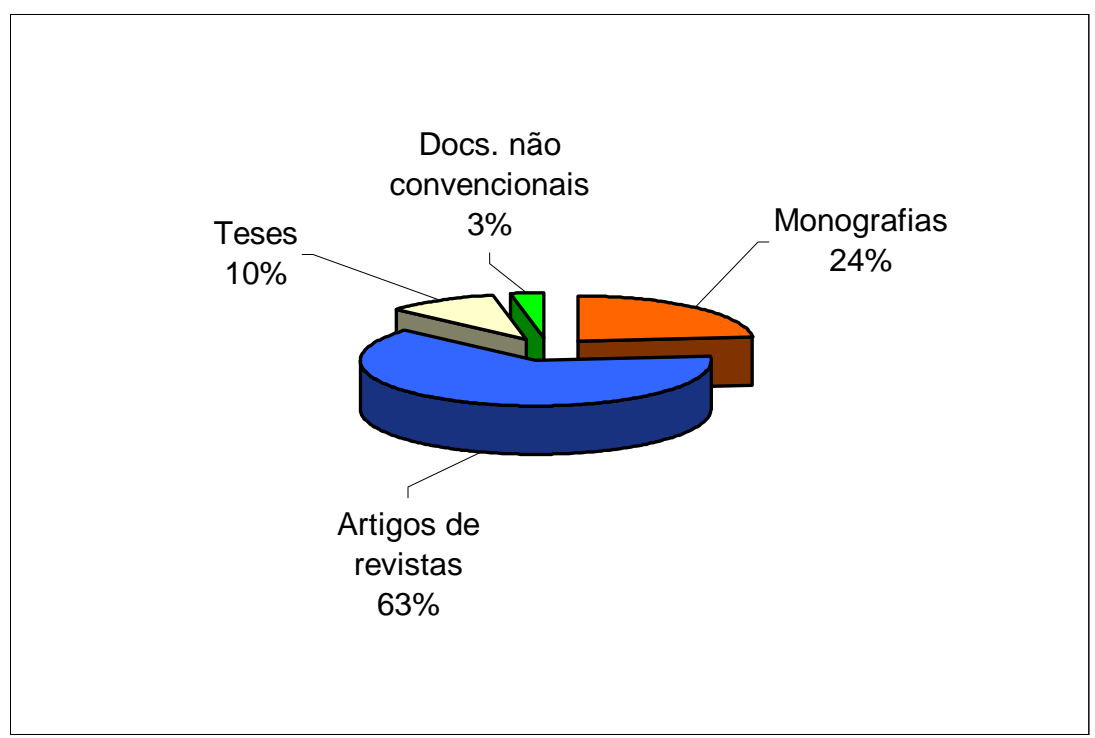

Fonte: LILACS-SP Brasil, abril de 2002

Figura 8 - Distribuição dos registros da produção brasileira de saúde pública na LILACS-SP Brasil, de 1990 a 2002, por tipos de documentos

ANDRADE (1984 e 1992) e NORONHA (1998), ao analisarem a produção científica brasileira na área de saúde pública e a literatura citada nas dissertações e teses, observaram que, na área acadêmica, os artigos de periódicos continuavam a ser os veículos mais utilizados pelos pesquisadores da área de saúde pública para a comunicação científica. NORONHA (1998) ressaltou que há uma tendência crescente de publicação dos resultados de dissertações e teses também em revistas científicas. Observou também, que na literatura da área de saúde pública produzida pela área acadêmica, havia ampla utilização de documentos legislativos (leis, decretos, acórdãos, resoluções etc.). 
Do total de registros da LILACS-SP Brasil, apenas 1.813 (7\%) corresponderam a anais de eventos científicos ou a trabalhos apresentados nos mesmos. Dos trabalhos expostos em eventos científicos, verificou-se que 60\% (1.093) foram publicados nos anais dos eventos, 32\% (589) como artigos de revistas, e 7\% (131) como trabalhos avulsos, identificados na base de dados como documentos não-convencionais.

MORAES (2001), ao analisar a literatura nacional sobre 'informações em saúde', afirmou que "os congressos brasileiros vêm se constituindo em um espaço privilegiado de troca e circulação de conhecimento" (p. 102). A autora constatou que os trabalhos de congressos e eventos científicos estavam mal representados nas bases e nos dados existentes e, para a realização de seu estudo, consultou 5.503 resumos de trabalhos apresentados nos Congressos Brasileiros de Saúde Coletiva, de Epidemiologia e de Ciências Sociais em Saúde, construindo uma base de dados específica para sua análise.

Na LILACS-SP Brasil, foram identificados 1.322 trabalhos apresentados em eventos científicos. Nem todos os trabalhos dos principais congressos da área de saúde pública mencionados por MORAES (2001) estavam indexados nessa base de dados. O motivo principal da diferença no registro poderia ser a inexistência de textos completos dos trabalhos, pois os resumos não são considerados para inclusão na LILACS-SP Brasil*. Os trabalhos de congressos e outros eventos científicos da área de saúde pública em geral incluem relatos de experiências, da prática dos programas e serviços de saúde e de estudos epidemiológicos. Além disso, esses trabalhos em geral são escritos em português (86\% do total) e discutem temas de interesse nacional, o que facilitaria sua utilização pelos gestores.

\footnotetext{
* BIREME. Guia de seleção de documentos para a base de dados LILACS: versão 3.0. [manual on line]. São Paulo; 2001. p. 9. Disponível em <URL: http://www.bireme.br/abd/P/Selguipt.pdf $>$. [2002 Nov 15]
} 
Se os trabalhos apresentados em eventos científicos são publicados em sua grande maioria apenas como resumos, poderiam servir de subsídio ao processo de tomada de decisão? Qual importância haveria para os gestores de localizar apenas os resumos de trabalhos ou experiências? Apesar de a divulgação dos resumos possibilitar conhecimento de trabalhos ou de experiências realizadas e contato com os autores para obtenção do documento na íntegra ou para intercâmbio de idéias, esse processo poderia não ser rápido e eficiente como exigido no processo de tomada de decisão. Segundo BRONFMAN et al. (2000), POUVORVILLE (1999) e TROSTLE et al. (1999), esse processo exigiria informações claras, que permitissem ações imediatas, dentro de um espaço de tempo mais curto que o da pesquisa científica.

A internet, que tem promovido profundas modificações na estrutura do fluxo da comunicação científica e técnica, poderia contribuir também para reverter essa situação. Como nessa mídia há menores limitações de espaço e como a maior parte dos autores utiliza meios eletrônicos para produzir seus trabalhos, os organizadores de eventos científicos poderiam usar mais amplamente a possibilidade de publicação de textos completos dos trabalhos na internet. Dessa forma, estes poderiam ser indexados em bases de dados e identificados rapidamente pelos usuários, que teriam a oportunidade de se beneficiar com a utilização mais efetiva desse tipo de documento.

A representatividade da literatura brasileira de saúde pública tem aumentado ano a ano na LILACS-SP: de uma média anual de pouco mais de 1.000 registros de documentos publicados de 1982 a 1985, a base de dados apresentou, nos últimos anos (1996-2000), um crescimento dessa média para mais de 2.500 registros de documentos publicados. A distribuição temporal dos registros de saúde pública na LILACS-SP Brasil pode ser verificada na Figura 9.

Cabe destacar que a probabilidade de identificação de documentos publicados em 2002 (ano em curso) ou em 2001 é relativamente inferior à dos anos anteriores, indicando uma defasagem de mais de um ano entre o tempo de publicação e de registro e a indexação dos documentos na base de dados LILACS-SP Brasil. Foram 
recuperados 2.071 documentos publicados em 2001, indexados de janeiro de 2001 até abril de 2002, o que representou $80 \%$ da média anual de registros nos últimos cinco anos. No entanto, apenas 52 documentos publicados em 2002 haviam sido registrados na base, de janeiro a abril de 2002.

Esse resultado é importante, pois, além da diferença entre os tempos e as agendas da pesquisa e da tomada de decisão política, exposta pelos autores citados na revisão de literatura, há de se considerar o tempo entre a publicação dos resultados e a indexação em bases de dados. Verificou-se, nesta análise, que a defasagem tem sido menor para as revistas científicas que têm utilizado amplamente a publicação eletrônica e se tornam disponíveis mais rápida e regularmente. Também nesse caso, os benefícios da publicação eletrônica poderiam ser explorados pelos produtores de informação científica e técnica em saúde, contribuindo para divulgação mais rápida dos resultados de pesquisa para os tomadores de decisão.

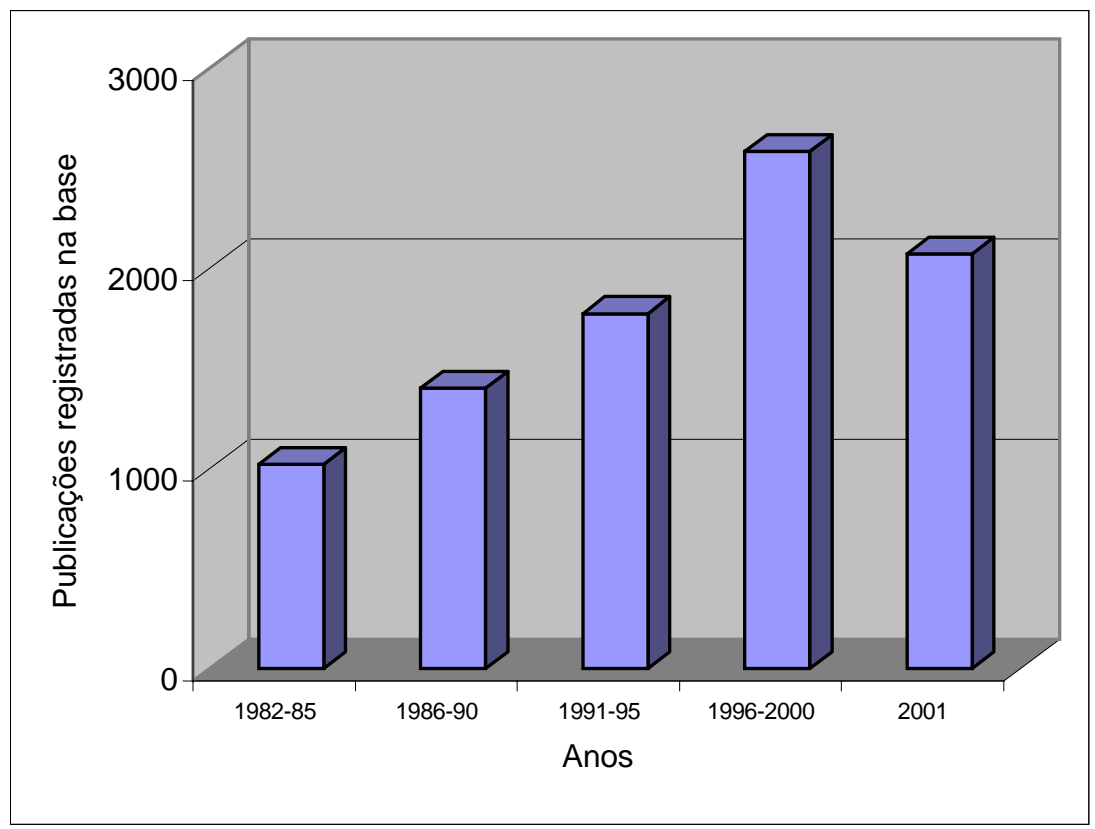

Fonte: LILACS-SP Brasil, abril de 2002

Figura 9 - Distribuição dos registros da produção brasileira de saúde pública da LILACS-SP Brasil, por ano de publicação 
Com relação ao idioma de publicação, a produção científica brasileira representada na LILACS-SP Brasil mostrou predominância (90\%) do idioma português, sendo 8\% dos documentos escritos em inglês. Estes corresponderam em sua grande maioria (93\%) a artigos de revistas, o que se justifica, uma vez que as principais revistas da área aceitam trabalhos em inglês para facilitar a divulgação da literatura brasileira para a comunidade internacional.

A predominância do idioma português nos registros da literatura científica e técnica brasileira indexada na LILACS-SP reveste-se de especial significado, quando se pensa em estimular o uso da informação científica e técnica para a tomada de decisão local.

Os resultados da análise da LILACS-SP e LILACS-SP Brasil indicaram que:

- a base de dados LILACS-SP mostrou ser a mais abrangente no que se refere à produção científica e técnica nacional em saúde pública publicada no país;

- os registros da área de saúde pública representados na LILACS-SP corresponderam a mais de um terço dos registros da LILACS;

- a produção científica brasileira na área de saúde pública registrada na LILACS-SP destacou-se no contexto latino-americano, sendo responsável por 39\% dos registros. Chile, Argentina e México também ocuparam lugar de destaque nessa produção;

- a representatividade da produção científica brasileira da área de saúde pública na LILACS-SP Brasil tem aumentado nos últimos anos;

- a porcentagem de livros, trabalhos apresentados em eventos científicos, teses e documentos não-convencionais é maior na área de saúde pública, que na de saúde em geral; 
- os congressos e outros eventos científicos da área de saúde pública estavam pouco representados na LILACS-SP Brasil, fato justificado talvez pela inexistência de textos completos dos trabalhos apresentados;

- a defasagem entre o tempo de publicação de um documento e de registro na LILACS-SP Brasil é de mais de um ano.

\subsubsection{AdSAÚDE}

Foram identificados na base de dados AdSAÚDE, em agosto de 2002, 11.978 registros, dos quais 9.146 (76\%) publicados desde 1990. Desse grupo de documentos, 7.483 (82\%) foram publicados no Brasil, sendo objeto desta análise.

A produção científica brasileira nessa base de dados referiu-se a $3.154(42 \%)$ artigos de revistas, 2.511 (34\%) livros ou capítulos de livros, 580 (8\%) trabalhos apresentados em congressos e outros eventos científicos, 978 (13\%) dissertações e teses e 260 (3\%) documentos não-convencionais (Figura 10).

Com relação ao idioma de publicação, embora tenha predominado o português (98\%), foram encontrados documentos em espanhol e inglês, que corresponderam principalmente a artigos de revistas e trabalhos apresentados em congressos internacionais realizados no país.

Os resultados sugeriram que a AdSAÚDE poderia ser utilizada como fonte de subsídio ao processo de tomada de decisão em saúde, principalmente no que se refere a livros, teses e anais de eventos científicos da área de administração de serviços de saúde.

É possível que uma porcentagem desses documentos também estivesse registrada na base de dados LILACS-SP, mas essa análise não foi objeto desta pesquisa. 


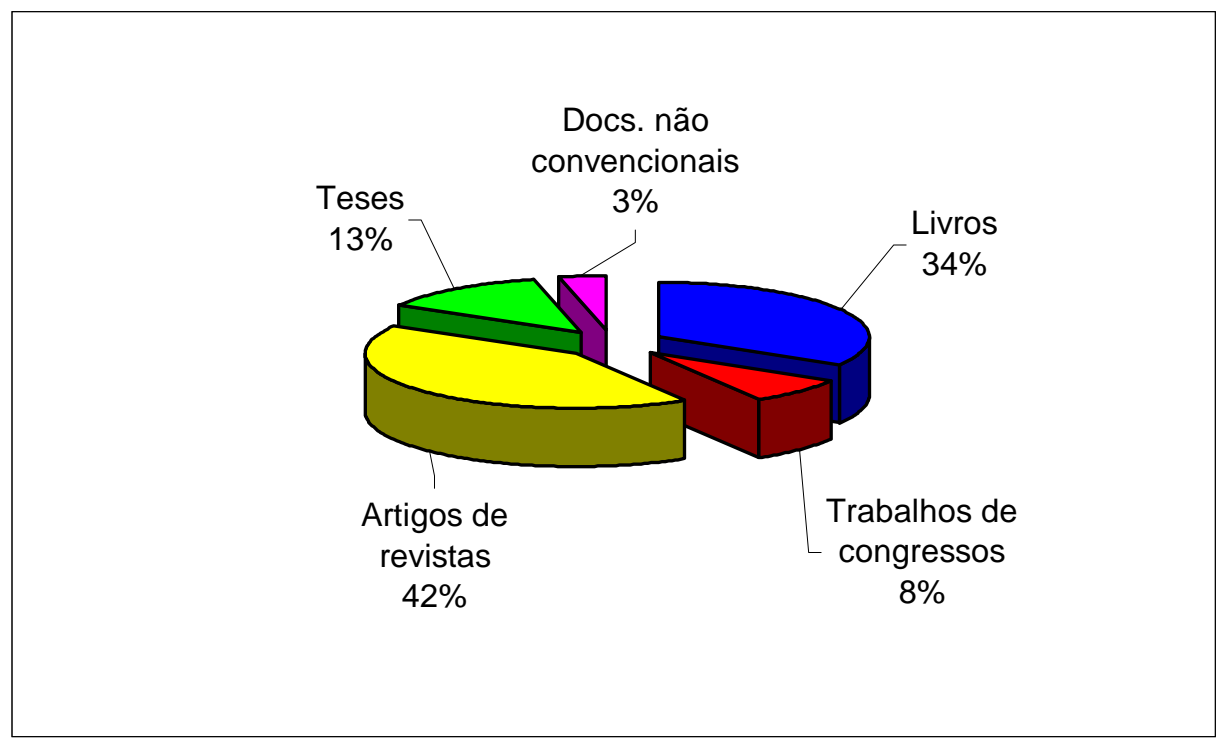

Fonte: AdSAÚDE, agosto de 2002

Figura 10 - Distribuição dos registros da produção científica brasileira indexada na base de dados AdSAÚDE, de 1990 a 2002, por tipos de documentos

\subsubsection{REPIDISCA}

A análise da produção científica e técnica brasileira representada na base de dados REPIDISCA mostrou que, em agosto de 2002, a literatura brasileira correspondia a $15 \%$ (19.070 registros) do total de registros da base.

Considerando os documentos publicados desde 1990, a produção científica brasileira registrada nessa base de dados equivaleu a 5.130 documentos (11\% do total). Desse total, 2.489 (48\%) corresponderam a livros e documentos governamentais, 1.626 (32\%) a trabalhos apresentados em eventos científicos, $231(5 \%)$ a teses, e 784 $(15 \%)$ a artigos de revistas (Figura 11). 


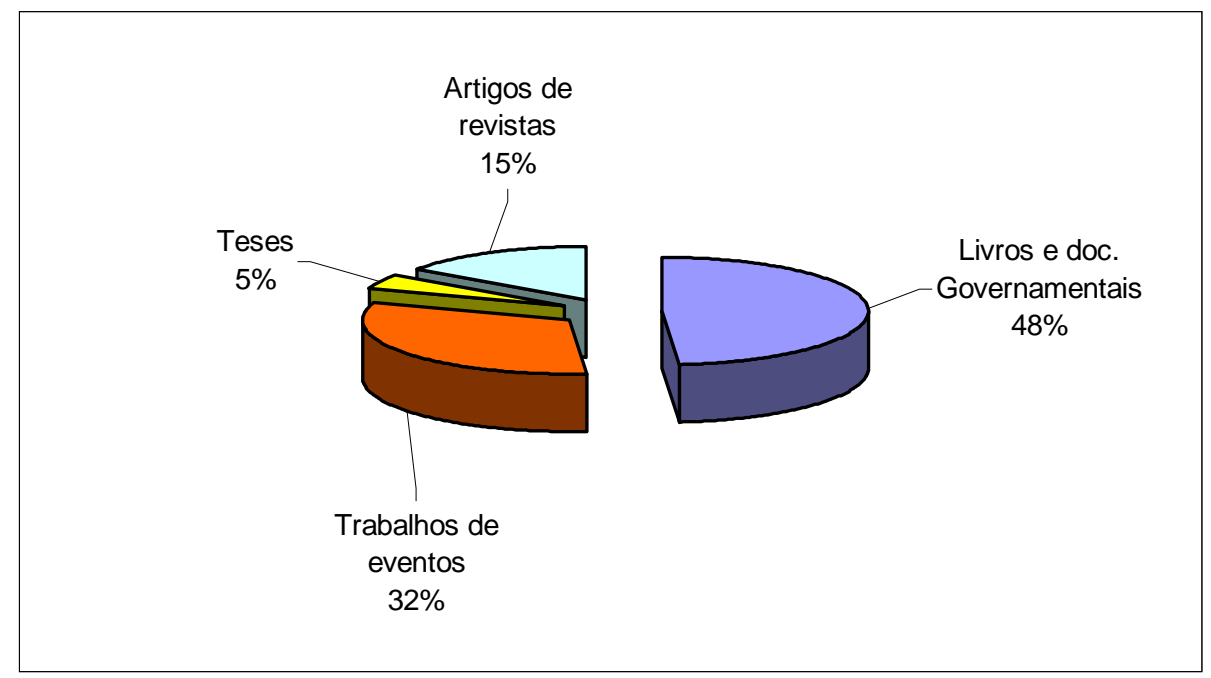

Fonte: REPIDISCA, agosto de 2002

Figura 11 - Distribuição dos registros da produção científica brasileira indexada na base de dados REPIDISCA, de 1990 a 2002, por tipos de documentos

Pelos resultados encontrados, a REPIDISCA poderia ser uma fonte de dados útil para os gestores, por contribuir na identificação de livros, teses e trabalhos apresentados em eventos científicos nas áreas de saneamento e meio ambiente, geralmente ausentes das bases de dados internacionais.

\subsubsection{MEDLINE}

Na versão disponível na BVS-SP da MEDLINE, foram encontrados, de 1989 a 2002, 17.212 registros (dados de agosto de 2002), correspondentes a artigos de revistas publicadas no Brasil. Como as revistas de saúde pública indexadas na MEDLINE também são indexadas na LILACS-SP, a análise desses documentos não acrescentaria muito à análise já realizada nesta.

Assim sendo, optou-se pela consulta direta à base de dados MEDLINE disponível no site da U.S. NLM, que permitia recuperação pelo campo de afiliação de autores. Foi possível identificar 29.494 trabalhos de autores brasileiros, publicados de 1990 a 
2002 (dados de julho de 2002). Destes, 8.157 (28\%) foram publicados em revistas brasileiras, e 21.337 (72\%) em revistas internacionais, o que evidenciou um alto grau de penetração da produção científica nacional em revistas científicas internacionais.

Dos 8.157 artigos publicados em revistas nacionais, 2.485 (30\%) foram veiculados nas seis publicações indexadas na base MEDLINE, identificadas nesta pesquisa como de interesse para a saúde pública. A busca pelo descritor 'public health' no campo de assunto permitiu encontrar outros 1.825 (22\%) registros, totalizando 4.310 (52\%) artigos nacionais da área de saúde pública indexados na base de dados MEDLINE no período.

Para os artigos publicados por autores nacionais em revistas internacionais, foram identificados $6.473(30 \%)$ artigos de saúde pública, utilizando a estratégia geral pelo descritor 'public health'.

Como não era objetivo desta pesquisa, não foi feita uma análise do tipo de artigos publicados no exterior ou uma identificação das revistas mais utilizadas por autores brasileiros para publicar seus trabalhos. Essas análises poderiam ser objeto de pesquisa posterior sobre o tema.

Os resultados da análise da produção científica brasileira de saúde pública na base de dados MEDLINE mostraram que:

- a produção científica da área de saúde pública está representada não somente em revistas nacionais e internacionais da área mas também naquelas de saúde em geral;

- essa base poderia ser útil, como subsídio ao processo de tomada de decisão em saúde, para identificação de resultados de pesquisas nacionais na área de saúde pública não representadas nas bases de dados latinoamericanas. 
Os resultados da análise da MEDLINE também contribuíram para algumas indagações, como: que tipo de pesquisa nacional é publicada em revistas internacionais? Quais seriam as probabilidades de efetiva utilização pelos gestores da produção científica nacional divulgada em revistas estrangeiras que, em geral, têm acesso mais difícil e utilizam idioma estrangeiro? Seria recomendável que se realizassem estudos sobre o conteúdo do que é publicado no exterior e do que é publicado em revistas nacionais, principalmente na área de saúde pública, em que as pesquisas poderiam ter impactos sobre políticas, programas de saúde ou organização de serviços.

O fato de as agências governamentais de apoio à pesquisa de ciência e tecnologia adotarem no Brasil um sistema de pontuação diferenciado para os pesquisadores que publicarem em revistas internacionais poderia estar contribuindo para a divulgação de resultados de pesquisa brasileira no exterior. O pesquisador divulga seu trabalho, normalmente em inglês, em revistas indexadas em bases de dados internacionais, para que sua pesquisa possa ser reconhecida pelas agências e pelos pares, mesmo que dessa forma seja menos conhecida pela comunidade em geral e pelos tomadores de decisão. Como a produção e utilização do conhecimento são funções sociais e grande parte das pesquisas é financiada com recursos nacionais, a publicação de resultados de pesquisas poderia atender melhor a essas funções se fosse feita em revistas nacionais que, por sua vez, também são financiadas pelas agências. Esse fato poderia contribuir para melhorar sua qualidade e até favorecer o impacto internacional das mesmas.

O impacto social no país não poderia ser equivalente ao da absorção do conhecimento científico, medido atualmente pelos índices de uso e citações na literatura? A questão seria desenvolver indicadores de impacto das pesquisas científicas nas decisões políticas, que não fossem apenas as quantificações de citações de artigos em revistas. É preciso pensar que se o gestor utilizasse uma informação contida na literatura científica, no processo de tomada de decisão local, 
provavelmente não publicaria seus resultados em revistas científicas. E, nesse caso, a utilização de pesquisas na prática e na política não seria quantificada pelos meios utilizados atualmente.

LÓPEZ CEREZO (2002) discutiu a importância da criação de novos indicadores de impacto social para medir a influência das inversões em ciência e tecnologia. " $O$ desafio é elaborar um novo conjunto de indicadores que, além das variáveis tradicionais de inversão de gastos, produção bibliográfica ou inovação, realizem uma avaliação mais específica do modo em que o gasto público em ciência e tecnologia produz um desenvolvimento social, sendo sensíveis à demanda social sem valor de mercado" (p. 3).

\subsubsection{BDSP}

A recuperação na base de dados Banque de Données Santé Publique por país mostrou que $41 \%$ dos documentos são franceses, e 59\% de 'outros países'.

Os resultados da recuperação, com dados de agosto de 2002, foram:

- 839 documentos sobre o Brasil ('Brésil' como assunto);

- 702 documentos de autores e/ou editores brasileiros ('Brasil' ou 'BRA' no campo de autores e/ou editores);

- 415 combinando as duas estratégias, ou seja, documentos sobre o Brasil e de autores brasileiros ('Brésil' como assunto e 'Brasil' ou 'BRA' no campo de autores e/ou editores).

Após combinação desses resultados, chegou-se a um total de 173 registros recuperados. Observou-se que $94 \%$ correspondiam a artigos de revistas, $2 \%$ a livros, e $2 \%$ a separatas de artigos de revistas. Cerca de $50 \%$ dos títulos de revistas recuperados se referiam a títulos também indexados na base MEDLINE. 
A recuperação por títulos de revistas brasileiras de saúde pública também foi realizada e mostrou que a indexação dos fascículos parece ser esporádica e desatualizada. Da Revista de Saúde Pública foram recuperados 99 registros, correspondentes principalmente aos anos de 1990 a 1994, mas nem todos os fascículos foram indexados na totalidade. Da revista Cadernos de Saúde Pública há apenas um fascículo especial indexado, publicado em 1994.

Os resultados da busca na BDSP, embora parciais, mostraram que:

- essa base de dados não seria uma fonte de apoio importante à tomada de decisão para os gestores brasileiros;

- poderia ser importante para estudos sobre a produção científica brasileira dispersa em revistas internacionais, principalmente nas francesas;

- para que essa base pudesse ser melhor explorada, seria preciso ter acesso à modalidade completa de pesquisa e não apenas à modalidade parcial, disponível atualmente na BVS-SP.

\subsubsection{Revistas científicas da área de saúde pública}

Considerando os resultados da análise da LILACS-SP Brasil, procurou-se verificar em que revistas nacionais da área da saúde seriam publicados os artigos científicos de temas relativos à saúde pública. Foram identificadas 380 revistas científicas brasileiras dentre os 22.764 registros da LILACS-SP Brasil analisados.

As 20 primeiras revistas com maior freqüência de artigos indexados, responsáveis por 36,2\% do total, foram: Revista de Saúde Pública, Cadernos de Saúde Pública, Jornal de Pediatria (Rio de Janeiro), Revista Brasileira de Enfermagem, Revista da Escola de Enfermagem da USP, Saúde em Debate, Higiene Alimentar, Memórias do Instituto Oswaldo Cruz, Revista Brasileira de Saúde Ocupacional, Brazilian Journal of Medical and Biological Research, Femina, Divulgação Saúde em Debate, Jornal 
Brasileiro de Psiquiatria, Revista de Administração Pública, Arquivos Brasileiros de Medicina Veterinária e Zootecnia, Revista de Microbiologia, Mundo da Saúde (1995), Texto e Contexto Enfermagem, Arquivos Brasileiros de Cardiologia e Pediatria (São Paulo).

O perfil dessas revistas mostrou que cinco delas seriam específicas de saúde pública (Revista de Saúde Pública, Cadernos de Saúde Pública, Saúde em Debate, Divulgação Saúde em Debate e Mundo da Saúde -1995) e responsáveis por 15,35\% dos registros; uma seria de área correlata (Memórias do Instituto Oswaldo Cruz); três da área de enfermagem (Revista Brasileira de Enfermagem, Revista da Escola de Enfermagem da USP, Texto e Contexto Enfermagem); duas da área de pediatria (Jornal de Pediatria - Rio de Janeiro -, Pediatria - São Paulo); e as demais de outras áreas especializadas, com um título cada. No Anexo 5, foram mostrados os 50 títulos de revistas com maior número de registros na LILACS-SP Brasil, com os respectivos números de artigos indexados na base e porcentagem em relação ao total.

Os resultados encontrados por GUIMARÃES (2001) sobre as revistas científicas mais utilizadas pelos pesquisadores da área de epidemiologia também apontaram para a dispersão da produção científica em revistas de outras áreas. Ele identificou 338 títulos de revistas nacionais e estrangeiros utilizados por pesquisadores brasileiros em epidemiologia para publicação de trabalhos. O autor observou que, dos 338 periódicos, 145 eram da área médico-cirúrgica, odontológica, de enfermagem e de psicologia. Os 20 periódicos mais utilizados responderam por $46 \%$ do total de artigos. Destes, sete $(9,8 \%)$ eram estrangeiros, e o restante, nacionais.

O perfil desses 20 periódicos mostra que oito são criações da área de saúde coletiva ou das áreas que a precederam e deram origem, com um total de 26,0\% dos artigos (Cadernos de Saúde Pública, Revista de Saúde Pública, Ciência e Saúde Coletiva, Informe Epidemiológico do SUS, Revista Brasileira de Epidemiologia, Cadernos de Saúde Coletiva, Série Estudos em Saúde Coletiva e Physis). Três periódicos, embora não sejam da área, possuem com 
ela estreitas e tradicionais relações de colaboração e, até certo ponto, também de genealogia. Esses três periódicos contribuem com 7,1\% dos artigos (Memórias do Instituto Oswaldo Cruz, Revista do Instituto de Medicina Tropical de São Paulo e Revista da Sociedade Brasileira de Medicina Tropical) (p. 335).

Embora se tratando de amostras e metodologias diferentes, há coincidência de alguns títulos dentre os destacados na área de saúde pública e epidemiologia em particular: Revista de Saúde Pública, Cadernos de Saúde Pública, Memórias do Instituto Oswaldo Cruz e Jornal de Pediatria aparecem nas duas listas.

O Jornal de Pediatria apareceu em ambas as listas, embora represente uma especialidade médica. Verificou-se que nessa revista foram publicados, de 1990 a 2002, 889 artigos registrados na base de dados LILACS, dos quais 330 foram selecionados para a LILACS-SP Brasil, significando que, em média, 37\% dos artigos são relativos à área de saúde pública. Essa porcentagem aumentou nos últimos anos: em 1999, foram publicados 27 (32\%) artigos de saúde pública; em 2000, 30 (28\%); e em 2001, 81 (68\%). Uma análise dos 81 artigos de 2001 mostrou que estes se referiam principalmente a temas da saúde pública (prevenção e controle de doenças, violência, mortalidade infantil, estudos epidemiológicos etc.) e também da área clínico-cirúrgica de saúde materno-infantil e da adolescência.

Concluiu-se que a análise dos temas tratados nos artigos sobre saúde pública dispersos em revistas de outras áreas científicas especializadas poderia dar uma dimensão mais exata de sua interdisciplinaridade e da caracterização da produção científica da área.

Concluiu-se também que a fragmentação das bases de dados, em subconjuntos especializados em saúde pública, não parece ser adequada aos usuários, dada a dispersão dos artigos de saúde pública em revistas de saúde em geral. O grau de 
satisfação das necessidades dos gestores e outros profissionais da saúde pública, com a utilização dessas bases de dados específicas deveria ser objeto de análise posterior.

\subsubsection{Instituições produtoras de informação científica e técnica em saúde pública}

No caso das revistas, a análise das instituições produtoras foi realizada, em caráter exploratório, pelo campo de afiliação de autores na SciELO. Foram analisados os artigos publicados nas revistas Cadernos de Saúde Pública e Revista de Saúde Pública, de 2000 e 2001.

Publicaram-se, nesse período, 604 artigos nessas duas revistas, com contribuição de 1.678 autores, numa relação de 2,78 autores por artigo. Foram identificadas contribuições de autores de 93 instituições distintas do Brasil, de outros países da América Latina (Argentina, Chile, Colômbia, Cuba, Equador, México, Paraguai, Peru, Uruguai, Venezuela), da América do Norte (Canadá, Estados Unidos), da Europa (Espanha, Holanda, Inglaterra, Itália, Portugal, Reino Unido, Suécia, Suíça), da África (Moçambique, Quênia) e da Austrália. Foram classificadas em 'outras organizações' as instituições que não puderam ser identificadas*, correspondentes a $231(13,77 \%)$ autores. Não foi encontrada nenhuma informação sobre afiliação para $146(8,70 \%)$ autores.

Verificou-se que a colaboração de autores pertencentes ao Ministério da Saúde e às secretarias estaduais ou municipais de Saúde foi pequena, evidenciando pouca integração entre a área da prática em saúde e dos serviços e a área acadêmica na publicação de resultados de pesquisas: foram identificados 23 (4\%) artigos com participação de autores do Ministério da Saúde e 25 (4\%) com autores de secretarias municipais ou estaduais de Saúde.

\footnotetext{
* A equivalência das instituições é feita de acordo com as tabelas de instituições do CNPq, utilizadas pela SciELO para a tabulação dos dados.
} 
Em relação ao total de autores dessas revistas, no período de 2000 e 2001, houve maior porcentagem de autores da Fundação Oswaldo Cruz (20\%), incluindo a Escola Nacional de Saúde Pública, e da Universidade de São Paulo (13\%), considerando todas as faculdades. Na seqüência, foram identificadas oito instituições com mais de 2\% do total de autores: Universidade Estadual de Campinas (5\%); Universidade Estadual de Pelotas (4\%); Universidade Federal do Rio de Janeiro, Universidade do Estado do Rio de Janeiro e Universidade Federal do Rio Grande do Sul (com 3\% cada); e Universidade Federal da Bahia, Universidade Federal de Minas Gerais e Universidade Federal de São Paulo (com 2\% cada). A porcentagem de autores sem afiliação de autor foi de $9 \%$, e a de instituições não identificadas, classificadas no índice da SciELO em 'outras organizações', foi de 14\%.

Em um estudo da OPAS citado por PELLEGRINI FILHO (2000), as universidades foram consideradas uma das principais instituições produtoras de conhecimento técnico-científico. Ele mostrou que, no processo de produção científica em saúde na América Latina, $70 \%$ a $80 \%$ da produção científica provinham das universidades, e que cerca de 50\% dos recursos alocados para o desenvolvimento científico e tecnológico pelas agências financiadoras dirigiam-se às universidades (p. 66).

PELLEGRINI FILHO destacou que a produção científica universitária esteve mais voltada, até o século passado, para a produção do conhecimento por si mesmo, segundo a estrutura organizacional da universidade, mas que, no último século, as universidades adaptaram-se à nova realidade e passaram a produzir conhecimento útil para a solução de problemas sociais e de conteúdo das próprias disciplinas. "De fato, com a noção de 'sociedade do conhecimento' ou de 'economia do conhecimento', vem a noção da universidade não apenas como geradora de conhecimento, mas também como um importante agente de crescimento econômico" (p. 66). Surgiram, nessa época, as redes de instituições periféricas, como os institutos de pesquisa, as empresas e os serviços ao redor da universidade, estabelecendo relações e acordos para desenvolvimento de projetos de interesse comum e vínculos maiores entre a universidade e o setor produtivo (PELLEGRINI FILHO 2000, p.667). 
Os resultados da literatura registrada na LILACS-SP indicaram que a produção das universidades esteve mais concentrada nos artigos de revistas e nas teses, estas exclusivamente produzidas nas universidades.

A análise das monografias existentes na LILACS-SP mostrou que 40\% são publicadas por instituições governamentais (21\% por departamentos do Ministério da Saúde, $10 \%$ por secretarias estaduais e municipais de Saúde, e $8 \%$ por outros ministérios e secretarias), $18 \%$ por universidades e institutos de pesquisa (muitos deles vinculados aos governos estadual ou federal), e 17\% por editoras comerciais (Tabela 3).

Tabela 3 - Instituições publicadoras de monografias registradas na LILACS -SP Brasil, por tipo de instituição, com total e porcentagem de registros na base

\begin{tabular}{lll}
\hline Tipo de instituição & Total de registros & $\%$ \\
\hline Instituições Governamentais: & & \\
$\quad$ Ministério da Saúde & 690 & $21 \%$ \\
$\quad$ Secretarias de Saúde & 351 & $10 \%$ \\
$\quad$ Outros Ministérios e Secretarias & 260 & $8 \%$ \\
Editoras comerciais & 568 & $17 \%$ \\
Universidades & 318 & $9 \%$ \\
Institutos de pesquisa & 286 & $9 \%$ \\
Organismos internacionais & 85 & $3 \%$ \\
Sociedades e associações & 69 & $2 \%$ \\
Outras instituições & 360 & $11 \%$ \\
Não identificadas & 377 & $11 \%$ \\
\hline Total & 3.354 & $100 \%$ \\
\hline
\end{tabular}

Fonte: LILACS -SP Brasil, abril de 2002

É provável que o registro da produção de livros, documentos governamentais e trabalhos apresentados em eventos científicos não esteja completo na LILACS-SP. Mas, pode-se afirmar, com base nesses resultados, que a base de dados LILACS-SP, 
no que se refere a documentos governamentais, atenderia às necessidades de informação dos gestores. A quantidade de documentos produzidos por organismos governamentais registrada nessa base de dados é significativa e caracteriza a LILACS-SP como uma das únicas fontes disponíveis na área da saúde para a recuperação dessa informação.

Quanto às dissertações e teses, 57\% dos registros nessa categoria corresponderam a dissertações de mestrado, 38\% a teses de doutorado, e 5\% a outros graus ou sem identificação do grau. As instituições com maior número de teses representadas na base de dados foram as que mantêm cursos específicos da área de saúde pública, seguida das áreas de medicina e de enfermagem. A Tabela 4 mostra as dez instituições responsáveis pela produção de $71 \%$ do total de teses e dissertações registradas na LILACS-SP.

Tabela 4 - Distribuição dos registros de dissertações e teses na LILACS-SP Brasil, por instituições em que as mesmas foram apresentadas

\begin{tabular}{lll}
\hline INSTITUIÇÃO & TOTAL & \% \\
\hline Universidade de São Paulo. Faculdade de Saúde Pública & 975 & $26 \%$ \\
Escola Nacional de Saúde Pública / FIOCRUZ & 462 & $12 \%$ \\
Universidade Federal de São Paulo. Escola Paulista de Medicina & 406 & $11 \%$ \\
Universidade de São Paulo. Escola de Enfermagem & 172 & $5 \%$ \\
Universidade de São Paulo. Escola de Enfermagem de Ribeirão Preto & 163 & $4 \%$ \\
Universidade do Estado do Rio de Janeiro. Instituto de Medicina Social & 121 & $3 \%$ \\
Universidade Federal do Rio de Janeiro. Escola de Enfermagem Anna Nery 118 & $3 \%$ \\
Universidade de São Paulo. Faculdade de Ciências Farmacêuticas & 101 & $3 \%$ \\
Universidade Federal da Bahia. Faculdade de Medicina & 72 & $2 \%$ \\
Universidade de São Paulo. Instituto de Psicologia & 69 & $2 \%$ \\
Outras & 1.061 & $29 \%$ \\
\hline TOTAL & $\mathbf{3 . 7 2 0}$ & $100 \%$ \\
\hline
\end{tabular}

Fonte: LILACS -SP Brasil, abril de 2002

\subsubsection{Análise da distribuição da produção científica por temas}

Para verificar a distribuição dos registros da LILACS-SP Brasil por temas de saúde pública, foi feita uma análise dessa base de dados, de acordo com as áreas temáticas 
da BVS-SP (Tabela 5). Observou-se que as áreas mais representadas foram as de Ciências sociais em saúde, Atenção à saúde e Ambiente e saúde, seguidas de Administração e planejamento em saúde, Epidemiologia, Demografia e Políticas públicas e saúde.

A predominância de artigos de revistas foi mais evidente em algumas áreas temáticas. Nas de Doenças crônicas e degenerativas e de Alimentação e nutrição, os artigos de revistas corresponderam a 75\% dos documentos da área, e as monografias a 12\%; na área de Drogas de uso terapêutico e social, $69 \%$ dos documentos foram artigos de revistas e 20\%, monografias; e na área de Doenças infecciosas e parasitárias, $63 \%$ foram artigos de revistas e $24 \%$, monografias.

As monografias apareceram em maior porcentagem nas áreas de Economia da Saúde (com $42 \%$ do total de documentos da área), Direito sanitário (com 39\% do total da área) e Recursos humanos em saúde e Ciência e tecnologia em saúde (com 38\% do total).

Em relação ao total de documentos não-convencionais registrados na base, a área de Recursos humanos em saúde apresentou percentual muito superior (10\%) aos 3\% da média. Outras áreas em que esse tipo de documento destacou-se foram: Ciência e tecnologia em saúde, Eqüidade em saúde e social e Políticas públicas e saúde, com $5 \%$ cada uma.

As teses se distribuíram, em termos percentuais, mais uniformemente entre todas as áreas, correspondendo, em média, a 13\% do total de documentos de cada área temática. 
Tabela 5 - Distribuição da literatura brasileira em saúde pública, de 1990 a 2002, indexada na LILACS-SP Brasil, por áreas temáticas da BVS-SP, com totais por tipo de documentos e porcentagem dentro de cada área temática

\begin{tabular}{|c|c|c|c|c|c|c|c|c|c|}
\hline & Mono- & & Artigos & & Teses & & $N \tilde{a} o$ & & \\
\hline Tema & grafias & $\%$ & & $\%$ & & $\%$ & convenc. & $\%$ & Total \\
\hline Acidentes e violência & 205 & $24 \%$ & 528 & $61 \%$ & 116 & $13 \%$ & 13 & $2 \%$ & 862 \\
\hline Adm. e planejamento em saúde & 3351 & $34 \%$ & 4943 & $50 \%$ & 1293 & $13 \%$ & 398 & $4 \%$ & 9985 \\
\hline Alimentação e nutrição & 472 & $12 \%$ & 2896 & $75 \%$ & 487 & $13 \%$ & 22 & $1 \%$ & 3877 \\
\hline Ambiente e saúde & 3152 & $22 \%$ & 9119 & $63 \%$ & 1855 & $13 \%$ & 285 & $2 \%$ & 14411 \\
\hline Atenção à saúde & 3851 & $26 \%$ & 8447 & $57 \%$ & 2086 & $14 \%$ & 379 & $3 \%$ & 14763 \\
\hline Ciência e Tecnologia em Saúde & 289 & $38 \%$ & 362 & $48 \%$ & 72 & $9 \%$ & 35 & $5 \%$ & 758 \\
\hline Ciências Sociais em Saúde & 4373 & $29 \%$ & 8261 & $55 \%$ & 2086 & $14 \%$ & 417 & $3 \%$ & 15137 \\
\hline Comunicação em Saúde & 658 & $34 \%$ & 910 & $48 \%$ & 298 & $16 \%$ & 43 & $2 \%$ & 1909 \\
\hline Demografia & 1835 & $27 \%$ & 3817 & $56 \%$ & 1024 & $15 \%$ & 155 & $2 \%$ & 6831 \\
\hline Direito Sanitário & 636 & $39 \%$ & 802 & $49 \%$ & 141 & $9 \%$ & 59 & $4 \%$ & 1638 \\
\hline $\begin{array}{c}\text { Doenças crônicas e } \\
\text { degenerativas }\end{array}$ & 318 & $12 \%$ & 1990 & $75 \%$ & 334 & $13 \%$ & 12 & $0 \%$ & 2654 \\
\hline $\begin{array}{c}\text { Doenças infecciosas e } \\
\text { parasitárias }\end{array}$ & 684 & $24 \%$ & 1823 & $63 \%$ & 325 & $11 \%$ & 44 & $2 \%$ & 2876 \\
\hline $\begin{array}{l}\text { Drogas de uso terapêutico e } \\
\text { social }\end{array}$ & 77 & $20 \%$ & 268 & $69 \%$ & 36 & $9 \%$ & 7 & $2 \%$ & 388 \\
\hline Economia da Saúde & 864 & $42 \%$ & 841 & $41 \%$ & 272 & $13 \%$ & 92 & $4 \%$ & 2069 \\
\hline Epidemiologia & 1254 & $18 \%$ & 4490 & $65 \%$ & 1020 & $15 \%$ & 166 & $2 \%$ & 6930 \\
\hline Equidade em saúde e social & 1206 & $31 \%$ & 1962 & $50 \%$ & 529 & $14 \%$ & 198 & $5 \%$ & 3895 \\
\hline Ética e Bioética & 66 & $25 \%$ & 177 & $66 \%$ & 23 & $9 \%$ & 1 & $0 \%$ & 267 \\
\hline História da Saúde pública & 360 & $33 \%$ & 516 & $47 \%$ & 174 & $16 \%$ & 37 & $3 \%$ & 1087 \\
\hline $\begin{array}{l}\text { Medicamentos, vacinas e } \\
\text { insumos }\end{array}$ & 166 & $29 \%$ & 327 & $57 \%$ & 61 & $11 \%$ & 15 & $3 \%$ & 569 \\
\hline Políticas públicas e saúde & 2061 & $33 \%$ & 3067 & $49 \%$ & 872 & $14 \%$ & 304 & $5 \%$ & 6304 \\
\hline Promoção e educação em saúde & 631 & $31 \%$ & 1044 & $51 \%$ & 287 & $14 \%$ & 70 & $3 \%$ & 2032 \\
\hline $\begin{array}{l}\text { Recursos humanos em } \\
\text { saúde pública }\end{array}$ & 267 & $38 \%$ & 280 & $40 \%$ & 85 & $12 \%$ & 67 & $10 \%$ & 699 \\
\hline Saúde animal & 17 & $28 \%$ & 35 & $58 \%$ & 6 & $10 \%$ & 2 & $3 \%$ & 60 \\
\hline$\underline{\text { Vigilância em saúde }}$ & 618 & $27 \%$ & 1261 & $56 \%$ & 285 & $13 \%$ & 84 & $4 \%$ & 2248 \\
\hline Total & 27411 & $27 \%$ & 558166 & $57 \%$ & 13767 & $13 \%$ & 2905 & $3 \%$ & 0102249 \\
\hline
\end{tabular}

Fonte: LILACS-SP Brasil, abril de 2002 


\subsection{Análise descritiva das Agendas Estaduais de Saúde de 2001}

Foram analisadas as Agendas Estaduais de Saúde de 19 Secretarias de Estado da Saúde para o ano de 2001*, em relação à Agenda Nacional de Saúde proposta pelo Ministério de Saúde para o mesmo período.

Conforme PORTARIA - 393 GM/MS,

Art. $3^{\circ}$. A Agenda Nacional de Saúde estabelece os seguintes eixos prioritários de intervenção para 2001:

a) redução da mortalidade infantil e materna;

b) controle de doenças e agravos prioritários;

c) reorientação do modelo assistencial e descentralização;

d) melhoria da gestão, do acesso e da qualidade das ações $e$ serviços de saúde;

e) desenvolvimento de recursos humanos do setor saúde;

f) qualificação do controle social (MINISTÉRIO DA SAÚDE 2001b).

Em cada um desses eixos, definiram-se, pelo Ministério da Saúde, metas e prioridades de intervenção, indicadores e fontes sugeridas para obtenção e verificação dos dados.

Caberia aos Estados identificar eixos prioritários de intervenção e metas para o ano de 2001, baseando-se nos eixos e metas definidos pela Agenda Nacional de Saúde.

\footnotetext{
* As agendas de saúde para 2001 foram publicadas no site do Ministério da Saúde no final de 2001 e as de 2002 não haviam sido publicadas na Internet até o fechamento desse estudo.
} 
O quadro demonstrativo da análise das metas das Agendas Estaduais de Saúde em relação às estabelecidas pela Agenda Nacional de Saúde pode ser consultado na Tabela 6. 
Tabela 6 - Demonstrativo das metas das Agendas Estaduais de Saúde em relação à Agenda

Nacional de Saúde para o ano de 2001

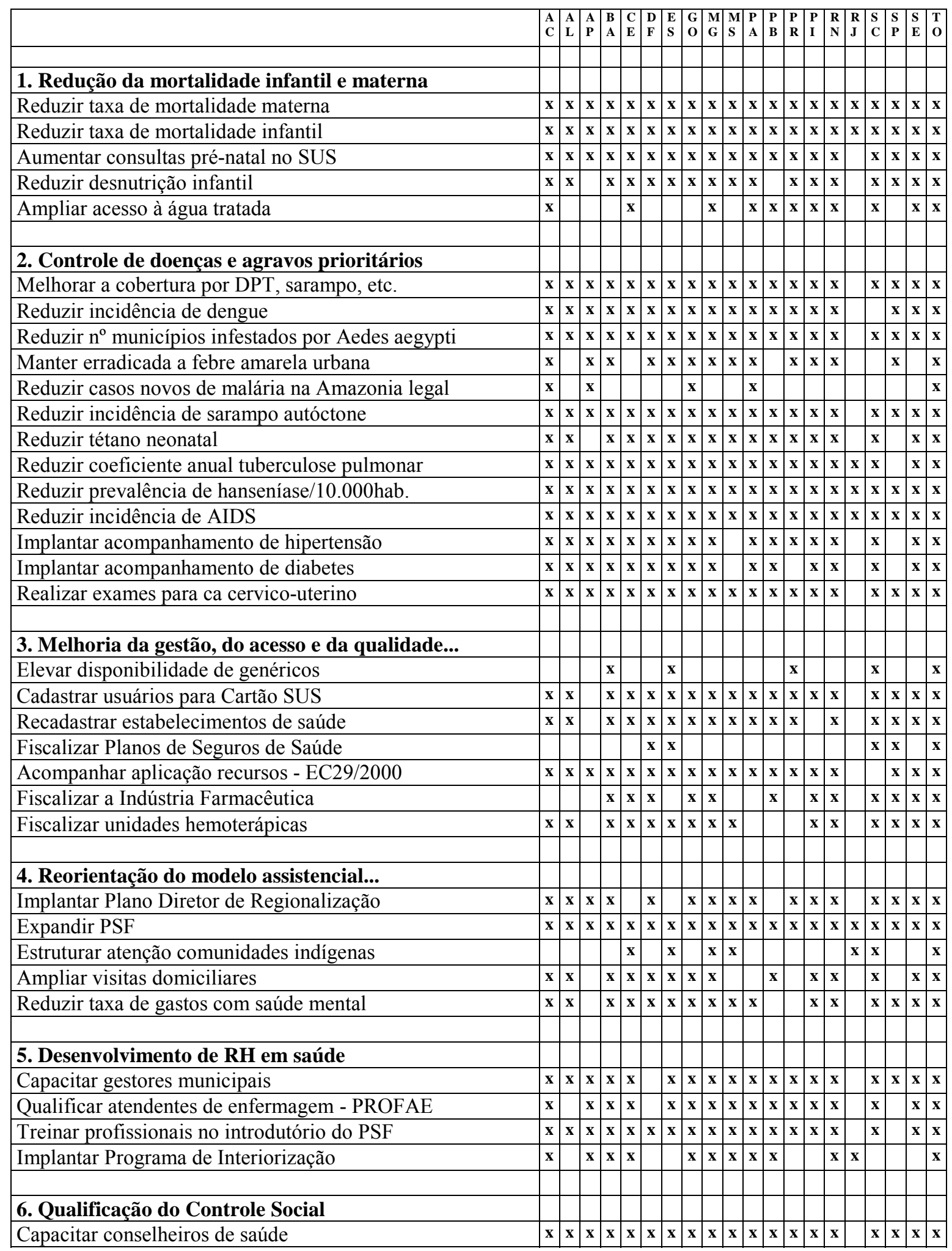

Fonte: Agendas Estaduais de Saúde 2001 (referenciadas na bibliografia) 
O objetivo principal da análise das Agendas Estaduais de Saúde foi verificar as prioridades e metas de intervenção propostas pelos governos estaduais, que deveriam corresponder a políticas ou necessidades locais.

Verificou-se que praticamente todos os eixos e prioridades de intervenção propostos pelo Ministério da Saúde foram adotados, com exceção de:

- eixos específicos para determinadas regiões geográficas, como 'Reduzir casos novos de malária na Amazônia Legal';

- eixos de intervenção que podem estar fora do âmbito da Secretaria da Saúde, como, por exemplo, 'Ampliar acesso à água tratada' no Estado de São Paulo.

No entanto, algumas prioridades de intervenção foram consideradas pela quase totalidade das Secretarias de Saúde:

- eixos com caráter normativo, como 'Acompanhar aplicação de recursos EC29/2000’ ou 'Implantar Plano Diretor de Regionalização’;

- $\quad$ eixos que estão associados à entrega de recursos do Governo Federal para o atendimento das mesmas, como 'Cadastrar usuários para o Cartão SUS' ou 'Expandir o PSF'.

Novas metas e indicadores foram definidas para todos os eixos de intervenção da Agenda Nacional de Saúde, e houve definição de novos eixos prioritários e metas de intervenção relacionadas. Na Tabela 7 , podem-se observar as ações locais propostas, que diferem das metas definidas pelo Governo Federal e representariam problemas específicos de cada Estado. 
Tabela 7 -Demonstrativo das metas específicas das Agendas Estaduais de Saúde para 2001

\begin{tabular}{|c|c|c|c|c|c|c|c|c|c|c|c|c|c|c|c|c|c|c|}
\hline METAS ESPECÍFICAS & P & ß & $\underset{D}{\infty}$ & $\widehat{A}$ & $\underset{T}{\nabla}$ & $\stackrel{\pi}{W}$ & $\tilde{\sigma}$ & $\bar{\Omega}$ & 3 & $\bar{P}$ & $\bar{\partial}$ & 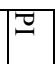 & $\bar{Z}$ & $\overline{0}$ & $\widetilde{\Omega}$ & W & 的 & $\overrightarrow{0}$ \\
\hline \multicolumn{19}{|l|}{ 1. Redução da mortalidade infantil e materna } \\
\hline Reduzir taxa de mortalidade perinatal & & & & & & & & & & $\mathbf{x}$ & & & & & & & & \\
\hline Implantar Programa Maria-Maria & & & & & & & & & & $\mathbf{x}$ & & & & & & & & \\
\hline Ampliar UBS para doenças diarreicas agudas & & & & & & & & & & & & $\mathbf{x}$ & & & & & & \\
\hline Reduzir hospitalização por diarréia & & & & & & & & & & & & $\mathbf{x}$ & & & & & & \\
\hline Estruturar e implantar casas de parto... & & & & & & & & & & & & $\mathbf{x}$ & & & & & & \\
\hline Implantar Programa de Humanização pré-natal... & & $\mathbf{x}$ & & & & & & & & & & $\mathbf{x}$ & & & & & & \\
\hline Melhorar cobertura do Sist. Inf. Mortalidade & & & & & & & & & & & & $\mathbf{x}$ & & & & & & \\
\hline Ampliar $n^{\circ}$ de redes de esgotos & & & & & & & & & & & & & $\mathbf{x}$ & & & & & \\
\hline Reduzir fatores de risco .. contaminação da água... & & & & & & & & & & & & & & & $\mathbf{x}$ & & & \\
\hline Acompanhar as gestantes adolescentes & & & & & & & & & & & $\mathbf{x}$ & & & & & & & \\
\hline Reduzir $\mathrm{n}^{\circ}$ de cesáreas & & & & & & & & & & & $\mathbf{x}$ & & & & & $\mathbf{x}$ & & \\
\hline Monitorar qualidade da água tratada & & & & & & & & & & & & & & & & $\mathbf{x}$ & & \\
\hline \multicolumn{19}{|l|}{ 2. Controle de doenças e agravos prioritários } \\
\hline Reduzir coeficiente anual tuberculose & & & & $\mathbf{x}$ & & & & & & & & & & & & & & \\
\hline Monitorar notificação Paralisia Flácida Aguda & $\mathbf{x}$ & & & & & & & & & & & & & & & & & \\
\hline Reduzir incidência de cólera & $\mathbf{x}$ & & & & & & & & & & & & & & & & & \\
\hline Reduzir letalidade por cólera & $\mathbf{x}$ & & & & & & & & & & & & & & & & & \\
\hline Reduzir prevalência de esquistossomose & $\mathbf{x}$ & & & & & & & & & & & & & & & & $\mathbf{x}$ & \\
\hline Controlar incidência calazar humano (leish. visceral) & $\mathbf{x}$ & & & & & & & & & & & & $\mathbf{x}$ & & & & & \\
\hline Reduzir letalidade de calazar humano & $\mathbf{x}$ & & & & & & & & & & & $\mathbf{x}$ & & & & & & \\
\hline Melhorar identif. intoxicação agrotóx., acid. trabalho & & & $\mathbf{x}$ & & & & & & & & & & & & & & & \\
\hline Reduzir casos novos de sífilis congênita & & & & & & & $\mathbf{x}$ & & & & & & & & & & & \\
\hline Atender violência domésica e sexual & & & & & & & $\mathbf{x}$ & & & & & & & & & & & \\
\hline Reduzir morbi-mortalidade doenças ap. circulatório & & & & & & & & & $\mathbf{x}$ & & & & & $\mathbf{x}$ & & $\mathbf{x}$ & & \\
\hline Reduzir morbi-mortalidade por diabetes & & & & & & & & & $\mathbf{x}$ & & & & & & & $\mathbf{x}$ & & \\
\hline Reduzir morbi-mortalidade por causas externas & & & & & & & & & $\mathbf{x}$ & & & & & & & $\mathbf{x}$ & & \\
\hline Reduzir casos de raiva humana & & & & & & & & & & $\mathbf{x}$ & & & & & & & & \\
\hline Reduzir incidência tétano em adultos & & & & & & & & & & & & & $\mathbf{x}$ & & & & & \\
\hline Ralizar exames para ca de mama & & & & & & & & & & & $\mathbf{x}$ & & $\mathbf{x}$ & & & $\mathbf{x}$ & $\mathbf{x}$ & \\
\hline Reduzir incidncia ca de próstata & & & & & & & & & & & & & $\mathbf{x}$ & & & & & \\
\hline Reduzir tabagismo & & & & & & & & & & & & & $\mathbf{x}$ & & & & & \\
\hline Reduzir letalidade da leishmaniose tegumentar & & & & & & & & & & & $\mathbf{x}$ & & $\mathbf{x}$ & & & & & \\
\hline Intensificar ação Núcleos Atenção ao Chagásico & & & & & & & & & & & & & $\mathbf{x}$ & & & & & \\
\hline Identificar \% meningites bacterianas confirmadas... & & & & & & & & & & & & & & & $\mathbf{x}$ & & & \\
\hline Monitorar casos de hantavirose & & & & & & & & & & & $\mathbf{x}$ & & & & $\mathbf{x}$ & & & \\
\hline Aumentar notificações de cisticercose & & & & & & & & & & & & & & & $\mathbf{x}$ & & & \\
\hline Ampliar distrib. grat. medicamentos hipert. diabetes... & & & & & & & & & & & & & & & $\mathbf{x}$ & & & \\
\hline Ampliar vigilância agravos subst. químicas perigosas & & & & & & & & & & & & & & & $\mathbf{x}$ & & & \\
\hline Reduzir coeficiente mortalidade fem. ca de mama & & & & & & & & & & & & & & & $\mathbf{x}$ & & & \\
\hline Implantar sistema detecção bucal & & & & & & & & & & & & & & & & & $\mathbf{x}$ & \\
\hline
\end{tabular}




\begin{tabular}{|c|c|c|c|c|c|c|c|c|c|c|c|c|c|c|c|c|c|c|c|}
\hline METAS ESPECÍFICAS & 巴 & B & $\underset{D}{\nabla}$ & ति & $\operatorname{T}_{T}$ & 㸗 & Q & Q & 疋 & $\bar{D}$ & $\bar{\partial}$ & $\Xi$ & $\bar{\pi}$ & & & $\bar{\Omega}$ & $\mathscr{\sigma}$ & 丽 & $\overline{0}$ \\
\hline Controle de doenças imunopreviníveis & & & & & & & & & & & & & & $x$ & & & & & \\
\hline Reduzir $\mathrm{n}^{\circ}$ casos influenza em idosos & & & & & & & & & & & $\mathbf{x}$ & & & & & & & & \\
\hline Implantar Vig. Epid. sífilis congênita & & & & & & & & & & & $\mathbf{x}$ & & & & & & & & \\
\hline Implantar invest. lab. do HIV no pré-natal & & & & & & & & & & & $\mathbf{x}$ & & & & & & & & \\
\hline Reduzir $\mathrm{n}^{\circ}$ casos acidentes de trabalho & & & & & & & & & & & $\mathbf{x}$ & & & & & & $\mathbf{x}$ & & \\
\hline Aumentar detecção tuberculose pulmonar & & & & & & & & & & & & & & & & & $\mathbf{x}$ & & \\
\hline Implantar sist. acompanhamento transt. mentais & & & & & & & & & & & & & & & & & $\mathbf{x}$ & & \\
\hline Melhorar proc. coletivos saúde bucal & & & & & & & & & & & & & & & & & $\mathbf{x}$ & & \\
\hline Redução de casos de leptospirose & & $\mathbf{x}$ & & & & & & & & & & & & & & & & & \\
\hline Redução de casos de leishmaniose & & $\mathbf{x}$ & & & & & & & & & & & & & & & & & \\
\hline & & & & & & & & & & & & & & & & & & & \\
\hline 3. Melhoria da gestão, do acesso e da qualidade... & & & & & & & & & & & & & & & & & & & \\
\hline Operacionalizar Assist. Farmacêutica Básica & $\mathbf{x}$ & & & & & & & & & & & & & $x$ & & & $\mathbf{x}$ & & \\
\hline Aumentar oferta de transplantes & $\mathbf{x}$ & & $\mathbf{x}$ & $\mathbf{x}$ & $\mathbf{x}$ & $\mathbf{x}$ & $\mathbf{x}$ & $\mathbf{x}$ & $\mathbf{x}$ & $\mathbf{x}$ & $\mathbf{x}$ & $\mathbf{x}$ & $\mathbf{x}$ & & $\mathbf{x}$ & $\mathbf{x}$ & $\mathbf{x}$ & $\mathbf{x}$ & $\mathbf{x}$ \\
\hline Fiscalizar unidades de hemodiálise & $\mathbf{x}$ & & & & & & $\mathbf{x}$ & $\mathbf{x}$ & & & & & & & $\mathbf{x}$ & $\underline{x}$ & $\mathbf{x}$ & & \\
\hline Fiscalizar farmácias de manipulação & $\mathbf{x}$ & & & & & & & & & & & & & & $\mathrm{x}$ & & & & \\
\hline Melhorar qualidade, utilização, ... inf. em saúde & $\mathbf{x}$ & & & & & & & & & & & & & & & & & & \\
\hline Fornecer medicamentos essenciais & & & & & $\mathbf{x}$ & & & & & & & & & & & & & & \\
\hline Estimular cadastramento de profissionais de saúde & & & & & & & & & & $\mathbf{x}$ & & & & & & & & & \\
\hline Implementar a Rede Estadual de Inf. em Saúde & & & & & & & & & & $\mathbf{x}$ & & & & & & & & & \\
\hline Melhorar assist. medic. especiais e excepcionais & & & & & & & & & & $\mathbf{x}$ & & & & & & & & & \\
\hline Implementar ações de Vigilância Sanitária & & & & & & & & & & $\mathbf{x}$ & & & & & & & & & \\
\hline Implementar ações de Vigilância Epidemiológica & & & & & & & & & & $\mathbf{x}$ & & & & & & & & & \\
\hline Estruturar Vigilância Ambiental em Saúde & & & & & & & & & & $\mathbf{x}$ & & & & & & & & & \\
\hline Qualificar.... Sist. Auditoria, Controle e Avaliação & & & & & & & & & & $\mathbf{x}$ & & & $\mathbf{x}$ & & & & $\mathrm{x}$ & & \\
\hline Ampliar e melhorar ... Sist. Nac. de Informação & & & & & & & & & & $\mathbf{x}$ & & & & 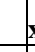 & $\mathrm{x}$ & & & & \\
\hline Implantar Comissões Bipartites Regionais & & & & & & & & & & & & $\mathbf{x}$ & & & & & & & \\
\hline Implantar Coord. Controle de cronico degenerativas & & & & & & & & & & & & $\mathbf{x}$ & & & & & & & \\
\hline Estruturar Escritórios Regionais de Saúde & & & & & & & & & & & & $\mathbf{x}$ & & & & & & & \\
\hline Implementação.... apoio política de saúde & & & & & & & & & & & & & $\mathbf{x}$ & & & & & & \\
\hline Estruturar atividade de regulação & & $\mathbf{x}$ & & & & & & & & & & & $\mathbf{x}$ & & & & $\mathbf{x}$ & & \\
\hline Ampliar inspeção lab. análises clínicas & & & & & & & & & & & & & & & $\mathbf{x}$ & $\mathrm{x}$ & & & \\
\hline Ampliar inspeção unidades hospitalares & & & & & & & & & & & & & & & $\mathrm{x}$ & & & & \\
\hline Municipalizar instituições hospitalares... & & & & & & & & & & & & & & & $\mathbf{x}$ & $\mathbf{x}$ & & & \\
\hline Ampliar $\mathrm{n}^{\circ}$ leitos de UTI & & & & & & & & & & & $\mathbf{x}$ & & & & & & & & \\
\hline Implementar Rede de Proteção à Vida & & & & & & & & & & & $\mathbf{x}$ & & & & & & & & \\
\hline Implementar Rede Urgências Emergências & & & & & & & & & & & $\mathbf{x}$ & & & & & & & & \\
\hline Implementar investimentos obras Hemorrede & & & & & & & & & & & $\mathbf{x}$ & & & & & & & & \\
\hline Implementar Rede do Frio & & & & & & & & & & & $\mathbf{x}$ & & & & & & & & \\
\hline Fiscalizar estab. saúde alta complexidade & & & & & & & & & & & $\mathbf{x}$ & & & & & & & & \\
\hline Fiscalizar estab. saúde média complexidade & & & & & & & & & & & $\mathbf{x}$ & & & & & & & & \\
\hline Implementar Prog. Est. Assist. Farm. Saúde Mental & & & & & & & & & & & & & & & & & $\mathbf{x}$ & & \\
\hline Manut. Prog. Medicamentos Alto Custo & & & & & & & & & & & & & & & & & $x$ & & \\
\hline Supervisionar serviços Vig. Sanitária & & & & & & & & & & & & & & & & & $\mathbf{x}$ & & \\
\hline Descentralização de Estab. de Saúde... & & $\mathbf{x}$ & & & & & & & & & & & & & & & & & \\
\hline
\end{tabular}




\begin{tabular}{|c|c|c|c|c|c|c|c|c|c|c|c|c|c|c|c|c|c|c|}
\hline METAS ESPECÍFICAS & $\mathbb{R}$ & B & & बि & $\bar{\nabla}$ & \begin{tabular}{|l|l|} 
藏 & \\
\end{tabular} & Q & Zె & 3 & $\vec{p}$ & $\bar{\partial}$ & $\Xi$ & $\bar{Z}$ & $\bar{Z}$ & $\tilde{\Omega}$ & $\bigoplus$ & 需 & $\bar{\sigma}$ \\
\hline \multicolumn{19}{|l|}{ 4. Reorientação do modelo assistencial... } \\
\hline Implantar atenção SUS a deficientes físicos & $\mathbf{x}$ & & & & & & & & & & & & & & & & & \\
\hline Aumentar procedimentos odontológicos coletivos & & & & & & $\mathbf{x}$ & $\underline{\mathbf{x}}$ & & & & & $\mathbf{x}$ & & & & & & \\
\hline Implantar sub-secretarias & & & & & & $\mathbf{x}$ & $\mathbf{x}$ & & & & & & & & & & & \\
\hline Implantar Centros Regionais Saúde Trabalhador & & & & & & $\mathbf{x}$ & $\mathbf{x}$ & & & & & & & & & & & \\
\hline Implantar Conselhos Regionais de Saúde & & & & & & $\mathbf{x}$ & $\mathbf{x}$ & & & & & & & & & & & \\
\hline Expandir equipes saúde bucal no PSF & & & & & & & & & $\mathbf{x}$ & & & & & $\mathbf{x}$ & & $\mathbf{x}$ & & \\
\hline Descentralizar Apoio Diagnóstico e Terapêutico & & & & & & & & & & $\mathbf{x}$ & & & & & & & & \\
\hline Estruturar Redes de Referência & & & & & & & & & & $\mathbf{x}$ & & & & & & & & \\
\hline Estimular implantação Prog. Humanização Parto... & & & & & & & & & & $\mathbf{x}$ & & & & & & & & \\
\hline \multicolumn{19}{|l|}{ Reduzir $\mathrm{n}^{\circ}$ cesáreas } \\
\hline Ampliar oferta tratamentos alternat. saúde mental & & & & & & & & & & & & $\mathbf{x}$ & & & & & & \\
\hline Reduzir taxa de hospitalização & & & & & & & & & & & & $\mathbf{x}$ & & & & & & \\
\hline \multicolumn{19}{|l|}{ Ampliar consultas especialidades básicas } \\
\hline Construir redes ref. saúde mental e reprodutiva & & & & & & & & & & & & & $\mathbf{x}$ & & & & & \\
\hline Habilitar municípios segundo NOAS/2001 & & & & & & & & & & & & & $\mathbf{x}$ & & & & & \\
\hline Criar Prog. Assist. para dependência química & & & & & & & & & & & & & $\mathbf{x}$ & & & & & \\
\hline \multicolumn{19}{|l|}{ Efetivar as PPI (assistência e vigilâncias)... } \\
\hline Transf. gastos saúde mental para at. ambulatorial & & & & & & & & & & & $\mathbf{x}$ & & & & & & & \\
\hline Ampliar rec. pp em ações e serviços saúde & & & & & & & & & & & $\mathrm{x}$ & & & & & & & \\
\hline Ampliar acesso serv. Saúde bucal & & & & & & & & & & & & & & & & $\mathbf{x}$ & & \\
\hline Aprimorar fornec. órteses, próteses... & & & & & & & & & & & & & & & & $\mathbf{x}$ & & \\
\hline Criação Núcleos de Reabilitação deficientes & & & & & & & & & & & & & & & & $\mathbf{x}$ & & \\
\hline Ampliar rede equip. extra-hosp. Saúde mental & & & & & & & & & & & & & & & & $\mathbf{x}$ & & \\
\hline \multicolumn{19}{|l|}{ 5. Desenvolvimento de RH em saúde } \\
\hline Capacitar gerentes de Centros de Saúde & & & & $\mathbf{x}$ & $\mathbf{x}$ & & & & & & & & & & & & & \\
\hline Capacitar técnicos de Vigilância Sanitária & & & & & & & & $\mathbf{x}$ & & & & & & & $\mathbf{x}$ & & & \\
\hline Treinar profissionais redes estratégicas referência & & & & & & & & & & & & & $\mathbf{x}$ & & & & & \\
\hline Treinar equipes regionais e CIS & & & & & & & & & & & & & $\mathbf{x}$ & & & & & \\
\hline Treinar técnicos para processamento dados SIS & & & & & & & & & & & & & $\mathbf{x}$ & & & & & \\
\hline \multicolumn{19}{|l|}{ Capacitar técnicos em fármacia } \\
\hline Realizar concurso público trabalhadores saúde & & & & & & & & & & & & & & & $\mathbf{x}$ & & & \\
\hline Adequar disfunções funcionais... & & & & & & & & & & & & & & & $\mathbf{x}$ & & & \\
\hline Inspecionar cursos profissionalizantes em saúde & & & & & & & & & & & & & & & $\mathbf{x}$ & & & \\
\hline Qualificar auxiliares de enfermagem em técnicos... & & & & & & & & & & & & & & & $\mathbf{x}$ & & & \\
\hline Implementar Plano de Cargos, Carreira e Salários... & & & & & & & & & & & & & & & $\mathbf{x}$ & & & \\
\hline Propor recomposição do poder de compra. & & & & & & & & & & & & & & & $\mathbf{x}$ & & & \\
\hline Formar... trab. nível básico e técnico & & & & & & & & & & & $\mathbf{x}$ & & & & & & & \\
\hline Capacitação profissionais qualidade serviços & & & & & & & & & & & & & & & & $\mathbf{x}$ & & \\
\hline Implantar Escola de Saúde & & $\mathbf{x}$ & & & & & & & & & & & & & & & & \\
\hline & & & & & & & & & & & & & & & & & & \\
\hline
\end{tabular}




\begin{tabular}{|c|c|c|c|c|c|c|c|c|c|c|c|c|c|c|c|c|c|}
\hline METAS ESPECÍFICAS & $\mathbb{R}$ & $B$ & $\mid \vec{D}$ & A & \begin{tabular}{|l|l}
$\overrightarrow{1}$ \\
\end{tabular} & 露 & $\bar{O}$ & 尚 & $\vec{P}$ & $\bar{\nabla}$ & $\bar{Z}$ & $\bar{Z}$ & 즌 & $\tilde{\Omega}$ & $\widetilde{\Omega}$ & 魚 & $\overline{0}$ \\
\hline \multicolumn{18}{|l|}{ 6. Qualificação do Controle Social } \\
\hline Incentivar estrutura Conselhos de Saúde & $\mathbf{x}$ & & & & & & & & & & & & & & & & \\
\hline Qualificar o controle social & & & & & & & & & & & & & & $\mathbf{x}$ & & & \\
\hline Intensificar fiscalização do funcionamento do CMS & & & & & & & & & & & & & & $\mathbf{x}$ & & & \\
\hline Ampliar Conf. Municipais de Saúde & & & & & & & & & & $\mathbf{x}$ & & & & & & & \\
\hline Expandir o controle social (conselhos gestores) & & & & & & & & & & & & & & $\mathbf{x}$ & & & \\
\hline Auditar Conselhos Municipais de Saúde & & & & & & & & & & $\mathbf{x}$ & & & & & & & \\
\hline Capacitar componentes Comissões Permanentes & & & & & & & & & & $\mathbf{x}$ & & & & & & & \\
\hline Realizar Ofic. Temáticas Controle Social & & & & & & & & & & $\mathbf{x}$ & & & & & & & \\
\hline Realizar plenárias estaduais Controle Social & & & & & & & & & & $\mathbf{x}$ & & & & & & & \\
\hline Editar Manual de Controle Social & & & & & & & & & & $\mathbf{x}$ & & & & & & & \\
\hline & & & & & & & & & & & & & & & & & \\
\hline \multicolumn{18}{|l|}{ Cumprimento dos Pactos entre gestores } \\
\hline Avaliar cumprimento do $\mathrm{PAB}$ & & & & & & $\mathbf{x}$ & & & & & & & & & & & \\
\hline & & & & & & & & & & & & & & & & & \\
\hline \multicolumn{18}{|l|}{ Melhoria da produção, .... Farmácia Básica } \\
\hline Produzir medicamentos da Farmácia Básica & & & & & & & $\mathbf{x}$ & & & & & & & & & & \\
\hline Produzir soros e vacinas & & & & & & & $\mathbf{x}$ & & & & & & & & & & \\
\hline \multicolumn{18}{|l|}{ Ampliação da oferta de sangue Hemorrede } \\
\hline Ofertar sangue e hemoderivados & & & & & & & $\mathbf{x}$ & & & & & & & & & & \\
\hline Atender doenças hematológicas hereditárias & & & & & & & $\mathbf{x}$ & & & & & & & & & & \\
\hline Consolidar Hemorrede Estadual & & & & & & & $\mathbf{x}$ & & & & & & & & & & \\
\hline Capacitar RH & & & & & & & $\mathbf{x}$ & & & & & & & & & & \\
\hline Produzir conhecimento técnico-científico & & & & & & & $\mathbf{x}$ & & & & & & & & & & \\
\hline & & & & & & & & & & & & & & & & & \\
\hline \multicolumn{18}{|l|}{ Qualificação e melhoria da Rede da FHEMIG } \\
\hline Prestar serviço médico urgências e emergências & & & & & & & $\mathbf{x}$ & & & & & & & & & & \\
\hline Formar especialistas médicos & & & & & & & $\mathbf{x}$ & & & & & & & & & & \\
\hline Readequar e melhorar rede física e predial & & & & & & & $\mathbf{x}$ & & & & & & & & & & \\
\hline
\end{tabular}

Fonte: Agendas Estaduais de Saúde (referenciadas na bibliografia) 
É interessante notar que foram acrescentadas algumas metas relacionadas à produção e utilização de informações em saúde e também científicas e técnicas:

- a Secretaria Estadual de Saúde de Minas Gerais acrescentou o Eixo Ampliação da oferta de sangue Hemorrede -, com uma meta específica para 'Produzir conhecimento técnico-científico';

- a Secretaria Estadual de Saúde do Paraná, dentro do Eixo 6 Qualificação do Controle Social -, propôs 'Editar Manual de Controle Social';

- as Secretarias do Paraná, Rio de Janeiro e Santa Catarina, dentro do Eixo 3 - Melhoria da gestão, do acesso e da qualidade... -, propuseram estratégias como: 'Implementar a Rede Estadual de Informação em Saúde’ (Paraná) e 'Ampliar e melhorar o Sistema Nacional de Informação em Saúde'.

Os estudos sobre uso da informação na tomada de decisão mostraram que as agendas de pesquisa nas universidades e nos institutos poderiam diferir das agendas de prioridades definidas pelos sistemas de saúde e que a informação científica e técnica nem sempre seria produzida com o enfoque em resultados na ação dos serviços de saúde. Mostraram também que não haveria uma linearidade entre a pesquisa e a tomada de decisão e que seria mais comum que a situação epidemiológica local, ou uma necessidade da prática dos serviços, induzisse a uma pesquisa, e não o contrário (FRENK 1992a, POUVORVILLE 1999, TROSTLE et al. 1999, BRONFMAN et al. 2000, STONE 2001).

Para verificar se haveria alguma correspondência entre prioridades definidas no nível local nas Agendas de Saúde e a literatura científica e técnica registrada nas bases de dados, foram analisadas duas metas selecionadas aleatoriamente: 'Aumentar a notificação de cisticercose' (Santa Catarina) e 'Reduzir incidência de cólera e letalidade por cólera' (Alagoas). 
Para a pesquisa de cisticercose na literatura nacional, localizaram-se:

- 23 documentos na LILACS-SP Brasil;

- 6 na base de dados do acervo do Ministério da Saúde;

- 12 na base de dados do acervo da Escola Nacional de Saúde Pública;

- 22 na base de dados do acervo da Biblioteca da Faculdade de Saúde Pública.

Foram encontrados dois trabalhos sobre essa doença em Santa Catarina, de uma mesma autora (publicados em 1996 e 1997, respectivamente). Houve maior concentração de documentos sobre ocorrência de cisticercose nos Estados de São Paulo e de Minas Gerais.

A pesquisa sobre cólera produziu um resultado de 322 documentos, assim distribuídos:

- 73 na LILACS-SP Brasil;

- 27 na AdSAÚDE;

- 108 na base de dados do acervo do Ministério da Saúde;

- 46 na base de dados do acervo da Escola Nacional de Saúde Pública;

- 68 na base de dados do acervo da Biblioteca da Faculdade de Saúde Pública.

Não foram encontrados trabalhos que sugerissem uma maior prevalência ou incidência dessa doença no Estado de Alagoas.

Os resultados sugeriram que a determinação de metas e prioridades locais definidas nas Agendas não poderia ter sido subsidiada pela literatura técnico-científica correspondente. No entanto, esta poderia servir como subsídio para tomada de decisão enquanto a medidas a serem tomadas, baseadas nas experiências relatadas na literatura. 


\subsection{Análise descritiva dos sites do Ministério e das Secretarias Estaduais de Saúde}

O primeiro resultado encontrado foi a própria existência de sites em praticamente todas as Secretarias Estaduais de Saúde (só não foi possível ter acesso ao de Rondônia, embora o endereço tivesse sido citado em sites de outras Secretarias de Saúde). A existência dos sites, com o conteúdo que neles foi observado, poderia indicar que o novo paradigma da internet está sendo aceito e assimilado pelos órgãos governamentais da Saúde como fonte de informação - dirigida tanto à população em geral e aos profissionais da área da saúde quanto aos gestores - e de apoio ao desenvolvimento do SUS, além de espaço para exercício da cidadania e da gestão descentralizada em saúde.

O uso da internet foi destacado pela Secretaria de Estado da Saúde de São Paulo*:

A construção de uma rede estadual de informações constitui-se no principal objetivo da Secretaria de Estado enquanto estratégia para a disseminação das informações em saúde. Para garantir acesso à informação a todos os gestores do SUS e cidadãos são necessárias mídias diversificadas e adequadas às regiões do Estado. Entre as mídias destaca-se o uso da internet, em especial, para a comunicação entre redes locais (municípios), regionais, a estadual e a Rede Nacional de Informações de Saúde - RNIS, em construção.

No site da Secretaria de Estado da Saúde do Rio de Janeiro, no texto sobre a Rede Estadual de Informações em Saúde**, também foi manifestada a opção pela internet para a gestão descentralizada dos municípios:

\footnotetext{
* Trecho extraído do texto de 'Apresentação' do site da Secretaria de Estado da Saúde de São Paulo. Disponível em: http://www.saude.sp.gov.br/html/fr_apres.htm

** Trecho extraído do site da Secretaria de Estado da Saúde do Rio de Janeiro. Disponível em: http://www.saude.rj.gov.br/site cisa/gestao_informa.shtml
} 
Todas as Secretarias Municipais de Saúde (SMS) do Estado receberam equipamentos e apoio técnico necessários ao estabelecimento da infra-estrutura de comunicação via Internet. (....) Coerente com o compromisso da transparência na gestão, o CISA [Centro de Informações em Saúde] desenvolveu opções de site para as SMS (e os "hospeda" quando necessário) que optaram pelo modelo e conteúdo que melhor se adeqüe às suas peculiaridades, com o objetivo de garantir um espaço de disseminação das informações em saúde de cada município do Estado. Permite o intercâmbio de informações para a gestão, planejamento, epidemiologia e atualização da equipe da SMS, com os profissionais podendo acessar, por exemplo, as bibliotecas virtuais existentes no Brasil e no mundo e participarem de Cursos que utilizam metodologia de educação à distância via Internet, como o Curso "Processos de Gestão e Tecnologias de Informação”, desenvolvido pelo CISA em conjunto com a ENSP/Fiocruz.

A iniciativa da Secretaria de Estado da Saúde do Rio de Janeiro de construir modelos de sites para as Secretarias Municipais de Saúde pareceu interessante. Cada município podia escolher o modelo que mais lhe agradasse, mas havia informações comuns a todos por sugestão da Secretaria Estadual, como, por exemplo, a página de links. Quando o site do Rio de Janeiro foi analisado, cerca de 50\% dos municípios havia adotado um dos modelos disponíveis, e, desses, $5 \%$ havia acrescentado novos links, o que poderia indicar apropriação do modelo com adaptação à realidade local. 
O resultado global da análise dos sites foi esquematizado na Tabela 8 e no Anexo 6 foram apresentados os resultados para cada site, por ordem alfabética de Estado.

Observa-se que, quanto à sua organização, a maioria usava uma estrutura de portal de informações, com notícias em destaque, links, acesso a produtos e serviços, já na página inicial. Os sites em geral mostraram ser bem estruturados e de fácil identificação dos conteúdos em cada uma das seções, representando, com raras exceções, ambientes agradáveis para consulta. A estrutura, embora diferenciada em termos da terminologia adotada, mostrou várias subdivisões comuns: estrutura organizacional, indicadores de saúde, informações de saúde, informações sobre programas, serviços e campanhas, links úteis e notícias.

Nem sempre ficou clara a data de atualização dos sites ou dos conteúdos dos mesmos. Apenas os das Secretarias da Saúde da Bahia, do Paraná e de São Paulo traziam data de atualização do site, e em muitos outros havia apenas data de atualização de alguns conteúdos informativos. Pela tabela 8, pode-se observar que apenas oito sites foram considerados desatualizados.

O conteúdo encontrado foi bastante variado: notícias, links, indicadores estatísticos, diretórios de serviços e instituições de saúde, textos completos de legislação, manuais, informes epidemiológicos, perguntas mais freqüentes, documentos de gestão e outras publicações técnicas das Secretarias. As categorias utilizadas para a análise do conteúdo foram: informações sobre estrutura institucional; indicadores; informações técnicas sobre os municípios e sobre programas e serviços; legislação; notícias e informações específicas para os gestores. Considerou-se a RNIS um item específico, pois mereceu destaque na maioria dos sites: foram encontrados textos informativos sobre esta Rede e sobre avaliação da participação dos Estados nela, além dos links para acesso e cadastramento dos municípios. 
Tabela 8 - Análise descritivas dos sites das Secretarias Estaduais de Saúde

\begin{tabular}{|c|c|c|c|c|c|c|c|c|c|c|c|c|c|c|c|c|c|c|c|c|}
\hline \multirow{2}{*}{$\begin{array}{l}\mathbf{S} \\
\mathbf{E} \\
\mathbf{S}\end{array}$} & \multirow[b]{2}{*}{ 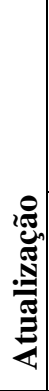 } & \multicolumn{8}{|c|}{ Conteúdo } & \multicolumn{6}{|c|}{ Links } & \multicolumn{2}{|c|}{ 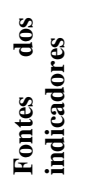 } & \multicolumn{3}{|c|}{ ICT } \\
\hline & & 节 & 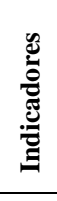 & $\stackrel{\Omega}{Z}$ & 蒿 & 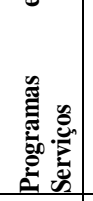 & 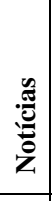 & 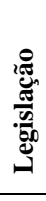 & 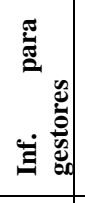 & 氛 & $\sum^{\infty}$ & 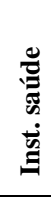 & 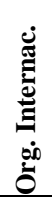 & 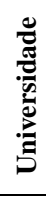 & zే & 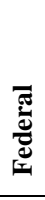 & 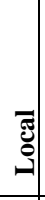 & 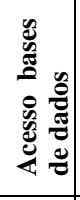 & है & 总 \\
\hline $\mathbf{A C}$ & $\mathbf{N}$ & $\mathbf{x}$ & $\mathbf{x}$ & $\mathbf{x}$ & $\mathbf{x}$ & $\mathbf{x}$ & & & & $\mathbf{x}$ & $\mathbf{x}$ & $\mathbf{x}$ & $\mathbf{x}$ & $\mathbf{x}$ & $\mathbf{x}$ & $\mathbf{x}$ & & $\mathbf{x}$ & & \\
\hline $\mathbf{A L}$ & $\mathbf{S}$ & $\begin{array}{l}\mathbf{x} \\
\end{array}$ & $\begin{array}{l}\mathbf{x} \\
\end{array}$ & $\begin{array}{l}\mathbf{x} \\
\end{array}$ & $\mathbf{x}$ & $\mathbf{x}$ & $\bar{x}$ & & & $\begin{array}{l}\mathbf{x} \\
\end{array}$ & $\mathbf{x}$ & & $\begin{array}{l}\mathbf{x} \\
\end{array}$ & & & $\mathbf{x}$ & & & & \\
\hline $\mathbf{A P}$ & $\mathbf{N}$ & & $\bar{x}$ & $\begin{array}{l}\mathbf{x} \\
\end{array}$ & $\mathbf{x}$ & $\bar{x}$ & $\begin{array}{l}\mathbf{x} \\
\end{array}$ & & $\begin{array}{l}\mathbf{x} \\
\end{array}$ & $\begin{array}{l}\mathbf{x} \\
\end{array}$ & & $\mathbf{x}$ & & & & $\mathbf{x}$ & $\begin{array}{l}\mathbf{x} \\
\end{array}$ & & & \\
\hline $\mathbf{A M}$ & $\mathbf{S}$ & $\mathbf{x}$ & $\begin{array}{l}\mathbf{x} \\
\end{array}$ & $\begin{array}{l}\mathbf{x} \\
\end{array}$ & $\bar{x}$ & $\bar{x}$ & & $\begin{array}{l}\mathbf{x} \\
\end{array}$ & $\mathbf{x}$ & & & & & & & $\mathbf{x}$ & $\mathbf{x}$ & & & \\
\hline BA & $\mathbf{S}$ & $\mathbf{x}$ & & & & $\bar{x}$ & $\begin{array}{l}\mathbf{x} \\
\end{array}$ & & & $\begin{array}{l}\mathbf{x} \\
\end{array}$ & $\begin{array}{l}\mathbf{x} \\
\end{array}$ & $\mathbf{x}$ & & $\begin{array}{l}\mathbf{x} \\
\end{array}$ & $\begin{array}{l}\mathbf{x} \\
\end{array}$ & & & & $\begin{array}{l}\mathbf{x} \\
\end{array}$ & \\
\hline $\mathrm{CE}$ & $\mathbf{S}$ & $\mathbf{x}$ & $\mathbf{x}$ & & & & & & $\mathbf{x}$ & & $\mathbf{x}$ & $\mathbf{x}$ & & $\mathbf{x}$ & & $\mathbf{x}$ & $\mathbf{x}$ & & & $\mathbf{x}$ \\
\hline DF & $\mathbf{S}$ & & & $\mathbf{x}$ & & & $\mathbf{x}$ & & & $\mathbf{x}$ & $\mathbf{x}$ & $\mathbf{x}$ & $\mathbf{x}$ & $\mathbf{x}$ & & $\mathbf{x}$ & & & & $\mathbf{x}$ \\
\hline ES & $\mathbf{S}$ & $\mathbf{x}$ & $\mathbf{x}$ & $\mathbf{x}$ & & & & $\mathbf{x}$ & $\mathbf{x}$ & $\begin{array}{l}\mathbf{x} \\
\end{array}$ & $\mathbf{x}$ & $\mathbf{x}$ & $\begin{array}{l}\mathbf{x} \\
\end{array}$ & $\begin{array}{l}\mathbf{x} \\
\end{array}$ & & $\mathbf{x}$ & & & & $\mathbf{x}$ \\
\hline GO & $\mathbf{N}$ & & & & & $\mathbf{x}$ & & & & & $\mathbf{x}$ & & & & & & & & & \\
\hline MA & $\mathbf{S}$ & $\mathbf{x}$ & & $\mathbf{x}$ & $\mathbf{x}$ & $\mathbf{x}$ & & & & & $\mathbf{x}$ & & & & & & & & & \\
\hline MT & $\mathbf{S}$ & & $\mathbf{x}$ & & & & $\mathbf{x}$ & $\mathbf{x}$ & $\mathbf{x}$ & & & & & & & $\mathbf{x}$ & $\mathbf{x}$ & & & \\
\hline MS & $\mathbf{S}$ & $\mathbf{x}$ & & & & $\mathbf{x}$ & $\mathbf{x}$ & & & & $\mathbf{x}$ & $\mathbf{x}$ & & & & & & & & \\
\hline MG & $\mathbf{N}$ & $\mathbf{x}$ & $\mathbf{x}$ & $\begin{array}{l}\mathbf{x} \\
\end{array}$ & & $\begin{array}{l}\mathbf{x} \\
\end{array}$ & & & & & $\begin{array}{l}\mathbf{x} \\
\end{array}$ & $\mathbf{x}$ & & & & $\mathbf{x}$ & \begin{tabular}{|l|l|}
$\mathbf{x}$ & \\
\end{tabular} & & $\begin{array}{l}\mathbf{x} \\
\end{array}$ & \\
\hline PA & $\mathbf{S}$ & $\mathbf{x}$ & $\mathbf{x}$ & & & & $\mathbf{x}$ & $\mathbf{x}$ & $\mathbf{x}$ & & $\mathbf{x}$ & $\mathbf{x}$ & & & & $\mathbf{x}$ & $\mathbf{x}$ & & $\mathbf{x}$ & \\
\hline PB & $\mathbf{N}$ & & & $\mathbf{x}$ & & & & & & $\begin{array}{l}\mathbf{x} \\
\end{array}$ & $\begin{array}{l}\mathbf{x} \\
\end{array}$ & $\mathbf{x}$ & & & & & & & & \\
\hline PR & $\mathbf{S}$ & $\mathbf{x}$ & & $\mathbf{x}$ & $\mathbf{x}$ & $\mathbf{x}$ & $\mathbf{x}$ & $\mathbf{x}$ & $\mathbf{x}$ & & & & & & & & $\mathbf{x}$ & $\mathbf{x}$ & $\mathbf{x}$ & $\mathbf{x}$ \\
\hline PE & $\mathbf{S}$ & & & & & & $\mathbf{x}$ & & & $\begin{array}{l}\mathbf{x} \\
\end{array}$ & $\mathbf{x}$ & $\mathbf{x}$ & $\begin{array}{l}x \\
\end{array}$ & & & & & & & \\
\hline PI & $\mathbf{N}$ & & $\mathbf{x}$ & & & & & & & $\begin{array}{l}\mathbf{x} \\
\end{array}$ & $\begin{array}{l}\mathbf{x} \\
\end{array}$ & $\mathbf{x}$ & $\mathbf{x}$ & & $\begin{array}{l}\mathbf{x} \\
\end{array}$ & $\mathbf{x}$ & & & & $\begin{array}{l}x \\
\end{array}$ \\
\hline $\mathbf{R N}$ & $\mathbf{N}$ & & & & & & & & $\begin{array}{l}\mathbf{x} \\
\end{array}$ & $\begin{array}{l}\mathbf{x} \\
\end{array}$ & & & & & & $\mathbf{x}$ & & & & \\
\hline $\mathbf{R S}$ & $\mathbf{S}$ & $\mathbf{x}$ & $\mathbf{x}$ & & & & & $\mathbf{x}$ & $\mathbf{x}$ & $\mathbf{x}$ & $\mathbf{x}$ & $\mathbf{x}$ & $\mathbf{x}$ & & & & & & & $\mathbf{x}$ \\
\hline RJ & $\mathbf{S}$ & $\bar{x}$ & $\bar{x}$ & $\begin{array}{l}\mathbf{x} \\
\end{array}$ & $\begin{array}{l}\mathbf{x} \\
\end{array}$ & & & $\mathbf{x}$ & $\begin{array}{l}\mathbf{x} \\
\end{array}$ & $\begin{array}{l}\mathbf{x} \\
\end{array}$ & $\begin{array}{l}\mathbf{x} \\
\end{array}$ & $\mathbf{x}$ & $\begin{array}{l}\mathbf{x} \\
\end{array}$ & $\begin{array}{l}\mathbf{x} \\
\end{array}$ & $\begin{array}{l}\mathbf{x} \\
\end{array}$ & $\mathbf{x}$ & & & & $\begin{array}{l}x \\
\end{array}$ \\
\hline $\mathbf{R R}$ & $\mathbf{S}$ & $\begin{array}{l}\mathbf{x} \\
\end{array}$ & $\mathbf{x}$ & $\mathbf{x}$ & $\mathbf{x}$ & $\begin{array}{l}\mathbf{x} \\
\end{array}$ & $\mathbf{x}$ & & & $\begin{array}{l}\mathbf{x} \\
\end{array}$ & $\mathbf{x}$ & $\mathbf{x}$ & & & & $\begin{array}{l}x \\
\end{array}$ & \begin{tabular}{l|l}
$\mathbf{x}$ \\
\end{tabular} & & & $\begin{array}{l}\mathbf{x} \\
\end{array}$ \\
\hline $\mathbf{S C}$ & $\mathbf{S}$ & $\mathbf{x}$ & $\mathbf{x}$ & $\mathbf{x}$ & $\begin{array}{l}\mathbf{x} \\
\end{array}$ & $\begin{array}{l}\mathbf{x} \\
\end{array}$ & $\begin{array}{l}\mathbf{x} \\
\end{array}$ & $\begin{array}{l}\mathbf{x} \\
\end{array}$ & $\begin{array}{l}\mathbf{x} \\
\end{array}$ & $\begin{array}{l}\mathbf{x} \\
\end{array}$ & $\begin{array}{l}\mathbf{x} \\
\end{array}$ & $\mathbf{x}$ & $\begin{array}{l}\mathbf{x} \\
\end{array}$ & $\mathbf{x}$ & $\mathbf{x}$ & $\begin{array}{l}\mathbf{x} \\
\end{array}$ & \begin{tabular}{l|l}
$\mathbf{x}$ \\
\end{tabular} & $\begin{array}{l}x \\
\end{array}$ & $\begin{array}{l}\mathbf{x} \\
\end{array}$ & $\begin{array}{l}\mathbf{x} \\
\end{array}$ \\
\hline SP & $\mathbf{S}$ & $\mathbf{x}$ & $\mathbf{x}$ & & $\mathbf{x}$ & $\begin{array}{l}x \\
\end{array}$ & $\begin{array}{l}\mathbf{x} \\
\end{array}$ & $\mathbf{x}$ & $\begin{array}{l}\mathbf{x} \\
\end{array}$ & $\mathbf{x}$ & $\begin{array}{l}x \\
\end{array}$ & $\mathbf{x}$ & $\begin{array}{l}\mathbf{x} \\
\end{array}$ & $\begin{array}{l}\mathbf{x} \\
\end{array}$ & $\mathbf{x}$ & & \begin{tabular}{l|l}
$\mathbf{x}$ \\
\end{tabular} & $\begin{array}{l}\mathbf{x} \\
\end{array}$ & $\begin{array}{l}\mathbf{x} \\
\end{array}$ & $\begin{array}{l}\mathbf{x} \\
\end{array}$ \\
\hline SE & $\mathbf{S}$ & $\mathbf{x}$ & & & $\mathbf{x}$ & $\mathbf{x}$ & $\mathbf{x}$ & $\mathbf{x}$ & & $\mathbf{x}$ & $\mathbf{x}$ & $\mathbf{x}$ & & & & & & & & $\mathbf{x}$ \\
\hline TO & $\mathbf{N}$ & $\mathbf{x}$ & $\mathbf{x}$ & $\mathbf{x}$ & & $\mathbf{x}$ & & & & $\mathbf{x}$ & $\begin{array}{l}\mathbf{x} \\
\end{array}$ & & & & & & $\mathbf{x}$ & & & \\
\hline
\end{tabular}


A quase totalidade dos sites apontou para links na internet, principalmente para o Ministério da Saúde, Datasus (Departamento de Informática do SUS), instituições vinculadas e de saúde em geral e outras Secretarias Estaduais de Saúde. Alguns tinham links também para as Secretarias Municipais de Saúde do Estado. Como o objetivo desta análise era verificar presença de informação científica e técnica nos sites, procurou-se observar se havia links para bases de dados, universidades ou bibliotecas, especialmente as do Ministério da Saúde e a BVS. Apenas oito (42\%) sites incluíram links de universidades, e outros seis (32\%), da Biblioteca do Ministério da Saúde ou da BVS regional. Nenhum incluiu link para a BVS-SP, nem mesmo os seis que indicavam link para o site da BVS regional, apesar de seu lançamento nacional ter sido anunciado oficialmente e divulgado pelo Ministério da Saúde como um suporte às ações de profissionais e gestores do SUS. Esses resultados sugeriram que o acesso à informação científica e técnica ainda não foi totalmente incorporado à gestão.

A verificação das fontes dos indicadores incluídos nos sites foi realizada para identificar que tipo de informação era utilizada para sua preparação. Em geral, foram utilizadas as bases de dados nacionais de indicadores disponíveis pelo Datasus e RNIS, e 11 (58\%) secretarias indicaram utilização de dados de sistemas de informações em saúde locais.

Os sites e documentos dirigidos aos gestores não sugeriram que o uso de informação científica e técnica no processo de gestão estivesse sendo incentivado. Apenas quatro (21\%) secretarias de Saúde incluíram acesso a bases de dados bibliográficas nos sites, e seis (32\%) adicionaram espaços específicos para informação dos Centros de Documentação existentes nas secretarias. Alguns conteúdos sugeriram integração com a comunidade acadêmica do Estado, como notícia* sobre "projetos financiados pela FAPEAL [Fundação de Amparo à Pesquisa do Estado de Alagoas] para

\footnotetext{
* Notícia de janeiro de 2002, divulgada no site da Secretaria de Saúde do Estado de Alagoas. Disponível em : http://www.saude.al.gov.br/).
} 
estudos para redução de mortalidades infantil, materna, câncer e doenças imunossupressíveis”.

No site da Secretaria de Estado da Saúde do Ceará, foi publicado o texto completo de um documento sobre 'Diretrizes de Reorganização da Atenção e dos Serviços do SUS', em que se destacava a criação de grupos multidisciplinares integrando representantes da secretaria de Saúde e da comunidade acadêmica para a gestão local:

Com o objetivo de aperfeiçoar a Gestão Estadual da Saúde e o modelo de atenção, a SESA vem contando com o apoio de consultorias externas que sugeriram a criação de grupos de trabalho que se responsabilizassem pelo estudo dos principais problemas do Sistema de Saúde e propusessem estratégias de solução. Estes grupos foram instituídos tendo como integrantes representantes da SESA, do nível central, regional, incluindo unidades de referência, representantes de sociedades médicas e de saúde, representantes de universidades, usuários do Sistema e outros segmentos afins (SECRETARIA DE ESTADO DA SAÚDE DO CEARÁ 1998, p.10).

No site da Secretaria de Estado da Saúde de Santa Catarina, que possui acesso a bases de dados e a textos completos e menciona existência de Centro de Documentação, foi encontrada a seguinte informação na seção Sala de Leitura*:

Este espaço contém alguns documentos técnicos-científicos, como manuais, guias e legislação específica, que podem ser selecionados por áreas. Especial ênfase é dada à produção científica de interesse para o setor saúde elaborada em Santa Catarina, devendo os interessados em divulgar seus trabalhos, encaminhálos à SES. O objetivo é disponibilizar informação, no formato de textos, relatórios e outros recursos para que você possa, através de

\footnotetext{
* Trecho extraído da Seção Sala de Leitura do site da Secretaria de Estado da Saúde de Santa Catarina. Disponível em: http://www.saude.sc.gov.br/sala_de_leitura/apresentacao.htm
} 
rápida consulta, selecionar as leituras sobre diferentes áreas, podendo ainda fazer o download da maioria dos documentos. No mesmo espaço, você encontra um link com a Biblioteca Virtual em Saúde, o que amplia e redimensiona as possibilidades de consulta bibliográfica.

Os textos completos disponíveis nos sites se referiam principalmente a legislação, manuais para gestores ou para os cidadãos, manuais técnicos e boletins epidemiológicos.

Foram encontrados manuais para gestores em texto completo nas Secretarias de Ceará, Mato Grosso e Rio de Janeiro. Esses manuais destacavam a legislação e os instrumentos da gestão do SUS. A Secretaria de Saúde do Estado de Mato Grosso, reconhecendo a importância da legislação do SUS, publicou em texto completo a Série 'Legislação do SUS', em quatro volumes: o primeiro, dirigido à legislação nacional e estadual; o segundo, ao papel da secretaria estadual na gestão do Sistema; e os outros dois, ainda não disponíveis no momento da consulta, dedicados às principais resoluções do Conselho Estadual de Saúde e da Comissão Intergestores Bipartite. Cabe ressaltar que foi interessante verificar que essa secretaria optou por reunir a legislação em um formato tradicional impresso, mas ao mesmo tempo a disponibilizou em texto completo na internet, refletindo o momento de transição ao paradigma da Sociedade da Informação, em que o modelo da publicação impressa ainda predomina nas veiculações eletrônicas.

O Caderno do Gestor Municipal de Saúde, existente no site da Secretaria de Saúde do Estado de Mato Grosso, ressaltou a importância da informação e dos sistemas de informação, referindo-se aos de informação em saúde (epidemiológicos e estatísticos), e não à informação científica e técnica. Nele indicaram-se as fontes de informação que deveriam ser utilizadas pelos gestores, dividindo-as em 'fontes notificadoras formais e informais': 
As fontes notificadoras formais são os serviços de Saúde pública e Privadas (postos e centros de saúde, hospitais, ambulatórios, laboratórios, bancos de sangue, consultórios) e cartórios.

As fontes notificadoras informais são as associações de bairros $e$ de moradores, os clubes de serviços, as lideranças comunitárias, as escolas, as parteiras, as rezadeiras, as farmácias, as creches, as empresas, imprensa, os Conselhos Municipais de Saúde, os cemitérios etc. (....)

A informação para a Vigilância Epidemiológica destina-se à tomada de decisões, e a notificação é a principal fonte a partir da qual, na maioria das vezes, se desencadeia o processo Informação - Decisão - Ação (SECRETARIA DE ESTADO DA SAÚDE DE MATO GROSSO 2001, p. 72).

Há certamente um longo caminho a ser percorrido quanto ao desenvolvimento dos sites, mas os resultados mostraram que já se avançou bastante. A análise dos sites, associada a outras observações e reflexões realizadas durante este trabalho, permitiu algumas considerações que poderão contribuir para fornecer subsídios para a preparação de fontes de informação disponíveis na internet que possam servir de apoio ao processo de tomada de decisão local.

\subsection{Informação científica para tomada de decisão local}

Com o objetivo de identificar se um gestor municipal, diante da necessidade de tomar decisões sobre combate a dengue em seu município, encontraria informação científica e técnica que subsidiasse o processo de tomada de decisão, foram analisadas as fontes de informação disponíveis ao gestor na BVS-SP.

$\mathrm{O}$ resultado dessa pesquisa indicou que existem documentos sobre esse tema em bases de dados bibliográficas, em catálogos de bibliotecas, em base de dados de textos completos e de sites na internet (Tabela 9). 
Tabela 9 - Resultado de pesquisa sobre dengue nas fontes de informação da BVS-SP

\section{Bases de dados bibliográficas}

LILACS-SP - Literatura Latino-Americana e do Caribe em Saúde Pública (352)

AdSAÚDE - Administração de Serviços de Saúde (32)

CidSaude - Literatura sobre Cidades - Municípios Saudáveis (0)

MS - Acervo da Biblioteca do Ministério da Saúde (40)

ENSP - Acervo da Biblioteca da Escola Nacional de Saúde pública (41)

FSP - Acervo da Biblioteca da Faculdade de Saúde pública da USP (101)

REPIDISCA - Literatura em Engenharia Sanitária e Ciências do Ambiente (62)

PAHO - Acervo da Biblioteca da Organização Pan-Americana da Saúde (243)

WHOLIS - Sistema de Informação da Biblioteca da OMS (150)

MEDLINE - MEDlars onLINE - Literatura Internacional (753)

Sites em Saúde pública - LIS (17)

Textos completos (87)

Fonte: BVS-SP, setembro de 2002

Para identificar a produção científica brasileira sobre dengue foram analisados os resultados das seguintes fontes: as bases de dados LILACS-SP, AdSAÚDE, REPIDISCA e MEDLINE, os catálogos dos acervos de instituições nacionais (Ministério da Saúde, Escola Nacional de Saúde Pública e Faculdade de Saúde Pública da Universidade de São Paulo e os sites em saúde pública (LIS).

Dos 352 registros recuperados na LILACS-SP, 149 foram publicados no Brasil; dos 62 da REPIDISCA, 11 eram brasileiros e dos 753 da MEDLINE, apenas 44.

A análise dos registros da produção brasileira foi feita por amostragem, conforme descrito no capítulo 8, exceto para os sites do LIS. A Tabela 10 mostra os totais das amostras calculadas para cada fonte. 
Tabela 10 - Distribuição da informação recuperada na BVS-SP sobre dengue, com resultados e totais da amostra por fonte de informação

\begin{tabular}{lll}
\hline Fontes de informação & Resultado & Total analisado \\
\hline LILACS-SP & 149 & 49 \\
AdSAÚDE & 32 & 10 \\
MS & 40 & 12 \\
ENSP & 41 & 14 \\
FSP & 101 & 35 \\
REPIDISCA & 11 & 4 \\
MEDLINE & 44 & 15 \\
LIS (sites) & 17 & 17 \\
\hline Total geral & $\mathbf{4 3 5}$ & $\mathbf{1 5 6}$ \\
\hline
\end{tabular}

Fonte: BVS-SP, setembro de 2002

Os resultados das amostras foram analisados de acordo com as seguintes categorias: autoria, tipo de documentos recuperados e temas. Os sites do LIS não puderam ser analisados por tipo de documentos e por temas, pois contém fontes de informação variadas.

Quanto à autoria, observou-se que predominaram na literatura nacional os documentos publicados por autores pessoais (69\%) e por instituições governamentais (16\%). Em algumas bases de dados de acervos institucionais (FSP e ENSP) e na base de textos completos, foram encontrados documentos de autoria de organismos internacionais, que corresponderam a $6 \%$ do total de autores (Tabela 11).

Quanto ao tipo de documentos sobre dengue (Tabela 12), predominaram os artigos de revistas (49\%), seguidos de livros ou capítulos de livros (25\%), teses (12\%), trabalhos apresentados em eventos científicos (9\%), documentos não-convencionais (4\%) e vídeos $(1 \%)$. 
Tabela 11 - Distribuição da informação recuperada na BVS-SP sobre dengue, por tipos de autoria e por fonte de informação

\begin{tabular}{|c|c|c|c|c|c|c|c|c|c|c|}
\hline Autores & $\begin{array}{l}\text { LILACS- } \\
\text { SP }\end{array}$ & AdSAÚDE & MS & FSP & ENSP & REPIDISCA & MEDLINE & LIS & Total & $\%$ \\
\hline Universidades & 0 & 0 & 0 & 0 & 0 & 0 & 0 & 4 & 4 & $2 \%$ \\
\hline Instituições & & & & & & & 0 & & & \\
\hline governamentais & 6 & 1 & 4 & 6 & 2 & 0 & & 6 & 25 & $16 \%$ \\
\hline $\begin{array}{l}\text { Organismos } \\
\text { internacionais }\end{array}$ & 0 & 0 & 0 & 4 & 1 & 0 & 0 & 5 & 10 & \\
\hline Autores pessoais & 43 & 8 & 2 & 25 & 10 & 3 & 15 & 1 & 107 & $69 \%$ \\
\hline $\begin{array}{l}\text { Empresas } \\
\text { Não identificados }\end{array}$ & $s^{0}$ & 0 & 0 & 0 & 1 & 1 & 0 & 1 & 3 & $2 \%$ \\
\hline ou Anônimos & 0 & 1 & 6 & 0 & 0 & 0 & 0 & 0 & 7 & $5 \%$ \\
\hline Total & 49 & 10 & 12 & 35 & 14 & 4 & 15 & 17 & 156 & $100 \%$ \\
\hline
\end{tabular}

Fonte: BVS-SP, setembro de 2002

Tabela 12 - Distribuição da informação recuperada na BVS-SP sobre dengue, por tipos de documentos e fontes de informação

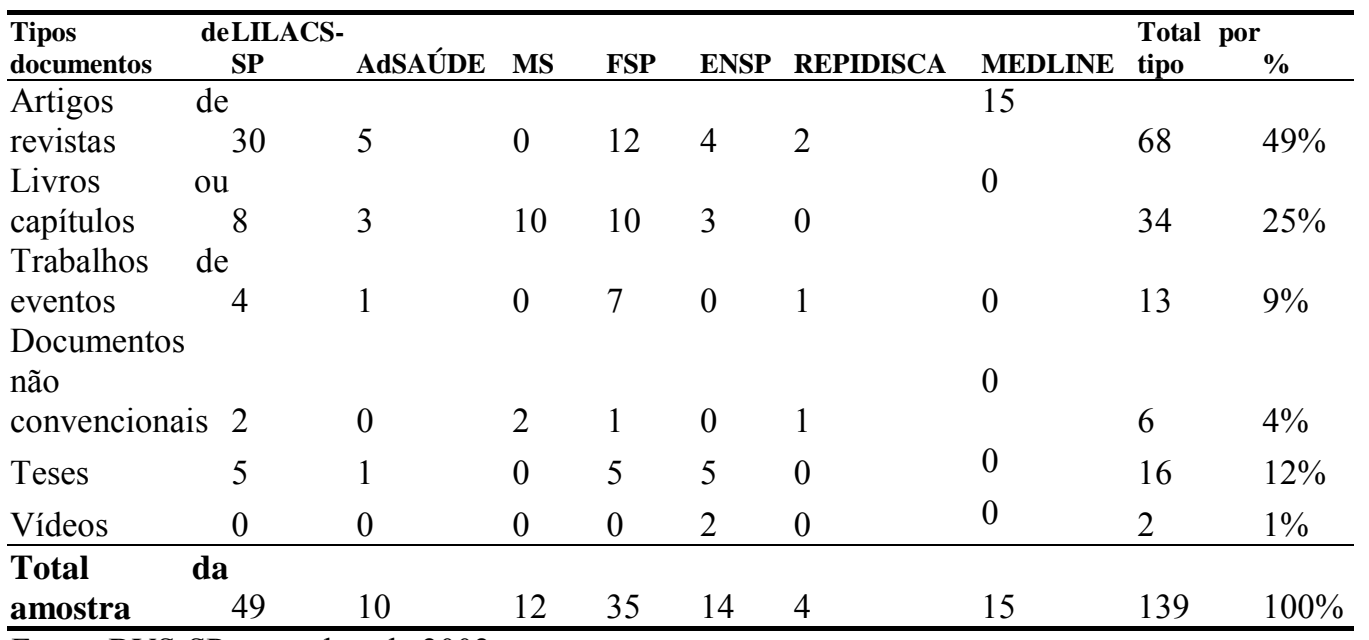

Fonte: BVS-SP, setembro de 2002

Uma análise comparativa dos dados da Tabela 12 evidenciou que:

- os artigos de revistas predominaram na maioria das fontes de informação analisadas, com exceção das bases de dados MS e ENSP. Isso se justifica pois essas bases de dados são catálogos de acervos dessas instituições; 
- na base MS foram localizados apenas livros e documentos nãoconvencionais, o que também se justifica pelo mesmo motivo acima;

- na base de dados MEDLINE são indexados apenas artigos de revistas;

- o catálogo da ENSP é o único que registra vídeos.

Para a classificação do conteúdo dos documentos recuperados, definiram-se algumas categorias temáticas, apresentadas no capítulo 8. Quando os documentos tratavam de mais de uma categoria, optou-se por classificá-los pelo tema predominante.

A distribuição dos registros analisados sobre dengue, de acordo com a classificação utilizada, pode ser verificada na Tabela 13. Os resultados indicaram predominância de documentos sobre aspectos de prevenção e controle da doença $(34 \%)$ e de epidemiologia (32\%).

O perfil predominante da produção científica e técnica sobre dengue existente nas fontes de informação da BVS-SP poderia ser assim definido: artigos de revistas científicas, publicados por autores pessoais, sobre epidemiologia e prevenção e controle.

Tabela 13- Distribuição da informação recuperada na BVS-SP sobre dengue, por temas e por fonte de informação

\begin{tabular}{|c|c|c|c|c|c|c|c|c|c|}
\hline Temas & LILACS-SP & AdSAÚDE & MS & FSP & ENSP & REPIDISCA & MEDLINE & $\begin{array}{c}\text { Total por } \\
\text { tema }\end{array}$ & $\%$ \\
\hline Pesquisa básica & 4 & 0 & 0 & 2 & 2 & 0 & 4 & 12 & 9 \\
\hline Aspectos clínicos & 0 & 0 & 1 & 0 & 1 & 0 & 2 & 4 & 3 \\
\hline Epidemiologia & 22 & 3 & 0 & 11 & 3 & 1 & 5 & 45 & 32 \\
\hline $\begin{array}{l}\text { Prevenção e } \\
\text { controle }\end{array}$ & 16 & 4 & 5 & 14 & 5 & 2 & 2 & 48 & 34 \\
\hline $\begin{array}{l}\text { Educação em } \\
\text { saúde }\end{array}$ & 4 & 1 & 1 & 1 & 0 & 0 & 0 & 7 & 5 \\
\hline $\begin{array}{l}\text { Políticas e } \\
\text { programas }\end{array}$ & 1 & 2 & 3 & 2 & 0 & 0 & 0 & 8 & 6 \\
\hline História & 2 & 0 & 1 & 0 & 0 & 0 & 0 & 3 & 2 \\
\hline Geral & 0 & 0 & 1 & 5 & 3 & 1 & 2 & 12 & 9 \\
\hline Total & 49 & 10 & 12 & 35 & 14 & 4 & 15 & 139 & $100 \%$ \\
\hline
\end{tabular}

Fonte: BVS-SP, setembro de 2002 
A base LIS tem características que a distingue das demais fontes. Os resultados indicaram que os manuais e documentos técnicos ali registrados estavam indexados em pelo menos uma das bases de dados bibliográficas disponíveis na BVS-SP, embora nem sempre elas indicassem o endereço eletrônico desses documentos. Outras informações disponíveis nos sites do LIS não teriam sido recuperadas pela consulta às bases de dados, o que parece indicar que essa fonte de informação poderia representar um apoio complementar para o gestor.

Informações complementares sobre o processo de gestão foram obtidas por meio de entrevistas com gestoras de programas técnicos que trabalham em áreas de decisão política. De acordo com a entrevistada da Secretaria Municipal de Saúde de Campinas, as fontes de informação consideradas mais importantes para a gestão de problemas locais foram: informações epidemiológicas locais; informações do Ministério da Saúde e da Secretaria Estadual de São Paulo dirigidas principalmente aos serviços; e legislação. Esta foi considerada essencial, pois é normativa e orienta sobre procedimentos que todos os municípios devem seguir.

A informação científica e técnica em geral não costuma ser utilizada diretamente pelos técnicos dessa secretaria. Há parceria com a universidade para as pesquisas científicas, principalmente na área de doenças transmissíveis e mortalidade e para a produção de material educativo utilizado nas campanhas de saúde. Segundo a entrevistada, "a lógica dos serviços nos mantém à distância da informação científica". Durante a entrevista, foi citada uma experiência de parceria com a Universidade Estadual de Campinas na revisão da metodologia para controle de atividade larvária de dengue. A atualização do conhecimento técnico-científico é geralmente feita por meio da mídia ou de outros técnicos que costumam indicar documentos de interesse. 
Os informes, boletins epidemiológicos e manuais produzidos pelos técnicos têm sido divulgados no site dessa secretaria. Como afirmou a entrevistada, "a internet estimulou a produção de documentos pelos técnicos da secretaria pela visibilidade que proporciona e pela rapidez na disseminação da informação”.

Na Secretaria Estadual de Saúde de São Paulo, os profissionais de saúde da equipe de vigilância epidemiológica estavam de alguma forma ligados à academia, com a participação em cursos de pós-graduação ou em grupos de pesquisas, mas não havia parceria formal com alguma universidade para pesquisas específicas para a tomada de decisão local.

A atualização do conhecimento pelos técnicos e profissionais do Centro de Vigilância Epidemiológica é realizada por meio de consulta a bases de dados, preferencialmente pela internet, para recuperação de informação e acesso a revistas científicas e a sites de interesse. A experiência recente mais significativa de uso de literatura científica foi na implantação do DOTS (Tratamento Supervisionado Diretamente Observado), estratégia de controle sugerida pela OMS para tuberculose.

As entrevistas realizadas mostraram duas realidades distintas, não somente por serem de níveis de administração distintos (municipal e estadual), mas também pela forma de utilização da informação científica e técnica no processo de tomada de decisão. Na Secretaria Municipal, a utilização da informação científica e técnica parece ser indireta, pela parceria com a universidade, que é responsável pela realização de pesquisas de interesse para os serviços. Na Secretaria Estadual, a atualização do conhecimento científico é feita pelos próprios profissionais de saúde da equipe, que têm conhecimento de busca de fontes de informação científica e técnica e participam de cursos acadêmicos e de grupos de pesquisa na universidade.

Ambas as instituições privilegiaram o uso da informação local coletada nos serviços ou nos levantamentos epidemiológicos para a tomada de decisão e também a necessidade de haver atualização em relação aos instrumentos normativos e 
legislação pertinente e às orientações das instâncias superiores de Saúde (Secretaria Estadual e Ministério da Saúde).

Quanto à utilização da internet para atualização do conhecimento, ficou claro que ela tem sido utilizada não somente para consulta a fontes de informação existentes mas também para divulgação, por meio dos respectivos sites, de documentos produzidos pelos técnicos das secretarias. 


\section{CAPÍTULO 10}

\section{DISCUSSÃO}

O processo de comunicação do conhecimento científico teve sua dinâmica alterada pela Sociedade do Conhecimento, que impôs uma nova dinâmica social. A informação deveria se transformar em ação; em ação integrada e integradora; em ação que dinamizasse o próprio processo de construção de conhecimento. Para atender a essa nova realidade, pôde-se observar que estão sendo promovidas mudanças na forma de disponibilizar os conteúdos informativos e na de induzir o uso efetivo e eficiente de toda informação disponível, seja ela científica, cultural, social, política ou normativa.

A análise dos documentos constitutivos do SUS e dos instrumentos de gestão mostrou reflexos da nova ordem social influenciada por essa Sociedade atual, principalmente no que se refere à descentralização do poder local. O que as estratégias do SUS parecem sugerir com a descentralização das decisões no nível local é a transformação do espaço da gestão em um de decisão. Nessa lógica, o processo de tomada de decisão em saúde deveria estender-se a todos os níveis da sociedade e chegar a promover a participação comunitária, a discussão política e o controle social das ações em saúde.

Para favorecer o controle social e a geração de novas idéias para ações efetivas e soluções apropriadas para o SUS, a informação gerada localmente deveria estar disponível nos sites das secretarias municipais e estaduais, antes mesmo de ser consolidada nos níveis estaduais e federais. $\mathrm{O}$ acesso irrestrito à informação poderia ampliar o espaço de poder, à medida que fosse explorada a capacidade de filtrar, de maneira eficiente, adequada e rápida, as informações já existentes e de transmiti-las de forma a acarretar a busca por novas, o que faria com que outras fossem geradas e contextualizadas. 
A internet constitui um espaço privilegiado e democrático para acesso e divulgação de informação, que favorece o conceito de eqüidade exposto nos princípios do SUS, pois a informação se torna presente como parte da inteligência coletiva, disponível igualmente para toda a sociedade, não sendo privilégio de nenhum grupo social. No entanto, como o acesso à rede mundial de computadores no país ainda se restringe aos municípios que contam com infra-estrutura de informática e de telecomunicações adequada, há os que contestam que a internet poderia promover um abismo social, e não integração.

Pelo contrário, além de favorecer a divulgação e utilização de informação, a rede oferece oportunidade de acesso eqüitativo e amplia a análise política pela sociedade em geral, caminhando para um processo democrático participativo na tomada de decisão política em saúde. A gestão em rede favorece a coordenação, a articulação e a negociação entre vários atores públicos e privados que participam no processo de decisão política, direta ou indiretamente: a mídia, os grupos de interesse, os partidos políticos, os parlamentares e legisladores, a comunidade em geral.

Observou-se, nos documentos do Ministério da Saúde, nas recomendações das Conferências Nacionais de Saúde e até mesmo na literatura científica, uma tendência crescente de desenvolver mecanismos para incorporar o conhecimento científico ao processo de gestão, promovendo a comunicação e o intercâmbio de informação entre as várias instâncias de controle social para dar cumprimento aos princípios do SUS. No entanto, os instrumentos de gestão parecem não favorecer essa integração. A informação normalmente utilizada nos serviços é a quantitativa e estatística, que se refere ao dado real, reflexo dos serviços e das características da população, compreendido num determinado âmbito de ação e de problemas.

Os instrumentos de gestão deveriam considerar, entre suas características intrínsecas, a capacidade de buscar e processar criticamente as informações e adequá-las ao contexto apropriado da decisão. As informações científicas e técnicas deveriam ser 
parte integrante do conjunto de informações em saúde, complementando-se mutuamente, conferindo significado e agregando valor umas às outras.

A informação científica tem sido mais reconhecida como meio de divulgação de resultados de pesquisas e experiências acadêmicas do que como ferramenta para o processo de tomada de decisão política. Observou-se, nos sites governamentais, uma tendência de informar o cidadão, o profissional de saúde e o gestor sobre políticas, programas, serviços e ações em saúde realizadas nos três níveis de governo. Mas, em geral, essa informação correspondeu mais a notícias breves e legislação que a conteúdos informativos mais densos ou documentos técnicos, evidenciando uma apropriação ainda tímida desse espaço virtual como fonte de disseminação de informação científica e técnica relacionada à saúde ou à gestão do SUS.

Da mesma forma que o uso da informação científico-técnica não é ainda incorporado à prática dos serviços e às instâncias de decisão política, os mecanismos para organização e preservação do conhecimento gerado nessas instituições são praticamente inexistentes. Parece paradoxal que justamente o saber produzido e relacionado à lógica dos serviços e da prática em saúde e que, portanto, poderia servir de subsídio à tomada de decisão local esteja distanciado do fluxo tradicional de comunicação científica e técnica. As experiências locais, as análises e os informes de situação, não necessariamente apoiados em conhecimento registrado em publicações convencionais ou publicados de forma tradicional, estão refletidos apenas no conhecimento coletivo, que permeia todo o sistema de saúde.

A análise das fontes de informação científica e técnica disponíveis na BVS-SP mostrou que é forte a presença da produção científica brasileira nas bases de dados nacionais e internacionais da área da saúde. A produção científica brasileira em saúde pública se destaca na América Latina e Caribe, correspondendo a 36\% dos registros da base de dados LILACS.

Mas a questão da tomada de decisão baseada em conhecimento científico não se resume a uma maior disponibilidade de informação para os gestores, embora 
necessariamente passe por ela. Como afirmou POUVORVILLE (1999), seria necessário haver uma 'tradução' de demandas e resultados, para integração entre tomadores de decisão e pesquisadores, que caminhasse nos dois sentidos: na explicação do contexto da decisão, pelo tomador de decisão, e na explicação dos resultados de pesquisas pelo pesquisador. A dificuldade disto residiria na definição de quem terá o papel de mediador, de criador dessa meta-informação, que amplificará o uso da informação disponível.

O desafio seria identificar como os códigos de comunicação do emissor e receptor poderiam ser suficientemente claros nesse processo de transferência de informação. A forma como é divulgado o conhecimento científico na área de saúde pública, principalmente em revistas científicas internacionais, distribuído na literatura de saúde em geral, não parece favorecer essa aproximação. Até que ponto a informação contida na produção científica acadêmica em saúde pode ser decodificada pelo receptor da área de gestão e de serviços de saúde? A utilização do conhecimento científico em situações reais de gestão em saúde deveria ser objeto de estudo posterior.

A linguagem científica e as interfaces de recuperação nas fontes de informação parecem apropriadas aos pesquisadores acadêmicos que utilizam o mesmo código de comunicação, mas não para as demandas dos gestores em linguagem natural. Verificou-se que a recuperação por texto livre, tipo de consulta que o gestor possivelmente utilizaria, é ampla e imprecisa, dificultando um resultado apropriado. Alguns resultados encontrados só foram conseguidos devido a conhecimento anterior sobre a estrutura dessas linguagens.

As publicações científicas não são normalmente produzidas para ser usadas na tomada de decisão, assim como as decisões políticas não têm considerado o uso de publicações científicas como parte do processo. Como incorporar o uso do conhecimento científico na rotina de tomada de decisão local em saúde, se, na geração desse conhecimento, as aplicações locais para solução de problemas ou as necessidades dos gestores não estão contempladas? Como produzir 'informação para 
a ação', se a ação não tem papel fundamental no momento da geração da informação? No Modo 2 da ciência proposto por GIBBONS (2000), as pesquisas científicas deveriam ser concebidas de forma integrada entre distintos atores, com definições claras dos resultados esperados.

Para que as pesquisas dos programas de pós-graduação do país publicadas nas dissertações e teses sejam amplamente divulgadas na comunidade científica em geral, os resultados são veiculados em revistas científicas. Por que não existir também documentos de divulgação desses resultados para os gestores, profissionais de saúde e outros atores do SUS? Esses documentos poderiam ser intermediários entre os de divulgação científica para a comunidade em geral e as publicações científicas acadêmicas. Daqueles, tomar-se-ia a linguagem acessível à compreensão dos não-acadêmicos; das publicações científicas, tomar-se-iam a validade e a autoridade da ciência na certificação dos resultados, para poder orientar de forma segura a tomada de decisão local. Se os documentos legais que regulam o SUS são posteriormente publicados em linguagem mais acessível aos gestores, por que também não adaptar as publicações científicas, seja pelos próprios pesquisadores, seja por outro intermediário capacitado para esse fim?

Como afirmou LÉVY (1999), as línguas foram feitas para a comunicação nas comunidades e para assegurar as relações entre os grupos sociais, e a escrita possibilitou um acréscimo de eficácia da comunicação e da organização social. Mas, “o problema da inteligência coletiva é descobrir ou inventar um além da escrita, um além da linguagem tal que o tratamento da informação seja distribuído e coordenado por toda a parte, que não seja mais o apanágio de órgãos sociais separados, mas que se integre naturalmente, pelo contrário, a todas as atividades humanas, volte às mãos de cada um” (p. 17).

As publicações científicas têm sido escritas para ser lidas e avaliadas pelos pares e pela própria comunidade acadêmica. Se os pesquisadores produzissem documentos em linguagem acessível aos tomadores de decisão, apontando caminhos e soluções para situações locais, com resultados que contribuíssem para uma mudança de 
comportamento na prática dos serviços de saúde em um município e beneficiando uma grande parcela da população, possivelmente esses documentos não seriam publicados nas revistas científicas e não seriam, portanto, considerados nos índices de impacto existentes. Faz-se necessário definir indicadores de impacto que atendam a essa nova realidade, que possam medir a importância e a validade acadêmica, evidenciando a importância para a ação e a influência dos resultados nos indicadores sociais e de saúde.

PATTON et al. (1977) e WEISS (1997) salientaram que o impacto e a influência da pesquisa social não deveriam estariam restritos às medidas de citações de outros pesquisadores na literatura e que deveriam ser consideradas as diferenças que produzissem na atenção em saúde ou nas políticas. Confirmaram que haveria necessidade de redefinir o que se considera utilização efetiva de resultados de pesquisa.

As políticas públicas de desenvolvimento científico e tecnológico deveriam ser capazes de promover os pesquisadores tanto quando realizam pesquisas para descobertas científicas quanto para solução de problemas práticos. Em ambos os casos, poderia haver análise de mérito dos projetos, envolvendo a comunidade científica e os gestores de saúde e de ciência e tecnologia.

É difícil afirmar se a informação científica poderá ser apropriada a cada processo de decisão, pois o conhecimento implícito ou gerado a partir da análise de uma determinada informação científica depende, antes de qualquer coisa, do contexto em que se encontra aquele que a busca e interpreta. Os resultados das buscas realizadas por temas específicos, simulando as feitas pelos gestores, mostraram que freqüentemente existem informações relacionadas aos temas, mas sua possível utilização pelos gestores não poderia ser medida, a não ser em situações reais.

Para que a decisão política em saúde seja progressivamente apoiada em conhecimento e para que a informação científica e técnica possa ser transformada em ‘informação para a ação’, seria necessário, além de criar e coletar novos dados, 
estabelecer novos vínculos entre as informações e bases de dados existentes e os novos papéis e ações no processo de produção e utilização da informação em saúde. Como afirmou CASTELLS (2000), os conhecimentos deveriam gerar ação sobre os próprios conhecimentos como fonte de produtividade. A integração entre as fontes de informação e os instrumentos de gestão e a coleta e organização, em fontes de informação apropriadas, das experiências locais, dos informes de análise de situação e de outros documentos técnicos produzidos localmente poderia contribuir para a tomada de decisão política local, para uma gestão democrática e participativa e para a definição de áreas de desenvolvimento de pesquisas aplicadas ao SUS.

Nesse sentido, poder-se-ia considerar como exemplo duas iniciativas já existentes: o Painel Permanente de Experiências Municipais Exitosas ${ }^{*}$, do Conselho Nacional de Secretários de Saúde (Conasems), cujos objetivos são contribuir para o intercâmbio de experiências municipais em saúde e reforçar a capacidade de gestão das Secretarias Municipais de Saúde; e a da Biblioteca Virtual em Saúde - Saúde Pública Brasil, cujo intuito é promover o acesso a fontes de informação técnico-científicas para o desenvolvimento da saúde. A organização das experiências bem-sucedidas do Painel em uma base de dados, com possibilidades de consulta integrada a fontes de informação científica e técnica disponíveis na BVS-SP, poderia ser um exemplo de contribuição para que a informação científica e técnica pudesse apoiar os processos de tomada de decisão e vice-versa. A coleta de indicadores de utilização de informação científico-técnica na tomada de decisão local constituiria uma fonte de informação única e inovadora.

O avanço do conhecimento esteve praticamente restrito às contínuas indagações formuladas pelos pesquisadores, sempre em busca do inovador, do original. Para pensar um novo processo de construção do conhecimento, seria necessário expandir as oportunidades e a participação coletiva, ampliando as chances de novas descobertas. Esse estímulo à participação coletiva no avanço do conhecimento teria particular importância na área da saúde pública, pois poderia ampliar o âmbito das

\footnotetext{
* Disponível em: http://www.conasems.com.br/projins/paiinf.htm
} 
pesquisas, não somente em relação a novas descobertas científicas, mas também em relação a trabalhos aplicados para solução de problemas reais e sobre a intrincada rede de relacionamentos sociais e políticos que compõem a gestão em saúde. Como afirmou MORAES (2001), “o aparecimento de novos saberes referidos à coleta, processamento, tratamento, análise e armazenamento de informações relacionadas a situações de saúde remete a condições de sua possibilidade externa a estes próprios saberes, não como efeito ou resultante, mas como elementos imanentes de dispositivos de natureza essencialmente estratégica” (p.7).

O caminho entre a pesquisa científica e a tomada de decisão política não é linear. A lógica acadêmica baseia-se no sentido de universidade: liberdade de pensar, autonomia, independência na busca e no desenvolvimento do saber. O conhecimento científico deveria ser livre, obedecendo a preocupações científicas, de formação acadêmica e dentro dessa lógica. A lógica política, no entanto, estaria influenciada por interesses e pressões de diversos poderes, a normas para utilização de recursos e para prestação de contas à sociedade. $\mathrm{O}$ conhecimento operacional tem de dar conta de realidades locais informadas por dados de outras bases que não as do conhecimento científico. Mas, como mostrou BRONFMAN (2000) no esquema de interação entre pesquisa e tomada de decisão (Figura 5), há muitos pontos em que os caminhos se encontram, e são eles que têm de ser explorados. Para essa interação, seria necessário identificar convergências e intersecções que respeitassem as particularidades e os elementos únicos de cada conjunto, identificando, ao mesmo tempo, elementos comuns de mútuo benefício.

Quanto ao fluxo de comunicação entre pesquisadores e gestores, ficou evidenciado que as realidades temporais da pesquisa e da prática são totalmente distintas.

Enquanto o gestor precisa dar respostas imediatas para problemas emergentes, diante de realidades complexas de orçamento, de normas administrativas, de ações intersetoriais integradas a outras esferas de governo, o pesquisador trabalha em situações, até certo ponto, controladas por ele para garantir análise de dados e dos resultados. As pesquisas podem levar meses ou até anos para ser concluídas, e, quando isto acontece, os resultados são normalmente transformados em um documento científico que segue o fluxo da comunicação científica, podendo levar muito tempo para ser disseminado e conhecido pelos gestores. 
Com a internet, até a linearidade de transmissão do conhecimento científico foi alterada: atualmente, o artigo científico pode ser colocado disponível na rede antes mesmo de haver sido discutido entre os pares; fica exposto a comentários, críticas e sugestões; pode ainda não ser um conhecimento consolidado, mas já está disponível, já suscitará novas questões, fará parte da inteligência coletiva e poderá ser influenciado por distintos atores sociais. Da mesma forma, a ampla disseminação de conteúdos informativos sobre a gestão do SUS, nos sites governamentais das três esferas de governo, poderia aumentar o conhecimento sobre as prioridades e necessidades locais existentes no país e a adequação da oferta de fontes de informação. O modelo de gestão em saúde deveria promover uma responsabilidade coletiva de construção do saber, de análise da situação e de conhecimento científico apropriados para a construção do sistema de saúde.

MORAES (2001) propôs que se elaborasse uma Norma Operacional Básica para a Informação em Saúde, que regulamentasse critérios institucionais orientadores da produção, disseminação e uso da informação em saúde. Caberia a essa norma, entre outras competências, definir padrões para a comunicação entre bases de dados, para metodologias de coleta e tratamento de dados. Se a informação científica e as bases de dados bibliográficas fossem incluídas no conceito de informação em saúde, poderse-ia promover integração entre conhecimento científico e a prática de saúde.

A Política de Ciência, Tecnologia e Inovação em Saúde, proposta em 2002 pelo Ministério da Saúde, poderia equacionar muitas dessas sugestões, pois sugere a ampliação da capacidade de produzir documentos que sintetizem os conhecimentos existentes na literatura científica e o estabelecimento de uma agenda da pesquisa científica e tecnológica que contribua para o desenvolvimento da saúde e para a decisão política. As agendas de pesquisa e as agendas e prioridades de ação na área da saúde, mais que unificadas, definidas em conjunto, convergindo para o objetivo maior da construção do SUS, poderiam contribuir significativamente para a consolidação de seus princípios e para o desenvolvimento de uma inteligência coletiva que permeasse todas as ações de saúde para a população. 


\section{CAPÍTULO 11}

\section{CONCLUSÕES E RECOMENDAÇÕES}

As análises e reflexões sobre o tema permitiram concluir que:

1) para abastecer-se de informação, os gestores encontrariam documentos científicos e técnicos nas bases de dados disponíveis na BVS-SP, tanto artigos publicados em revistas científicas, que constituem os veículos preferenciais para divulgação dos resultados de pesquisas, quanto documentos governamentais, livros e teses. No entanto, os trabalhos apresentados em eventos científicos, em que geralmente são relatadas experiências e práticas locais dos serviços de saúde, e os documentos técnicos governamentais poderiam estar melhor representados nas bases de dados;

2) o caminho entre a produção de conhecimento científico e sua utilização na tomada de decisão política não é linear. O estímulo ao acesso e ao uso das informações científicas e técnicas dependerá mais da definição de uma metainformação do que da disponibilidade das fontes de informação. Os caminhos não seriam, em si, lineares e nem trilhados num único sentido, mas as intersecções entre eles teriam de ser mais exploradas;

3) a base de dados LILACS é a fonte de informação mais completa para apoio aos processos de gestão, pois inclui vários tipos de documentos que representam a produção bibliográfica em saúde pública do país. A base MEDLINE poderia ser uma fonte importante para localização de produção científica brasileira em revistas científicas estrangeiras. As demais bases poderiam ser consideradas complementares para temas específicos; 
4) as universidades são as principais responsáveis pela produção científica brasileira na área. Embora pareça haver parcerias entre elas e os serviços de saúde, a literatura recuperada não evidenciou participação conjunta na divulgação de resultados de pesquisas em saúde;

5) a fragmentação das fontes de informação em áreas específicas não parece ser recomendada, pois limita a recuperação de informação relevante para a gestão. A produção científica de interesse para a área de saúde pública está representada em publicações de outras áreas do conhecimento em saúde;

6) a linguagem científica e as interfaces de consulta das fontes de informação disponíveis seguem mais a lógica acadêmica que a de gestão. Haveria necessidade de definir mecanismos de recuperação em linguagem e formatos que favorecessem a utilização pelos gestores e a interligação entre as fontes de informação e os instrumentos de gestão;

7) a produção científica brasileira em saúde pública reflete mais o conceito tradicional da área, dirigido a problemas epidemiológicos e de controle e prevenção de doenças, do que o conceito ampliado de promoção de saúde e de interdisciplinaridade na gestão de recursos para a saúde;

8) a forma de preparação dos instrumentos de gestão normatizada pelo SUS não parece favorecer a utilização de informação científica e técnica como complemento às fontes de informações quantitativas em saúde;

9) a internet pode ser considerada um ambiente favorável para disseminação de conhecimento científico como apoio aos processos de tomada de decisão em saúde, pois já é utilizada pelo ministério e pelas secretarias de saúde para divulgação de outras informações do setor. 
Sendo assim, para que o conhecimento científico possa servir de apoio ao processo de tomada de decisão em saúde, recomenda-se que:

- todas as fontes de informação em saúde (estatísticas, numéricas, científicas, técnicas etc.) existentes no país sejam integradas, aproveitando as iniciativas existentes e o espaço de convergência proporcionado pela BVS-SP, ampliando o conceito existente de 'informações em saúde';

- as bases de dados bibliográficas existentes no país desenvolvam iniciativas para aumentar a coleta de produção científica e técnica produzida nas três esferas de governo e para que a oferta de informação seja mais adequada às necessidades e prioridades da gestão;

- sejam construídas articulações entre Ministério da Saúde, secretarias de Saúde e universidades para a definição conjunta de prioridades de pesquisa e de ação em saúde;

- as interfaces de consulta às bases de dados sejam aprimoradas, de forma a utilizar recursos de linguagens naturais de comunicação;

- o uso de informação científica e técnica na gestão seja progressivamente estimulado, incluindo nos sites governamentais acesso visível e destacado às fontes de informação disponíveis da BVS-SP, a exemplo do que ocorre com a RNIS e bases de dados do Datasus.

- os programas de capacitações para gestores e de educação permanente dos profissionais que atuam no SUS incluam cursos de acesso a fontes de informação científico-técnica;

- o desenvolvimento e a produção de indicadores de impacto social e de reconhecimento de mérito de pesquisas aplicadas à gestão do SUS sejam considerados pelas agências de ciência e tecnologia. 


\section{REFERÊNCIAS}

[ABRASCO] Associação Brasileira de Pós-Graduação em Saúde Coletiva. Comissão de Ciência e Tecnologia. [on line]. Política nacional de ciência, tecnologia e inovação em saúde: uma proposta. sl; abril de 2002. Disponível em: <URL: http://www.abrasco.org.br/noticias/PNCTISaudeDocAbrasco.doc > [2002 Nov 21]

Almeida MF. O uso de informações em saúde na gestão dos serviços. Saúde Soc 1995; (1-2): 39-42.

Anais da I Conferência Nacional de Ciência e Tecnologia em Saúde; 1994 out. 24-8; Brasília. Brasília (DF): Ministério da Saúde. Coordenação Geral de Desenvolvimento Científico e Tecnológico; 1994.

Andrade MTD. Literatura citada em dissertações e teses no campo da Epidemiologia, apresentadas à Faculdade de Saúde Pública da Universidade de São Paulo, no período de 1979-1982. São Paulo; 1984. [Dissertação de Mestrado Faculdade de Saúde Pública da USP].

Andrade MTD. Pesquisa científica em saúde pública: produtividade da comunidade acadêmica brasileira 1983-1989. São Paulo; 1992. [Tese de Doutorado - Escola de Comunicações e Artes da USP].

Banque de Données Santé Publique (BDSP). Structure de la base documentaire (bilan annuel avril 2001). [en ligne]. Paris; 2001. Disponible à $<$ URL: http://www.bdsp.tm.fr/Base/Stats/Default.asp > [2002 Nov 15]

Baumgarten M, organizadora. A era do conhecimento: matrix ou ágora? Porto Alegre: Editora da Universidade; 2001.

Brasil. Lei 8.080, de 19de setembro de 1990. Dispõe sobre as condições para a promoção, proteção e recuperação da saúde, a organização e o funcionamento dos serviços correspondentes e dá outras providências. [legislação on line]. Brasília (DF); 1990a. Disponível em: <URL: http://portalweb02.saude.gov.br/saude/arquivos/pdf/LEI8080.pdf $>$ [2002 Nov 15] 
Brasil. Lei 8.142, de 28 de dezembro de 1990. Dispõe sobre a participação da comunidade na gestão do Sistema Único de Saúde (SUS) e sobre as transferências intergovernamentais de recursos financeiros na área da saúde e dá outras providências. [legislação on line]. Brasília (DF); 1990b. Disponível em: <URL: http://portalweb02.saude.gov.br/saude/arquivos/pdf/LEI8142.pdf. > [2002 Nov 15]

Brasil. Constituição da República Federativa do Brasil. $22^{\text {a }}$ ed. São Paulo: Saraiva; 1999.

Bronfman M, Langer A, Trostle J. De la investigación en salud a la política: la difícil traducción. México (DF): Instituto Nacional de Saúde Pública; 2000.

Bronfman M; Herrera C. Obstáculos y retos para un vínculo más dinámico entre investigación y políticas de salud. In: Workshop on Utilization of Scientific Information; 2001 June 5-7; Cuernavaca, Mexico. [on line]. Washington (DC): Organización Panamericana de la Salud; 2001. Disponible en: <URL: http://www.paho.org/English/HDP/hdr/mb-mex.pdf $>$ [2002 Nov 21]

Browson RC, Newschaffer, CJ, Ali-Abarghoui F. Policy research for disease prevention: challenges and practical recommendations. Am J Public Health 1997; 87(5):735-9.

Burlandy L, Bodstein RCA. Política e saúde coletiva: reflexão sobre a produção científica (1976-1992). Cad Saúde Pública [periódico on line] 1998; 14(3): 543-54. Disponível em: <URL: http://www.scielo.br/pdf/csp/v14n3/0091.pdf > [2002 Nov 15]

Castells M. A sociedade em rede. A era da informação: economia, sociedade e cultura. São Paulo: Paz e Terra; 2000. Vol. 1.

Cohn A, Westphal MF. Informação técnico-científica no processo decisório em saúde: o caso do Estado de São Paulo. São Paulo; 2000. [Relatório final de projeto]

Coimbra Junior CEA. Produção científica em saúde pública e as bases de dados bibliográficas internacionais. Cad Saúde Pública [periódico on line] 1999;15(4): 8388. Disponível em: <URL: http://www.scielo.br/pdf/csp/v15n4/1028.pdf $>$ [2002 Nov 15] 
Conselho Nacional de Desenvolvimento Científico e Tecnológico. Tabela de áreas do conhecimento. [on line]. Brasília (DF); 2002. Disponível em: $<\mathrm{URL}$ : http://www.cnpq.br/areas/tabconhecimento/index.htm $>$ [2002 Nov 15]

Conselho de Secretários Municipais de Saúde do Estado do Rio de Janeiro. Manual do Gestor. [monografia on line]. Rio de Janeiro; 2001. Disponível em: <URL: http://www.saude.rj.gov.br/cosems/index.htm > [2002 Nov 28]

Davis P, Howden-Chapman P. Translating research findings into health policy. Soc Sci med 1996; 43(5): 865-72.

De Meis L, Leta J. O perfil da ciência brasileira. Rio de Janeiro: UFRJ; 1996.

Frenk J, Bobadilla JF, Sepúlveda J, Rosenthal J, Ruelas E. Un modelo conceptual para la investigación en salud pública. Bol Oficina Sanit Panam 1986; 101: 477-92.

Frenk J. Balancing relevance and excellence: organizational responses to link research with decision making. Soc Sci Med 1992a; 35(1):1397-1404.

Frenk J. La nueva salud pública. In: Organización Panamericana de la Salud. La crisis de la salud pública: reflexiones para el debate. Washington (DC); 1992b. p. 75-93. (OPS Publicación Científica, 540)

Gibbons M, Limoges C, Nowotny H, Schwartzman S, Scott P, Trow M. The new production of knowledge: the dynamics of science and research in contemporary societies. London: Sage; 2000.

Governo do Estado do Maranhão. Gerência de Qualidade de Vida. Agenda 2001/2002. [on line]. São Luís; 2001. Disponível em: <URL:http://www.saude.ma.gov.br/Projetos Programas.htm> [2002 Jun 23]

Guimarães R, Lourenço R, Cosac S. A pesquisa em epidemiologia no Brasil. Rev. Saúde Pública [periódico on line] 2001; 35(4): 321-40. Disponível em: <URL: http://www.scielo.br/pdf/rsp/v35n4/6004.pdf > [2002 Nov 15]

Lévy P. A inteligência coletiva: por uma antropologia do ciberespaço. $2^{\mathrm{a}}$ ed. São Paulo: Loyola; 1999.]

Lévy P. A conexão planetária: o mercado, o ciberespaço, a consciência. São Paulo: 34; 2001.

López Cerezo JA, Luján JL. Observaciones sobre los indicadores de impacto social. Rev Iberoamer Cienc Tecnol Sociedade Innovación [periódico on line] 2002; (3): 
[15 telas]. Disponível em: <URL:

http://www.campusoei.org/revistactsi/numero3/art03.htm $>$ [2002 Nov 15]

Lyon D. Pós-modernidade. São Paulo: Paulus; 1998.

Meadows AJ. A comunicação científica. Trad. de AA Briquet de Lemos. Brasília (DF): Briquet de Lemos Livros; 1999.

Ministério de Ciência e Tecnologia. Indicadores de ciência e tecnologia. [on line]. Brasília (DF): Ministério de Ciência e Tecnologia; 2002. Disponível em: <URL: http://www.mct.gov.br/estat/ascavpp/portugues/menu2page.htm > [2002 Nov 17]

Ministério da Saúde. Portaria GM-2.203, de 6 de novembro de 1996. Aprova a Norma Operacional Básica do Sistema Único de Saúde - SUS (NOB-SUS 1996). [on line]. Brasília (DF); 1996. Disponível em: <URL:

http://portalweb01.saude.gov.br/saude/arquivos/pdf/nob96.pdf $>$ [2002 Nov 15]

Ministério da Saúde. Políticas de saúde: metodologia de formulação. Brasília (DF); 1999.

Ministério da Saúde. Sistema Único de Saúde (SUS) descentralização. Brasília (DF): Secretaria Executiva; dezembro de 2000.

Ministério da Saúde. Portaria GM-95, de 26 de janeiro de 2001. Aprova a Norma Operacional de Atenção à Saúde do Sistema Único de Saúde - SUS (NOAS - SUS 01/01). [on line]. Brasília (DF); 2001a. Disponível em: <URL:

http://sna.saude.gov.br/legisla/informes/GM_P95_01_informes.doc $>$ [2002 Nov 15]

Ministério da Saúde. Portaria GM-393, de 29 de março de 2001. Aprova a Agenda Nacional de Saúde para o ano de 2001. [on line]. Brasília (DF); 2001b Disponível em: <URL: http://www.saude.gov.br/sas/PORTARIAS/Port2001/GM/GM-393.htm $>$ [2002 Nov 15]

Ministério da Saúde. Portaria GM-548, de 16 de abril de 2001. Aprova o documento "Orientações Gerais para a Elaboração e Aplicação da Agenda de Saúde, do Plano de Saúde, dos Quadros de Metas, e do Relatório de Gestão como Instrumentos de Gestão do SUS", parte integrante desta portaria. [on line]. Brasília 
(DF); 2001c Disponível em:

<URL:http://www.saude.gov.br/sas/PORTARIAS/Port2001/GM/GM-548.htm>

[2002 Nov 15]

Ministério da Saúde. SUS: instrumentos de gestão em saúde. Brasília (DF):

Secretaria Executiva; setembro de 2001d.

Ministério da Saúde. Portaria GM-373, de 27 de fevereiro de 2002. Aprova a Norma Operacional de Atenção à Saúde do Sistema Único de Saúde - SUS (NOAS SUS 01/02). [on line]. Brasília (DF); 2002. Disponível em: <URL:

http://www.saude.gov.br/portarias/2002/k\%20373\%20APROVAR\%20NORMAS $\% 2$ 0OPERACIONAL\%20\%20NOAS\%20SUS\%201-2002.rtf $>$ [2003 Fev 15]

Ministério da Saúde. Consulta Pública $\mathbf{N}^{\mathbf{0}}$ 1, de 16 de outubro de 2002. Submete à consulta pública o documento preliminar de PNCTeI/S, constante do Anexo desta consulta. [on line]. Brasília (DF); 2002. Disponível em: <URL:

http://portal.saude.gov.br/saude/visualizar texto.cfm?idxt=13410 $>$ [2002 Nov 21]

Moraes IHS. Informações em saúde: da prática fragmentada ao exercício da cidadania. São Paulo: HUCITEC; 1994.

Moraes IHS. Informações em saúde: para andarilhos e argonautas de uma tecnodemocracia emancipadora. Rio de Janeiro; 2001. [Tese de doutorado Escola Nacional de Saúde Pública da Fundação Oswaldo Cruz].

Noronha DP. Análise das citações das dissertações de mestrado e teses de doutorado em saúde pública (1990-1994): estudo exploratório. Ci Inf [periódico on line] 1998; 27(1): 66-75. Disponível em: <URL: http://www.scielo.br/pdf/csp/v14n3/0091.pdf> [2002 Nov 15]

Nowotny H; Scott P; Gibbons M. Re-thinking science: knowledge and the public in an age of uncertainty. Cambridge: Polito; 2001.

Organización Panamericana de la Salud. Funciones esenciales de salud pública. [Presentado al $42^{\circ}$ Consejo Directivo y 52 ${ }^{\text {a }}$ Sesión del Comité Regional de la OPAS; 2000 Sept 25-29; Washington (DC); 2000]. Washington (DC); 2000. (CD42/15) 
Paim JS, Almeida Filho N. Saúde coletiva: uma "nova saúde pública" ou campo aberto a novos paradigmas. Rev. Saúde Pública [periódico on line] 1998; 32(4): 299-316. Disponível em: <URL: http://www.scielo.br/pdf/rsp/v32n4/a2593.pdf> [2002 Nov 15]

Patton MQ, Grimes PS, Guthrie KM, Brennan NJ, French BD, Blyth DA. In search of impact: an analysis of the utilization of federal health evaluation research. In: Weiss $\mathrm{CH}$, editor. Using social research in public policy making. Lexington (Massachusetts): Lexington Books; 1977. p.141-164.

Pellegrini Filho A, Goldbaum M, Silvi J. Producción de artículos científicos sobre salud en seis países de América Latina, 1973 a 1992. Rev Panam Salud Pública [periódico on line] 1997; 1(1): 23-34. Disponível em Internet: <URL: http://www.scielosp.org/pdf/rpsp/v1n1/1n1a4.pdf $>$ [2002 Nov 15]

Pellegrini Filho A. Ciencia en pro de la salud: notas sobre la organización de la actividad científica para el desarrollo de la salud en América Latina y el Caribe. Washington (DC): Organización Panamericana de la Salud; 2000. (OPS Publicación Científica y Técnica, 578).

Pouvourville G. Public health research: between science and action? [periódico on line]. Cad Saúde Pública [periódico on line] 1999; 15(4): 889-94. Disponível em: <URL: http://www.scielo.br/pdf/csp/v15n4/1029.pdf > [2002 Nov 15]

Pouvourville G. Is scientific knowledge useful for decision making? In: Anales del $5^{\circ}$ Congreso Regional de Información en Ciencias de la Salud; 2001. abr. 23-7; Havana, Cuba. [ on line]. São Paulo: BIREME; 2001. Disponible en: <URL: http://www.bireme.br/crics5/proceedings/Pouvorville/cricsV/sld001.htm $>[2002$ nov 15]

Presidência da República. Câmara da Reforma do Estado. Plano Diretor da Reforma do Aparelho de Estado. Brasília (DF); 1996.

Relatório da $10^{\text {a }}$ Conferência Nacional de Saúde; 1996 set 2-6; Brasília, Brasil. [monografia on line]. [snt]. Disponível em: < URL: http://www.datasus.gov.br/cns/rel10.htm $><2002$ Nov 18> 
Relatório final da $8^{\text {a }}$ Conferência Nacional de Saúde. In: Anais da $8^{\mathbf{a}}$ Conferência Nacional de Saúde; 1986 mar 17-21; Brasília, Brasil. Brasília (DF): Centro de Documentação do Ministério da Saúde; 1987. p.379-89.

Relatório final da $11^{a}$ Conferência Nacional de Saúde; 2000 dez 15-19; Brasília (DF), Brasil. [monografia on line]. [snt]. Disponível em: $<$ URL:

http://conselho.saude.gov.br/11 conferencia/index.htm> [2002 Nov 18]

Rodrigues RJ, Israel K. Conceptual framework and guidelines for the establishment of district-based information systems. Barbados: Pan American Health Organization. Office of Caribbean Program Coordination; 1995. (PAHO/CPC/3.1/95.1)

Secretaria Especial de Proteção Social do Pará. Resolução SES 009, de 16 de maio de 2001. Aprova a agenda estadual de saúde 2001. Diário Oficial do Estado do Pará [periódico on line] Belém, 25 maio 2001, ed. 029464. Disponível em: <URL: http://www.saude.pa.gov.br/agPA.pdf $>$ [2002 Maio 18]

Secretaria de Estado da Saúde de Alagoas. Portaria SESAU 278, de 2 de agosto de 2001. Aprova a Agenda Estadual de Saúde para o ano de 2001. [on line]. [snt]. Disponível em: <URL: http://www.saude.gov.br/descen/agendas.htm > [2002 Maio $15]$

Secretaria de Estado da Saúde do Amapá. Agenda Estadual de Saúde e pactuação das metas para 2001. [on line]. Macapá; 2001. Disponível em: $<U R L:$ http://www.saude.ap.gov.br/saude/Metas $\% 20 \mathrm{da} \% 20$ Agenda $\% 20$ Estadual $\% 20 \mathrm{de} \% 20$ $\underline{\mathrm{Sa} \% \text { FAde.xls }}>[2002$ Nov 28]

Secretaria de Estado da Saúde da Bahia. Agenda Estadual de Saúde 2001. [on line]. [snt]. Disponível em: <URL: http://www.saude.gov.br/descen/agendas.htm $>$ [2002 Maio 18]

Secretaria de Estado da Saúde de Brasília. Agenda Estadual de Saúde 2001. [on line]. Brasília (DF): Ministério da Saúde; 2001. Disponível em: <URL: http://www.saude.gov.br/descen/agendas.htm $>$ [2002 Maio 18]

Secretaria de Estado da Saúde do Ceará. Diretrizes de reorganização da atenção e dos serviços do SUS. [on line]. Fortaleza; 1998. Disponível em: <URL: http://sesanet.saude.ce.gov.br/sesanet/sesanet.wwv main.main?p language $=$ us\&p c ornerid $=81 \& p$ currcornerid $=473 \& p$ full $=1>[2002$ Nov 28] 
Secretaria de Estado da Saúde do Ceará. Agenda Estadual de Saúde 2001. [on line]. [snt]. Disponível em: <URL: http://www.saude.gov.br/descen/agendas.htm > [2002 Maio 18]

Secretaria de Estado da Saúde do Espírito Santo. Agenda Estadual de Saúde Ano 2001. [on line]. Vitória; 2001. Disponível em: <URL: http://www.saude.es.gov.br/> [2002 Maio 18]

Secretaria de Estado da Saúde de Goiás. Resolução 044/2001 - CIB, de 6 de agosto de 2001. Aprova a Agenda Estadual / 2001. [on line]. Goiânia; 2001. Disponível em: <URL: http://www.saude.gov.br/descen/agendas.htm > [2002 Maio 18]

Secretaria de Estado da Saúde de Mato Grosso. Manual do gestor municipal de saúde. [monografia on line]. Cuiabá; 2001. Disponível em:

<URL:http://www.saude.mt.gov.br/caderno_do_gestor.doc> [2002 Nov 28]

Secretaria de Estado da Saúde de Mato Grosso do Sul. Deliberação 137/01/CES/MS, de 16 de julho de 2001. Aprova a Agenda Estadual de Saúde e dá outras providências. [republicada por incorreção em 19 de julho de 2001]. [on line]. [snt]. Disponível em: <URL: http://www.saude.gov.br/descen/agendas.htm > [2002 Maio $18]$

Secretaria de Estado da Saúde de Minas Gerais. Resolução SES 790, de 03 de agosto de 2001. Aprova a Agenda Estadual de Saúde para 2001. [on line]. Belo Horizonte; 2001. Disponível em: <URL: http://www.saude.gov.br/descen/agendas.htm > [2002 Maio 18]

Secretaria de Estado da Saúde da Paraíba. Agenda Estadual de Saúde para 2001. [on line]. [snt]. Disponível em: <URL: http://www.saude.gov.br/descen/agendas.htm $>$ [2002 Maio 18]

Secretaria de Estado da Saúde do Paraná. Agenda Estadual de Saúde 2001. [on line]. Curitiba; 2001. Disponível em: <URL: http://www.saude.pr.gov.br/Agenda_Estadual/agenda.htm $>$ [2002 Jun 23] 
Secretaria de Estado da Saúde do Piauí. Agenda de Saúde do Estado do Piauí 2001. [on line]. Teresina; 2001. Disponível em: <URL:

http://www.saude.gov.br/descen/agendas.htm > [2002 Maio 18]

Secretaria de Estado da Saúde Pública do Rio Grande do Norte. Agenda Estadual de Saúde. [on line]. [snt]. Disponível em: <URL:

http://www.saude.gov.br/descen/agendas.htm $>$ [2002 Maio 18]

Secretaria de Estado de Saúde do Rio de Janeiro. Agenda Estadual de Saúde 2001. [on line]. [snt]. Disponível em: <URL: http://www.saude.gov.br/descen/agendas.htm $>$ [2002 Maio 18]

Secretaria de Estado de Saúde e Saneamento do Acre. Agenda Estadual de Saúde. [on line]. [snt]. Disponível em: <URL:

http://www.saude.gov.br/descen/agendas.htm $>$ [2002 Maio 18]

Secretaria de Estado da Saúde de Santa Catarina. Portaria 425/SES, de 21 de maio de 2001. Aprova a Agenda Estadual de Saúde para o ano de 2001. [on line] [snt].

Disponível em: <URL:

http://www.saude.sc.gov.br/agendaestadualsaude/agenda nacional de saude.htm $>$ [2002 Maio 18]

Secretaria de Estado da Saúde de São Paulo. Agenda Estadual de Saúde. [on line] [snt]. Disponível em: <URL: http://www.saude.gov.br/descen/agendas.htm > [2002 Maio 18]

Secretaria de Estado da Saúde de Sergipe. Agenda de Saúde do Estado de Sergipe. [on line]. [snt]. Disponível em: $<$ URL: http://www.saude.gov.br/descen/agendas.htm $>$ [2002 Maio 18]

Secretaria de Estado da Saúde de Tocantins. Agenda Estadual de Saúde. [on line] [snt]. Disponível em: <URL: http://www.saude.gov.br/descen/agendas.htm $>$ [2002 Maio 18]

Stehr N. Da desigualdade de classe à desigualdade de conhecimentos. Rev bras Ci Soc [periódico on line] 2000; 15(42): 101-12. Disponível: < URL: http://www.scielo.br/pdf/rbcsoc/v15n42/1739.pdf $>$ [2002 Nov 15]

Stehr N. Modern societies as knowledge societies: the implications for health and health care. In: Anales del $5^{\circ}$ Congreso Regional de Información en Ciencias de la Salud; 2001. abr. 23-7; Havana, Cuba. [ on line]. São Paulo: BIREME; 2001. 
Disponible en: $<$ URL:

http://www.bireme.br/crics5/proceedings/Stehr/havana_stehr.htm> [2002 nov 15]

Stone D, Maxwell S, Keating M. Bridging research and policy: an international workshop funded by the UK Department for International Development, Radcliffe House, Warwick University, 16-17 July 2001. [monograph online]. Coventry: Warwick University; 2001. Available from:

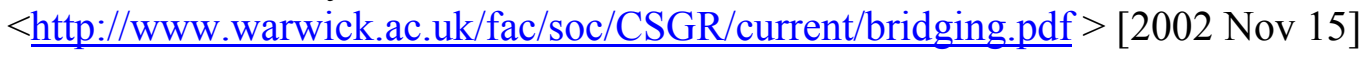

Toffler A. A terceira onda. 18 a ed. Rio de Janeiro: Record; 1992.

Trigueiro MGS. A formação dos cientistas: necessidades e soluções. In: Baumgarten $\mathrm{M}$, organizadora. A era do conhecimento: matrix ou ágora? Porto Alegre: Editora da Universidade; 2001. p. 61-70.

Trostle J, Bronfman M, Langer A. How do researchers influence decision makers? Case studies of Mexican policies. Health Policy Planning 1999;14(2):103-14.

United States National Science Foundation. Chapter 5: Academic research and development: financial and personnel resources, integration with graduate education, and outputs. In: Science and Engineering Indicators, 1998. [monograph on line] Arlington, VA: The National Science Foundation; 1998. Disponível em: <URL: http://www.nsf.gov/sbe/srs/seind98/access/c5/c5s4.htm\#c5s4l2 $>$ [2002 Nov 15]

United States National Science Foundation. Chapter 5: Academic research and development: financial and personnel resources, integration with graduate education, and outputs. In: Science and Engineering Indicators, 2002. [monograph on line] Arlington, VA: The National Science Foundation; 2002. Disponível em: <URL: http://www.nsf.gov/sbe/srs/seind02/pdf/c05.pdf $>$ [2002 Nov 15]

Walt G, Gilson L. Reforming the health sector in developing countries: the central role of policy analysis. Health policy planning 1994; 9(4): 353-70.

Weiss $\mathrm{CH}$, editor. Using social research in public policy making. Lexington (Massachusetts): Lexington Books; 1977 


\section{ANEXO 1}

\section{Categorias Temáticas da BVS-SP Brasil ${ }^{*}$}

Acidentes e violência

Administração e planejamento em saúde

Alimentação e nutrição

Ambiente e saúde

Atenção à saúde

Ciência e tecnologia em saúde

Ciências sociais em saúde

Comunicação em saúde

Demografia

Direito sanitário

Doenças crônicas e degenerativas

Doenças infecciosas e parasitárias

Drogas de uso terapêutico e social

Economia da saúde

Epidemiologia

Equidade em saúde e social

Ética e bioética

* Disponível em:

http://saudepublica.bvs.br/xml2html/xmlListT.php?xml=xml/pt/bvs.xml\&xsl=xsl/bvs-topicList.xsl 
História da saúde pública

Medicamentos, vacinas e insumos

Políticas públicas e saúde

Promoção e educação em saúde

Recursos humanos em saúde pública

Saúde animal

Vigilância em saúde

(cont.) 


\section{Escopo das Categorias:}

Acidentes e violência: Refere-se ao conjunto de agravos à saúde que pode levar a óbito ou seqüelas irreversíveis que inclui as causas ditas acidentais: devidas ao trânsito, trabalho, quedas, envenenamentos, afogamentos e outros tipos de acidentes, e as causas intencionais como agressões e lesões autoprovocadas.

Administração e planejamento em saúde: Refere-se à organização, elaboração de planos e políticas públicas e governamentais, ao conjunto de normas e funções regidas por princípios e práticas administrativas, gestão, planificação e gerência.

Alimentação e nutrição: Refere-se a todos os tipos de substâncias que têm por função alimentar ou nutrir seres humanos e animais.

Ambiente e saúde: Refere-se ao estudo das interações entre os seres vivos e o meio, dedica-se a analisar as formas de vida, substâncias agressivas e condições adequadas ou inadequadas, produzidas pela ação humana, que podem exercer alguma influência sobre a sua saúde e sobre o meio em que vive.

Atenção à saúde: Refere-se à proteção e atenção à saúde dos diversos grupos etários que correspondem aos ciclos vitais: feto, criança, adolescente, jovem, mulher, homem, adulto e idoso; e aos serviços de saúde correspondentes às ações de atenção.

Ciência e tecnologia em saúde: Refere-se a investimentos públicos em ciência e tecnologia; desenvolvimento institucional e de formação de pessoal voltados à ciência e tecnologia em saúde; políticas públicas e de gestão em Ciência e Tecnologia.

Ciências sociais em saúde: Refere-se aos estudos que se utilizam ou são elaborados pelas ciências sociais aplicados ao campo da saúde pública. Abrange: dinâmicas e movimentos socioculturais, relações interpessoais e de grupos; diversidades étnicas, questões de gênero; modos de vida relacionados à proteção ou agressão à saúde, sofrimentos psíquicos e doenças sociais.

Comunicação em saúde: Refere-se ao conjunto dos meios de comunicação de massa voltados a divulgação de produtos, serviços, ações preventivas e identificação de riscos relacionados à saúde ou morbidades de interesse individual ou coletivo.

Demografia: Refere-se aos estudos das populações humanas, com o objetivo de caracterizá-las e analisar tendências populacionais. 
Direito sanitário: Refere-se ao conjunto de leis e normas, nacional e internacional, que compõe o sistema jurídico no que se refere à saúde dos cidadãos e da coletividade. Abrange organização da administração sanitária, responsabilidade ética, administrativa, civil e penal dos profissionais e dos serviços de saúde e a aplicação dos instrumentos legais para a tutela e garantia do direito à saúde.

Doenças crônicas e degenerativas: Refere-se ao conjunto de doenças relacionadas a múltiplos fatores de risco ambientais (hábitos de vida, ambiente ocupacional, ambientes em geral), fatores genéticos e envelhecimento populacional.

Doenças infecciosas e parasitárias: Refere-se ao conjunto de infecções que podem ser adquiridas por contato direto de pessoa a pessoa, indireto e por contaminação biológica, alimentar e ambiental, e também por vetores biológicos.

Drogas de uso terapêutico e social: Refere-se aos efeitos causados pelo consumo de substâncias químicas e seus desdobramentos sobre as atividades físicas, psíquicas ou sobre o comportamento humano.

Economia da saúde: Refere-se aos estudos sobre gasto e financiamento em saúde, alocação e utilização de recursos no setor saúde, avaliação econômica (análise custoefetividade e custo-benefício de programas, procedimentos, intervenções e políticas públicas), eficiência e custos na prestação de serviços, análise da demanda e utilização de serviços, processos de reforma setorial, organização dos serviços e modalidades de pagamento, análise do funcionamento e das falhas de mercado no setor saúde.

Epidemiologia: Refere-se aos estudos retrospectivos e prospectivos da distribuição e dos determinantes da prevalência das doenças em pessoas e animais, envolvendo o estudo dos fatores que propiciam a ocorrência das doenças, inquéritos e investigação epidemiológica.

Equiidade em saúde e social: Refere-se à igualdade de recursos para necessidades iguais, de oportunidades de acesso para iguais necessidades, utilização dos mesmos recursos políticos, materais, de pessoal e econômico, para neceesidades iguais, ética na aplicação de tecnologia e recursos financeiros às demandas sociais.

Ética e bioética: Refere-se ao conjunto de regras de conduta moral, deontológica e social que regulamentam as relações mútuas entre os indivíduos ou entre estes e a comunidade e o meio. A bioética volta-se ao estudo dos valores morais das ciências da vida e dos cuidados da saúde, de abrangência individual ou coletiva. 
História da saúde pública: Refere-se às investigações voltadas a história das políticas, instituições e profissões de saúde pública, história das ciências biomédicas e das doenças, modos de vida e práticas curativas populares; saúde e cidades.

(cont.) 
Medicamentos, vacinas e insumos: Refere-se à produção científica e tecnológica referentes à biotecnologia e farmacologia de produtos de origem sintética e natural para consumo da população.

Políticas públicas e saúde: Refere-se à arena de interesses políticos, sociais e econômicos relativos à coisa pública de domínio público relacionados ao setor da saúde.

Promoção e educação em saúde: Refere-se às diferentes formas de organização da sociedade no enfrentamento de seus problemas de ausência de atenção à saúde e ao meio ambiente pelos poderes públicos, aos direitos do consumidor e informação em saúde, controle público sobre a utilização de recursos públicos do setor saúde, cidadania e saúde, educação em saúde.

Recursos humanos em saúde pública: Refere-se à formação e capacitação de pessoal técnico especializado, necessário ao funcionamento do sistema público de saúde local, estadual e nacional para as atividades de ação, regulação, controle e fiscalização, administração, gerenciamento e gestão, pesquisa, ensino e treinamento de pessoal.

Saúde animal: Refere-se aos cuidados e atenção à saúde dos animais, particularmente os de convívio humano ou como fonte alimentar para o consumo humano.

Vigilância em saúde: Refere-se à proteção e promoção à saúde da população por meio da segurança sanitária de produtos, comercialização e serviços ofertados. Abrange: ambientes, processos de produção de insumos e tecnologias a ela relacionadas, vigilância de alimentos, cosméticos, derivados de tabaco, farmacovigilância, monitoramento de mercado, portos, aeroportos, zonas de fronteiras, produtos para saúde, saneantes, sangue e derivados, serviços de saúde, tecnovigilância, toxicologia, campanhas sanitárias. 


\section{ANEXO 2}

Formulário para análise dos sites das Secretarias Estaduais de Saúde

\begin{tabular}{|c|c|c|}
\hline \multicolumn{3}{|c|}{ Secretaria de Estado da Saúde de ...........................< $<$ endereço do site $]>$} \\
\hline \multicolumn{2}{|c|}{ Organização do site } & \\
\hline \multicolumn{2}{|l|}{ Atualização } & \\
\hline \multicolumn{2}{|l|}{ Conteúdo } & \\
\hline \multicolumn{2}{|c|}{ Informação específica para gestores } & \\
\hline \multicolumn{2}{|l|}{ Links } & \\
\hline \multicolumn{2}{|c|}{ Fontes das tabelas de indicadores } & \\
\hline \multirow{4}{*}{$\begin{array}{l}\text { Informação } \\
\text { científico- } \\
\text { técnica }\end{array}$} & Acesso a bases de dados & \\
\hline & $\begin{array}{l}\text { Textos completos ou publicações } \\
\text { técnico-científicas }\end{array}$ & \\
\hline & $\begin{array}{l}\text { Existência de Centro de } \\
\text { Documentação }\end{array}$ & \\
\hline & Indicação de utilização de ICT & \\
\hline
\end{tabular}

Data da

consulta: 


\section{ANEXO 3 \\ Roteiro utilizado nas entrevistas}

Nome:

Cargo:

Profissão:

Formação acadêmica (grau):

Instituição em que se formou:

Departamento/unidade na Secretaria:

Tempo de trabalho nessa unidade:

1. Que fontes de informação você utiliza para pesquisa ou para resolver os problemas de saúde relacionados a seu trabalho?

2. Quais as necessidades de informação sentidas por você como gestor em saúde para realização satisfatória de seu trabalho?

3. Descreva a última vez que você teve que buscar informação para apoiar alguma decisão em saúde.

4. Que tipo de tecnologias são utilizadas na sua unidade para acesso a informações? Quem as utiliza ou está capacitado para utilizá-las?

5. Que tipo de documentos técnicos e/ou científicos você produz? Como são publicados e/ou divulgados?

6. Como você atualiza seu conhecimento técnico-científico?

7. Além dos dados epidemiológicos locais, que outra informação é utilizada no processo de tomada de decisão? Onde é encontrada?

8. Para os programas de capacitação ou campanhas de saúde, que material informativo e/ou científico-técnico é utilizado? 


\section{ANEXO 4}

\section{Revistas da área de saúde pública indexadas em bases de dados internacionais}

\begin{tabular}{|c|c|c|c|c|c|}
\hline TÍTULO DA REVISTA & País & $\begin{array}{l}\text { MEDLINE } \\
2002\end{array}$ & $\begin{array}{c}\text { Index } \\
\text { Medicus } \\
2002\end{array}$ & $\begin{array}{c}\text { JCR } \\
\text { Science } \\
2001 \\
\end{array}$ & $\begin{array}{c}\text { JCR Social } \\
\text { Sciences } \\
2001\end{array}$ \\
\hline ACCIDENT ANALYSIS AND PREVENTION & US & & & & • \\
\hline $\begin{array}{l}\text { ADMINISTRATION AND POLICY IN MENTAL } \\
\text { HEALTH }\end{array}$ & US & & & & $\bullet$ \\
\hline AIDS AND PUBLIC POLICY JOURNAL & US & & & & $\bullet$ \\
\hline $\begin{array}{l}\text { ADVANCES IN HEALTH SCIENCES EDUCATION: } \\
\text { THEORY AND PRACTICE }\end{array}$ & NL & $\bullet$ & $\bullet$ & & \\
\hline AHOT-BE YSRAEL & $\mathrm{IL}$ & - & & & \\
\hline AIDS CARE & UK & & & & $\bullet$ \\
\hline AIDS EDUCATION AND PREVENTION & US & & & & - \\
\hline AIDS PACIENT CARE AND STDS & US & & & & $\bullet$ \\
\hline AIHAJ & US & & & $\bullet$ & \\
\hline $\begin{array}{l}\text { AMERICAN INDUSTRIAL HYGIENE ASSOCIATION } \\
\text { JOURNAL }\end{array}$ & US & & & $\bullet$ & \\
\hline AMERICAN JOURNAL OF COMMUNITY PSYCHOLOGY & US & & & & - \\
\hline AMERICAN JOURNAL OF EPIDEMIOLOGY & US & - & & - & \\
\hline AMERICAN JOURNAL OF HEALTH BEHAVIOUR & US & & & & - \\
\hline AMERICAN JOURNAL OF HEALTH PROMOTION & US & & & & - \\
\hline AMERICAN JOURNAL OF INDUSTRIAL MEDICINE & US & & & - & \\
\hline AMERICAN JOURNAL OF PREVENTIVE MEDICINE & US & - & - & - & \\
\hline AMERICAN JOURNAL OF PUBLIC HEALTH & US & $\bullet$ & $\bullet$ & $\bullet$ & $\bullet$ \\
\hline $\begin{array}{l}\text { AMERICAN JOURNAL OF TROPICAL MEDICINE } \\
\text { AND HYGIENE }\end{array}$ & US & & & $\bullet$ & \\
\hline ANNALI DELL ISTITUTO SUPERIORE DI SANITA & IT & $\bullet$ & $\bullet$ & & \\
\hline ANNALI DI IGIENE & IT & - & & & \\
\hline ANNALS OF EPIDEMIOLOGY & US & $\bullet$ & & - & \\
\hline ANNALS OF HUMAN BIOLOGY & UK & & & - & \\
\hline ANNALS OF OCCUPATIONAL HYGIENE & UK & & & - & \\
\hline ANNALS OF TROPICAL MEDICINE AND PARASITOLOGY & UK & & & - & \\
\hline ANNUAL REVIEW OF PUBLIC HEALTH & US & - & - & - & $\bullet$ \\
\hline ARCHIVES DE L INSTITUT PASTEUR DE MADAGASCAR & MG & $\bullet$ & $\bullet$ & & \\
\hline ARCHIVES DE L INSTITUT PASTEUR DE TUNIS & TN & - & - & & \\
\hline ARCHIVES OF ENVIRONMENTAL HEALTH & US & & & - & \\
\hline ASIA-PACIFIC JOURNAL OF PUBLIC HEALTH & $\mathrm{CN}$ & $\bullet$ & $\bullet$ & & \\
\hline $\begin{array}{l}\text { AUSTRALIAN AND NEW ZEALAND JOURNAL OF } \\
\text { PUBLIC HEALTH }\end{array}$ & $\mathrm{AU}$ & $\bullet$ & $\bullet$ & & $\bullet$ \\
\hline AUSTRALIAN JOURNAL OF RURAL HEALTH & $\mathrm{AU}$ & - & & & \\
\hline AVIATION, SPACE AND ENVIRONMENTAL MEDICINE & US & & & - & \\
\hline BMC PUBLIC HEALTH (ELECTRONIC RESEARCH) & UK & - & - & & \\
\hline BIOMEDICAL AND ENVIRONMENTAL SCIENCES & $\mathrm{CN}$ & & & $\bullet$ & \\
\hline $\begin{array}{l}\text { BULLETIN DE LA SOCIETE DE PATHOLOGIE EXOTIQUE } \\
\text { ET DE SES FILIALES }\end{array}$ & & & & $\bullet$ & \\
\hline BULLETIN OF THE WORLD HEALTH ORGANIZATION & $\mathrm{CH}$ & $\bullet$ & $\bullet$ & $\bullet$ & \\
\hline CADERNOS DE SAUDE PUBLICA & BR & - & - & & \\
\hline $\begin{array}{l}\text { CAHIERS DE SOCIOLOGIE ET DE DEMOGRAPHIE } \\
\text { MEDICALES }\end{array}$ & FR & - & $\bullet$ & & \\
\hline $\begin{array}{l}\text { CANADIAN JOURNAL OF PUBLIC HEALTH. REVUE } \\
\text { CANADIENNE DE SANTE PUBLIQUE }\end{array}$ & CA & $\bullet$ & $\bullet$ & & $\bullet$ \\
\hline CANCER CAUSES AND CONTROL & UK & $\bullet$ & & $\bullet$ & \\
\hline
\end{tabular}




\section{ANEXO 4 (cont.)}

\begin{tabular}{|c|c|c|c|c|c|}
\hline TÍTULO REVISTA & País & $\begin{array}{l}\text { MEDLINE } \\
2002\end{array}$ & $\begin{array}{c}\text { Index } \\
\text { Medicus } \\
2002 \\
\end{array}$ & $\begin{array}{c}\text { JCR } \\
\text { Science } \\
2001 \\
\end{array}$ & $\begin{array}{c}\text { JCR Social } \\
\text { Sciences } \\
2001 \\
\end{array}$ \\
\hline $\begin{array}{l}\text { CANCER EPIDEMIOLOGY, BIOMARKERS AND } \\
\text { PREVENTION }\end{array}$ & US & $\bullet$ & & $\bullet$ & \\
\hline $\begin{array}{l}\text { CENTRAL EUROPEAN JOURNAL OF PUBLIC } \\
\text { HEALTH }\end{array}$ & SK & $\bullet$ & - & & \\
\hline CHILDREN'S HEALTH CARE & US & & & & • \\
\hline COMMUNITY DENTAL HEALTH & UK & - & $\bullet$ & - & \\
\hline $\begin{array}{l}\text { COMMUNITY DENTISTRY AND ORAL } \\
\text { EPIDEMIOLOGY }\end{array}$ & DK & $\bullet$ & & & \\
\hline COMMUNITY MENTAL HEALTH JOURNAL & US & & & & $\bullet$ \\
\hline $\begin{array}{l}\text { COMMUNITY PRACTITIONER ; THE JOURNAL OF } \\
\text { THE COMMUNITY, PRACTITIONERS \& HEALTH } \\
\text { VISITORS ASSOCIATION }\end{array}$ & UK & $\bullet$ & & & \\
\hline DEMOGRAPHY & US & - & - & & \\
\hline DRUG SAFETY & $\mathrm{NZ}$ & & & $\bullet$ & \\
\hline ENVIRONMENTAL GEOCHEMISTRY AND HEALTH & $\mathrm{NE}$ & & & $\bullet$ & \\
\hline ENVIRONMENTAL HEALTH PERSPECTIVES & US & & & $\bullet$ & \\
\hline ENVIRONMENTAL RESEARCH & US & & & - & \\
\hline EPIDEMIOLOGIC REVIEWS & US & & & • & \\
\hline EPIDEMIOLOGY & US & & & $\bullet$ & \\
\hline EPIDEMIOLOGY AND INFECTION & US & & & - & \\
\hline ETHNICITY AND DISEASE & US & $\bullet$ & $\bullet$ & & \\
\hline EUROPEAN JOURNAL OF CANCER PREVENTION & UK & $\bullet$ & $\bullet$ & & \\
\hline EUROPEAN JOURNAL OF EPIDEMIOLOGY & $\mathrm{DE}$ & & & $\bullet$ & \\
\hline EUROPEAN JOURNAL OF PUBLIC HEALTH & UK & $\bullet$ & $\bullet$ & $\bullet$ & $\bullet$ \\
\hline FAMILY AND COMMUNITY HEALTH & US & & & & $\bullet$ \\
\hline FLUORIDE & US & & & $\bullet$ & \\
\hline GACETA SANITARIA & ES & $\bullet$ & $\bullet$ & & \\
\hline GENETIC EPIDEMIOLOGY & US & & & $\bullet$ & \\
\hline GESUNDHEITSWESEN & $\mathrm{DE}$ & $\bullet$ & $\bullet$ & & \\
\hline GIGIENA I SANITARIIA & RU & $\bullet$ & $\bullet$ & & \\
\hline HEALTH AND SOCIAL CARE IN THE COMMUNITY & UK & & & & $\bullet$ \\
\hline HEALTH AFFAIRS & US & - & $\bullet$ & & \\
\hline HEALTH AND HUMAN RIGHTS & US & $\bullet$ & $\bullet$ & & \\
\hline HEALTH AND PLACE & UK & $\bullet$ & & & \\
\hline HEALTH BULLETIN & UK & $\bullet$ & $\bullet$ & & \\
\hline HEALTH EDUCATION AND BEHAVIOR & US & - & $\bullet$ & & - \\
\hline HEALTH EDUCATION RESEARCH & UK & & & & $\bullet$ \\
\hline HEALTH PHYSICS & US & & & $\bullet$ & \\
\hline HEALTH PROMOTION INTERNATIONAL & UK & & & & $\bullet$ \\
\hline HEALTH REPORTS & $\mathrm{CA}$ & $\bullet$ & $\bullet$ & & \\
\hline HEALTH SERVICE JOURNAL, THE & UK & $\bullet$ & & & \\
\hline HEALTH TECHNOLOGY ASSESSMENT & US & $\bullet$ & $\bullet$ & & \\
\hline $\begin{array}{l}\text { HEALTHY PEOPLE } 2000 \text { STATISTICS AND SURVEILLANCE / } \\
\text { NATIONAL CENTER FOR HEALTH STATISTICS }\end{array}$ & US & $\bullet$ & & & \\
\hline HOME HEALTHCARE NURSE & US & $\bullet$ & & & \\
\hline INDIAN JOURNAL OF PUBLIC HEALTH & IN & • & • & & \\
\hline INDOOR AND BUILT ENVIRONMENT & $\mathrm{CH}$ & & & - & \\
\hline INDUSTRIAL HEALTH & JP & & & - & \\
\hline INFECTION CONTROL AND HOSPITAL EPIDEMIOLOGY & US & & & $\bullet$ & \\
\hline $\begin{array}{l}\text { INTERNATIONAL ARCHIVES OF OCCUPATIONAL AND } \\
\text { ENVIRONMENTAL HEALTH }\end{array}$ & $\mathrm{DE}$ & & & $\bullet$ & \\
\hline $\begin{array}{l}\text { INTERNATIONAL JOURNAL OF ENVIRONMENTAL } \\
\text { HEALTH RESEARCH }\end{array}$ & UK & & & $\bullet$ & \\
\hline $\begin{array}{l}\text { INTERNATIONAL JOURNAL OF HEALTH SERVICES: } \\
\text { PLANNING ADMINISTRATIO EVALUATION }\end{array}$ & US & & $\bullet$ & & \\
\hline
\end{tabular}




\section{ANEXO 4 (cont.)}

\begin{tabular}{|c|c|c|c|c|c|}
\hline TÍTULO REVISTA & País & $\begin{array}{l}\text { MEDLINE } \\
2002\end{array}$ & $\begin{array}{l}\text { Index } \\
\text { Medicus } \\
2002 \\
\end{array}$ & $\begin{array}{c}\text { JCR } \\
\text { Science } \\
2001 \\
\end{array}$ & $\begin{array}{c}\text { JCR Social } \\
\text { Sciences } \\
2001 \\
\end{array}$ \\
\hline INTERNATIONAL JOURNAL OF EPIDEMIOLOGY & UK & & & - & \\
\hline $\begin{array}{l}\text { INTERNATIONAL JOURNAL OF HEALTH PLANNING } \\
\text { AND MANAGEMENT, THE }\end{array}$ & UK & & & & - \\
\hline $\begin{array}{l}\text { INTERNATIONAL JOURNAL OF TECHNOLOGY } \\
\text { ASSESSMENT IN HEALTH CARE }\end{array}$ & UK & & & - & \\
\hline $\begin{array}{l}\text { INTERNATIONAL JOURNAL OF HYGIENE AND } \\
\text { ENVIRONMENTAL HEALTH }\end{array}$ & $\mathrm{DE}$ & $\bullet$ & $\bullet$ & & \\
\hline ISSUE BRIEF (HEALTH POLICY TRACKING SERVICE & US & $\bullet$ & & & \\
\hline JOURNAL OF ADOLESCENT HEALTH & US & & & $\bullet$ & $\bullet$ \\
\hline JOURNAL OF AEROSOL MEDICINE & US & & & - & \\
\hline JOURNAL OF AGING AND SOCIAL POLICY & US & $\bullet$ & & & \\
\hline JOURNAL OF AGRICULTURAL SAFETY AND HEALTH & US & $\bullet$ & $\bullet$ & & \\
\hline JOURNAL OF AMERICAN COLLEGE HEALTH & & & & & $\bullet$ \\
\hline JOURNAL OF CLINICAL EPIDEMIOLOGY & US & & & $\bullet$ & \\
\hline JOURNAL OF COMMUNITY HEALTH & US & - & - & & - \\
\hline JOURNAL OF COMMUNITY HEALTH NURSING & US & $\bullet$ & $\bullet$ & & \\
\hline JOURNAL OF COMMUNITY PSYCHOLOGY & US & & & & $\bullet$ \\
\hline JOURNAL OF ENVIRONMENTAL HEALTH & US & & & $\bullet$ & \\
\hline $\begin{array}{l}\text { JOURNAL OF ENVIRONMENTAL SCIENCE AND } \\
\text { HEALTH. PART B. PESTICIDES, FOOD, CONTAMINANTS, } \\
\text { AND AGRICULTURAL WASTES }\end{array}$ & US & & & $\bullet$ & \\
\hline $\begin{array}{l}\text { JOURNAL OF EPIDEMIOLOGY AND COMMUNITY } \\
\text { HEALTH }\end{array}$ & UK & $\bullet$ & $\bullet$ & $\bullet$ & \\
\hline $\begin{array}{l}\text { JOURNAL OF EXPOSURE ANALYSIS AND ENVIRONMENTAL } \\
\text { EPIDEMIOLOGY }\end{array}$ & US & & & $\bullet$ & \\
\hline JOURNAL OF HEALTH ADMINISTRATION EDUCATION & US & $\bullet$ & & & \\
\hline JOURNAL OF HEALTH AND SOCIAL BEHAVIOR & US & & & & - \\
\hline $\begin{array}{l}\text { JOURNAL OF HEALTH CARE FOR THE POOR AND } \\
\text { UNDERSERVED }\end{array}$ & US & & & & $\bullet$ \\
\hline JOURNAL OF HEALTH POLITICS, POLICY AND LAW & UK & - & - & & \\
\hline JOURNAL OF HEALTH POPULATION AND NUTRITION & $\mathrm{BD}$ & & & - & \\
\hline JOURNAL OF HIV THERAPY & UK & & $\bullet$ & & \\
\hline JOURNAL OF MEDICAL SCREENING & UK & $\bullet$ & $\bullet$ & & \\
\hline $\begin{array}{l}\text { JOURNAL OF OCCUPATIONAL AND ENVIRONMENTAL } \\
\text { MEDICINE }\end{array}$ & US & & & $\bullet$ & \\
\hline JOURNAL OF OCCUPATIONAL HEALTH & JP & & & - & \\
\hline JOURNAL OF PALLIATIVE CARE & $\mathrm{CA}$ & & & & $\bullet$ \\
\hline JOURNAL OF PUBLIC HEALTH DENTISTRY & US & - & - & - & \\
\hline $\begin{array}{l}\text { JOURNAL OF PUBLIC HEALTH MANAGEMENT } \\
\text { AND PRACTICE }\end{array}$ & US & $\bullet$ & & & \\
\hline JOURNAL OF PUBLIC HEALTH MEDICINE & UK & $\bullet$ & $\bullet$ & $\bullet$ & $\bullet$ \\
\hline JOURNAL OF PUBLIC HEALTH POLICY & US & $\bullet$ & $\bullet$ & $\bullet$ & $\bullet$ \\
\hline JOURNAL OF RELIGION AND HEALTH & US & & & & - \\
\hline JOURNAL OF RURAL HEALTH & US & & & $\bullet$ & - \\
\hline JOURNAL OF SAFETY RESEARCH & US & & & & - \\
\hline JOURNAL OF SCHOOL HEALTH & US & & & & $\bullet$ \\
\hline $\begin{array}{l}\text { JOURNAL OF THE EGYPTIAN PUBLIC HEALTH } \\
\text { ASSOCIATION }\end{array}$ & EG & & $\bullet$ & & \\
\hline $\begin{array}{l}\text { JOURNAL OF THE ROYAL SOCIETY FOR THE PROMOTION } \\
\text { OF HEALTH }\end{array}$ & UK & & & & $\bullet$ \\
\hline JOURNAL OF THE ROYAL SOCIETY OF HEALTH & UK & - & - & & - \\
\hline $\begin{array}{l}\text { JOURNAL OF TOXICOLOGY AND ENVIRONMENTAL } \\
\text { HEALTH }\end{array}$ & US & & & $\bullet$ & \\
\hline $\begin{array}{l}\text { JOURNAL OF TOXICOLOGY AND ENVIRONMENTAL } \\
\text { HEALTH. PART B, CRITICAL REVIEWS }\end{array}$ & US & & & $\bullet$ & \\
\hline JOURNAL OF TRAVEL MEDICINE & CA & - & - & & \\
\hline
\end{tabular}


ANEXO 4 (cont.)

\begin{tabular}{|c|c|c|c|c|c|}
\hline TÍTULO REVISTA & País & $\begin{array}{l}\text { MEDLINE } \\
2002\end{array}$ & $\begin{array}{l}\text { Index } \\
\text { Medicus } \\
2002\end{array}$ & $\begin{array}{l}\text { JCR } \\
\text { Science } \\
2001\end{array}$ & $\begin{array}{l}\text { JCR Social } \\
\text { Sciences } \\
2001\end{array}$ \\
\hline JOURNAL OF URBAN HEALTH & US & & & $\bullet$ & \\
\hline JOURNAL OF WOMENS HEALTH & US & & & $\bullet$ & $\bullet$ \\
\hline $\begin{array}{l}\text { JOURNAL OF WOMENS HEALTH AND GENDER BASED } \\
\text { MEDICINE }\end{array}$ & US & & & $\bullet$ & $\bullet$ \\
\hline $\begin{array}{l}\text { KOKURITSU IYAKUHIN SHOKUHIN EISEI } \\
\text { KENKYUSHO HOKOKU }\end{array}$ & $\mathrm{JP}$ & $\bullet$ & $\bullet$ & & \\
\hline MEDICAL CARE & US & & & $\bullet$ & \\
\hline MMWR :RECOMMENDATIONS AND REPORTS & US & - & - & & \\
\hline MILBANK QUARTERLY & US & $\bullet$ & $\bullet$ & & \\
\hline NEUROEPIDEMIOLOGY & US & & & - & \\
\hline NEW SOUTH WALES PUBLIC HEALTH BULLETIN & $\mathrm{AU}$ & $\bullet$ & $\bullet$ & & \\
\hline NICOTINE \& TOBACCO RESEARCH & UK & & - & & \\
\hline $\begin{array}{l}\text { NIPPON EISEIGAKU ZASSHI. JAPANESE JOURNAL } \\
\text { OF HYGIENE }\end{array}$ & JP & $\bullet$ & $\bullet$ & & \\
\hline $\begin{array}{l}\text { NIPPON KOSHU EISEI ZASSHI. JAPANESE JOURNAL } \\
\text { OF PUBLIC HEALTH }\end{array}$ & JP & $\bullet$ & $\bullet$ & & \\
\hline OCCUPATIONAL AND ENVIRONMENTAL MEDICINE & UK & & & • & \\
\hline OCCUPATIONAL MEDICINE (OXFORD) & UK & & & - & \\
\hline OPHTHALMIC EPIDEMIOLOGYI & ND & - & - & & \\
\hline PACIFIC HEALTH DIALOG & $\mathrm{NZ}$ & $\bullet$ & $\bullet$ & & \\
\hline PAEDIATRIC AND PERINATAL EPIDEMIOLOGY & US & & & - & \\
\hline PALLIATIVE MEDICINE & UK & & & $\bullet$ & \\
\hline PATIENT EDUCATION AND COUNSELING & UK & & & - & \\
\hline $\begin{array}{l}\text { POPULATION REPORTS. SERIES L: ISSUES } \\
\text { IN WORLD HEALTH }\end{array}$ & US & $\bullet$ & $\bullet$ & & \\
\hline $\begin{array}{l}\text { POSTEPY HIGIENY I MEDYCYNY } \\
\text { DOSWIADCZALNEJ }\end{array}$ & PL & $\bullet$ & $\bullet$ & & \\
\hline PREVENTIVE MEDICINE & US & $\bullet$ & $\bullet$ & $\bullet$ & \\
\hline PROBLEMI NA KHIGIENATA & BG & $\bullet$ & & & \\
\hline $\begin{array}{l}\text { PROBLEMY SOTSIALNOI GIGIENY I ISTORIIA } \\
\text { MEDITSINY }\end{array}$ & RU & $\bullet$ & $\bullet$ & & \\
\hline PROMOTION ET EDUCATION & FR & $\bullet$ & $\bullet$ & & \\
\hline PRZEGLAD LEKARSKI & RU & $\bullet$ & $\bullet$ & & \\
\hline PSYCHIATRIC SERVICES & US & & & $\bullet$ & - \\
\hline PSYCHOLOGY AND HEALTH & UK & & & & $\bullet$ \\
\hline PUBLIC HEALTH & UK & $\bullet$ & $\bullet$ & $\bullet$ & $\bullet$ \\
\hline PUBLIC HEALTH NURSING & US & $\bullet$ & $\bullet$ & & $\bullet$ \\
\hline PUBLIC HEATH NUTRITION & UK & & $\bullet$ & & \\
\hline $\begin{array}{l}\text { PUBLIC HEALTH REPORTS } \\
\end{array}$ & US & $\bullet$ & - & $\bullet$ & $\bullet$ \\
\hline PUBLIC HEALTH REVIEWS & IL & $\bullet$ & - & & \\
\hline QUALITY IN HEALTH CARE & UK & & & $\bullet$ & \\
\hline QUALITY OF LIFE RESEARCH & UK & & & $\bullet$ & \\
\hline REPORTS ON HEALTH AND SOCIAL SUBJECTS & UK & $\bullet$ & - & & \\
\hline REVISTA DE SAUDE PUBLICA & $\mathrm{BR}$ & $\bullet$ & $\bullet$ & & $\bullet$ \\
\hline REVISTA ESPANOLA DE SALUD PUBLICA & ES & $\bullet$ & $\bullet$ & & \\
\hline REVISTA PANAMERICANA DE SALUD PUBLICA & US & • & $\bullet$ & & \\
\hline REVUE D EPIDEMIOLOGIE ET DE SANTE PUBLIQUE & FR & $\bullet$ & - & $\bullet$ & \\
\hline $\begin{array}{l}\text { REVUE INTERNATIONALE DU TRACHOME ET DE } \\
\text { PATHOLOGIE OCULAIRE TROPICALE ET } \\
\text { SUBTROPICALE ET DE SANTE PUBLIQUE }\end{array}$ & FR & $\bullet$ & $\bullet$ & & \\
\hline ROCZNIKI PANSTWOWEGO ZAKLADU HIGIENY & PL & $\bullet$ & $\bullet$ & & \\
\hline SALUD PUBLICA DE MEXICO & ME & $\bullet$ & $\bullet$ & & - \\
\hline SANTE & FR & $\bullet$ & $\bullet$ & & \\
\hline SANTE PUBLIQUE & FR & - & - & & \\
\hline
\end{tabular}




\section{ANEXO 4 (cont.)}

\begin{tabular}{|c|c|c|c|c|c|}
\hline TÍTULO REVISTA & País & $\begin{array}{l}\text { MEDLINE } \\
2002\end{array}$ & $\begin{array}{c}\text { INDEX } \\
\text { MEDIC } \\
\text { US 2002 } \\
\end{array}$ & $\begin{array}{c}\text { JCR } \\
\text { Science } \\
2001 \\
\end{array}$ & $\begin{array}{c}\text { JCR Social } \\
\text { Sciences } \\
2001 \\
\end{array}$ \\
\hline $\begin{array}{l}\text { SHOKUHIN EISEIGAKU ZASSHI. JOURNAL OF THE } \\
\text { FOOD HYGIENE SOCIETY OF JAPAN }\end{array}$ & JP & & $\bullet$ & & \\
\hline SCANDINAVIAN JOURNAL OF PUBLIC HEALTH & $\mathrm{NO}$ & $\bullet$ & & $\bullet$ & $\bullet$ \\
\hline SCANDINAVIAN JOURNAL OF SOCIAL MEDICINE & $\mathrm{NO}$ & $\bullet$ & & & $\bullet$ \\
\hline $\begin{array}{l}\text { SCANDINAVIAN JOURNAL OF WORK, ENVIRONMENT } \\
\text { AND HEALTH }\end{array}$ & FI & & & $\bullet$ & \\
\hline $\begin{array}{l}\text { SHOKUHIN EISEIGAKU ZASSHI. JOURNAL OF THE } \\
\text { FOOD HYGIENIC SOCIETY OF JAPAN }\end{array}$ & $\mathrm{JP}$ & $\bullet$ & $\bullet$ & & \\
\hline SOCIAL SCIENCE AND MEDICINE & UK & & & & $\bullet$ \\
\hline SOCIOLOGY OF HEALTH AND ILLNESS & UK & & & & $\bullet$ \\
\hline $\begin{array}{l}\text { SOUTHEAST ASIAN JOURNAL OF TROPICAL MEDICINE } \\
\text { AND PUBLIC HEALTH }\end{array}$ & $\mathrm{TH}$ & $\bullet$ & $\bullet$ & & \\
\hline SOZIAL-UND PRAVENTIVMEDIZIN & $\mathrm{DE}$ & & & • & \\
\hline STATISTICS IN MEDICINE & UK & & & $\bullet$ & \\
\hline THER DRUG MONIT & US & & & • & \\
\hline TOBACCO CONTROL & UK & & & - & - \\
\hline TOXICOLOGY AND INDUSTRIAL HEALTH & US & & & - & \\
\hline $\begin{array}{l}\text { TRANSACTIONS OF THE ROYAL SOCIETY OF TROPICAL } \\
\text { MEDICINE AND HYGIENE }\end{array}$ & UK & $\bullet$ & $\bullet$ & $\bullet$ & \\
\hline TROPICAL DOCTOR & UK & & & $\bullet$ & \\
\hline TROPICAL MEDICINE AND INTERNATIONAL HEALTH & UK & $\bullet$ & $\bullet$ & $\bullet$ & \\
\hline VENEREOLOGY & $\mathrm{AU}$ & & & & $\bullet$ \\
\hline $\begin{array}{l}\text { VITAL AND HEALTH STATISTICS. SERIES 1: } \\
\text { PROGRAMS AND COLLECTION PROCEDURES }\end{array}$ & US & $\bullet$ & $\bullet$ & & \\
\hline $\begin{array}{l}\text { VITAL AND HEALTH STATISTICS. SERIES 10: } \\
\text { DATA FROM THE NATIONAL HEALTH SURVEY }\end{array}$ & US & $\bullet$ & $\bullet$ & & \\
\hline $\begin{array}{l}\text { VITAL AND HEALTH STATISTICS. SERIES 11: } \\
\text { DATA FROM THE NATIONAL HEALTH SURVEY }\end{array}$ & US & $\bullet$ & $\bullet$ & & \\
\hline $\begin{array}{l}\text { VITAL AND HEALTH STATISTICS. SERIES 13: } \\
\text { DATA FROM THE NATIONAL HEALTH SURVEY }\end{array}$ & US & $\bullet$ & $\bullet$ & & \\
\hline $\begin{array}{l}\text { VITAL AND HEALTH STATISTICS. SERIES 14: } \\
\text { DATA FROM THE NATIONAL HEALTH SURVEY }\end{array}$ & US & $\bullet$ & $\bullet$ & & \\
\hline $\begin{array}{l}\text { VITAL AND HEALTH STATISTICS. SERIES 2: DATA } \\
\text { EVALUATION AND METHODS RESEARCH }\end{array}$ & US & $\bullet$ & $\bullet$ & & \\
\hline $\begin{array}{l}\text { VITAL AND HEALTH STATISTICS. SERIES 20: } \\
\text { DATA FROM THE NATIONAL VITAL STATISTICS SYSTEM }\end{array}$ & US & $\bullet$ & $\bullet$ & & \\
\hline $\begin{array}{l}\text { VITAL AND HEALTH STATISTICS. SERIES 21: } \\
\text { DATA ON NATALITY, MARRIAGE, AND DIVORCE }\end{array}$ & US & • & • & & \\
\hline $\begin{array}{l}\text { VITAL AND HEALTH STATISTICS. SERIES 23: } \\
\text { DATA FROM THE NATIONAL SURVEY OF FAMILY GROWTH }\end{array}$ & US & $\bullet$ & $\bullet$ & & \\
\hline $\begin{array}{l}\text { VITAL AND HEALTH STATISTICS. SERIES 3: } \\
\text { ANALYTICAL AND EPIDEMIOLOGICAL STUDIES }\end{array}$ & US & $\bullet$ & $\bullet$ & & \\
\hline $\begin{array}{l}\text { VITAL AND HEALTH STATISTICS. SERIES 4: } \\
\text { DOCUMENTS AND COMMITTEE REPORTS }\end{array}$ & US & $\bullet$ & $\bullet$ & & \\
\hline $\begin{array}{l}\text { VITAL AND HEALTH STATISTICS. SERIES 5: } \\
\text { COMPARATIVE INTERNATIONAL }\end{array}$ & US & $\bullet$ & $\bullet$ & & \\
\hline $\begin{array}{l}\text { WEI SHENG YEN CHIU JOURNAL OF HYGIENE } \\
\text { RESEARCH }\end{array}$ & $\mathrm{CN}$ & $\bullet$ & $\bullet$ & & \\
\hline WILDERNESS \& ENVIRONMENT MEDICINE & US & & & $\bullet$ & \\
\hline WOMEN AND HEALTH & US & & & & - \\
\hline WOMEN'S HEALTH ISSUES & US & & & & $\bullet$ \\
\hline $\begin{array}{l}\text { WORLD HEALTH ORGANIZATION TECHNICAL } \\
\text { REPORT SERIES }\end{array}$ & $\mathrm{CH}$ & $\bullet$ & $\bullet$ & $\bullet$ & \\
\hline ZENTRALBLATT FUR HYGIENE UND UMWELTMEDIZIN & $\mathrm{DE}$ & & & $\bullet$ & \\
\hline
\end{tabular}




\section{Revistas científicas nacionais incluídas na LILACS-SP Brasil, 1982- 2002, por ordem decrescente de número de registros}

\begin{tabular}{|c|c|c|}
\hline TÍTULO DA REVISTA & $\begin{array}{c}\text { Total de } \\
\text { artigos }\end{array}$ & $\%$ \\
\hline 1. Revista de Saúde Pública & 1447 & $6 \%$ \\
\hline 2. Cadernos de Saúde Pública & 1116 & $5 \%$ \\
\hline 3. Jornal de Pediatria (Rio de Janeiro) & 525 & $2 \%$ \\
\hline 4. Revista Brasileira de Enfermagem & 490 & $2 \%$ \\
\hline 5. Revista da Escola de Enfermagem da USP & 420 & $2 \%$ \\
\hline 6. Saúde em Debate & 416 & $2 \%$ \\
\hline 7. Higiene Alimentar & 357 & $2 \%$ \\
\hline 8. Memórias do Instituto Oswaldo Cruz & 355 & $2 \%$ \\
\hline 9. Revista Brasileira de Saúde Ocupacional & 304 & $1 \%$ \\
\hline 10. Brazilian Journal of Medical and Biological Research & 303 & $1 \%$ \\
\hline 11. Femina & 294 & $1 \%$ \\
\hline 12. Divulgação Saúde em Debate & 292 & $1 \%$ \\
\hline 13. Jornal Brasileiro de Psiquiatria & 281 & $1 \%$ \\
\hline 14. Revista de Administração Pública & 279 & $1 \%$ \\
\hline 15. Arquivos Brasileiros de Medicina Veterinária e Zootecnia & 241 & $1 \%$ \\
\hline 16. Revista de Microbiologia & 238 & $1 \%$ \\
\hline 17. Mundo da Saúde (1995) & 230 & $1 \%$ \\
\hline 18. Texto \& Contexto Enfermagem & 227 & $1 \%$ \\
\hline 19. Arquivos Brasileiros de Cardiologia & 217 & $1 \%$ \\
\hline 20. Pediatria (São Paulo) & 210 & $1 \%$ \\
\hline 21. Jornal Brasileiro de Medicina & 206 & $1 \%$ \\
\hline 22. Revista Paulista de Hospitais & 205 & $1 \%$ \\
\hline 23. Revista do Instituto Adolfo Lutz & 202 & $1 \%$ \\
\hline 24. Revista Latinoamericana de Enfermagem & 202 & $1 \%$ \\
\hline 25. Revista Paulista de Enfermagem & 200 & $1 \%$ \\
\hline 26. Revista do Instituto de Medicina Tropical de São Paulo & 197 & $1 \%$ \\
\hline 27. Ciência e Cultura (São Paulo) & 196 & $1 \%$ \\
\hline 28. Acta Paulista de Enfermagem & 173 & $1 \%$ \\
\hline 29. Jornal Brasileiro de Ginecologia & 173 & $1 \%$ \\
\hline 30. Folha Médica & 167 & $1 \%$ \\
\hline
\end{tabular}




\section{ANEXO 5 (cont.)}

\begin{tabular}{lcc}
\hline \multicolumn{1}{c}{ TÍTULO DA REVISTA } & $\begin{array}{c}\text { Total } \\
\text { de } \\
\text { artigos }\end{array}$ & $\%$ \\
\hline 31. Revista Sociedade Brasileira de Medicina Tropical & 167 & $1 \%$ \\
32. Pediatria Moderna & 165 & $1 \%$ \\
33. Anais Brasileiros de Dermatologia & 162 & $1 \%$ \\
34. Medicina (Ribeirão Preto) & 157 & $1 \%$ \\
35. Revista Paulista de Pediatria & 154 & $1 \%$ \\
36. Arquivos de Neuropsiquiatria & 152 & $1 \%$ \\
37. Revista Brasileira de Odontologia & 152 & $1 \%$ \\
38. Revista do Hospital das Clinícias da Faculdade de Medicina & & \\
$\quad$ da USP & 150 & $1 \%$ \\
39. Coletânea do Instituto de Tecnologia de Alimentos & 134 & $1 \%$ \\
40. Arquivos Brasileiros de Medicina & 131 & $1 \%$ \\
41. Revista Brasileira de Ginecologia e Obstetrícia & 131 & $1 \%$ \\
42. Hospital Administração e Saúde & 128 & $1 \%$ \\
43. Revista de Saúde do Distrito Federal & 126 & $1 \%$ \\
44. CCS & 122 & $1 \%$ \\
45. Revista Brasileira de Cancerologia & 119 & $1 \%$ \\
46. Revista de Enfermagem da Uerj & 118 & $1 \%$ \\
47. Arquivos Brasileiros de Oftalmologia & 116 & $1 \%$ \\
48. Revista da Associação Paulista de Cirurgia Dentária & 115 & $1 \%$ \\
49. Revista Brasileira de Oftalmologia & 115 & $1 \%$ \\
50. História Ciências e Saúde & 112 & $0 \%$ \\
51. Outros títulos & 9875 & $43 \%$ \\
\hline TOTAL & $\mathbf{2 2 7 6 4}$ & $100 \%$ \\
\hline
\end{tabular}

Fonte: LILACS-SP Brasil, abril de 2002 


\section{ANEXO 6}

\section{Análise descritiva dos sites das Secretarias Estaduais de Saúde}

\begin{tabular}{|c|c|c|}
\hline \multicolumn{3}{|c|}{ Secretaria de Estado da Saúde do Acre: $<$ http://www.saude.ac.gov.br/flash index1.html $>$} \\
\hline \multicolumn{2}{|c|}{ Organização do site } & $\begin{array}{l}\text { Site organizado em } 6 \text { seções: municípios, } \\
\text { estrutura, programas e projetos, informações } \\
\text { em saúde, rede assistencial, links. }\end{array}$ \\
\hline \multicolumn{2}{|l|}{ Atualização } & $\begin{array}{l}\text { Sem data de atualização. Textos sugerem } \\
\text { desatualização do site. }\end{array}$ \\
\hline \multicolumn{2}{|l|}{ Conteúdo } & $\begin{array}{l}\text { Informações sobre os municípios, acesso a } \\
\text { bancos de dados do DATASUS, informações } \\
\text { sobre a RNIS }\end{array}$ \\
\hline \multicolumn{2}{|c|}{ Informação específica para gestores } & Não \\
\hline \multicolumn{2}{|l|}{ Links } & $\begin{array}{l}\text { Para todas as SES, organizações } \\
\text { governamentais e internacionais, universidades } \\
\text { e outras instituições de interesse. } \\
\text { Indica sites de pesquisas na Internet, como } \\
\text { IBGE, DATASUS, IPEA, Biblioteca Virtual de } \\
\text { Engenharia Biomédica, Doctor BBS, NLM, } \\
\text { CDC. }\end{array}$ \\
\hline \multicolumn{2}{|c|}{ Fontes das tabelas de indicadores } & $\begin{array}{l}\text { Inclui pesquisa no DATASUS e indica que } \\
\text { futuramente publicará informações } \\
\text { epidemiológicas do Estado. }\end{array}$ \\
\hline \multirow[t]{4}{*}{$\begin{array}{l}\text { Informação } \\
\text { científico- } \\
\text { técnica }\end{array}$} & Acesso a bases de dados & $\begin{array}{l}\text { Indica BIREME e SciELO, sugerindo consulta } \\
\text { a bases de dados. }\end{array}$ \\
\hline & $\begin{array}{l}\text { Textos completos ou } \\
\text { publicações técnico-científicas }\end{array}$ & Não inclui \\
\hline & $\begin{array}{l}\text { Existência de Centro de } \\
\text { Documentação }\end{array}$ & Não indica \\
\hline & Indicação de utilização de ICT & Indiretamente pelas bases de dados \\
\hline
\end{tabular}

Data da consulta: $15 / 05 / 02$ 


\section{ANEXO 6 (cont.)}

\section{Análise descritiva dos sites das Secretarias Estaduais de Saúde}

\begin{tabular}{|c|c|c|}
\hline \multicolumn{3}{|c|}{ Secretaria de Estado da Saúde de Alagoas < $\underline{\text { http://www.saude.al.gov.br/ }}$} \\
\hline \multicolumn{2}{|c|}{ Organização do site } & $\begin{array}{l}\text { Site organizado em } 3 \text { grandes áreas: conteúdo } \\
\text { (informações gerais, links, organograma, } \\
\text { secretarias municipais, etc.) programas (Cartão } \\
\text { SUS, Governo no Interior, Projeto Estadual de } \\
\text { Redução de Mortalidade Infantil) e setores } \\
\text { (Sala de situação, Central de Regulação e } \\
\text { Conselho Estadual de Saúde). }\end{array}$ \\
\hline \multicolumn{2}{|l|}{ Atualização } & $\begin{array}{l}\text { Textos e tabelas da seção setores sugerem } \\
\text { atualização até } 2002 .\end{array}$ \\
\hline \multicolumn{2}{|l|}{ Conteúdo } & $\begin{array}{l}\text { Notícias, programas, informações em saúde, } \\
\text { sala de situação, informações sobre o Conselho } \\
\text { Estadual de Saúde. Tem mapa dos municípios, } \\
\text { mas sem informações sobre eles (somente } 4 \\
\text { tem links para sites). Inclui informações e } \\
\text { avaliação da RNIS. }\end{array}$ \\
\hline \multicolumn{2}{|c|}{ Informação específica para gestores } & $\begin{array}{l}\text { Não, somente link para a página do MS sobre } \\
\text { regionalização. }\end{array}$ \\
\hline \multicolumn{2}{|l|}{ Links } & $\begin{array}{l}\text { Para } 17 \text { SES. Não tem link para BVS-SP ou } \\
\text { Biblioteca do MS. }\end{array}$ \\
\hline \multicolumn{2}{|c|}{ Fontes das tabelas de indicadores } & $\begin{array}{l}\text { Nacionais: DATASUS, SIA, SIH, SISRH, } \\
\text { SIM, SINASC }\end{array}$ \\
\hline \multirow{4}{*}{$\begin{array}{l}\text { Informação } \\
\text { científico- } \\
\text { técnica }\end{array}$} & Acesso a bases de dados & Não tem acesso a bases de dados. \\
\hline & $\begin{array}{l}\text { Textos completos ou } \\
\text { publicações técnico-científicas }\end{array}$ & Não inclui textos completos. \\
\hline & $\begin{array}{l}\text { Existência de Centro de } \\
\text { Documentação }\end{array}$ & $\begin{array}{l}\text { Não indica existência de Centro de } \\
\text { Documentação/ Informação na SES }\end{array}$ \\
\hline & Indicação de utilização de ICT & $\begin{array}{l}\text { Sugere integração com a comunidade } \\
\text { acadêmica do Estado (UFAL). }\end{array}$ \\
\hline
\end{tabular}

Data da consulta: 16/05/02 


\section{ANEXO 6 (cont.)}

\section{Análise descritiva dos sites das Secretarias Estaduais de Saúde}

\begin{tabular}{|c|c|c|}
\hline \multicolumn{3}{|c|}{ Secretaria de Estado da Saúde do Amapá < http://www.saude.ap.gov.br/> } \\
\hline \multicolumn{2}{|c|}{ Organização do site } & $\begin{array}{l}\text { Site organizado em } 7 \text { menus: gestão do SUS, } \\
\text { ações e projetos, fundo estadual, saúde nos } \\
\text { municípios, serviços, indicadores, informes. }\end{array}$ \\
\hline \multicolumn{2}{|l|}{ Atualização } & $\begin{array}{l}\text { Sem data de atualização. Dados e textos } \\
\text { sugerem desatualização do site. }\end{array}$ \\
\hline \multicolumn{2}{|l|}{ Conteúdo } & $\begin{array}{l}\text { Informações sobre os municípios, informações } \\
\text { sobre a RNIS. }\end{array}$ \\
\hline \multicolumn{2}{|c|}{ Informação específica para gestores } & Não \\
\hline \multicolumn{2}{|l|}{ Links } & $\begin{array}{l}\text { Para } 19 \text { SES e outras instituições de saúde. } \\
\text { Muitos links não ativos. Não tem link para } \\
\text { BVS-SP ou Biblioteca do MS. }\end{array}$ \\
\hline \multicolumn{2}{|c|}{ Fontes das tabelas de indicadores } & $\begin{array}{l}\text { Locais: UVE/DE/CVS/SESA/AP, } \\
\text { INFORMÁTICA/SESA-AP } \\
\text { Nacionais: SINASC. }\end{array}$ \\
\hline \multirow{4}{*}{$\begin{array}{l}\text { Informação } \\
\text { científico- } \\
\text { técnica }\end{array}$} & Acesso a bases de dados & Não tem acesso a bases de dados. \\
\hline & $\begin{array}{l}\text { Textos completos ou } \\
\text { publicações técnico-científicas }\end{array}$ & $\begin{array}{l}\text { Em "Publicações", um Boletim Epidemiológico } \\
\text { sem data de publicação. }\end{array}$ \\
\hline & $\begin{array}{l}\text { Existência de Centro de } \\
\text { Documentação }\end{array}$ & $\begin{array}{l}\text { Não indica existência de Centro de } \\
\text { Documentação/ Informação na SES. }\end{array}$ \\
\hline & Indicação de utilização de ICT & Não sugere utilização de informação científica. \\
\hline
\end{tabular}

Data da consulta: 17/05/02 


\section{ANEXO 6 (cont.) \\ Análise descritiva dos sites das Secretarias Estaduais de Saúde}

\begin{tabular}{|c|c|c|}
\hline \multicolumn{3}{|c|}{ Secretaria de Estado da Saúde do Amazonas < $\underline{\text { http: } / / w w w . s a u d e . a m . g o v . b r />~}$} \\
\hline \multicolumn{2}{|c|}{ Organização do site } & $\begin{array}{l}\text { Site organizado em } 8 \text { menus: pólos regionais, } \\
\text { conheça a secretaria, conselho, serviços de } \\
\text { saúde, publicações, informações sobre saúde, } \\
\text { contatos, links }\end{array}$ \\
\hline \multicolumn{2}{|l|}{ Atualização } & $\begin{array}{l}\text { Não traz data de atualização do site, mas inclui } \\
\text { informação atualizada. }\end{array}$ \\
\hline \multicolumn{2}{|l|}{ Conteúdo } & $\begin{array}{l}\text { Informações sobre os pólos regionais, agenda e } \\
\text { atas dos conselhos de saúde, da Comissão } \\
\text { Bipartite e do COSEMS/AM. }\end{array}$ \\
\hline \multicolumn{2}{|c|}{ Informação específica para gestores } & $\begin{array}{l}\text { Não há informação específica. Poderiam ser } \\
\text { consideradas: as informações dos municípios } \\
\text { em "Pólos Regionais", o Plano Estadual de } \\
\text { Saúde em "Conheça a Secretaria", a legislação }\end{array}$ \\
\hline \multicolumn{2}{|l|}{ Links } & $\begin{array}{l}18 \text { SES, MS, RNIS, FUNASA, organismos } \\
\text { internacionais, escolas médicas e vários links } \\
\text { de interesse. Não tem link para BVS-SP ou } \\
\text { Biblioteca do MS }\end{array}$ \\
\hline \multicolumn{2}{|c|}{ Fontes das tabelas de indicadores } & $\begin{array}{l}\text { Locais: SUSAM (Gerência de Informática), } \\
\text { DEVIS } \\
\text { Nacionais: DATASUS }\end{array}$ \\
\hline \multirow{4}{*}{$\begin{array}{l}\text { Informação } \\
\text { científico- } \\
\text { técnica }\end{array}$} & Acesso a bases de dados & Não tem acesso a bases de dados.. \\
\hline & $\begin{array}{l}\text { Textos completos ou } \\
\text { publicações técnico-científicas }\end{array}$ & Não inclui textos completos de ICT \\
\hline & $\begin{array}{l}\text { Existência de Centro de } \\
\text { Documentação }\end{array}$ & $\begin{array}{l}\text { Não indica existência de Centro de } \\
\text { Documentação/ Informação na SES. }\end{array}$ \\
\hline & Indicação de utilização de ICT & Não sugere utilização de informação científica. \\
\hline
\end{tabular}

Data da consulta: 18/05/02 


\section{ANEXO 6 (cont.) \\ Análise descritiva dos sites das Secretarias Estaduais de Saúde}

\begin{tabular}{|c|c|c|}
\hline \multicolumn{3}{|c|}{ Secretaria de Estado da Saúde da Bahia <http://www.saude.ba.gov.br/ > } \\
\hline \multicolumn{2}{|c|}{ Organização do site } & $\begin{array}{l}\text { Site organizado em } 8 \text { seções: a SESAB, planejamento, } \\
\text { ações, prevenção de doenças, utilidade pública, } \\
\text { comunicação, dados da saúde na Bahia }\end{array}$ \\
\hline \multicolumn{2}{|l|}{ Atualização } & $\begin{array}{l}\text { Site atualizado, mas muitos textos das seções estavam } \\
\text { desatualizados }\end{array}$ \\
\hline \multicolumn{2}{|l|}{ Conteúdo } & $\begin{array}{l}\text { Inclui Plano Estadual de Saúde, mas não especifica o } \\
\text { ano. Inclui notícias atualizadas sobre campanhas, } \\
\text { programas, etc. Não contém dados completos de saúde } \\
\text { do Estado: publica Anuário Estatístico } 1996 \text { e 1997, } \\
\text { inclui links para download de sistemas do DATASUS } \\
\text { e dados sobre campanha de vacinação antipólio em } \\
2001\end{array}$ \\
\hline \multicolumn{2}{|c|}{ Informação específica para gestores } & Não \\
\hline \multicolumn{2}{|l|}{ Links } & $\begin{array}{l}\text { Para } 13 \text { SES, hospitais, MS, etc. Tem link para a } \\
\text { BVS, para bibliotecas e revistas de Saúde Pública (site } \\
\text { original das revistas) }\end{array}$ \\
\hline \multicolumn{2}{|c|}{ Fontes das tabelas de indicadores } & Não publica indicadores. \\
\hline \multirow{4}{*}{$\begin{array}{l}\text { Informação } \\
\text { científico- } \\
\text { técnica }\end{array}$} & Acesso a bases de dados & $\begin{array}{l}\text { Não tem acesso a bases de dados, mas tem link para a } \\
\text { BVS }\end{array}$ \\
\hline & $\begin{array}{l}\text { Textos completos ou } \\
\text { publicações técnico- } \\
\text { científicas }\end{array}$ & Não inclui textos completos de ICT \\
\hline & $\begin{array}{l}\text { Existência de Centro de } \\
\text { Documentação }\end{array}$ & $\begin{array}{l}\text { Existe "Diretoria de Informação e Comunicação em } \\
\text { Saúde" no organograma, responsável pelas } \\
\text { informações em saúde, RNIS, educação em saúde, etc. } \\
\text { (http://www.saude.ba.gov.br/int_organ1.html\#dirinfo). }\end{array}$ \\
\hline & $\begin{array}{l}\text { Indicação de utilização de } \\
\text { ICT }\end{array}$ & Não sugere utilização de informação científica. \\
\hline
\end{tabular}

Data da consulta: 18/05/02 


\section{ANEXO 6 (cont.)}

\section{Análise descritiva dos sites das Secretarias Estaduais de Saúde}

\begin{tabular}{|c|c|c|}
\hline \multicolumn{3}{|c|}{ Secretaria de Estado da Saúde do Ceará <http://sesanet.saude.ce.gov.br/sesanet/sesanet.home> } \\
\hline \multicolumn{2}{|c|}{ Organização do site } & $\begin{array}{l}\text { Site estruturado em } 8 \text { seções: missão, políticas } \\
\text { de saúde, responsabilidades de gestão, } \\
\text { programas/projetos estratégicos, informações } \\
\text { em saúde, publicações, orientações em saúde, } \\
\text { serviços. }\end{array}$ \\
\hline \multicolumn{2}{|l|}{ Atualização } & $\begin{array}{l}\text { Não há data de atualização do site, mas textos e } \\
\text { tabelas estão atualizados, com data da última } \\
\text { atualização. }\end{array}$ \\
\hline \multicolumn{2}{|l|}{ Conteúdo } & $\begin{array}{l}\text { Contém informações sobre programas, } \\
\text { serviços, políticas, etc. }\end{array}$ \\
\hline \multicolumn{2}{|c|}{ Informação específica para gestores } & $\begin{array}{l}\text { Sob o item "Responsabilidades de Gestão" e } \\
\text { sob "Publicações", um documento sobre } \\
\text { "Diretrizes de Reorganização da Atenção e dos } \\
\text { Serviços do SUS" }\end{array}$ \\
\hline \multicolumn{2}{|l|}{ Links } & $\begin{array}{l}\text { Para MS, FUNASA, DATASUS, UFC, } \\
\text { UNIFOR, UEC e Governo do Ceará. Não tem } \\
\text { link para a BVS-SP ou Biblioteca do MS. }\end{array}$ \\
\hline \multicolumn{2}{|c|}{ Fontes das tabelas de indicadores } & $\begin{array}{l}\text { Nacionais: SIAB, SIM } \\
\text { Locais: informações coletadas pela SES }\end{array}$ \\
\hline \multirow{4}{*}{$\begin{array}{l}\text { Informação } \\
\text { científico- } \\
\text { técnica }\end{array}$} & Acesso a bases de dados & Não tem acesso a bases de dados. \\
\hline & $\begin{array}{l}\text { Textos completos ou } \\
\text { publicações técnico-científicas }\end{array}$ & $\begin{array}{l}\text { Há documentos em textos completos sob o item } \\
\text { "Publicações" }\end{array}$ \\
\hline & $\begin{array}{l}\text { Existência de Centro de } \\
\text { Documentação }\end{array}$ & $\begin{array}{l}\text { Não indica existência de Centro de } \\
\text { Documentação/ Informação na SES }\end{array}$ \\
\hline & Indicação de utilização de ICT & $\begin{array}{l}\text { Na Introdução do documento "Diretrizes ..." há } \\
\text { um parágrafo que sugere o uso de informação } \\
\text { científica e pesquisa acadêmica nos processos } \\
\text { de decisão através de consultorias com as } \\
\text { Universidades e sociedades científicas. } \\
\text { Inclui entre os projetos especiais o de } \\
\text { "Produção de conhecimentos e difusão de } \\
\text { informações educativas". }\end{array}$ \\
\hline
\end{tabular}

Data da consulta: 18/05/02 


\section{ANEXO 6 (cont.)}

\section{Análise descritiva dos sites das Secretarias Estaduais de Saúde}

\begin{tabular}{|c|c|c|}
\hline \multicolumn{3}{|c|}{ Secretaria de Estado da Saúde do Distrito Federal < $\underline{\text { http://www.saude.df.gov.br/ }>}$} \\
\hline \multicolumn{2}{|c|}{ Organização do site } & $\begin{array}{l}\text { Organizado como um portal de informações, } \\
\text { com seções de destaques, programas, artigos } \\
\text { em saúde, FAQ, espaço do cidadão e links para } \\
\text { MS, RNIS, DATASUS, FEPECS (Fundação } \\
\text { para o Ensino e Pesquisa em Ciências da } \\
\text { Saúde) e Central de Captação de Órgãos. }\end{array}$ \\
\hline \multicolumn{2}{|l|}{ Atualização } & Não traz data de atualização do site. \\
\hline \multicolumn{2}{|l|}{ Conteúdo } & $\begin{array}{l}\text { Boletim Informativo com notícias diárias de } \\
\text { interesse da comunidade. Publica Agenda } \\
\text { Estadual de Saúde } 2001 \text {. }\end{array}$ \\
\hline \multicolumn{2}{|c|}{ Informação específica para gestores } & Não, apenas informação dirigida à população. \\
\hline \multicolumn{2}{|l|}{ Links } & $\begin{array}{l}\text { Para hospitais, centros de saúde, } 19 \text { SES e } 7 \\
\text { SMS, MS, RNIS, DATASUS, FEPECS } \\
\text { (Fundação para o Ensino e Pesquisa em } \\
\text { Ciências da Saúde) e Central de Captação de } \\
\text { Órgãos, organismos internacionais, } \\
\text { universidades, etc. Não tem link para a BVS-SP } \\
\text { ou Biblioteca do MS. }\end{array}$ \\
\hline \multicolumn{2}{|c|}{ Fontes das tabelas de indicadores } & Nacionais: RNIS, DATASUS \\
\hline \multirow{4}{*}{$\begin{array}{l}\text { Informação } \\
\text { científico- } \\
\text { técnica }\end{array}$} & Acesso a bases de dados & Não tem acesso a bases de dados \\
\hline & $\begin{array}{l}\text { Textos completos ou } \\
\text { publicações técnico-científicas }\end{array}$ & $\begin{array}{l}\text { Traz textos completos de artigos, monografias, } \\
\text { relatórios e outros documentos sobre situação } \\
\text { de saúde no DF }\end{array}$ \\
\hline & $\begin{array}{l}\text { Existência de Centro de } \\
\text { Documentação }\end{array}$ & $\begin{array}{l}\text { Não indica existência de Centro de } \\
\text { Documentação/ Informação na SES. }\end{array}$ \\
\hline & Indicação de utilização de ICT & $\begin{array}{l}\text { A única indicação de utilização de informação } \\
\text { científica seriam os textos de publicações } \\
\text { científicas }\end{array}$ \\
\hline
\end{tabular}

Data da consulta: 18/05/02 


\section{ANEXO 6 (cont.)}

\section{Análise descritiva dos sites das Secretarias Estaduais de Saúde}

\begin{tabular}{|c|c|c|}
\hline \multicolumn{3}{|c|}{ Secretaria de Estado da Saúde do Espírito Santo < $<\underline{\text { http://www.saude.es.gov.br/ }>}$} \\
\hline \multicolumn{2}{|c|}{ Organização do site } & $\begin{array}{l}\text { Site organizado em várias seções: institucional, } \\
\text { serviços, saúde da criança, vigilância } \\
\text { epidemiológica, saúde da mulher, orientação ao } \\
\text { usuário, vigilância sanitária, investimentos, } \\
\text { legislação, vacinação, saúde mental, } \\
\text { estatísticas, cursos e eventos, publicações, } \\
\text { portadores de deficiência e assistência } \\
\text { farmacêutica }\end{array}$ \\
\hline \multicolumn{2}{|l|}{ Atualização } & $\begin{array}{l}\text { Não traz data de atualização do site, só data de } \\
\text { copyright 2001/2002 }\end{array}$ \\
\hline \multicolumn{2}{|l|}{ Conteúdo } & $\begin{array}{l}\text { Traz informações institucionais, orientações } \\
\text { para os gestores municipais, legislação, etc., a } \\
\text { maioria em arquivos .zip. Em "Publicações" } \\
\text { traz boletins epidemiológicos e informativos } \\
\text { desatualizados (2001). Publica a Agenda } \\
\text { Estadual de Saúde } 2001 \text { no site (arquivo .zip). }\end{array}$ \\
\hline \multicolumn{2}{|c|}{ Informação específica para gestores } & $\begin{array}{l}\text { Informa sobre curso destinado a integrantes de } \\
\text { equipes gestoras das Secretarias Estadual e } \\
\text { municipais, com carga horária de } 460 \text { hs. O } \\
\text { programa do curso não sugere uso de } \\
\text { informação científica para a gestão. Em } 2001 \text {, } \\
\text { foi realizado Curso de Atualização em Gestão } \\
\text { Municipal na Área de Saúde, com carga horária } \\
\text { de } 120 \text { hs. }\end{array}$ \\
\hline \multicolumn{2}{|l|}{ Links } & $\begin{array}{l}\text { Para todas as SES, organizações } \\
\text { governamentais, universidades e outros sites de } \\
\text { interesse para a saúde. além de ícones diretos } \\
\text { para MS, DATASUS, RNIS, CONASEMS, } \\
\text { Conselho Nacional de Saúde, CONASS, } \\
\text { VIGISUS, SIOPS e ANVISA. Não tem link } \\
\text { para a BIREME BVS-SP ou Biblioteca do MS. }\end{array}$ \\
\hline \multicolumn{2}{|c|}{ Fontes das tabelas de indicadores } & Nacionais: SIM, SINASC, SINAN, IBGE \\
\hline \multirow{4}{*}{$\begin{array}{l}\text { Informação } \\
\text { científico- } \\
\text { técnica }\end{array}$} & Acesso a bases de dados & Não tem acesso a base de dados. \\
\hline & $\begin{array}{l}\text { Textos completos ou } \\
\text { publicações técnico-científicas }\end{array}$ & $\begin{array}{l}\text { Publica alguns textos completos de boletins } \\
\text { epidemiológicos e informativos, que estão } \\
\text { desatualizados (2001) }\end{array}$ \\
\hline & $\begin{array}{l}\text { Existência de Centro de } \\
\text { Documentação }\end{array}$ & $\begin{array}{l}\text { Não indica existência de Centro de } \\
\text { Documentação/ Informação na SES. }\end{array}$ \\
\hline & Indicação de utilização de ICT & Não sugere utilização de informação científica. \\
\hline
\end{tabular}

Data da consulta: $18 / 05 / 02$ 


\section{ANEXO 6 (cont.)}

\section{Análise descritiva dos sites das Secretarias Estaduais de Saúde}

\begin{tabular}{|c|c|c|}
\hline \multicolumn{3}{|c|}{ Secretaria de Estado da Saúde de Goiás <http://www.saude.go.gov.br/> } \\
\hline \multicolumn{2}{|c|}{ Organização do site } & $\begin{array}{l}\text { Site dividido em menus: Gabinete, } \\
\text { Superintendências, Unidades de Saúde e Saúde } \\
\text { em Pauta e por assuntos (alguns coincidentes } \\
\text { com os do menu superior): Apresentação, } \\
\text { Regionais de Saúde, Unidades de Saúde, } \\
\text { Processos, Resoluções, Saúde em Pauta, } \\
\text { Catálogo Telefônico, Trabalhos Científicos, } \\
\text { Comissão Especial de Licitação, Links, } \\
\text { Concurso. }\end{array}$ \\
\hline \multicolumn{2}{|l|}{ Atualização } & $\begin{array}{l}\text { Não tem data de atualização do site. Páginas } \\
\text { em construção e páginas não ativas. Boletim } \\
\text { Informativo que aparece na página principal é } \\
\text { de fevereiro de } 2002 \text {. Informações sobre } \\
\text { processos até } 2001 \text {. }\end{array}$ \\
\hline \multicolumn{2}{|l|}{ Conteúdo } & $\begin{array}{l}\text { Como muitas páginas não estavam ativas, não } \\
\text { foi possível verificar conteúdo do site. }\end{array}$ \\
\hline \multicolumn{2}{|c|}{ Informação específica para gestores } & Não \\
\hline \multicolumn{2}{|l|}{ Links } & $\begin{array}{l}\text { Links na página principal para GOIASNET } \\
\text { (Site do Estado), MS, LACEN-GO, Central de } \\
\text { Transplantes do Estado, Superintendência de } \\
\text { Vigilância Sanitária da SES/GO, Coordenação } \\
\text { de DST/AIDS da SES/GO, NTIS - Núcleo de } \\
\text { Tecnologia e Informação em Saúde da } \\
\text { SES/GO, SIATE - Sistema Integrado de } \\
\text { Atendimento ao Trauma e Emergências da } \\
\text { SES/GO. }\end{array}$ \\
\hline \multicolumn{2}{|c|}{ Fontes das tabelas de indicadores } & Tabelas não disponíveis. \\
\hline \multirow{4}{*}{$\begin{array}{l}\text { Informação } \\
\text { científico- } \\
\text { técnica }\end{array}$} & Acesso a bases de dados & Não tem acesso a bases de dados \\
\hline & $\begin{array}{l}\text { Textos completos ou } \\
\text { publicações técnico-científicas }\end{array}$ & $\begin{array}{l}\text { Não inclui textos completos de ICT, embora } \\
\text { indique seção de "Trabalhos Científicos". }\end{array}$ \\
\hline & $\begin{array}{l}\text { Existência de Centro de } \\
\text { Documentação }\end{array}$ & $\begin{array}{l}\text { Não indica existência de Centro de } \\
\text { Documentação/ Informação na SES. }\end{array}$ \\
\hline & Indicação de utilização de ICT & Não sugere utilização de informação científica. \\
\hline
\end{tabular}

Data da consulta: 20/05/02 


\section{ANEXO 6 (cont.)}

\section{Análise descritiva dos sites das Secretarias Estaduais de Saúde}

\begin{tabular}{|c|c|c|}
\hline \multicolumn{3}{|c|}{ Secretaria de Estado da Saúde do Maranhão <http://www.saude.ma.gov.br/> } \\
\hline \multicolumn{2}{|c|}{ Organização do site } & $\begin{array}{l}\text { O site se divide basicamente em } 4 \text { menus: } \\
\text { Informações, Gerências regionais, } \\
\text { Projetos/programas, Recursos municipais. Foi } \\
\text { criado pela Gerência de Qualidade de Vida do } \\
\text { Estado do Maranhão, que inclui saúde, meio } \\
\text { ambiente e recursos hídricos, saneamento. }\end{array}$ \\
\hline \multicolumn{2}{|l|}{ Atualização } & $\begin{array}{l}\text { Não há data de atualização do site, mas } \\
\text { gráficos apresentados sugerem atualização até } \\
\text { final de } 2001 .\end{array}$ \\
\hline \multicolumn{2}{|l|}{ Conteúdo } & $\begin{array}{l}\text { Sob o menu "Informações" aparecem a } \\
\text { estrutura organizacional, a integralidade das } \\
\text { acões de saúde e o organograma da Gerência } \\
\text { de Qualidade de Vida. Sob "Gerências } \\
\text { Regionais" aparecem informações gerais sobre } \\
\text { localização, endereço, área, população, etc das } \\
\text { regionais. A Agenda 2001/2002 para saúde, } \\
\text { nutrição e melhoria das condições de vida } \\
\text { aparece sob o menu "Projetos/Programas". }\end{array}$ \\
\hline \multicolumn{2}{|c|}{ Informação específica para gestores } & $\begin{array}{l}\text { Não há. As diretrizes políticas e a agenda de } \\
\text { saúde não estavam direcionadas } \\
\text { especificamente aos gestores. }\end{array}$ \\
\hline \multicolumn{2}{|l|}{ Links } & $\begin{array}{l}\text { Na página inicial há links para o MS e } \\
\text { DATASUS. Há cadastro para inscrição das } \\
\text { instituições na RNIS. }\end{array}$ \\
\hline \multicolumn{2}{|c|}{ Fontes das tabelas de indicadores } & $\begin{array}{l}\text { Locais: as tabelas apresentadas são produzidas } \\
\text { com dados da própria Gerência de Qualidade } \\
\text { de Vida. }\end{array}$ \\
\hline \multirow{4}{*}{$\begin{array}{l}\text { Informação } \\
\text { científico- } \\
\text { técnica }\end{array}$} & Acesso a bases de dados & Não tem acesso a bases de dados. \\
\hline & $\begin{array}{l}\text { Textos completos ou } \\
\text { publicações técnico-científicas }\end{array}$ & Site não inclui textos completos de ICT \\
\hline & $\begin{array}{l}\text { Existência de Centro de } \\
\text { Documentação }\end{array}$ & $\begin{array}{l}\text { No organograma, sob a Subgerência de } \\
\text { Programas, aparece o Departamento de } \\
\text { Informação, Educação e Comunicação, mas no } \\
\text { site não há mais informações sobre as } \\
\text { atividades do Departamento. }\end{array}$ \\
\hline & Indicação de utilização de ICT & Não sugere utilização de informação científica. \\
\hline
\end{tabular}

Data da consulta: 20/05/02 


\section{ANEXO 6 (cont.)}

\section{Análise descritiva dos sites das Secretarias Estaduais de Saúde}

\begin{tabular}{|c|c|c|}
\hline \multicolumn{3}{|c|}{ Secretaria de Estado da Saúde de Mato Grosso <http://www.saude.mt.gov.br/ > } \\
\hline \multicolumn{2}{|c|}{ Organização do site } & $\begin{array}{l}\text { Somente alguns menus estavam disponíveis } \\
\text { para consulta. Não dá para confirmar } \\
\text { organização do site nesse momento. }\end{array}$ \\
\hline \multicolumn{2}{|l|}{ Atualização } & $\begin{array}{l}\text { A data de copyright do site é de } 2002, \\
\text { indicando que o site é recente. As páginas } \\
\text { disponíveis no menu estavam atualizadas. }\end{array}$ \\
\hline \multicolumn{2}{|l|}{ Conteúdo } & $\begin{array}{l}\text { Os menus disponíveis para consulta eram: } \\
\text { Combate a dengue (com indicadores da própria } \\
\text { SES), Informações do SUS, Licitações } \\
\text { (tomadas de preço, editais, resultados), Plano } \\
\text { de Carreira (texto completo de lei estadual } \\
\text { sobre o tema), Plano Estadual de Saúde } \\
\text { (Missão da SES, Objetivo, Compromisso, } \\
\text { Plano Estadual Plurianual de Saúde } \\
\text { 2000/2003), Legislação (textos completos de } \\
\text { legislação), Caderno do Gestor (manual para o } \\
\text { gestor), NOB } 96 \text { (link para o site do MS). }\end{array}$ \\
\hline \multicolumn{2}{|c|}{ Informação específica para gestores } & $\begin{array}{l}\text { Publica no site o "Caderno do Gestor } \\
\text { Municipal de Saúde", de } 2001 \text { e a Série } \\
\text { Legislação do SUS. }\end{array}$ \\
\hline \multicolumn{2}{|l|}{ Links } & Não se aplica. \\
\hline \multicolumn{2}{|c|}{ Fontes das tabelas de indicadores } & $\begin{array}{l}\text { Locais: tabelas sobre dengue, produzidas com } \\
\text { dados da própria SES. }\end{array}$ \\
\hline \multirow{4}{*}{$\begin{array}{l}\text { Informação } \\
\text { científico- } \\
\text { técnica }\end{array}$} & Acesso a bases de dados & Não tem acesso a bases de dados \\
\hline & $\begin{array}{l}\text { Textos completos ou } \\
\text { publicações técnico-científicas }\end{array}$ & Não inclui textos completos de ICT. \\
\hline & $\begin{array}{l}\text { Existência de Centro de } \\
\text { Documentação }\end{array}$ & $\begin{array}{l}\text { Não indica existência de Centro de } \\
\text { Documentação/ Informação na SES. }\end{array}$ \\
\hline & Indicação de utilização de ICT & $\begin{array}{l}\text { A introdução do Manual do Gestor diz que um } \\
\text { dos objetivo do manual é ressaltar a } \\
\text { importância da informação e dos sistemas de } \\
\text { informação, mas se refere aos SIS } \\
\text { epidemiológicos e estatísticos do Sistema de } \\
\text { Saúde e não à ICT. }\end{array}$ \\
\hline
\end{tabular}

Data da consulta: $21 / 05 / 02$ 


\section{ANEXO 6 (cont.) \\ Análise descritiva dos sites das Secretarias Estaduais de Saúde}

\begin{tabular}{|c|c|c|}
\hline \multicolumn{3}{|c|}{ Secretaria de Estado da Saúde de Mato Grosso do Sul <http://www.saude.ms.gov.br/> } \\
\hline \multicolumn{2}{|c|}{ Organização do site } & $\begin{array}{l}\text { Site organizado como um portal de } \\
\text { informações, com notícias, informações em } \\
\text { saúde, publicações, informações institucionais } \\
\text { e sobre programas e serviços, enquetes, links, } \\
\text { etc. }\end{array}$ \\
\hline \multicolumn{2}{|l|}{ Atualização } & $\begin{array}{l}\text { Não há data de atualização do site. Notícias } \\
\text { atualizadas. Muitos links de páginas do site não } \\
\text { ativos. }\end{array}$ \\
\hline \multicolumn{2}{|l|}{ Conteúdo } & $\begin{array}{l}\text { Conteúdo repetitivo: vários itens do menu } \\
\text { conduzem à mesma informação (ex: estatísticas } \\
\text { e publicações conduzem às mesmas tabelas de } \\
\text { indicadores. Informações sobre as Secretarias } \\
\text { Municipais de Saúde (endereço e nome do } \\
\text { Secretário). Arquivo de notícias desde janeiro } \\
\text { de } 2001 \text { com consulta somente por data. }\end{array}$ \\
\hline \multicolumn{2}{|c|}{ Informação específica para gestores } & Não há. \\
\hline \multicolumn{2}{|l|}{ Links } & $\begin{array}{l}\text { Links para MS, Governo do Estado, ANVISA, } \\
\text { RNIS, INCA, IBGE, CNS, FUNASA. Não há } \\
\text { link para outras SES, universidades, hospitais, } \\
\text { etc. nem para BVS-SP ou Biblioteca do MS. }\end{array}$ \\
\hline \multicolumn{2}{|c|}{ Fontes das tabelas de indicadores } & $\begin{array}{l}\text { Inclui indicadores de nascidos vivos e } \\
\text { mortalidade de } 1997 \text { a 2001, em arquivos .zip. }\end{array}$ \\
\hline \multirow{4}{*}{$\begin{array}{l}\text { Informação } \\
\text { científico- } \\
\text { técnica }\end{array}$} & Acesso a bases de dados & Não tem acesso a bases de dados. \\
\hline & $\begin{array}{l}\text { Textos completos ou } \\
\text { publicações técnico-científicas }\end{array}$ & Não inclui textos completos de ICT. \\
\hline & $\begin{array}{l}\text { Existência de Centro de } \\
\text { Documentação }\end{array}$ & $\begin{array}{l}\text { Não indica existência de Centro de } \\
\text { Documentação/ Informação na SES. }\end{array}$ \\
\hline & Indicação de utilização de ICT & Não sugere utilização de informação científica. \\
\hline
\end{tabular}

Data da consulta: $23 / 05 / 02$ 


\section{ANEXO 6 (cont.) \\ Análise descritiva dos sites das Secretarias Estaduais de Saúde}

\begin{tabular}{|c|c|c|}
\hline \multicolumn{3}{|c|}{ Secretaria de Estado da Saúde de Minas Gerais $<$ http://www.saude.mg.gov.br/ $>$} \\
\hline \multicolumn{2}{|c|}{ Organização do site } & $\begin{array}{l}\text { Site organizado como um portal de } \\
\text { informações com } 4 \text { grandes menus: estrutura } \\
\text { organizacional, informações ao cidadão, } \\
\text { informações em saúde, programas e projetos. }\end{array}$ \\
\hline \multicolumn{2}{|l|}{ Atualização } & $\begin{array}{l}\text { Não há data de atualização do site. Tabelas de } \\
\text { indicadores atualizadas até 1997/1998. Outras } \\
\text { informações atualizadas até } 2001 \text {. }\end{array}$ \\
\hline \multicolumn{2}{|l|}{ Conteúdo } & $\begin{array}{l}\text { Notícias, informações institucionais, } \\
\text { informações ao usuário, informações em saúde } \\
\text { (políticas de saúde, indicadores de endemias, } \\
\text { de infra-estrutura de serviços, financiamento e } \\
\text { ressarcimento), programas e projetos (saúde da } \\
\text { família, farmácia essencial, urgência e } \\
\text { emergência, consórcios de saúde). }\end{array}$ \\
\hline \multicolumn{2}{|c|}{ Informação específica para gestores } & $\begin{array}{l}\text { No item "Superintendência de Recursos } \\
\text { Humanos", sob Estrutura Organizacional, } \\
\text { informa sobre curso para gestores. O programa } \\
\text { do curso não sugere informação sobre acesso e } \\
\text { utilização de informação científica. }\end{array}$ \\
\hline \multicolumn{2}{|l|}{ Links } & $\begin{array}{l}\text { Links para sites da área da saúde. Destaques do } \\
\text { site: Portal Minas (do Governo do Estado), MS, } \\
\text { DATASUS, RNIS, RMIS - Rede Mineira de } \\
\text { Informações em Saúde, Bibliomed - Biblioteca } \\
\text { de Saúde da Bibliomed, Inc., SIOPS, Armazém } \\
\text { de Informações (acesso restrito), PPI estadual, } \\
\text { Campanha da Febre Amarela. Não há link para } \\
\text { outras SES, universidades, hospitais, etc. nem } \\
\text { para BVS-SP ou Biblioteca do MS. }\end{array}$ \\
\hline \multicolumn{2}{|c|}{ Fontes das tabelas de indicadores } & $\begin{array}{l}\text { Locais: SES, FUNED - Fundação Ezequiel } \\
\text { Dias. }\end{array}$ \\
\hline \multirow{4}{*}{$\begin{array}{l}\text { Informação } \\
\text { científico- } \\
\text { técnica }\end{array}$} & Acesso a bases de dados & Não tem acesso a bases de dados. \\
\hline & $\begin{array}{l}\text { Textos completos ou } \\
\text { publicações técnico-científicas }\end{array}$ & Não inclui textos completos de ICT \\
\hline & $\begin{array}{l}\text { Existência de Centro de } \\
\text { Documentação }\end{array}$ & $\begin{array}{l}\text { O organograma indica existência de Divisão de } \\
\text { Biblioteca e Documentação, sob a } \\
\text { Superintendência de Recursos Humanos, } \\
\text { Diretoria de Capacitação, mas não há acesso no } \\
\text { site a produtos e serviços dessa Divisão. }\end{array}$ \\
\hline & Indicação de utilização de ICT & Não sugere utilização de informação científica. \\
\hline
\end{tabular}

Data da consulta: $23 / 05 / 02$ 


\section{ANEXO 6 (cont.)}

\section{Análise descritiva dos sites das Secretarias Estaduais de Saúde}

\begin{tabular}{|c|c|c|}
\hline \multicolumn{3}{|c|}{ Secretaria de Estado da Saúde do Pará < $\underline{\text { http://www.saude.pa.gov.br/> }}$} \\
\hline \multicolumn{2}{|c|}{ Organização do site } & $\begin{array}{l}\text { Site organizado em } 15 \text { seções: apresentação, o } \\
\text { Estado, o governo, a SESPA, política de saúde, } \\
\text { legislação, o SUS, controle social, } \\
\text { financiamento, projetos de saúde, situação de } \\
\text { saúde, atenção à saúde, agravos à saúde, } \\
\text { variedades e links. }\end{array}$ \\
\hline \multicolumn{2}{|l|}{ Atualização } & $\begin{array}{l}\text { Não há data de atualização do site. A legislação } \\
\text { está atualizada até } 2002 \text {. }\end{array}$ \\
\hline \multicolumn{2}{|l|}{ Conteúdo } & $\begin{array}{l}\text { Inclui informações institucionais, informações } \\
\text { sobre o SUS, legislação, indicadores de saúde, } \\
\text { projetos nacionais em saúde, etc. A Agenda } \\
\text { Estadual da Saúde 2001, o Plano Plurianual de } \\
\text { saúde e o Plano Diretor de Regionalização } \\
\text { aparecem sob o item Política de Saúde. }\end{array}$ \\
\hline \multicolumn{2}{|c|}{ Informação específica para gestores } & $\begin{array}{l}\text { Informações sobre o SUS, instrumentos de } \\
\text { gestão, sistemas de informação do SUS, } \\
\text { financiamentos, atos administrativos, etc. }\end{array}$ \\
\hline \multicolumn{2}{|l|}{ Links } & $\begin{array}{l}\text { Para organismos governamentais (MS, } \\
\text { DATASUS, RNIS, INCa, IBGE, etc.), } \\
\text { OPAS/BRA, etc. Não há link para outras SES, } \\
\text { universidades, hospitais, etc. nem para BVS-SP } \\
\text { ou Biblioteca do MS. }\end{array}$ \\
\hline \multicolumn{2}{|c|}{ Fontes das tabelas de indicadores } & $\begin{array}{l}\text { Publica indicadores de saúde estaduais e } \\
\text { nacionais, provenientes da SES, MS, SIM, } \\
\text { SINASC, IBGE, SIH, SIA e outros sistemas de } \\
\text { informação do SUS. }\end{array}$ \\
\hline \multirow{4}{*}{$\begin{array}{l}\text { Informação } \\
\text { científico- } \\
\text { técnica }\end{array}$} & Acesso a bases de dados & Não tem acesso a bases de dados. \\
\hline & $\begin{array}{l}\text { Textos completos ou } \\
\text { publicações técnico-científicas }\end{array}$ & Não inclui textos completos de ICT. \\
\hline & $\begin{array}{l}\text { Existência de Centro de } \\
\text { Documentação }\end{array}$ & $\begin{array}{l}\text { Existe no organograma uma Divisão de } \\
\text { Documentação e Divulgação, sob o } \\
\text { Departamento de Recursos Humanos, mas não } \\
\text { há acesso no site a produtos e serviços dessa } \\
\text { Divisão. }\end{array}$ \\
\hline & Indicação de utilização de ICT & Não sugere utilização de informação científica \\
\hline
\end{tabular}

Data da consulta: $24 / 05 / 02$ 


\section{ANEXO 6 (cont.) \\ Análise descritiva dos sites das Secretarias Estaduais de Saúde}

\begin{tabular}{|c|c|c|}
\hline \multicolumn{3}{|c|}{ Secretaria de Estado da Saúde da Paraíba <http://www.saude.pb.gov.br/ > } \\
\hline \multicolumn{2}{|c|}{ Organização do site } & $\begin{array}{l}\text { Organizado como portal de informações, em } 11 \\
\text { seções: missão, intranet, setores, informática, } \\
\text { editais, links, e-mail, estrutura, CES, regionais } \\
\text { e eventos. }\end{array}$ \\
\hline \multicolumn{2}{|l|}{ Atualização } & $\begin{array}{l}\text { Não há data de atualização do site. A maior } \\
\text { parte das seções não estava ativa. }\end{array}$ \\
\hline \multicolumn{2}{|l|}{ Conteúdo } & $\begin{array}{l}\text { Notícias, links e arquivos para download. Não } \\
\text { foi possível verificar o conteúdo completo do } \\
\text { site, pois muitas páginas não puderam ser } \\
\text { abertas. }\end{array}$ \\
\hline \multicolumn{2}{|c|}{ Informação específica para gestores } & Não. \\
\hline \multicolumn{2}{|l|}{ Links } & $\begin{array}{l}\text { Para sites do governo federal (MS, RNIS, } \\
\text { REFORSUS, DATASUS, CNS, FUNASA) e } \\
12 \text { SES. Não há link para universidades, } \\
\text { hospitais, etc. nem para BVS-SP ou Biblioteca } \\
\text { do MS. }\end{array}$ \\
\hline \multicolumn{2}{|c|}{ Fontes das tabelas de indicadores } & Não se aplica. \\
\hline \multirow{4}{*}{$\begin{array}{l}\text { Informação } \\
\text { científico- } \\
\text { técnica }\end{array}$} & Acesso a bases de dados & Não tem acesso a bases de dados. \\
\hline & $\begin{array}{l}\text { Textos completos ou } \\
\text { publicações técnico-científicas }\end{array}$ & Não inclui textos completos de ICT \\
\hline & $\begin{array}{l}\text { Existência de Centro de } \\
\text { Documentação }\end{array}$ & $\begin{array}{l}\text { Não indica existência de Centro de } \\
\text { Documentação/ Informação na SES }\end{array}$ \\
\hline & Indicação de utilização de ICT & Não sugere utilização de informação científica. \\
\hline
\end{tabular}

Data da consulta: $25 / 05 / 02$ 


\section{ANEXO 6 (cont.) \\ Análise descritiva dos sites das Secretarias Estaduais de Saúde}

\begin{tabular}{|c|c|c|}
\hline \multicolumn{3}{|c|}{ Secretaria de Estado da Saúde do Paraná < $\underline{\text { http://www.saude.pr.gov.br/ > }}$} \\
\hline \multicolumn{2}{|c|}{ Organização do site } & $\begin{array}{l}\text { Site organizado como portal de informações, } \\
\text { agrupadas em } 12 \text { seções: estrutura, o que a } \\
\text { Secretaria está fazendo, informações sobre } \\
\text { serviços, gestor municipal, informações sobre } \\
\text { agravos de interesse epidemiológico, } \\
\text { intoxicações, artigos e publicações, informações } \\
\text { e estatísticas de saúde, retroalimentação, } \\
\text { eventos, arquivos para download e links. }\end{array}$ \\
\hline \multicolumn{2}{|l|}{ Atualização } & $\begin{array}{l}\text { Mostra data da última atualização do site, } \\
\text { atualizada (mesmo mês da consulta). }\end{array}$ \\
\hline \multicolumn{2}{|l|}{ Conteúdo } & $\begin{array}{l}\text { Notícias, informações sobre programas e } \\
\text { serviços, informações sobre agravos, } \\
\text { documentos em texto completo, estatísticas e } \\
\text { indicadores, legislação, calendário de eventos, } \\
\text { atas, deliberações e outras informações sobre os } \\
\text { Conselhos de Saúde, Comissão Bipartite, etc. } \\
\text { Destacam-se: Agenda Estadual de Saúde, } \\
\text { Código de Saúde do Estado do Paraná, Perfil de } \\
\text { Saúde dos Municípios, Plano Diretor de } \\
\text { Regionalização. }\end{array}$ \\
\hline \multicolumn{2}{|c|}{ Informação específica para gestores } & $\begin{array}{l}\text { Tem uma seção na página principal para o } \\
\text { Gestor Municipal, que contem informações } \\
\text { sobre: Comissão Bipartite, Conselho Estadual } \\
\text { de Saúde, Comitês específicos, legislação, perfil } \\
\text { de saúde dos municípios, SIOPS, Plano Diretor } \\
\text { de Regionalização. }\end{array}$ \\
\hline \multicolumn{2}{|l|}{ Links } & $\begin{array}{l}\text { Não tem seção específica de links externos, mas } \\
\text { aponta para alguns sites: MS, RNIS, } \\
\text { DATASUS, Agência Estadual de Notícias. Não } \\
\text { há link para outras SES, universidades, } \\
\text { hospitais, etc. nem para BVS-SP ou Biblioteca } \\
\text { do MS. }\end{array}$ \\
\hline \multicolumn{2}{|c|}{ Fontes das tabelas de indicadores } & $\begin{array}{l}\text { Locais: dados da própria SES } \\
\text { Nacionais: DATASUS e RNIS. }\end{array}$ \\
\hline \multirow{4}{*}{$\begin{array}{l}\text { Informação } \\
\text { científico- } \\
\text { técnica }\end{array}$} & Acesso a bases de dados & Tem acesso a bases de dados. \\
\hline & $\begin{array}{l}\text { Textos completos ou } \\
\text { publicações técnico-científicas }\end{array}$ & Não inclui textos completos de ICT. \\
\hline & $\begin{array}{l}\text { Existência de Centro de } \\
\text { Documentação }\end{array}$ & $\begin{array}{l}\text { Tem biblioteca, sob Diretoria de } \\
\text { Desenvolvimento de Recursos Humanos. Traz } \\
\text { informações sobre a Biblioteca, com indicações } \\
\text { sobre recursos, serviços }\end{array}$ \\
\hline & Indicação de utilização de ICT & \\
\hline
\end{tabular}

Data da consulta: $25 / 05 / 02$ 


\section{ANEXO 6 (cont.)}

\section{Análise descritiva dos sites das Secretarias Estaduais de Saúde}

\begin{tabular}{|c|c|c|}
\hline \multicolumn{3}{|c|}{ Secretaria de Estado da Saúde de Pernambuco <http://www.saude.pe.gov.br/> } \\
\hline \multicolumn{2}{|c|}{ Organização do site } & $\begin{array}{l}\text { O site está dividido em: Secretaria da Saúde, } \\
\text { programas e projetos, hospitais, outros } \\
\text { serviços, notícias, informações em saúde, links. }\end{array}$ \\
\hline \multicolumn{2}{|l|}{ Atualização } & $\begin{array}{l}\text { Não há data de atualização do site, mas os } \\
\text { conteúdos indicam atualização. As notícias } \\
\text { estavam atualizadas até a semana da consulta } \\
\text { realizada no site. }\end{array}$ \\
\hline \multicolumn{2}{|l|}{ Conteúdo } & $\begin{array}{l}\text { O conteúdo parece estar em desenvolvimento, } \\
\text { constando basicamente de links, diretório de } \\
\text { instituições e notícias. Há um edital do } \\
\text { Programa de C\&T em Saúde da SES, mas o } \\
\text { programa não é mencionado no site. Há busca } \\
\text { no site. }\end{array}$ \\
\hline \multicolumn{2}{|c|}{ Informação específica para gestores } & Não há. \\
\hline \multicolumn{2}{|l|}{ Links } & $\begin{array}{l}\text { Tem links para todas as SES, organismos } \\
\text { governamentais nacionais e organismos } \\
\text { internacionais. Não há link para universidades, } \\
\text { hospitais, etc. nem para BVS-SP ou Biblioteca } \\
\text { do MS. }\end{array}$ \\
\hline \multicolumn{2}{|c|}{ Fontes das tabelas de indicadores } & Não se aplica. \\
\hline \multirow{4}{*}{$\begin{array}{l}\text { Informação } \\
\text { científico- } \\
\text { técnica }\end{array}$} & Acesso a bases de dados & Não tem acesso a bases de dados. \\
\hline & $\begin{array}{l}\text { Textos completos ou } \\
\text { publicações técnico-científicas }\end{array}$ & Não inclui textos completos de ICT. \\
\hline & $\begin{array}{l}\text { Existência de Centro de } \\
\text { Documentação }\end{array}$ & $\begin{array}{l}\text { Não indica existência de Centro de } \\
\text { Documentação/ Informação na SES. }\end{array}$ \\
\hline & Indicação de utilização de ICT & $\begin{array}{l}\text { Anuncia edital do Programa de C\&T em Saúde } \\
\text { para projetos na área de: Controle de Doenças } \\
\text { e Agravos Prioritários e Melhoria da Gestão, } \\
\text { do Acesso e da Qualidade das Ações e Serviços } \\
\text { em Saúde. }\end{array}$ \\
\hline
\end{tabular}

Data da consulta: $25 / 05 / 02$ 


\section{ANEXO 6 (cont.)}

\section{Análise descritiva dos sites das Secretarias Estaduais de Saúde}

\begin{tabular}{|c|c|c|}
\hline \multicolumn{3}{|c|}{ Secretaria de Estado da Saúde do Piauí <http://www.saude.pi.gov.br/> } \\
\hline \multicolumn{2}{|c|}{ Organização do site } & $\begin{array}{l}\text { Organizado como um portal, com links para } \\
\text { diversos sites, muitos deles inativos. }\end{array}$ \\
\hline \multicolumn{2}{|l|}{ Atualização } & Não há data de atualização do site. \\
\hline \multicolumn{2}{|l|}{ Conteúdo } & $\begin{array}{l}\text { Não tem conteúdo próprio, só links para } \\
\text { diversos sites que aparecem no menu lateral } \\
\text { esquerdo e na área central do site (com ícones). } \\
\text { Traz sob "Publicações em saúde" um arquivo } \\
\text { da Memória Epidemiológica do Piauí. }\end{array}$ \\
\hline \multicolumn{2}{|c|}{ Informação específica para gestores } & Não. \\
\hline \multicolumn{2}{|l|}{ Links } & $\begin{array}{l}\text { Para SES, instituições da área da saúde, } \\
\text { hospitais, organismos internacionais. É } \\
\text { interessante notar que o link para hospitais, } \\
\text { indica somente instituições de outros Estados. } \\
\text { Tem link para Biblioteca do MS, mas não para } \\
\text { BVS-SP. }\end{array}$ \\
\hline \multicolumn{2}{|c|}{ Fontes das tabelas de indicadores } & $\begin{array}{l}\text { "Informações sobre saúde no Piauí" e } \\
\text { "Programas de Saúde no Piauí" são links para o } \\
\text { DATASUS. }\end{array}$ \\
\hline \multirow{4}{*}{$\begin{array}{l}\text { Informação } \\
\text { científico- } \\
\text { técnica }\end{array}$} & Acesso a bases de dados & Não tem acesso a bases de dados. \\
\hline & $\begin{array}{l}\text { Textos completos ou } \\
\text { publicações técnico-científicas }\end{array}$ & Não inclui textos completos de ICT. \\
\hline & $\begin{array}{l}\text { Existência de Centro de } \\
\text { Documentação }\end{array}$ & $\begin{array}{l}\text { Não indica existência de Centro de } \\
\text { Documentação/ Informação na SES. }\end{array}$ \\
\hline & Indicação de utilização de ICT & Não sugere utilização de informação científica. \\
\hline
\end{tabular}

Data da consulta: $26 / 05 / 02$ 


\section{ANEXO 6 (cont.)}

\section{Análise descritiva dos sites das Secretarias Estaduais de Saúde}

\begin{tabular}{|c|c|c|}
\hline \multicolumn{3}{|c|}{ Secretaria de Estado da Saúde do Rio Grande do Norte $<\underline{\text { http: } / / w w w . s a u d e . r n . g o v . b r / ~}>$} \\
\hline \multicolumn{2}{|c|}{ Organização do site } & $\begin{array}{l}\text { Organizado como portal, com as seguintes } \\
\text { seções: apresentação, unidades do SUS, } \\
\text { downloads, gerenciamento dos serviços, gestão } \\
\text { do SUS, guia de doenças, Hemonorte, } \\
\text { informações de Saúde, outras SES, perfil dos } \\
\text { hospitais, população. }\end{array}$ \\
\hline \multicolumn{2}{|l|}{ Atualização } & Não há data de atualização do site. \\
\hline \multicolumn{2}{|l|}{ Conteúdo } & $\begin{array}{l}\text { Traz "Guia de Doenças" da FUNASA, com } \\
\text { glossário de doenças e termos comuns em } \\
\text { linguagem leiga. }\end{array}$ \\
\hline \multicolumn{2}{|c|}{ Informação específica para gestores } & $\begin{array}{l}\text { No espaço "Gestão do SUS" se definem os } \\
\text { principais instrumentos de gestão (SIOPS, } \\
\text { PPA, LDO, etc.). Traz Plano Diretor de } \\
\text { Regionalização do Estado. }\end{array}$ \\
\hline \multicolumn{2}{|l|}{ Links } & Não se aplica. \\
\hline \multicolumn{2}{|c|}{ Fontes das tabelas de indicadores } & DATASUS \\
\hline \multirow{4}{*}{$\begin{array}{l}\text { Informação } \\
\text { científico- } \\
\text { técnica }\end{array}$} & Acesso a bases de dados & Não tem acesso a bases de dados. \\
\hline & $\begin{array}{l}\text { Textos completos ou } \\
\text { publicações técnico-científicas }\end{array}$ & Não inclui textos completos de ICT. \\
\hline & $\begin{array}{l}\text { Existência de Centro de } \\
\text { Documentação }\end{array}$ & $\begin{array}{l}\text { Não indica existência de Centro de } \\
\text { Documentação/ Informação na SES. }\end{array}$ \\
\hline & Indicação de utilização de ICT & Não sugere utilização de informação científica. \\
\hline
\end{tabular}

Data da consulta: $26 / 05 / 02$ 


\section{ANEXO 6 (cont.)}

\section{Análise descritiva dos sites das Secretarias Estaduais de Saúde}

\begin{tabular}{|c|c|c|}
\hline \multicolumn{3}{|c|}{ Secretaria de Estado da Saúde do Rio Grande do Sul < http://www.saude.rs.gov.br/ > } \\
\hline \multicolumn{2}{|c|}{ Organização do site } & $\begin{array}{l}\text { Site dividido em } 4 \text { grandes seções: estrutura, } \\
\text { informações, SUS é legal, links. Traz ainda na } \\
\text { página principal links para Saúde Informa, } \\
\text { Boletim Epidemiológico, Escola de Saúde } \\
\text { Pública. }\end{array}$ \\
\hline \multicolumn{2}{|l|}{ Atualização } & $\begin{array}{l}\text { Não há data de atualização do site, mas os } \\
\text { conteúdos indicam atualização. }\end{array}$ \\
\hline \multicolumn{2}{|l|}{ Conteúdo } & $\begin{array}{l}\text { Informações sobre a estrutura e atribuições da } \\
\text { SES. há textos completos, apresentações em } \\
\text { slides (estatísticas de mortalidade), legislação, } \\
\text { indicadores de saúde, informações sobre } \\
\text { programas (municipalização solidária, AIH, } \\
\text { SIA, etc.), legislação estadual e federal em } \\
\text { texto completo, Boletim Epidemiológico, } \\
\text { repasses aos municípios, Código Estadual de } \\
\text { Saúde, Contraponto jornal da saúde, eventos, } \\
\text { campanhas e links. }\end{array}$ \\
\hline \multicolumn{2}{|c|}{ Informação específica para gestores } & $\begin{array}{l}\text { A seção ‘Informações’ traz informação de } \\
\text { interesse dos gestores como: legislação, } \\
\text { análises de indicadores, atribuições, etc. Os } \\
\text { indicadores apresentados sob a forma de } \\
\text { apresentações em slides ou relatórios, como é o } \\
\text { caso dos de mortalidade, constituem um auxílio } \\
\text { aos gestores não só pela consolidação e análise } \\
\text { dos dados em si, mas para indicar como podem } \\
\text { ser analisados os indicadores. Essas } \\
\text { apresentações funcionariam como salas de } \\
\text { situação. }\end{array}$ \\
\hline \multirow{2}{*}{\multicolumn{2}{|c|}{ Fontes das }} & $\begin{array}{l}\text { Para todas as SES, organismos nacionais e } \\
\text { internacionais de saúde, organismos federais e } \\
\text { estaduais, conselhos, Diário Oficial, Population } \\
\text { Reference Bureau e Measure Gateway. Não há } \\
\text { link para universidades, hospitais, etc. nem para } \\
\text { BVS-SP ou Biblioteca do MS. }\end{array}$ \\
\hline & & Locais: CIS/SES. \\
\hline \multirow{4}{*}{$\begin{array}{l}\text { Informação } \\
\text { científico- } \\
\text { técnica }\end{array}$} & Acesso a bases de dados & Não tem acesso a bases de dados. \\
\hline & $\begin{array}{l}\text { Textos completos ou } \\
\text { publicações técnico-científicas }\end{array}$ & Não inclui textos completos de ICT. \\
\hline & $\begin{array}{l}\text { Existência de Centro de } \\
\text { Documentação }\end{array}$ & $\begin{array}{l}\text { Não indica existência de Centro de } \\
\text { Documentação/ Informação na SES. }\end{array}$ \\
\hline & Indicação de utilização de ICT & $\begin{array}{l}\text { Há link para a Escola de Saúde Pública, mas } \\
\text { parece estimular acesso a ICT. }\end{array}$ \\
\hline
\end{tabular}

Data da consulta: $26 / 05 / 02$ 


\section{ANEXO 6 (cont.)}

\section{Análise descritiva dos sites das Secretarias Estaduais de Saúde}

\begin{tabular}{|c|c|c|}
\hline \multicolumn{3}{|c|}{ Secretaria de Estado da Saúde do Rio de Janeiro < <http://www.saude.rj.gov.br/> } \\
\hline \multicolumn{2}{|c|}{ Organização do site } & $\begin{array}{l}\text { Site organizado como um portal, dividido em } 6 \\
\text { grandes seções: Secretaria da Saúde, Guia do } \\
\text { cidadão, informações em Saúde, informe ao } \\
\text { gestor, ações em saúde e eventos. Há em } \\
\text { destaque também informações sobre } \\
\text { campanhas, um diretório de hospitais e serviços } \\
\text { de saúde do Estado do Rio de Janeiro, links, } \\
\text { busca no site. Há link para contato para } \\
\text { denúncia e com a CISA. }\end{array}$ \\
\hline \multicolumn{2}{|l|}{ Atualização } & $\begin{array}{l}\text { Não há data de atualização do site, mas os } \\
\text { conteúdos indicam atualização }\end{array}$ \\
\hline \multicolumn{2}{|l|}{ Conteúdo } & $\begin{array}{l}\text { Informações sobre estrutura e programas, } \\
\text { Indicadores e informações em saúde, diretórios, } \\
\text { secretarias municipais de saúde, guias, etc.Em } \\
\text { "Eventos", traz relação de eventos da SES/RJ, } \\
\text { ordenados por ano e mes (2001, 2002). Oferece } \\
\text { serviços como as licitações em andamento na } \\
\text { SES, onde está o processo e o Serviço de } \\
\text { Atendimento do Cidadão. }\end{array}$ \\
\hline \multicolumn{2}{|c|}{ Informação específica para gestores } & $\begin{array}{l}\text { Há uma seção dedicada especificamente aos } \\
\text { gestores "Informe ao gestor", que contém } \\
\text { informação sobre instrumentos de gestão, } \\
\text { legislação, Conselhos, etc. No "Informe aos } \\
\text { municípios", modelos de sites (3) para as SMS, } \\
\text { diretrizes, eventos, notícias. }\end{array}$ \\
\hline \multicolumn{2}{|l|}{ Links } & $\begin{array}{l}\text { Para } 12 \text { SES, MS, instituições governamentais, } \\
\text { associações, sociedades científicas, } \\
\text { universidades, institutos de pesquisa, } \\
\text { organismos internacionais, Há link para a } \\
\text { BIREME, mas não para a BVS-SP ou } \\
\text { Biblioteca do MS. Propõe modelos de sites } \\
\text { para as SMS, com seleção de links; cerca de } \\
5 \% \text { das SMS acrescentou links à lista. }\end{array}$ \\
\hline \multicolumn{2}{|c|}{ Fontes das tabelas de indicadores } & $\begin{array}{l}\text { Nacionais: RNIS. } \\
\text { Locais: CISA }\end{array}$ \\
\hline \multirow{4}{*}{$\begin{array}{l}\text { Informação } \\
\text { científico- } \\
\text { técnica }\end{array}$} & Acesso a bases de dados & Não tem acesso a bases de dados. \\
\hline & $\begin{array}{l}\text { Textos completos ou } \\
\text { publicações técnico-científicas }\end{array}$ & Não inclui textos completos de ICT \\
\hline & $\begin{array}{l}\text { Existência de Centro de } \\
\text { Documentação }\end{array}$ & $\begin{array}{l}\text { Não indica existência de Centro de } \\
\text { Documentação/ Informação na SES }\end{array}$ \\
\hline & Indicação de utilização de ICT & Não sugere utilização de informação científica \\
\hline
\end{tabular}

Data da consulta: $27 / 05 / 02$ 


\section{ANEXO 6 (cont.)}

\section{Análise descritiva dos sites das Secretarias Estaduais de Saúde}

\begin{tabular}{|c|c|c|}
\hline \multicolumn{3}{|c|}{ Secretaria de Estado da Saúde de Roraima < http://www.saude.rr.gov.br/> } \\
\hline \multicolumn{2}{|c|}{ Organização do site } & $\begin{array}{l}\text { Site organizado como portal de informações, } \\
\text { com várias áreas: Perfil do Estado, } \\
\text { Administração, Sala de Situação, Vigilância } \\
\text { Sanitária, Programas de Saúde, Unidades de } \\
\text { Saúde, Estatística de Saúde, Epidemiologia, } \\
\text { CES e CIB. }\end{array}$ \\
\hline \multicolumn{2}{|l|}{ Atualização } & $\begin{array}{l}\text { Não há data de atualização do site, mas } \\
\text { conteúdos sugerem atualização. }\end{array}$ \\
\hline \multicolumn{2}{|l|}{ Conteúdo } & $\begin{array}{l}\text { Informes epidemiológicos, notícias, diretório } \\
\text { de instituições, links, informações gerais sobre } \\
\text { os municípios e programas de saúde, } \\
\text { informações administrativas. }\end{array}$ \\
\hline \multicolumn{2}{|c|}{ Informação específica para gestores } & $\begin{array}{l}\text { Menciona realização de "Curso de } \\
\text { Especialização em Gestão de Sistemas e } \\
\text { Serviços de Saúde", mas não traz programa do } \\
\text { curso, que permita avaliar conteúdo oferecido. }\end{array}$ \\
\hline \multicolumn{2}{|l|}{ Links } & $\begin{array}{l}\text { Divide em links municipais (não ativos) e } \\
\text { estaduais (todas as SES, MS e REFORSUS). } \\
\text { Na página principal ainda há links para RNIS, } \\
\text { ANVISA, CNS, Governo de Estado. Não há } \\
\text { link para universidades, instituições de saúde, } \\
\text { etc. nem para BVS-SP ou Biblioteca do MS. }\end{array}$ \\
\hline \multicolumn{2}{|c|}{ Fontes das tabelas de indicadores } & $\begin{array}{l}\text { Nacionais: SIM, SINASC, SINAM } \\
\text { Locais: SIS Estadual. }\end{array}$ \\
\hline \multirow{4}{*}{$\begin{array}{l}\text { Informação } \\
\text { científico- } \\
\text { técnica }\end{array}$} & Acesso a bases de dados & Não tem acesso a bases de dados. \\
\hline & $\begin{array}{l}\text { Textos completos ou } \\
\text { publicações técnico-científicas }\end{array}$ & $\begin{array}{l}\text { Inclui somente informes epidemiológicos e um } \\
\text { artigo sobre controle biológico de malária em } \\
\text { texto completo. }\end{array}$ \\
\hline & $\begin{array}{l}\text { Existência de Centro de } \\
\text { Documentação }\end{array}$ & $\begin{array}{l}\text { Não indica existência de Centro de } \\
\text { Documentação/ Informação na SES. }\end{array}$ \\
\hline & Indicação de utilização de ICT & Não sugere utilização de informação científica. \\
\hline
\end{tabular}

Data da consulta: 29/05/02 


\section{ANEXO 6 (cont.)}

\section{Análise descritiva dos sites das Secretarias Estaduais de Saúde}

\begin{tabular}{|c|c|c|}
\hline \multicolumn{3}{|c|}{ Secretaria de Estado da Saúde de Santa Catarina < } \\
\hline \multicolumn{2}{|c|}{ Organização do site } & $\begin{array}{l}\text { Site organizado como portal, dividido em } \\
\text { seções: institucional, informações de Saúde, } \\
\text { programas e projetos, sala de leitura, controle } \\
\text { social, de olho na saúde, compras e } \\
\text { contratações, programas do SIS-SUS, links e } \\
\text { notícias. }\end{array}$ \\
\hline \multicolumn{2}{|c|}{ Atualização } & $\begin{array}{l}\text { Não há data de atualização do site, mas } \\
\text { conteúdos sugerem atualização. }\end{array}$ \\
\hline \multicolumn{2}{|l|}{ Conteúdo } & $\begin{array}{l}\text { Textos completos na Sala de Leitura, acesso a } \\
\text { fontes de informação bibliográfica, indicadores } \\
\text { de saúde, informações para compras e } \\
\text { licitações incluindo legislação nacional } \\
\text { correspondente, notícias, links, arquivos para } \\
\text { download, resoluções, atas e membros do } \\
\text { CMS. Inclui Plano Estadual de Saúde, Agenda } \\
\text { Estadual de Saúde informações sobre } \\
\text { programas e projetos da SES/SC e MS. }\end{array}$ \\
\hline \multicolumn{2}{|c|}{ Informação específica para gestores } & $\begin{array}{l}\text { Informa sobre Capacitação de Gestores } \\
\text { Municipais e traz arquivo de apresentação feita } \\
\text { no curso de "Capacitação NOAS". }\end{array}$ \\
\hline \multicolumn{2}{|l|}{ Links } & $\begin{array}{l}\text { Instituições governamentais, universidades e } \\
\text { institutos de pesquisa, SES e SMS, } \\
\text { organizações internacionais, hospitais e } \\
\text { associações médicas. Tem link para BVS e } \\
\text { BVS/Adolec Brasil, mas não para BVS-SP ou } \\
\text { Biblioteca do MS. }\end{array}$ \\
\hline \multirow{2}{*}{\multicolumn{2}{|c|}{ Fontes das tabelas de indicadores }} & Nacionais: RNIS, DATASUS. \\
\hline & & Locais: indicadores próprios \\
\hline \multirow{4}{*}{$\begin{array}{l}\text { formação } \\
\text { científico- } \\
\text { técnica }\end{array}$} & Acesso a bases de dados & $\begin{array}{l}\text { No espaço da "Biblioteca de Tuberculose" tem } \\
\text { links para bases de dados. }\end{array}$ \\
\hline & $\begin{array}{l}\text { Textos completos ou } \\
\text { publicações técnico-científicas }\end{array}$ & $\begin{array}{l}\text { Sites de revistas em texto completo, editoras, } \\
\text { jornais locais, estaduais e internacionais e } \\
\text { bibliotecas. }\end{array}$ \\
\hline & $\begin{array}{l}\text { Existência de Centro de } \\
\text { Documentação }\end{array}$ & $\begin{array}{l}\text { Não indica existência de Centro de } \\
\text { Documentação/ Informação na SES. }\end{array}$ \\
\hline & Indicação de utilização de ICT & Sugere uso de ICT na "Sala de Leitura. \\
\hline
\end{tabular}

Data da consulta: $29 / 05 / 02$ 


\section{ANEXO 6 (cont.) \\ Análise descritiva dos sites das Secretarias Estaduais de Saúde}

\begin{tabular}{|c|c|c|}
\hline \multicolumn{3}{|c|}{ Secretaria de Estado da Saúde de São Paulo < http://www.saude.sp.gov.br/> } \\
\hline \multicolumn{2}{|c|}{ Organização do site } & $\begin{array}{l}\text { Organizado em } 7 \text { grandes áreas: apresentação, } \\
\text { estrutura organizacional, tipo de gestão, dados } \\
\text { de saúde, links, downloads, novidades. }\end{array}$ \\
\hline \multicolumn{2}{|l|}{ Atualização } & $\begin{array}{l}\text { Indica data de atualização do site e conteúdos } \\
\text { atualizados. }\end{array}$ \\
\hline \multicolumn{2}{|l|}{ Conteúdo } & $\begin{array}{l}\text { Mapas e tabelas da condição de gestão dos } \\
\text { municípios segundo a NOB/96, indicadores de } \\
\text { saúde, demográficos, sociais, financeiros e } \\
\text { epidemiológicos do Estado, legislação em texto } \\
\text { completo. Os Boletins CIS trazem análise de } \\
\text { informações disponíveis na área da saúde e os } \\
\text { Informes CIS, informações atualizadas das } \\
\text { principais bases de dados da área da saúde. } \\
\text { Apresenta arquivos e tabelas para download. }\end{array}$ \\
\hline \multicolumn{2}{|c|}{ Informação específica para gestores } & $\begin{array}{l}\text { Traz normas, portarias e instruções normativas, } \\
\text { implantação da NOAS no Estado de São Paulo, } \\
\text { Agenda Estadual de Saúde, Plano Diretor de } \\
\text { Regionalização, etc. Publica textos de apoio } \\
\text { para análise dos indicadores (gestão, } \\
\text { mortalidade), manual de orientações para } \\
\text { elaboração dos indicadores de gestão. }\end{array}$ \\
\hline \multicolumn{2}{|l|}{ Links } & $\begin{array}{l}\text { Instituições vinculadas à SES-SP e ao governo } \\
\text { estadual, } 19 \text { SES e } 5 \text { SMS, universidades, } \\
\text { instituições federais de saúde, organizações } \\
\text { internacionais, bibliotecas e revistas. Traz link } \\
\text { para BVS mas não para BVS-SP ou Biblioteca } \\
\text { do MS. }\end{array}$ \\
\hline \multicolumn{2}{|c|}{ Fontes das tabelas de indicadores } & Locais: SES-SP \\
\hline \multirow{4}{*}{$\begin{array}{l}\text { Informação } \\
\text { científico- } \\
\text { técnica }\end{array}$} & Acesso a bases de dados & $\begin{array}{l}\text { Inclui acesso a bases de dados da Biblioteca da } \\
\text { SES (acervo desde 1970). }\end{array}$ \\
\hline & $\begin{array}{l}\text { Textos completos ou } \\
\text { publicações técnico-científicas }\end{array}$ & $\begin{array}{l}\text { Publicações da SES (desde 1987), legislação } \\
\text { (legislação estadual 2000/01, com acesso ao } \\
\text { texto completo). }\end{array}$ \\
\hline & $\begin{array}{l}\text { Existência de Centro de } \\
\text { Documentação }\end{array}$ & Indica existência de Biblioteca. \\
\hline & Indicação de utilização de ICT & $\begin{array}{l}\text { Utilização de ICT poderia ser sugerida com } \\
\text { acesso a bases de dados, bibliotecas e revistas, } \\
\text { e publicações da SES em textos completos. }\end{array}$ \\
\hline
\end{tabular}

Data da consulta: 29/05/02 


\section{ANEXO 6 (cont.)}

\section{Análise descritiva dos sites das Secretarias Estaduais de Saúde}

\begin{tabular}{|c|c|c|}
\hline \multicolumn{3}{|c|}{ Secretaria de Estado da Saúde de Sergipe <http://www.saude.se.gov.br/> } \\
\hline \multicolumn{2}{|c|}{ Organização do site } & $\begin{array}{l}\text { Site organizado em } 3 \text { grandes seções: } \\
\text { informações gerais (assistência, controle social, } \\
\text { saúde Sergipe, dados saúde, projetos, estrutura, } \\
\text { legislação), links e notícias. }\end{array}$ \\
\hline \multicolumn{2}{|l|}{ Atualização } & $\begin{array}{l}\text { Há data de criação do site (2001) e conteúdo } \\
\text { sugere atualização do site. }\end{array}$ \\
\hline \multicolumn{2}{|l|}{ Conteúdo } & $\begin{array}{l}\text { Informações sobre entidades de saúde do } \\
\text { Estado, composição dos CIB e CES, } \\
\text { informação sobre programas de saúde e } \\
\text { doenças específicas (dengue, tuberculose, } \\
\text { DST/AIDS, hanseníase), legislação de texto } \\
\text { completo, informações sobre licitações. }\end{array}$ \\
\hline \multicolumn{2}{|c|}{ Informação específica para gestores } & Não há. \\
\hline \multicolumn{2}{|l|}{ Links } & $\begin{array}{l}\text { Para MS, organismos internacionais, } 16 \text { SES. } \\
\text { Não há link para universidades, hospitais, etc. } \\
\text { nem para BVS-SP ou Biblioteca do MS. }\end{array}$ \\
\hline \multicolumn{2}{|c|}{ Fontes das tabelas de indicadores } & Não se aplica. \\
\hline \multirow{4}{*}{$\begin{array}{l}\text { Informação } \\
\text { científico- } \\
\text { técnica }\end{array}$} & Acesso a bases de dados & Não tem acesso a bases de dados. \\
\hline & $\begin{array}{l}\text { Textos completos ou } \\
\text { publicações técnico-científicas }\end{array}$ & Legislação em texto completo \\
\hline & $\begin{array}{l}\text { Existência de Centro de } \\
\text { Documentação }\end{array}$ & $\begin{array}{l}\text { Não indica existência de Centro de } \\
\text { Documentação/ Informação na SES. }\end{array}$ \\
\hline & Indicação de utilização de ICT & Não sugere utilização de ICT. \\
\hline
\end{tabular}

Data da consulta: $31 / 05 / 02$ 


\section{ANEXO 6 (cont.)}

\section{Análise descritiva dos sites das Secretarias Estaduais de Saúde}

\begin{tabular}{|c|c|c|}
\hline \multicolumn{3}{|c|}{ Secretaria de Estado da Saúde de Tocantins <http://www.saude.to.gov.br/> } \\
\hline \multicolumn{2}{|c|}{ Organização do site } & $\begin{array}{l}\text { Site organizado em } 5 \text { seções: estrutura, } \\
\text { programas e projetos, RNIS, Pró-Saúde e links. }\end{array}$ \\
\hline \multicolumn{2}{|l|}{ Atualização } & Não há data de atualização do site. \\
\hline \multicolumn{2}{|l|}{ Conteúdo } & $\begin{array}{l}\text { Contém tabelas de indicadores, estrutura da } \\
\text { SES, programas e projetos, links, histórico e } \\
\text { endereço de hospitais do Tocantins. }\end{array}$ \\
\hline \multicolumn{2}{|c|}{ Informação específica para gestores } & Não há. \\
\hline \multicolumn{2}{|l|}{ Links } & $\begin{array}{l}\text { Para } 14 \text { SES, MS, Pró-saúde, hospitais do } \\
\text { Tocantins, RNIS e Conselho Nacional de } \\
\text { Saúde. }\end{array}$ \\
\hline \multicolumn{2}{|c|}{ Fontes das tabelas de indicadores } & $\begin{array}{l}\text { Locais: SES / Núcleo de Análise de } \\
\text { Informações em Saúde (NAIS) }\end{array}$ \\
\hline \multirow{4}{*}{$\begin{array}{l}\text { Informação } \\
\text { científico- } \\
\text { técnica }\end{array}$} & Acesso a bases de dados & Não tem acesso a bases de dados. \\
\hline & $\begin{array}{l}\text { Textos completos ou } \\
\text { publicações técnico-científicas }\end{array}$ & Não inclui textos completos de ICT. \\
\hline & $\begin{array}{l}\text { Existência de Centro de } \\
\text { Documentação }\end{array}$ & $\begin{array}{l}\text { Não indica existência de Centro de } \\
\text { Documentação/ Informação na SES. }\end{array}$ \\
\hline & Indicação de utilização de ICT & Não sugere indicação de utilização de ICT. \\
\hline
\end{tabular}

Data da consulta: $31 / 05 / 02$ 